\title{
Unemployment and Labour Market Policy Attitudes
}

Political Predispositions, Economic SelfInterest, and Questions of Causality

Nadja Wehl, M.A., M.Sc., University of Bamberg

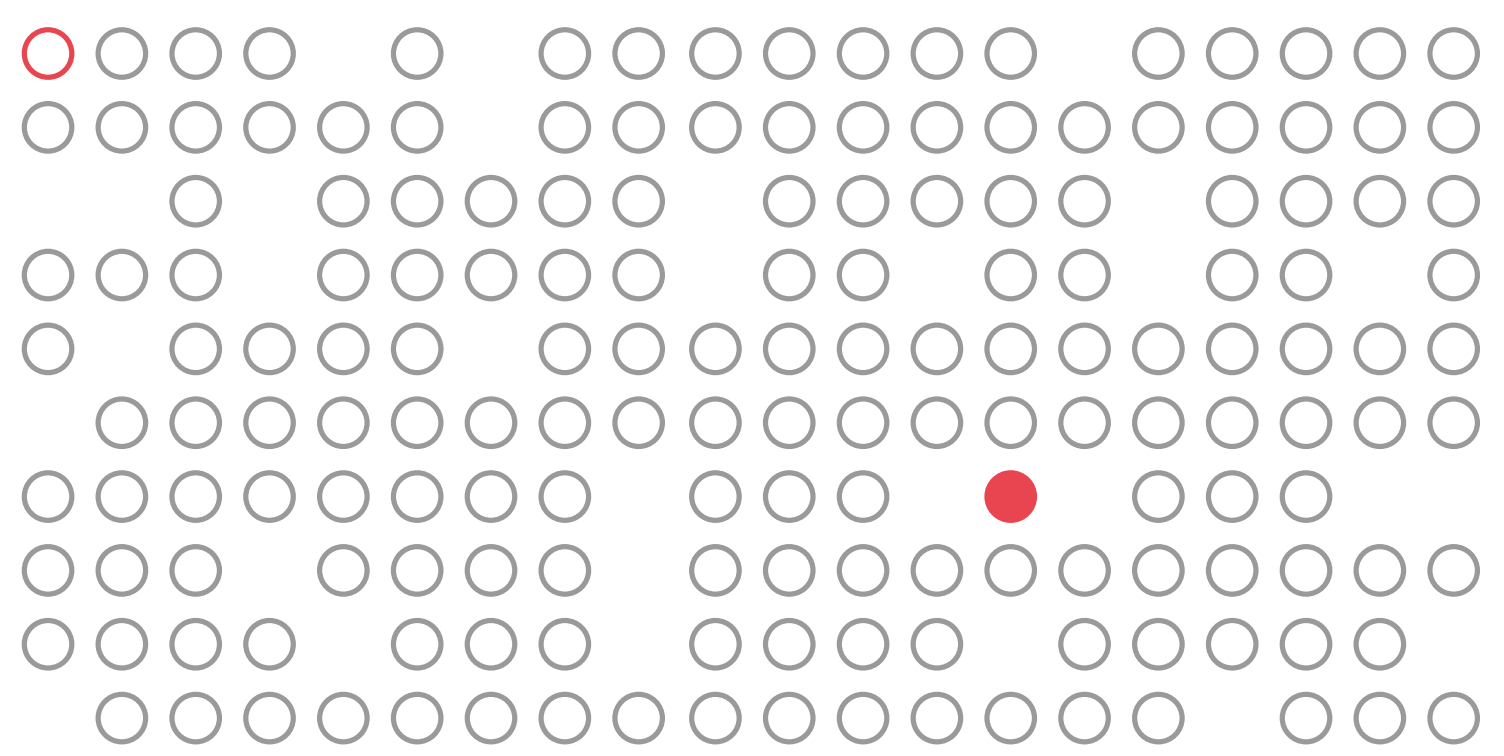





\title{
Unemployment and Labour Market Policy Attitudes \\ Political Predispositions, Economic Self-Interest, and Questions of Causality
}

\author{
Cumulative Dissertation \\ for obtaining the academic grade \\ Doctor rerum politicarum (Dr. rer. pol.) \\ submitted to the
}

Faculty for Social Sciences, Economics, and Business Administration of the University of Bamberg

by Nadja Wehl, M.A., M.Sc.

First advisor: Prof. Dr. Marc Helbling

Second advisor: Prof. Dr. Steffen Schindler

Additional member of the committee: Prof. Dr. Silja Häusermann

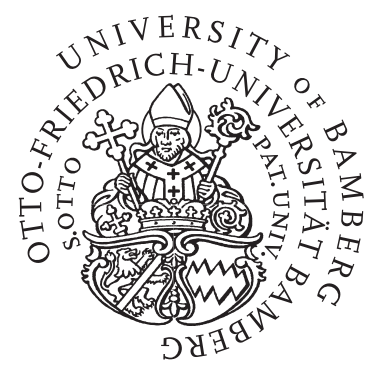


This work is available as a free online version via the Current Research Information System (FIS; fis.uni-bamberg.de) of the University of Bamberg. The work - with the exception of cover, quotations and illustrations - is licensed under the CC-License CC-BY.

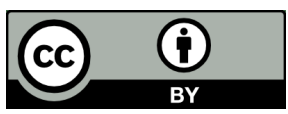

Lizenzvertrag: Creative Commons Namensnennung 4.0 http://creativecommons.org/licenses/by/4.0.

URN: urn:nbn:de:bvb:473-irb-521273

DOI: https://doi.org/10.20378/irb-52127 


\section{Acknowledgements}

This dissertation project is the result of an academic journey with ups and downs. During this time I was surrounded by a few amazing people. Together we celebrated my successes and you supported me in times of failure and rejection. You know who you are ;) And I'm honoured and grateful to have you!

Finishing this dissertation project means I had to make many decisions. Fortunately, when in doubt, I always knew I would get useful advice from my first supervisor, Marc Helbling.

Thanks, Marc, for all your guidance and support during this time. And I'm not only referring to research-related issues here. I really appreciate, how you supported me in my application phase, helped me in navigating the peer-review process, or how you created the connection to Silja. Apropos, to my third supervisor, Silja Häusermann: Silja, I am both happy and honoured you joined the committee.

At the beginning of this dissertation project I had to learn that the academic world is a little bigger than I initially thought during my studies. Among other things I learned how close sociological research can be to my research interests. Consequently, I joined sociological colloquia of the graduate school and got a sociologist as second supervisor, Steffen Schindler. Thanks Steffen, for joining the interdisciplinary ride and for your helpful feedback on the way.

I had the chance to work on part of this dissertation during a research stay in Tilburg, since Tim Reeskens agreed to host me. Thanks to you Tim, and the rest of the Department of Sociology in Tilburg, for making this both an interesting and fun time.

Finally, this research stay was only one instance of many others in which the Bamberg Graduate School of Social Sciences supported me financially. I am grateful for the opportunity to conduct my PhD at an institution offering so many opportunities to take part in conferences, workshops, and summer and winter schools. 



\section{Contents}

1 Framework 13

1.1 Introduction . . . . . . . . . . . . . . . . . 13

1.2 Previous Research . . . . . . . . . . . . . . . . . . . . 17

1.3 Theoretical Framework . . . . . . . . . . . . . . . . 23

1.3.1 Self-Interest . . . . . . . . . . . . . . . 23

1.3.2 Predispositions ........................... 24

1.4 Questions of Causality . . . . . . . . . . . . . . . . 33

1.4.1 Stratified Socialization as Explanation for Confounding . . . . . . . . . 33

1.4.2 Research Design of the 3 Papers . . . . . . . . . . . . . . . . 35

1.5 Summary of the 3 Articles . . . . . . . . . . . . . . 37

1.5.1 Summary Article $1 \ldots \ldots . \ldots . \ldots 37$

1.5.2 Summary Article $2 \ldots \ldots . \ldots . \ldots . \ldots 38$

1.5.3 Summary Article $3 \ldots \ldots$. . . . . . . . . . . 40

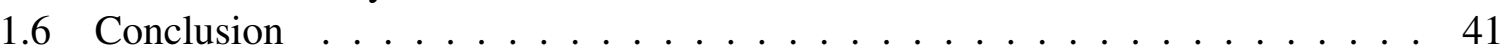

References . . . . . . . . . . . . . . . . . . . . 44

2 Article 1: The (ir)relevance of unemployment for labour market policy attitudes $\begin{array}{ll}\text { and welfare state attitudes } & 49\end{array}$

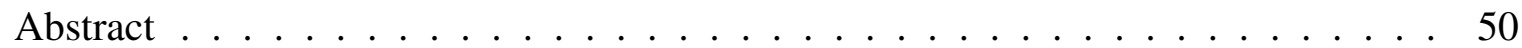

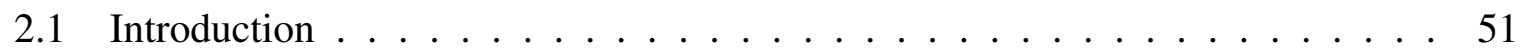

2.2 Unemployment and Labour Market Policy (LMP) Attitudes: Causal and Non-

Causal Mechanisms . . . . . . . . . . . . . . . . . . . . 53

2.2.1 Self-Interest Driven Attitudes . . . . . . . . . . . . . . 53

2.2.2 Political Predispositions: Another Look at Attitudes . . . . . . . . . . 53

2.2.3 Alternative Explanation: Stratified Predispositions and Stratified Unemployment Risks . . . . . . . . . . . . . . . . . . 54

2.3 Data and Methods . . . . . . . . . . . . . . . . . . . . . 56

2.3 .1 Data . . . . . . . . . . . . . . . 56

2.3.2 Controlling Selection Bias with Entropy Balancing (EB) . . . . . . . 57

2.3 .3 Outcome Analyses . . . . . . . . . . . . . . . . . . . 58

2.4 Analysis . . . . . . . . . . . . . . . . . . . . . . 59

2.4.1 Robustness Checks and Bayes Factor Replication . . . . . . . . . . . 63

2.5 Summary and Discussion . . . . . . . . . . . . . . . . . . 67

References .............................. 71

3 Article 2: Going beyond values versus self-interest. Whose attitudes change $\begin{array}{ll}\text { after employment transitions? } & 77\end{array}$

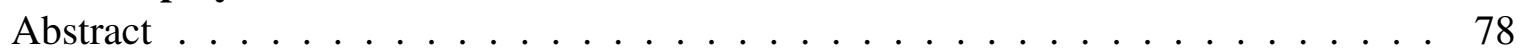

3.1 Introduction . . . . . . . . . . . . . . . . 79 
3.2 Values versus Self-Interest and Beyond . . . . . . . . . . . . . . 80

3.2.1 Who experiences self-interest based attitude changes? . . . . . . . . 82

3.3 Data and Methods . . . . . . . . . . . . . . . . . 86

3.3.1 Measurement . . . . . . . . . . . . . 86

3.3 .2 Analytical Strategy . . . . . . . . . . . . . . . . . 87

3.4 Results . . . . . . . . . . . . . . . . . . . . . . . 88

3.4.1 Descriptive Overview . . . . . . . . . . . . . . . . . 88

3.4 .2 Main Effects . . . . . . . . . . . . . . . . . 92

3.4 .3 Subgroup Analyses . . . . . . . . . . . . . . . . . . 93

3.4.4 Results Summary and Robustness Checks . . . . . . . . . . . . . . 96

3.5 Conclusion . . . . . . . . . . . . . . . . . . . . . . 99

References . . . . . . . . . . . . . . . . . . 103

4 Article 3: The dynamics of unemployment, risk, and left-right ideology. Con$\begin{array}{lr}\text { strained change or changed constraints? } & 107\end{array}$

Abstract . . . . . . . . . . . . . . . . . . . . . 108

4.1 Introduction . . . . . . . . . . . . . . . . . . . . 109

4.2 Labour Market Transitions and Ideology . . . . . . . . . . . . . . . . . 111

4.2.1 Constraining Change or Changing Constraints . . . . . . . . . . . . . 112

4.2.2 Stratified Socialization: Two Challenges for Causal Inference . . . . . 112

4.2.3 Effect Heterogeneity . . . . . . . . . . . . . . . . . . . 114

4.3 Data and Methods . . . . . . . . . . . . . . . . . 115

4.3.1 Measurement of Ideology, Unemployment, and Job Insecurity . . . . 116

4.3.2 Moderators: Prior Left-Right Ideology, Age, and Salience . . . . . . . 117

4.3.3 Fixed Effects (FE) \& Fixed Effects with Individual Specific Slopes (FEIS) 117

4.3.4 Applied Methodological Considerations: Sample Restrictions and Interactions . . . . . . . . . . . . . . . . . . 119

4.4 Analysis . . . . . . . . . . . . . . . . . . . . . . 120

4.4.1 Main Effects . . . . . . . . . . . . . . . . 120

4.4 .2 Effect Heterogeneity . . . . . . . . . . . . . . . . . . . . 124

4.4.3 Country Differences in Context . . . . . . . . . . . . . . 128

4.5 Summary . . . . . . . . . . . . . . . . . . . . . . . . 129

References . . . . . . . . . . . . . . . . . . . 132

$\begin{array}{lll}\text { A Appendix for Article 1 } & 137\end{array}$

B Appendix for Article 2 154

C Appendix for Article 3 189 


\section{List of Figures}

1.1 The Theoretical Model and the Three Articles . . . . . . . . . . . . . . . 15

1.2 The Theoretical Model and the Theoretical Mechanisms . . . . . . . . . . . 32

1.3 The Causal Identification Strategies of the Three Articles . . . . . . . . . . . 36

2.1 (Non)causality in associations between unemployment and LMP attitudes and political predispositions . . . . . . . . . . . . . . 56

2.2 The Problem of Selection Bias . . . . . . . . . . . . . . . . . 58

2.3 Unemployment and LMP Attitudes . . . . . . . . . . . . . . . . . . . 61

2.4 Unemployment and Egalitarian Orientations . . . . . . . . . . . . . . 62

2.5 Bayes Factors . . . . . . . . . . . . . . . . . . . . 66

3.1 Attitude Changes within the three Subgroups . . . . . . . . . . . . 85

3.2 SOEP: Descriptive Overview: The 3 Subgroups . . . . . . . . . . . . . . . . 89

3.3 SOEP: Descriptive Overview: Employment Changes in the 3 Subgroups . . . . 91

3.4 SOEP: Main Effects . . . . . . . . . . . . . . . . . . . . . . . . 93

3.5 SOEP: Results for Employment Transitions . . . . . . . . . . . . . . . . . . . . . . . . . . . . . . .

3.6 SOEP: Results for Job Insecurity . . . . . . . . . . . . . . . . . . . . . . . . 95

3.7 Results Summary . . . . . . . . . . . . . . . . . . . . . . . . . 98

4.1 Time-Constant (left) and Time-Varying (right) Confounding of Relations between Unemployment and Ideology . . . . . . . . . . . . . . . 113

4.2 Comparing the Logic of Fixed Effects Estimates with and without Individual Slopes . . . . . . . . . . . . . . . . . . . . . . 118

4.3 Main Effects of Unemployment and Job Insecurity on Left-Right Ideology . 122

4.4 Heterogeneity in Effects of Unemployment: Prior Left-Right Moderation . . . 125

4.5 Heterogeneity in Effects of Unemployment: Age Moderation . . . . . . . . . 127

A.1 Maximum EB Weights . . . . . . . . . . . . . . . . . . . . 143

A.2 Balance . . . . . . . . . . . . . . . . . . . . . 144

A.3 Worries . . . . . . . . . . . . . . . . . . 145

A.4 Sensitivity Check: Results with trimmed EB weights . . . . . . . . . . 146

A.5 Sensitivity Check: Results with Confounders in Outcome Regression with EB Weights . . . . . . . . . . . . . . . . . . . . . . . 147

A.6 Sensitivity Check: Controlling Selection Bias with Propensity Score Adjustment 148

A.7 Sensitivity Check: Controlling Selection Bias with Confounders in Outcome Regression . . . . . . . . . . . . . . . . . . . . . . . 149

A.8 Sensitivity Check: Results without controlling for previous unemployment experience . . . . . . . . . . . . . . . . . . 150

A.9 Sensitivity Check: 2012 Replication . . . . . . . . . . . . . . 151

A.10 Unemployment Rate . . . . . . . . . . . . . . . . . . . . . 152 
B.1 SOEP Robustness Checks for Employment Transitions . . . . . . . . . . . . 182

B.2 SOEP Results for Employment Transitions with Separate Models for Active and Passive LMP Attitudes . . . . . . . . . . . . . . . . . . 183

B.3 SOEP Results for Job Insecurity with Separate Models for Active and Passive LMP Attitudes . . . . . . . . . . . . . . . . . . . . . . 184

C.1 Main Effects (FEIS) with lagged treatment effects of Unemployment and Job Insecurity on Left-Right Ideology . . . . . . . . . . . . . . . . . . 191

C.2 Continuous Job Insecurity Measure: Main Effects . . . . . . . . . . . . . . . 192

C.3 Lagged Insecurity Measure: Main Effects . . . . . . . . . . . . . . . . . 194

C.4 Heterogeneity in Effects of Unemployment: Prior Left-Right Moderation with Categorical Interaction Term . . . . . . . . . . . . . . 196

C.5 Heterogeneity in Effects of Unemployment: Age Moderation with Categorical Interaction Term . . . . . . . . . . . . . . . . . . . . 198

C.6 Alternative (Un)Employment Measurement: Main Effects . . . . . . . . . . 200

C.7 Heterogeneity in Effects of Unemployment: Prior Left-Right Moderation with Alternative (Un)Employment Measure . . . . . . . . . . . . . . . . . 201

C.8 Heterogeneity in Effects of Unemployment: Age Moderation with Alternative (Un)Employment Measure . . . . . . . . . . . . . . . . . . 202

C.9 Salience Indicators (Eurobarometer) . . . . . . . . . . . . . . . . . 204

C.10 Salience Indicators: Switzerland . . . . . . . . . . . . . . . 205

C.11 High Salience Period: Main Effects . . . . . . . . . . . . . . . . . 206

C.12 Heterogeneity in Effects of Unemployment: Prior Left-Right Moderation During High Salience Period . . . . . . . . . . . . . . . 207

C.13 Heterogeneity in Effects of Unemployment: Age Moderation During High Salience Period . . . . . . . . . . . . . . . . . . . 208 


\section{List of Tables}

1.1 Examplary Evidence on Associations Between Unemployment and Labour Market Policy Attitudes . . . . . . . . . . . . . . . . . . . . . 18

1.2 Causal Evidence . . . . . . . . . . . . . . . . . . . 21

2.1 Summary of Robustness Checks _ . . . . . . . . . . . . . . . . . . . 64

B.1 SOEP Results: Main Effects . . . . . . . . . . . . . . . . . . 156

B.2 SOEP Results for First Wave LMP Sceptics . . . . . . . . . . . . . 158

B.3 SOEP Results for First Wave LMP Neutrals . . . . . . . . . . . . . . . . . . 159

B.4 SOEP Results for First Wave LMP Supporters . . . . . . . . . . . . . . . 160

B.5 SOEP Results for First Wave Right Party Identifiers . . . . . . . . . . . . . . . 161

B.6 SOEP Results for First Wave Non-Party Identifiers . . . . . . . . . . . . . . 162

B.7 SOEP Results for First Wave Left Party Identifiers . . . . . . . . . . . . . . . 163

B.8 SOEP Results: Interaction Models for Employment Deteriorations . . . . . . 165

B.9 SOEP Results: Interaction Models for Employment Improvements . . . . . . 166

B.10 SOEP Results: Interaction Models for Temporary Unemployment . . . . . . . 167

B.11 SOEP Results: Interaction Models for Increasing Job Insecurity . . . . . . 168

B.12 SOEP Results: Interaction Models for Decreasing Job Insecurity . . . . . . . 169

B.13 SOEP Results: Interaction Models for Decreasing Reemployment Chances . 170

B.14 SOEP Results: Interaction Models for Increasing Reemployment Chances . . 171

B.15 SOEP Results: Pairwise Comparison of Average Marginal Effects for Employment Transitions . . . . . . . . . . . . . . . . . . . . . 173

B.16 SOEP Results: Pairwise Comparison of Average Marginal Effects for Job Insecurity Perceptions . . . . . . . . . . . . . . . . . . . 173

B.17 SOEP Results for Transitions and first wave LMP Sceptics \& Right PID: Comparison between Subgroup Analyses and Interaction Models . . . . . . . . . 175

B.18 SOEP Results for Transitions and first Wave LMP Neutrals \& No PID: Comparison between Subgroup Analyses and Interaction Models . . . . . . . . . 176

B.19 SOEP Results for Transitions and first Wave LMP Supporters \& Left PID: Comparison between Subgroup Analyses and Interaction Models . . . . . . . 177

B.20 SOEP Results for Perception Changes and first Wave LMP Sceptics \& Right PID: Comparison between Subgroup Analyses and Interaction Models . . . . . 178

B.21 SOEP Results for Perception Changes and first Wave LMP Neutrals \& No PID: Comparison between Subgroup Analyses and Interaction Models . . . . . 179

B.22 SOEP Results for Perception Changes and first wave LMP Supporters \& Left PID: Comparison between Subgroup Snalyses and Interaction Models . . . . 180

C.1 Main Effects (OLS) . . . . . . . . . . . . . . . . . . . . 210

C.2 Main Results (FE) . . . . . . . . . . . . . . . . . . . . . 210

C.3 Main Effects (FEIS) . . . . . . . . . . . . . . . . . . . . 210 
C.4 Prior Left-Right Interaction Effects . . . . . . . . . . . . . . . . . 212

C.5 Age Interaction Effects . . . . . . . . . . . . . . . . . . . . . 214

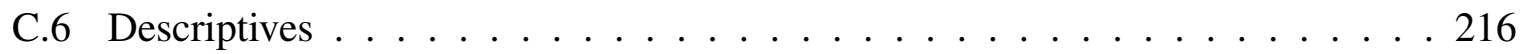

C.7 Results from Artificial Example . . . . . . . . . . . . . . . . 218

C.8 "Manual" OLS Results from Artificial Example . . . . . . . . . . . . . . 218 


\section{Framework}

\subsection{Introduction}

This cumulative dissertation project deals with the political consequences of unemployment. More precisely, it focuses on the effects on labour market policy attitudes, as the title suggests: "Unemployment and Labour Market Policy Attitudes". The subtitle - "Political Predispositions, Economic Self-Interest, and Questions of Causality" - summarizes its theoretical perspective.

Self-interest arguments typically serve as a basis for ideas on how unemployment impacts people's political demands. Politically, people want what benefits them economically. Thus, their political demands should directly react to their economic situation. But, at the same time, we know that individual political opinions are relatively stable over time and influenced by people's broader political worldview: their political predispositions. This raises doubts about a direct, causal relationship between unemployment and political demands. At the same time, it is beyond any doubt that unemployed people have distinct political demands. Unemployed people prefer more government action and spending to fight unemployment and to financially assist during unemployment. Yet, it is possible that these distinct political demands are not the direct, causal result of unemployment. The roots of a non-causal relation between unemployment and these distinct demands could also lie in early socialization.

Taken together, this thesis combines one of the core political economy questions (what are the political consequences of economic risk and hardship?) with one of the core tenets in the literature on political behaviour: attitude change is the exception, not the rule. Thus, this thesis can offer lessons to both research traditions. Doing so, the thesis contributes to the field of welfare state research, which often combines both perspectives, as well.

The contribution to political behaviour research is to examine the assumption of attitudinal and predispositional stability under circumstances where such stability is least likely: unemployment - a major material shock. Indeed, Krosnick and Alwin's (1989, p. 423) study on attitudinal change and stability over the life cycle already concluded that the observation of stability can have two sources: 1) individuals' attitudes are barely susceptible to change and 2) individuals are not or less exposed to change-inducing events. Building on this idea, I complement the study of unemployment, a least likely case for attitudinal stability, with analyses on the link between unemployment and labour market policy attitudes, a most likely case for self-interest effects.

The contribution to the political economy literature is to examine the relationship between unemployment and labour market policy attitudes with more realistic assumptions of political 
reasoning. First, this means to take seriously the possibility of attitudinal stability after unemployment. This leads to the main question of the dissertation.

1. Is there a causal impact of unemployment on labour market policy attitudes?

The main question of causality of this thesis is: causality or confounding? In conceptual terms, this means considering economic risk as a confounding factor in the relationship between economic hardship and political demands. Various socio-economic factors can create a non-causal relationship between unemployment and labour market policy attitudes by influencing both: the chances (risk) of becoming unemployed and the political demands one raises. In methodological terms, this means adopting a counterfactual perspective on causality. In theoretical terms, unemployment effects that are confounded by the risk of unemployment can be explained by self-interest. Yet, this thesis proposes to think of the roots of this confounding as emerging from unequal, "stratified" early socialization experiences between different socio-economic groups. These three steps - a) doubting a causal relation b) adopting a counterfactual perspective, and c) seeing confounding as a result of stratified early socialization - guide the whole thesis. With these three steps this thesis is part of a small, yet steadily growing, literature with a similar perspective on the effects of material hardship (including unemployment) on political attitudes (including labour market policy attitudes), predispositions, and behaviour (Emmenegger et al., 2017; O’Grady, 2019).

The second contribution to the political economy literature is to examine exceptions to attitudinal stability that are well known in the literature on political behaviour. There are two primary exceptions: first, people without strong predispositions like young adults still in their impressionable years or people who, for different reasons, never developed strong predispositions; second, people whose prior predispositions color the attitudinal adaption to a new situation or information. Are such factors decisive for the question of attitudinal change or stability after unemployment? The theoretical and empirical focus on these questions is a unique contribution in the study of unemployment and labour market policy attitudes with a counterfactual perspective. In particular, the second and third paper of this cumulative dissertation look closer into these exceptions and ask:

2. Is the impact of unemployment on labour market policy attitudes greater in circumstances where people's self-interest and their predispositions are not opposing forces?

3. Is there an impact of unemployment on political predispositions? And again, is this impact greater in circumstances where predispositions and self-interest are not opposing forces?

Focusing on the question of when self-interest prevails over predispositional influences, and when the opposite is true, is also a contribution to research on welfare state support. The conclusion is often that both, self-interest and value orientations (the kind of predisposition mostly discussed in this research) matter. A vague and somewhat unsatisfactory conclusion given how both theoretical perspectives and their empirical expectations are pitted against each other (Owens and Pedulla, 2014). 
Parallel to these three research questions, this cumulative dissertation is comprised of the following three articles:

Article 1: Wehl, N. (2019): The (ir)relevance of unemployment for labour market policy attitudes and welfare state attitudes, in: European Journal of Political Research 58(1), 141-162.

Article 2: Wehl, N. (2020): Going beyond values versus self-interest: whose attitudes change after employment transitions?, in: Political Research Exchange 2(1), 1-23.

Article 3: Wehl, N. (2021): The dynamics of unemployment, risk, and left-right ideology. Constrained change or changed constraints? (Under review)

The first article analyses the relationship between unemployment and labour market policy attitudes, between unemployment and redistributive attitudes, and the role of socio-economic risk factors in these relationships. The second paper looks at several employment transitions including job loss and job insecurity changes and how related labour market policy attitude changes depend on individuals' prior predispositions. The third paper directly examines the effect of transitions into unemployment on predispositions - left-right ideology - and how they vary by age, prior predispositions, and the political context. Figure 1.1 summarizes the research questions of the three articles and embeds them in the theoretical perspective of the dissertation.

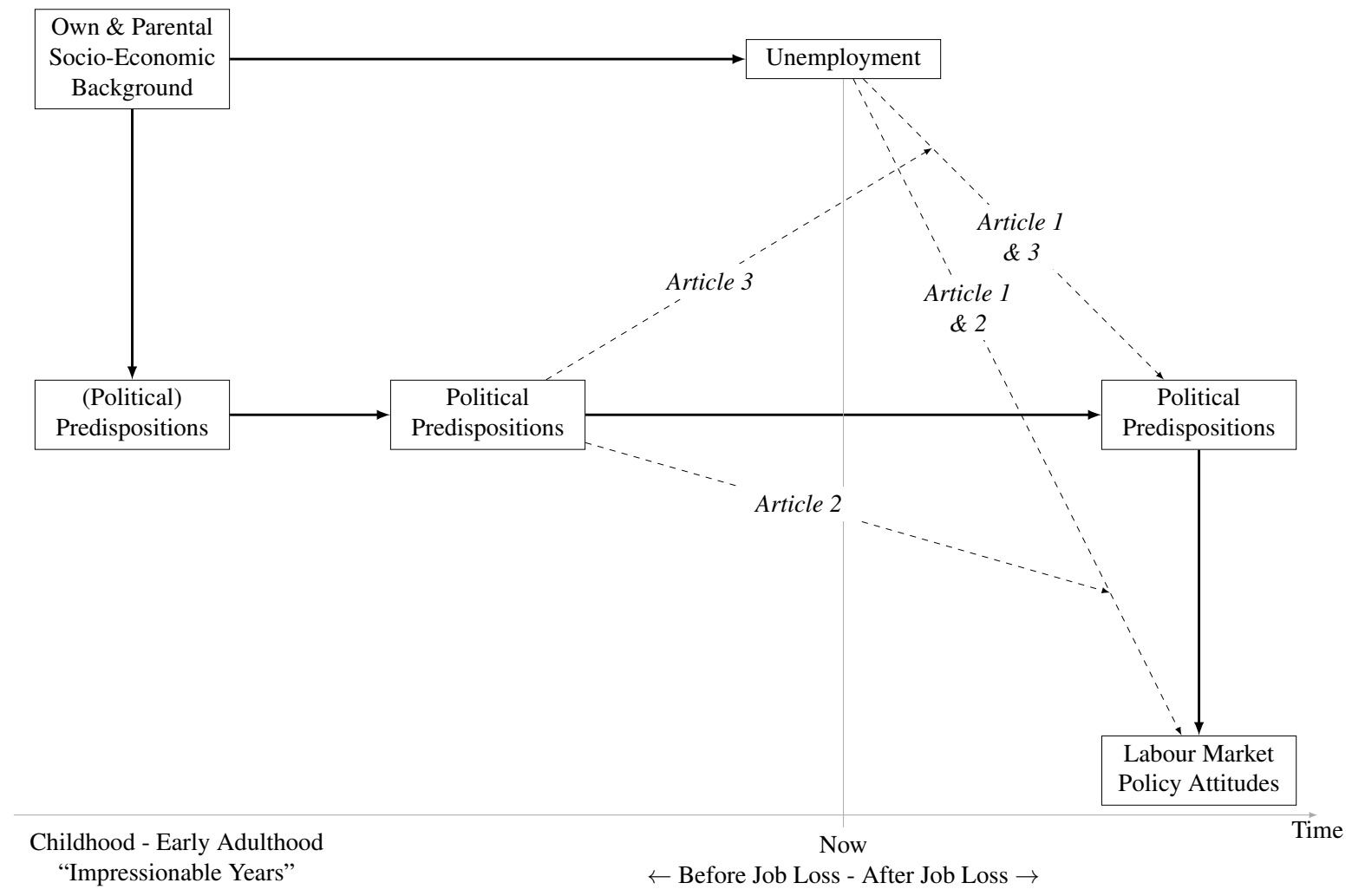

Figure 1.1: The Theoretical Model and the Three Articles

The main message from the project is that the effects of unemployment on individual political beliefs are the exception rather than the rule once adequate designs and methods for causal 
inference are applied. The first article examines the effects of unemployment in 31 countries and finds effects on labour market policy attitudes only in a handful of countries and effects on redistributive attitudes in an even small number of countries. The second article finds that the effect of job loss on changes in labour market policy attitudes exists only for supporters of left parties and policies. The third article finds that young and left-leaning people are more prone to left shifts in response to unemployment. Considering that reactions of labour market policy attitudes to job loss are a most likely case for self-interest effects, these small and limited effects of unemployment are already a strong signal against the relevance of self-interest effects.

These results fit nicely into similar debates with a slightly different empirical focus. After all, whether there are causal relationships and whether these differ between societal groups is a question raised with regard to various instances of economic circumstances and various kinds of political attitudes, predispositions, and types of political behaviour. First, very similar discussions exist with regard to other individual economic shocks - most prominently income changes (Gidron and Mijs, 2019; O'Grady, 2019; Ojeda, 2018). Second, not only individual level economic shocks, but also the effects of macroeconomic shocks, like e.g. the economic crisis from 2008 onwards (Brooks and Manza, 2013), can be discussed in similar terms. Third, other political outcomes like political engagement (Emmenegger et al., 2017; Ojeda, 2018) or support for right-wing policies like restrictive migration policies (Lancee and Pardos-Prado, 2013) are also among these scholarly discussions. Some of these studies do not find any effects of material circumstances, while others only find small effects or effects on specific subgroups only, like young people. The central message from these studies is that the biggest part of the coincidence of material hardship and specific political demands and or types of political behaviour is not due to a direct reaction to material hardship.

So, how should we interpret the finding that the causal impact of material circumstances like unemployment on political attitudes like labour market policy attitudes is at best limited? Why is it even important to differentiate between people who prefer certain policies because of a material shock and other people who already did so before experiencing this material shock? For predictive purposes, for knowing who supports which policies, or whether a majority supports a specific proposal, the question of causality is, at best, a small nuance. It starts to matter when considering the question of why sometimes the prediction that a randomly chosen unemployed person will support a certain policy works better, and sometimes worse. Based on a self-interest logic research already developed answers centering around a policy feedback logic. The lesson from this kind of research is that material risk and hardship is a poor predictor of social policy preferences in contexts where social policies build a dense security net (Gingrich and Ansell, 2012). But if this self-interest assumption of a causal relation is wrong or has only limited empirical validity, this kind of reasoning might limit our understanding of the true context factors that shape this relationship. In particular, if limited causal relations between material circumstances and political attitudes or behaviour are the result of early socialization experiences, then context factors shaping these socialization experiences are probably more relevant for the socio-economic structure of political conflicts (Gingrich, 2019).

In the following section, I begin with an overview of previous work on the relationship between unemployment and social policy attitudes. I continue with discussing in detail the theoretical foundation of this thesis - self-interest and predispositions - and deriving the hypotheses I test 
in the three articles. Afterwards, I delineate the theory behind the questions about causality, and how the research of the three articles addresses these issues. Finally, I summarize each of the three articles, highlight their contributions, outline lessons and limitations of this dissertation, and discuss open questions for future research.

\subsection{Previous Research}

Previous research identified a clear and robust pattern: existing studies showed repeatedly that unemployed people support active and passive labour market policies - more so than employed persons. Table 1.1 provides some examples of such studies in a non-exhaustive list. Unemployed persons are more in favour of government action to secure a certain living standard during unemployment, spending on unemployment benefits, and similar "passive" labour market policies. Furthermore, unemployed people are more in favour of "active" measures, i.e. government action to create new jobs as long as they do not demand too much from the unemployed (Fossati, 2018), or state intervention in the labour market to avoid unemployment in declining industries. Unsurprisingly, such patterns can also be seen from the descriptive, bivariate evidence in this dissertation project. In particular, figure 2.3 in article 1 shows significant bivariate associations between unemployment and labour market policy attitudes in the majority of all analysed countries. It should be clear from this review that this dissertation project is neither able nor willing to question the existence of such associations.

One reason for the wealth of evidence on the association between labour market policy attitudes and unemployment is that researchers with diverse interests focus on it. First, there is the literature on support for the welfare state (Andreß and Heien, 2001), often from a sociological perspective. This literature on welfare state attitudes often centers around a theoretical dichotomy between different determinants of these attitudes: self-interest and value orientations. This dichotomy is subsequently modelled empirically with variables capturing self-interest (including unemployment) and variables capturing a certain value orientation (for example egalitarianism). In table 1.1 this description covers the studies by Baslevent and Kirmanoglu (2011) and Blekesaune and Quadagno (2003)

This literature on welfare state support does not only tell us that unemployed people prefer more labour market policies. Studies with a comparable design using some self-interest and some value indicators also show that unemployed people support all kinds of social policies, often analysed as indices (Arts and Gelissen, 2001; Andreß and Heien, 2001; Gelissen, 2000). And of course, a large amount of studies directly focuses on support for redistribution or redistributive tax schemes. This literature shows that unemployed persons show high support for redistribution as well (Jæger, 2006; Jaime-Castillo and Sáez-Lozano, 2016). Of course, political economists are also interested in redistributive demand (Meltzer and Richard, 1981). In contrast to the discussed sociological literature, this political economy research generally refrains from directly modelling the impact of value orientations. But with regard to the effects of unemployment, the results point in the same direction: unemployed people want more redistribution (Alesina and La Ferrara, 2005; Cusack et al., 2006). 


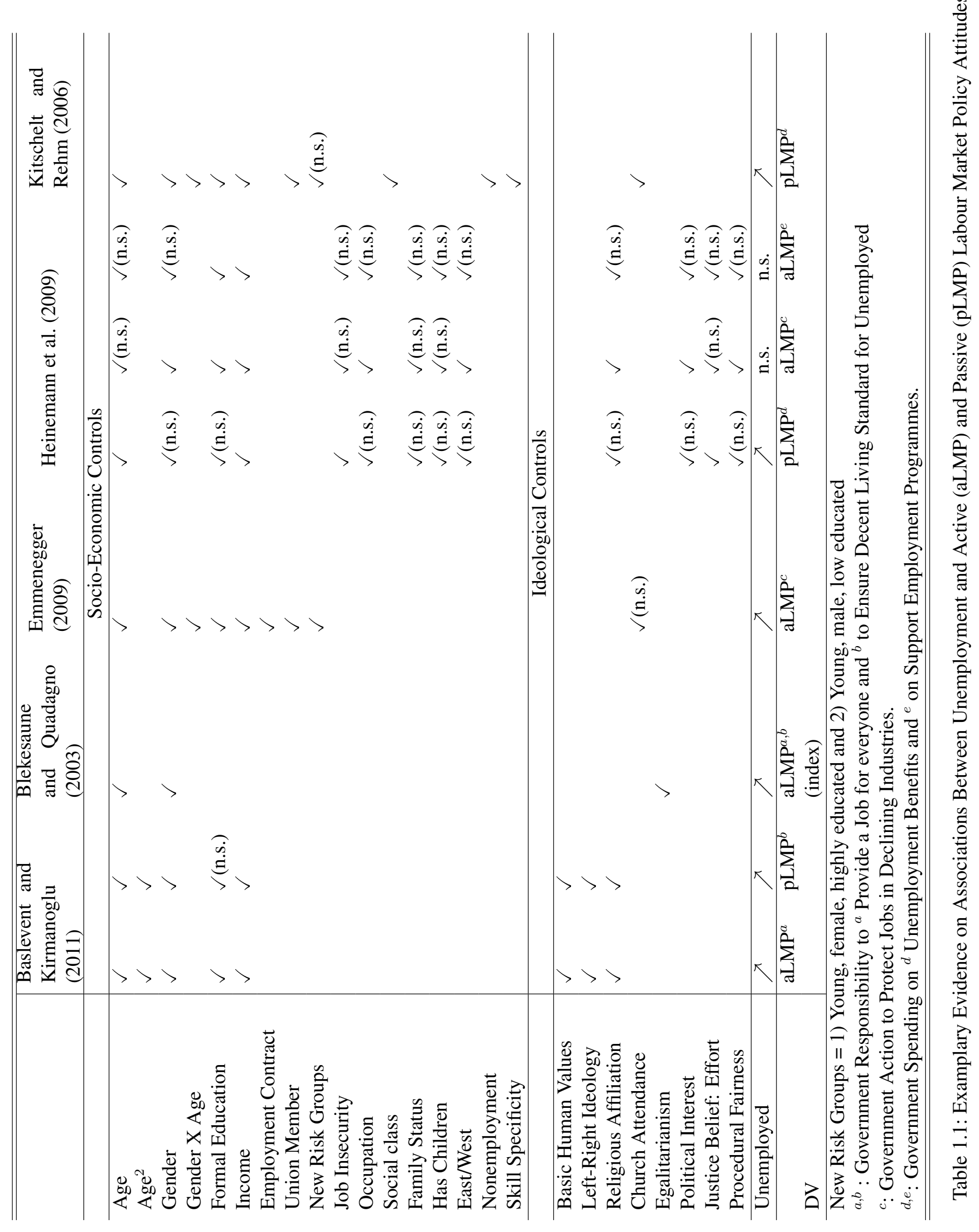


Finally, the political economy literature has produced a substantial amount of research on labour market dualization (Rueda, 2005) and related consequences for political attitudes and behaviour. In table 1.1 this kind of research is exemplified by the paper form Emmenegger (2009). But with its emphasis on the distinction between labour market insider and outsider, this research focuses not so much on the effects of unemployment per se, but more on the effects of unemployment risk. After all, labour market "outsiders" are those with a high unemployment risk, whether this categorization is based on the type of the employment contract - like in Emmenegger's (2009) study - occupation-based (Rehm, 2009; 2016), or a continuous measure of different risk factors (Schwander and Häusermann, 2013). Thus, the main message from this literature is that not only unemployment but also unemployment risk is an important predictor of support for labour market policy and other social policy attitudes.

Typically, the conclusion from these studies on different social policy attitudes (including labour market policy attitudes) and redistributive attitudes is that both, self-interest and values matter. The reason for this conclusion is that both, self-interest indicators like unemployment (as "realized risk") or other risk factors and value indicators turn out as significant predictors of these attitudes. Concerning these associations with values and other predispositions, it can be seen in table 1.1 that basic human values, left-right ideology, and welfare-related egalitarian orientations or other justice principles predict support for labour market policies.

Yet, this predictive power does not say anything about how and why these factors matter for labour market policy attitudes (or other political attitudes, predispositions, and behaviors). Two main problems complicate the interpretation of the presented findings. First, each empty cell in table 1.1 is an instance of omitted variable bias. And variables capturing the socio-economic situation while individuals are growing up, during the "impressionable years", are completely missing. Second, studies including both socio-economic and ideological indicators lead to some unknown, uninterpretable mix of omitted variable bias and post-treatment bias. This is equally true for existing cross-sectional studies, that try to see how self-interest and predispositions interact (Armingeon and Weisstanner, 2021).

Contributing to this kind of research with a clear causal design is a core aim of this research. Doing so, this dissertation project is in line with a still small but growing number of articles from the last five to ten years with such a causal focus. Table 1.2 gives an overview of these studies. It tries to be exhaustive with regard to a) published studies at the time of the submission (May 2021) of this dissertation that b) employ a causal identification strategy with regard to c) effects of short-term material shocks (unemployment and income shocks) on d) labour market policy attitudes and other welfare state attitudes (first part of the table) and left-right ideology and party support (including voting, preferences, and attachments). 


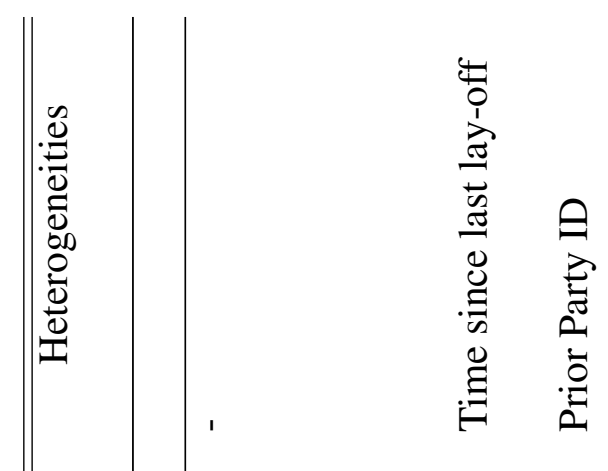

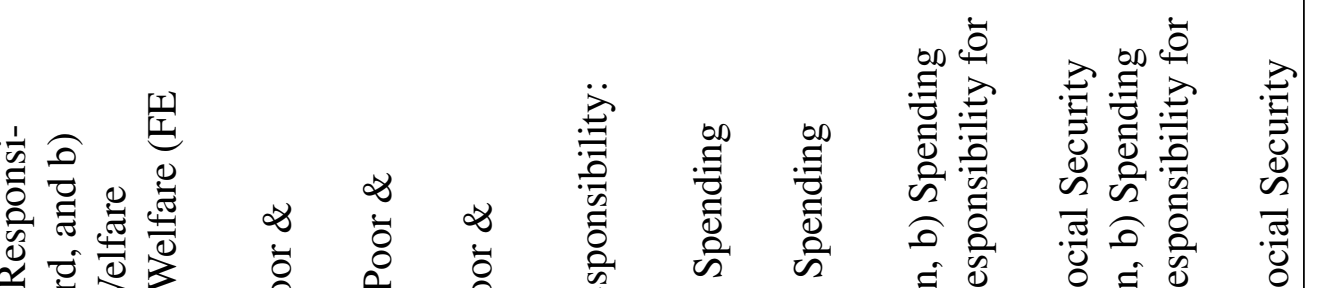

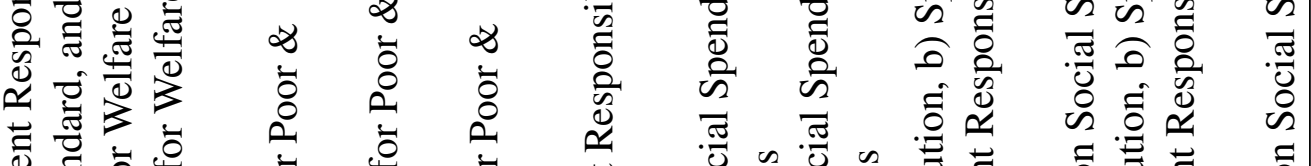

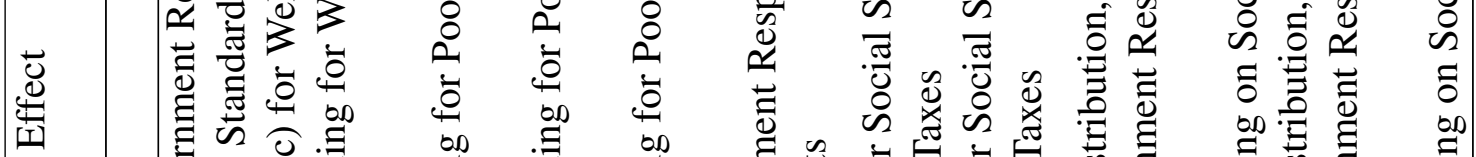

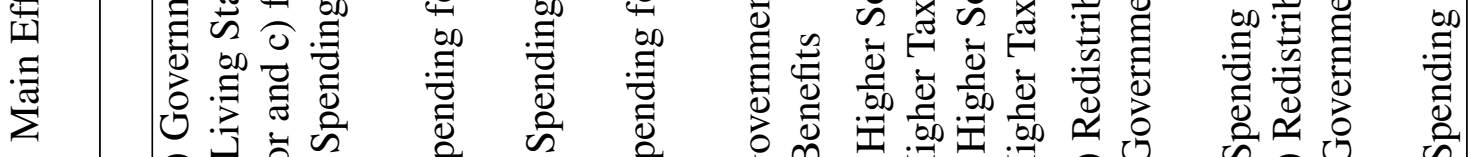
ति के के के की

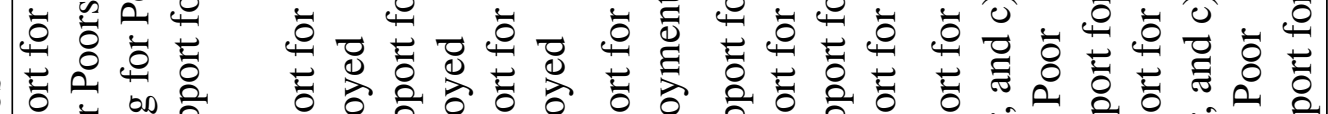

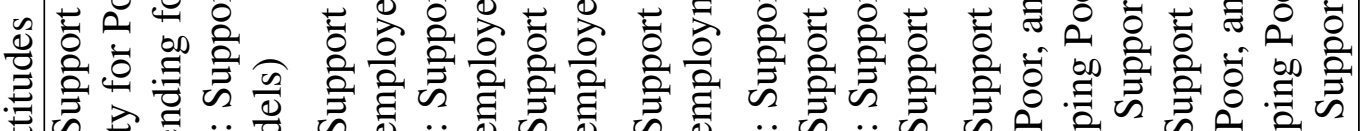

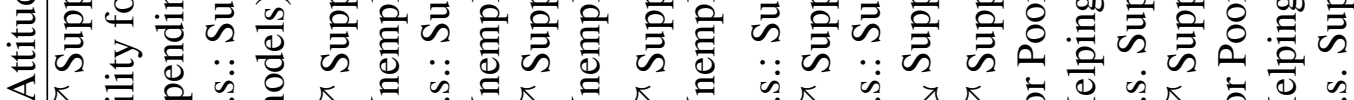

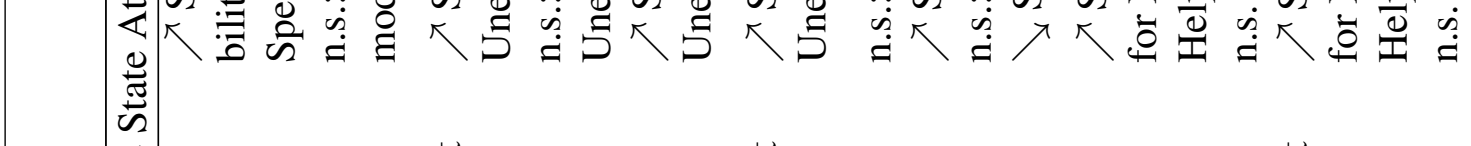

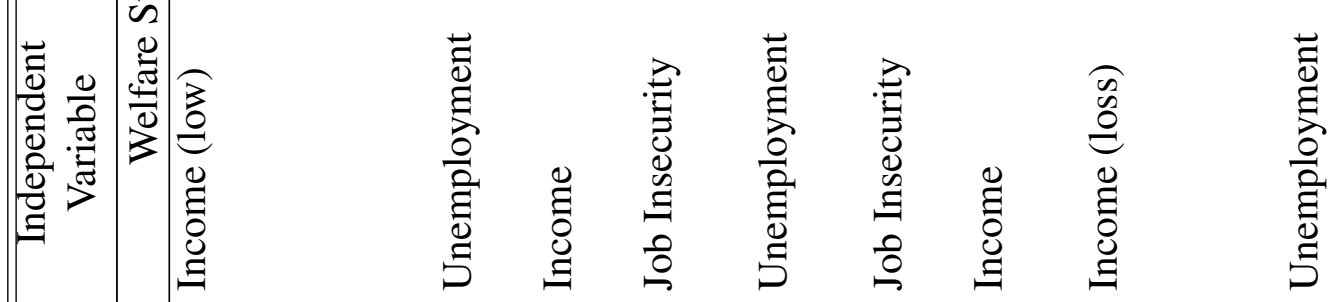

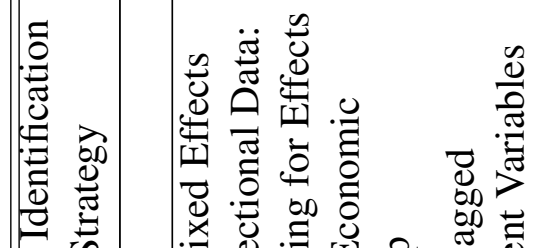

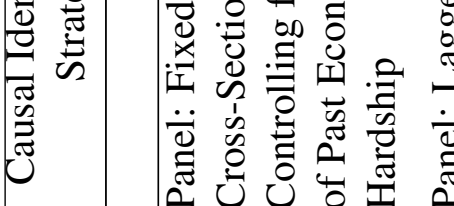

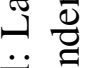

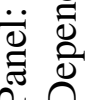

荎

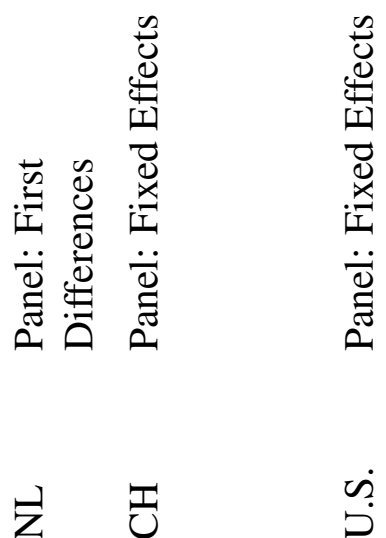

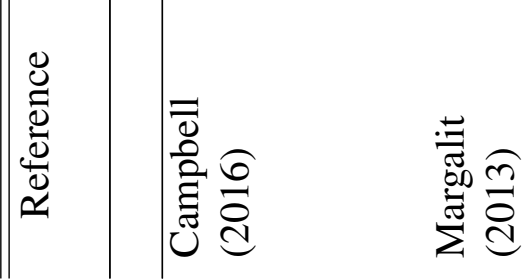

Z 艺 $\stackrel{\dot{\varphi}}{\varpi}$

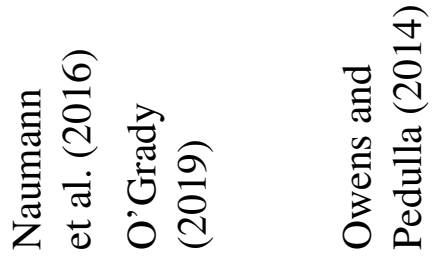




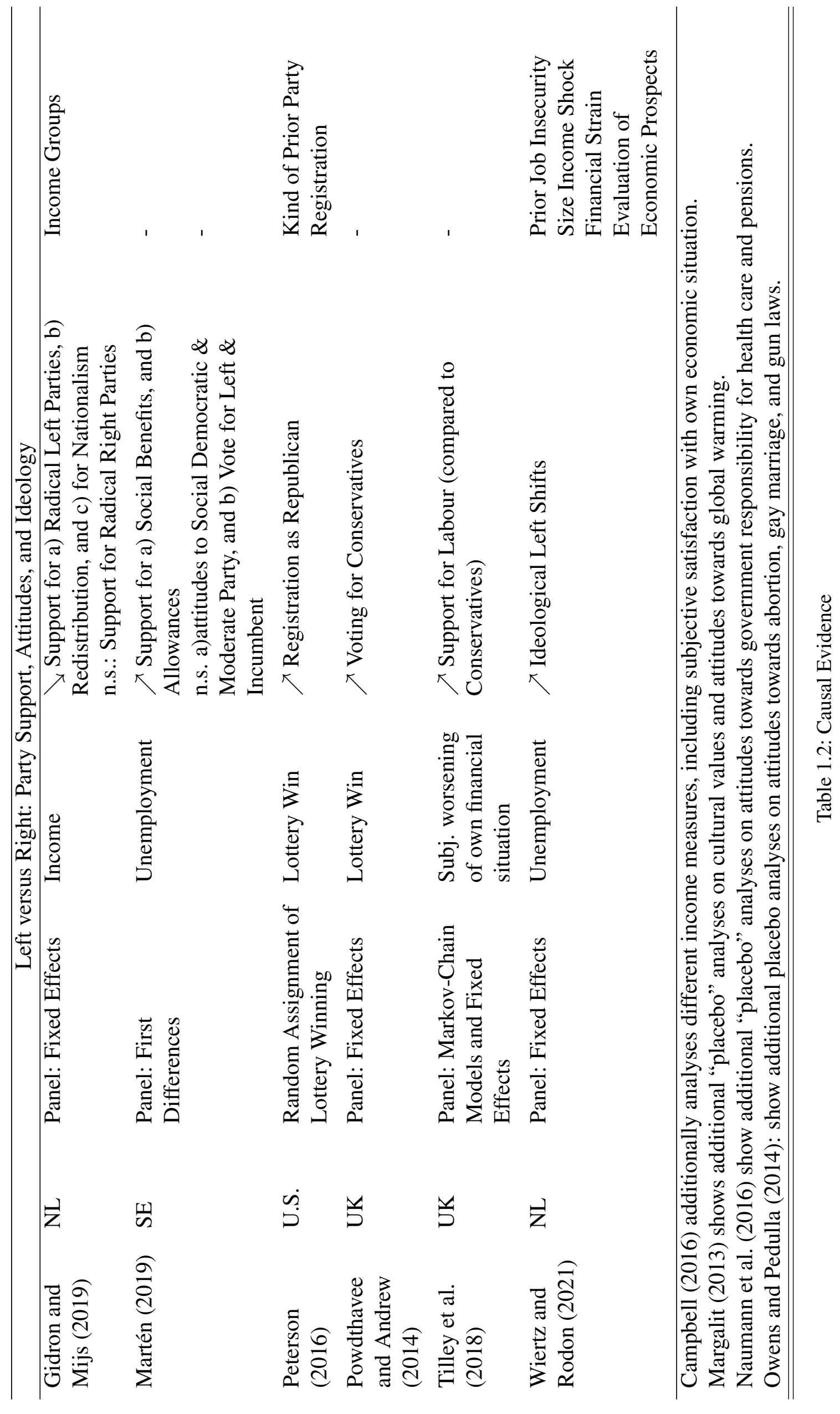


Table 1.2 includes eleven studies often covering multiple analyses. Six of those studies contain one or several null results of material shocks on labour market policy or welfare attitudes or party support. Thus, even though the majority of findings do suggest a causal effect of material shocks, the evidence is mixed. This is problematic since studies finding effects of material shocks conclude that political reasoning is self-interest driven (Naumann et al., 2016), while studies with null-effects highlight that in presence of economic shocks people use their pre-existing values or other predispositions as heuristics for their attitudes (O'Grady, 2019). Previous literature remains largely silent with regard to the question, how both kinds of results are possible. This statement can be broken down into two major gaps of the previous literature that the present dissertation tries to overcome.

First, all studies in table 1.2 are single-country studies. On top of that, these eleven studies cover only five different countries. The evidence we have so far is thus highly selective. It is possible that due to certain context factors the existing evidence either overemphasizes the effects of material shocks or overemphasizes null-effects. To give an example, both the U.S. and the UK are typically classified as liberal welfare regimes, Switzerland often as well (Ferragina and Seeleib-Kaiser, 2011). This could be the basis for an argument that, indeed, results suggesting a causal effect of material shocks are overrepresented. After all, as previously mentioned, crossnational research suggests that unemployment (risk) is more predictive for social policy support when social protection is weaker (Gingrich and Ansell, 2012), as it is the case in liberal welfare regimes. This gap in the literature is addressed by the cross-national analyses of around 30 countries in the first article and by the comparison of longitudinal data from several countries in the third article.

Second, a possible answer to the mixed findings is that predispositions and self-interest somehow interact with each other in influencing people's attitudes. Yet this possibility is completely ignored from the literature with a causal perspective. One notable exception are the analyses by Margalit (2013) on partisan-based heterogeneity in unemployment effects. Empirically somewhat further away from this thesis, another exception is Peterson's (2016) study on partisan support after winning the lottery. While both studies are from the U.S., they suggest opposite mechanisms. Margalit (2013) finds effects of job loss only among Republicans but not Democrats, suggesting that self-interest dominates for people whose self-interest and predispositions are opposing forces. Peterson finds effects of a lottery win only among Republicans, suggesting that effects are only present when self-interest and predispositions are not opposing forces, but aligned. Note that the recent cross-sectional study without such a clear causal design by Armingeon and Weisstanner (2021) supports the findings from Margalit (2013). They also conclude that right-leaning people, who are "cross-pressured", because for them self-interest and ideology do constitute opposing forces, tend to give greater weight to their self-interest. But it might not only matter whether predispositions and self-interest constitute opposing forces. It is also possible, that circumstances under which predispositions are weaker matter as well. This is a possibility that none of the listed studies analyses.

To put this empirical evidence and its gaps into context, it's worth widening the focus on the dependent variable side of studies with a causal design on effects of material shocks. Table 1.2 does not include research on the relationship between material shocks and political participation or engagement (Bauer, 2018; Emmenegger et al., 2017; Schraff, 2018; Schraff, 2019) or on the 
relation between material shocks and migration-related attitudes (Lancee and Pardos-Prado, 2013).

Even when widening the empirical focus to other political outcome variables, the picture does not change substantially. Of course, some other countries are covered. Consider, for example, Emmenegger et al.'s (2017) study on unemployment and political interest in Germany or Lancee and Pardos-Prado's (2013) study on unemployment and migration-related attitudes in Germany. Emmenegger et al.'s (2017) study on age heterogeneities in unemployment effects on political interest is noteworthy. In line with the arguments in this thesis, this study argues and finds, that once individuals' impressionable years end, unemployment does not impact political interest anymore. Before, however, it does. Additionally, widening the empirical focus leads to some other causal inference methods that are covered, like in the case of the Swiss study by Pecoraro and Ruedin (2016) on the interaction between education and unemployment risk in shaping migration-related attitudes. However, the overall picture - mixed findings, singlecountry studies, and a widespread disregard of political heterogeneities - stays the same.

\subsection{Theoretical Framework}

In the following I discuss in detail the theoretical underpinning of the thesis: predispositions and economic self-interest. I start with a discussion of self-interest in the relation between unemployment and labour market policy attitudes. This first part answers the question why we would expect a causal relation between both. I continue with a discussion of political predispositions. They give reason to doubt such a causal relationship. Furthermore, functional characteristics of predispositions allow for more nuanced hypotheses, for what kind of societal groups this causal relationship might nevertheless exist. Thus, from this second part I deduct the hypotheses I test in the three articles of this thesis.

\subsubsection{Self-Interest}

The starting point for arguments about unemployment effects on (labor market) policy preferences is the traditional political economy assumption of self-interest driving the formation of these preferences. People prefer those policies that benefit them in an economic sense, i.e. that maximize their utility (Meltzer and Richard, 1981).

In the case of unemployment benefits and active measures to bring the unemployed back into employment, it is straightforward that they benefit the unemployed. In contrast, employed persons do not directly benefit from these measures, while they ultimately pay for these policies with their taxes. Both considerations lead to the expectation that the result of the cost-benefit calculation of employed and unemployed people differs substantially (Rueda, 2005). 
But self-interest accounts do not only assume that current material hardship like unemployment, but also the mere risk to experience such hardship, especially unemployment risk, can influence the result of such cost-benefit calculations. The only additional assumption needed is that people take into account the future. Accordingly, not only the unemployed "homo economicus", but also the "homo insecuritas" (Rehm, 2016), who is likely to experience job loss in the future, prefers active and passive labour market policies based on material self-interest.

Criticizing self-interest perspectives and broader rational choice perspectives is of course pervasive in the social sciences. First, this means that there are already many ideas out there, if and how rational, self-interested reasoning and heuristic reasoning can be combined. One type of solution is to incorporate predispositions into the cost-benefit calculation. Probably the most widespread example within political science is the discussion about the rationality of voter turnout. Narrow perspectives on self-interested voters lead to the conclusion that (nearly) no one should turn out to vote, since the act of voting incurs costs but practically no benefits for each individual. Obviously, this is empirically wrong. Therefore, it has been suggested to include the value for democracy, or citizens' civic duty, i.e. probably the most potent predisposition for turnout, into the cost-benefit calculations. Or in other words: it has been suggested to adopt a broader perspective on self-interest (Blais, 2000). A very similar move to adopt a wider perspective on self-interest could be done with regard to political attitudes, including labour market policy attitudes (Weeden and Kurzban, 2017). For example, one could add individuals' orientations towards meritocracy, equality, or equity to their cost-benefit calculations.

Here, I intentionally avoid such a broad view on self-interest, that would treat predispositional influences as part of self-interested political reasoning. Treating both as separate in contrast allows me both: conceptualizing observational differences between the two perspectives and theorizing about how self-interest and predispositions interact.

\subsubsection{Predispositions}

The fundamental idea behind speaking about "predispositions" is that predispositions are not just another kind of attitude, but functionally different from attitudes. Throughout this thesis, I mainly subsume party identification, political ideology, and value orientations under the term "political predispositions". In contrast to other attitudes, predispositions are more stable over time, more abstract, and exert influences over attitudes (Maio et al., 2003). In the following, I discuss in more detail the characteristics of political predispositions and how I use these to derive hypotheses about the relationship between unemployment and labour market policy attitudes.

\section{Predispositions as Central Components in Political Belief Systems}

First, it is noteworthy that political predispositions are not the only kind of predispositions. If one moves backwards in the causal chain, personality traits and genetic factors can also be seen 
as predispositions. Indeed, one could even say that genes and personality factors predispose people to develop a certain political predisposition (Weinschenk and Dawes, 2017). In contrast to political predispositions, personality and genetic factors do not have a heuristic (Goren, 2013) function to guide attitude formation. To give an example, while a certain ideal about equality can help me to think about a social policy proposal, my genes or my personality cannot. Nevertheless, genes and personality certainly influence political attitudes and behaviour, including welfare attitudes (Gerber et al., 2010; Hatemi et al., 2014). Such (possibly confounding) effects should not be forgotten.

Second, value orientations, party attachments, and ideology do not cover the whole range of political predispositions. For example, Sears and Funk (1999) also treat racial and ethnic prejudice and nationalism as predispositions. Similarly, political interest is also considered as a core political predisposition (Prior, 2010; Schumann and Schoen, 2009), yet certainly with higher relevance for political engagement. Since this list of examples could be further continued, it is important to consider the characteristics that political predispositions share and how they differ from political attitudes.

The core definitional difference between political predispositions and political attitudes is that the former are more abstract. They are related to a multitude of more specific situations, objects, or policy areas. Indeed, this is a feature that the various conceptions of value orientations - from more recent accounts of policy principles (Goren, 2013) to older accounts of value systems by Rokeach or Schwartz (Feldman, 2003; Maio et al., 2003) - share. As example, one can think of an egalitarian value orientation. Such an orientation can be applied to numerous policy questions - from several social policy areas to daily life decisions. All this is even more true for ideologies, which are typically thought of as combining different values. And while support for a certain party is not as abstract as an egalitarian ideal, also party identification can be applied to a multitude of different political questions. That predispositions transcend more specific situations is only a definitional feature and does not say anything about the empirical use of predispositions as heuristics. Yet their abstractness is certainly a precondition to think of them as a heuristic.

This differentiation between attitudes and predispositions can also be done more formally by pointing to the eminent role of political predispositions in individuals' political belief systems. Belief systems according to Converse (2004, p. 181) are a "configuration of ideas and attitudes in which the elements are bound together by some form of constraint or functional interdependence." Thinking of a belief system thus means focusing not only on one specific political attitude. In contrast, thinking about a belief system means to think about all attitudes people possess, and how they are related. This lead more recent work to depict belief systems either as correlation matrices between all kinds of attitudes (Baldassarri and Gelman, 2008; Munzert and Bauer, 2013) or as networks with each attitude (and predisposition) as node and their relations as ties connecting those nodes (Baldassarri and Goldberg, 2014; Brandt et al., 2019).

Political predispositions are the central elements in political belief systems. Basically, this statement reiterates my statement in the beginning of this section: political predispositions are more stable than attitudes, influence (constrain) attitudes and thus structure individuals' political belief systems. Yet the belief system logic highlights that predispositions are so stable 
because they influence the other attitudes in the belief system. Indeed, it can be shown that a hypothetical, simulated belief system becomes more stable and consistent when the influence of central on peripheral elements (i.e. constraint) is increased (Brandt and Sleegers, 2021).

It is of course an empirical question whether predispositions are really the central elements of individuals' belief systems and, thus, are more stable than attitudes, and whether causality runs from predispositions to attitudes or vice versa. The next sections discuss the empirical evidence for these questions.

\section{Predispositional Stability}

The general stability of political predispositions is a rather uncontroversial idea with many instances of empirical support. There is empirical evidence on the stability of predispositions over the short- and medium-term, i.e. with repeated measurements less than ten years apart, often only two or four years apart (Bartle, 2000; Goren, 2005; Schumann and Schoen, 2009). Additionally, there are studies on the long-term stability of predispositions over several decades (Sears and Funk, 1999). While such studies often model stability and report stability coefficients, there are also readily interpretable examples: Sears and Funk (1999) find that $60 \%$ of respondents had same party identification over almost forty years. And Schumann and Schoen (2009) find $80 \%$ of respondents with a similar (exactly the same or \pm 2 ) left-right self-placement after 8 years.

Yet, while the overall idea of predispositional stability is uncontroversial, the relevant literature considers several nuances. First, there is often a concern that while findings from the U.S. context are very widespread, they might not be directly applicable to the European context. In particular, both, the prevalence of multiparty systems in Europe compared to the two-party system in the U.S. (Rekker et al., 2018) and the decrease of political polarization in several European countries compared to the increase in the U.S. (Munzert and Bauer, 2013) could suggest such differences in the stability and impact of predispositions. In general, this concern seems unwarranted. To give a few examples, the above-mentioned study by Schumann and Schoen (2009) comes from the German context and shows high levels of ideological stability. Importantly for the German context, this holds for both, East-Germans and West-Germans. Arzheimer and Schoen (2005) also show high stability and no relevant East-West differences in Germany concerning party identification. In the Dutch context, Rekker et al. (2018) suggest that left-right ideology is the stronger predisposition compared to party identification, partly because ideology proves to be very stable, while party identification is somewhat more volatile. And as final example from the European context, Schickler and Green (1997) show the high stability of party identification for the British context. Taken together, these findings suggest that predispositional stability is an equally relevant pattern in the European context, even though the role of specific predispositions might be different than U.S.-based findings suggest.

I take the theoretical considerations about the central role of predispositions in belief systems and the empirically proven high stability of predispositions as a basis for doubts about selfinterest effects. In particular, I hypothesize that it is possible to observe no effect of unem- 
ployment on political predispositions. I test this hypothesis in the third article with regard to unemployment effects on left-right ideology. To some extent, I also test this argument in the first article where I examine - among other things - unemployment effects on redistributive attitudes and beliefs in justice principles. The qualification in the previous sentence reflects that redistributive attitudes are certainly not the typical case for a predisposition. While they are sometimes treated as simply another policy attitude or redistributive preference (Alesina and La Ferrara, 2005), they are also sometimes treated as redistributive value orientation (Blekesaune and Quadagno, 2003). It probably makes sense to see it either as a rather specific and probably somewhat less central predisposition or as a rather unspecific policy attitude. As discussed in the next paragraph, this does not affect the hypothesis.

More central to the main interest of this thesis, I hypothesize, that it is possible to observe no unemployment effect on labour market policy attitudes. On the one hand, this hypothesis might seem implausible. After all, I discussed that predispositions and attitudes are conceptually different and behave differently. Among other things, it is typically believed that attitudes are less stable than predispositions. On the other hand, this hypothesis about attitudinal stability reflects the discussed idea that the stability of predispositions also stabilizes the rest of the political belief system (Brandt and Sleegers, 2021), including attitudes. Indeed, the comparison between attitudinal stability and predispositional stability is part of a long-standing debate. Some suggest that lower attitudinal stability is only a result of measurement error artefacts (Ansolabehere et al., 2008; Freeze and Montgomery, 2016; Krosnick, 1991). Taking into account these considerations this hypothesis is, indeed, not implausible. At the same time, it is probably fair to say that it is more likely to empirically falsify the hypothesis about attitudinal stability than the hypothesis about predispositional stability in the face of unemployment.

As a more general point is important to note that self-interest effects and predispositional stability do not exclude each other logically. After all, no one assumes or can prove perfect stability. It is possible that the experience of a material shock like unemployment is the exception to predispositional and especially attitudinal stability. But, it is also possible that the question of self-interest effects or stable predispositions is not a simple yes or no question. This idea motivates the following theoretical discussions that try to create a better understanding when, for whom, or under which conditions self-interest effects are more likely and when the stability of predispositions is likely to be the end of the story. In general, I expect that self-interest effects are more likely when self-interest and predispositions are not opposing forces. This is true in two cases: First, when predispositions are weak, and second, when self-interest and predispositions suggest the same political reaction.

\section{Predispositional Instability in the "Impressionable Years"}

Speaking about predispositional stability in adult life one should not forget about the other side of the coin: early socialization. This is the time in which political predispositions are not yet stable or strong predictors of other attitudes. Attitudes and especially predispositions characterized by high stability in adult life need to be formed in the first place. The formation of attitudes takes place during the so-called "impressionable years" from childhood to early adult- 
hood. During that time political beliefs become "crystallized" (Neundorf and Smets, 2018). This involves three parallel processes. Children and adolescents become ever more opinionated over time and develop a clear opinion on ever more issues. At the same time, these opinions become more and more stable over time, as they grow older. And finally, all these opinions become more and more structured, or consistent, during adolescence (Rekker et al., 2018). Or in other words: the belief system develops its structure, while different external influences, "socialization agents" like parents, schools, or peers are present.

There is ample evidence that political predispositions and political attitudes are more volatile in early years and grow more stable over time - mostly in political science literature, but also in sociological research (Kiley and Vaisey, 2020; Vaisey and Kiley, 2021). However, there is no agreed-upon endpoint to the phase of the impressionable years. Thus, empirical evidence for higher predispositional and attitudinal volatility "early" in life exists for various definitions of this early life stage. This is relevant for the thesis because it suggests that first labour market experiences and some part of the impressionable years coincide.

To give an idea of the available evidence, let's at first consider the example of Kiley and Vaisey (2020) in the U.S. context, who empirically study a wide range of attitudes, political and nonpolitical attitudes alike. They find higher attitudinal stability for people aged over 30 for some, but far from all of the studied attitudes - including political attitudes. However, they state that they tested several cutoff points for "young age" ranging from 20 to 45 years, highlighting again the non-existence of a clear endpoint of the impressionable years. More evidence from the U.S. context comes from Alwin and Krosnick (1991) who find evidence for more volatility in party identification for people aged 18-25 than for others. While in this study they do not find similar evidence for other studied political attitudes and predispositions, the same authors do provide such evidence for a broader range of political attitudes and predispositions in another similar study (Krosnick and Alwin, 1989). Finally, there is also European evidence, like from the previously discussed study by Rekker et al. (2018) from the Netherlands. The authors found that between 12 to 25 years left-right ideology became increasingly stable. A similar effect was not observed for party identification which (among other things) lead the authors to the previously mentioned conclusion that in the Dutch context ideology is the more central predisposition. An earlier study by Rekker et al. (2015) also showed increasing stability of economic and cultural attitudinal scales during adolescence and young adulthood.

Finally, as already mentioned in the section on previous research, the study by Emmenegger et al. (2017) on political interest - an important political predisposition in the realm of political participation - is noteworthy. This study showed that the effects of unemployment on political interest are stronger for younger people and fade out later in life. Consequently, I hypothesize that unemployment effects on predispositions are more likely to be observed for younger people. This is tested in the third article concerning the effect of unemployment on left-right ideology. 


\section{Predispositional Influences on Attitudes: Constraint \& Motivated Reasoning}

The previous two sections dealt with empirical evidence for predispositional stability and the main exception to that rule: the impressionable years. But thinking back to the logic of predispositions as central elements in individuals' belief systems, not only predispositional stability but also the influence of predispositions on attitudes is crucial. Evidence on predispositional effects on attitudes comes from two distinct research traditions. On the one hand, there is literature that starts where findings on predispositional stability end. Both attitudinal and predispositional stability is very common but both, attitudinal and predispositional change is possible. The first research tradition asks what happens in that case and directly compares attitudinal reactions to predispositional change with predispositional reactions to attitudinal change. The second research tradition centers on motivated reasoning. Here, the focus is on how predispositions affect the way people perceive and interpret new situations and how this ultimately affects their attitudes. Basically, both research traditions simply deal with the question of where consistency in belief systems comes from.

The direction of causality between attitudes and predispositions is part of a longstanding debate in political science (Gerber and Green, 1998). Some claim that predispositions affect attitudes (i.e. constraint attitudes), while others believe that attitudes affect predispositions (i.e. update predispositions). On the one hand, the interest in this question is fuelled by its relation to the fundamental mechanisms of democracy. The view that predispositions are a "running tally" (Gerber and Green, 1998) of policy attitudes is part of a broader view on citizens as rational actors in the democratic process. The view that predispositions influence attitudes, in contrast, is often seen as at odds with both rationality and standard accounts of democratic theory (Carsey and Layman, 2006; Highton and Kam, 2011). On the other hand interest in the question of the direction of causality between attitudes and predispositions is fuelled by mixed findings in the literature. However, more recent research established that previously mixed findings overlooked the decisive factors: the importance and salience of the policies for which people hold a certain attitude. In the case of highly important and salient issues, it is far more likely that people adjust their predispositions to their attitudes than when the policies at stake are not important or not salient. Issue salience and importance are decisive for the direction of causality between predispositions and attitudes both on the contextual level of the political discourse and on the individual level (Carsey and Layman, 2006; Dancey and Goren, 2010; Highton and Kam, 2011; Weber and Saris, 2014). I apply these insights to the question of whether unemployment affects predispositions. I hypothesize that unemployment effects on predispositions are more likely when economic issues are more salient. I test this with regard to unemployment effects on left-right ideology and how they are moderated by the salience of topics in the public (i.e. country-wide) discourses in the different countries analysed in the third paper. Of course, these insights are also relevant for the question of unemployment effects on labour market policy attitudes. While I do not focus on this question empirically, these considerations suggest that attitudinal reactions to unemployment are also less likely when economic issues are not salient. After all, in this case, predispositions are more likely to stabilize attitudes.

So far, all arguments and hypotheses simply deal with the question, whether there is, or there is not a predispositional or attitudinal reaction to unemployment. Motivated reasoning accounts 
additionally suggest that the direction of change can be different, depending on individuals' prior political predispositions. Fundamentally, it can be seen as a modern version of the argument already raised in "The American Voter" that partisanship filters how people perceive and interpret the world (Campbell et al., 1960).

The basic idea of motivated reasoning is that people's prior beliefs and predispositions bias how they seek out new information and how they interpret new information or situations. According to Taber and Lodge (2006) there are three distinct motivated reasoning mechanisms: a confirmation bias (people seek out information congruent with their prior beliefs); a disconfirmation bias (people spend more time counterarguing arguments incongruent with their prior beliefs); and a prior attitude bias (people evaluate arguments congruent with their prior beliefs as more plausible). The consequence of all three mechanisms or biases is polarization. New information and new situations reinforce pre-existing beliefs. In empirical terms, this thesis is more concerned with this consequence - polarization - than with disentangling the different motivated reasoning mechanisms.

In this thesis, I use motivated reasoning arguments, that among other things have been applied to the study of aggregate economic circumstances, and apply them to the effects of individual economic circumstances. However, doing so is not straightforward, as a look at typical motivated reasoning studies shows. First, there are studies directly concerned with the information people seek out and how this is biased by their predispositions. This is, what Taber and Lodge (2006) tested. Second, there are studies on how people perceive objective facts and how this is biased by their predispositions. A typical application of this type of motivated reasoning studies is the question of how people perceive a country's economic situation (Schaffner and Roche, 2017). Thus, in both cases, the explanation for a polarized political reaction is the different (polarized) subjective knowledge or perception of an objective fact. Yet such arguments are implausible for the political consequences of unemployment. After all, being unemployed is an undeniable fact, no matter how strong motivated reasoning is.

But even when confronted with undeniable facts, motivated reasoning "finds a way" (Bisgaard, 2015). Bisgaard shows that during the economic crisis - when economic downturn became an undeniable fact - motivated reasoning skipped the step of perceiving the economic downturn and lead to polarized interpretations of the economic situation. Responsibility attributions became polarized (Bisgaard, 2015; Fernandez-Albertos et al., 2013). In applying motivated reasoning to the study of the political consequences of unemployment I follow this logic and assume that individuals' predispositions color how individuals interpret their job loss. Consequently, I hypothesize in the third article that left-leaning people react with an ideological left-shift and right-leaning people react with an ideological right-shift to unemployment. While left shifts can be associated with economic concerns, ideological right shifts after unemployment can be related to migration-related concerns. In the second article, I apply motivated reasoning arguments to the effects of unemployment on labour market policy attitudes. I hypothesize that left-leaning people react with increased support for labour market policies after job loss. Not that decreased support for labour market policy attitudes after job loss goes directly against the self-interest of individuals. Therefore, I did not consider a proper polarization effect for labour market policy attitudes, where, additionally to the increased support by left-leaning individuals, right-leaning individuals decrease their support. 
Additionally, I consider circumstances, under which motivated reasoning is less likely. People without strong predispositions should have a lesser basis for biases based on motivated reasoning (Taber and Lodge, 2006). Therefore, I hypothesize in the second paper that people without strong predispositions show a bigger increase in support for labour market policy attitudes in response to job loss. This follows the same logic as the hypothesis about stronger effects during the impressionable years. When predispositions are weak, self-interest effects might be stronger as self-interest and predispositions are not opposite forces. 


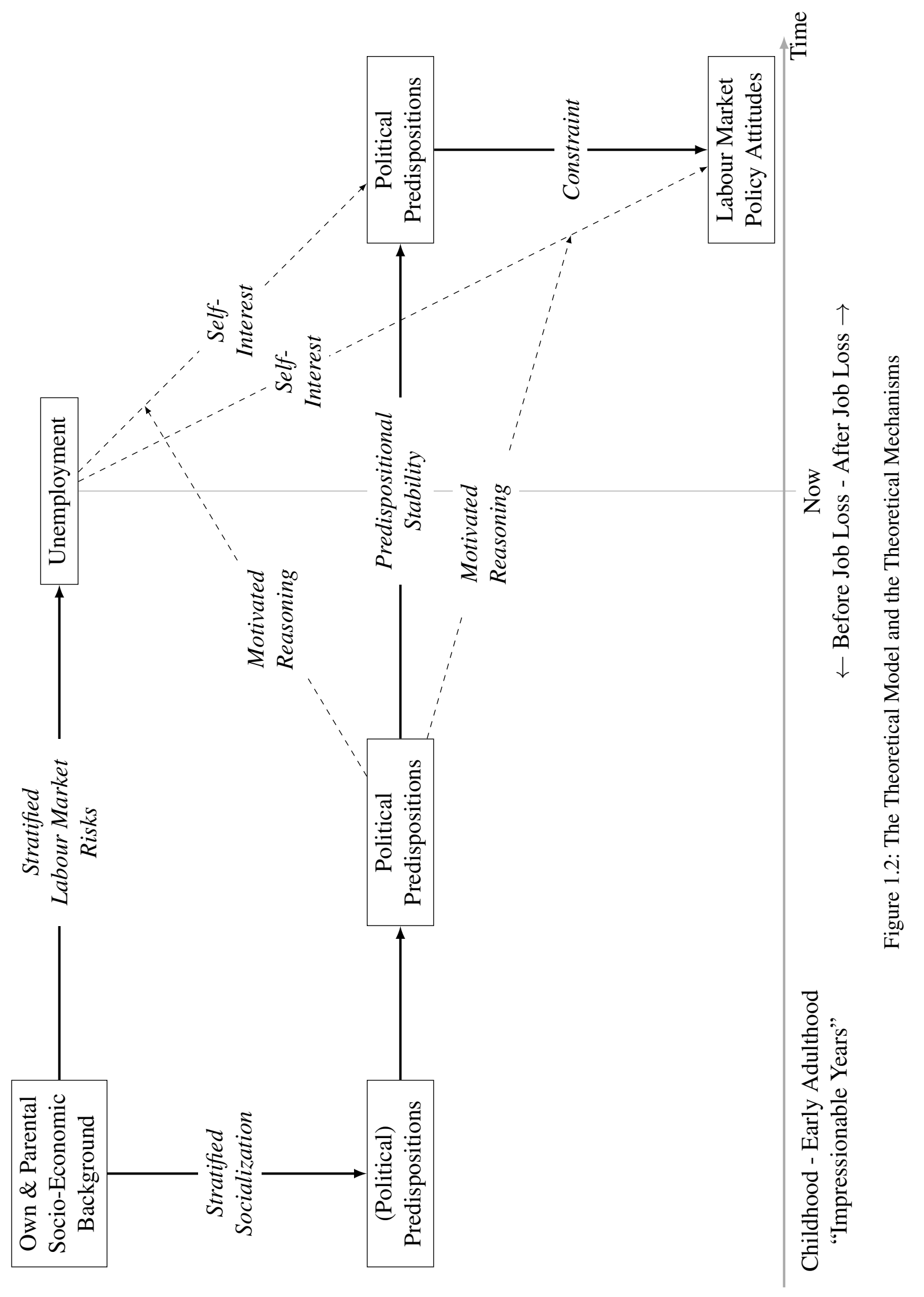




\subsection{Questions of Causality}

\subsubsection{Stratified Socialization as Explanation for Confounding}

So far we have seen that there are robust associations between unemployment and labour market policy attitudes and between unemployment and other welfare-related attitudes. Evidence on whether these associations are the result of a causal effect is scarce and mixed. Later, I discussed various reasons to expect such a causal effect, to doubt such a causal effect, and to refine the expectation of such a causal effect to specific subgroups of the population. In the following, I start by contrasting how these different arguments relate to or contribute to the idea of non-causal associations between unemployment and labour market policy attitudes. Afterwards, I discuss the research design applied in the three articles. I conclude by discussing how far these designs allow conclusions about which causal or non-causal mechanism creates the associations between unemployment and labour market policy attitudes.

First, there is the self-interest argument which I equate with the expectation of a causal effect of unemployment on political attitudes and predispositions for everyone. Two qualifications are due for this statement. On the one hand, this self-interest based expectation of a causal effect of unemployment does not exclude that some or all of the other mechanisms delineated below also play a role. On the other hand, equating the self-interest argument with the expectation of a causal effect does not mean that I prove self-interest as the mechanism behind the causal effect. After all, it is possible to imagine such a causal effect without any self-interest considerations. To give an example, every causal effect of unemployment could also be the result of a somewhat altruistic concern with similar others. Thus, a causal effect of unemployment could simply reflect that employment transitions change the group of people altruistic individuals are concerned about. Importantly, however, I interpret insignificant unemployment effects after applying a credible causal design as a sign that self-interest does not play a role.

Second, there is the idea that (probably) self-interest-based causal effects of unemployment are only observable for people whose predispositions do not favour political consequences against the individuals' self-interest. This covers both the idea that people with weak predispositions are more likely to react in such a way and the motivated reasoning based idea that polarization can be expected. This constitutes a middle way between predispositional accounts and the selfinterest perspective since this argument assumes a causal effect while taking into account the power of predispositions. As the title of the second article puts it, this idea goes beyond the "self-interest versus predispositions" story. In contrast to the first pure self-interest argument, here it is clear, that some groups are not expected to react to self-interest: stronger support for labour market policies or another kind of left-shift after job loss for previously right-leaning people would clearly falsify this idea. Conversely, if everyone reacted to unemployment, but people with certain predispositions reacted more, this would certainly still be consistent with the pure self-interest story previously delineated.

Third, there is the additional self-interest argument that people react to economic risk, just as they react to economic shocks like unemployment. Importantly, this economic risk to become 
unemployed at some point is unequally distributed in society. Unemployment risk is stratified. This point is at the core of many political economy arguments. We know that especially labour market outsiders, i.e. people with non-standard (especially temporary) employment, but also certain occupational groups, face higher unemployment risks. For both, additional gender and age differences have been shown (Giesecke, 2009; Schwander and Häusermann, 2013). Thus, self-interest arguments "automatically" come with an expectation of and explanation for confounding in the relation between unemployment and political attitudes predispositions. However, a self-interested individual should react to all these economic risks and to the realization of that risk - unemployment.

Fourth, based on the idea that the impressionable years coincide with the first labour market experiences, one could argue that only these first unemployment experiences in early adulthood affect attitudes and predispositions. Taking into account that youth unemployment is related to later unemployment, either causally via "scarring effects" (Schmillen and Umkehrer, 2017) or simply because of the persistence of unemployment risk factors, this creates a possibility for a completely confounded relationship between unemployment and labour market policy attitudes in later adulthood. For this, these effects during the impressionable years have to be persistent. Of course, this simply restates the impressionable years hypothesis.

And fifth and finally, there is a second argument based on the idea of the impressionable years. In contrast to the previous fourth mechanism, it is also possible to make such an argument without any reference to any labour market experiences. This means to make an argument for a completely confounded relationship between unemployment and political attitudes and predispositions for everyone. To do so, one needs to combine the already discussed assumption about stratified labour market risks with an argument that there are stratified early political socialization experiences already before labour market entry. Such stratified early socialization experiences can result from different mechanisms, that are not necessarily mutually exclusive. First, this can mean that the transmission of political attitudes and predispositions from parents to children (Jennings et al., 2009; Rico and Jennings, 2016) transmits stratification as well. Of course, this argument would still leave open where stratification comes from in the first place. Second, this can mean that the economic circumstances during childhood and adolescence directly impact the development of political predispositions and attitudes. Finally, this can result from different experiences with other socialization agents, especially schools (Gingrich, 2019). Whatever the exact mechanisms, as long as at least part of these early acquired predispositions as well as the disadvantages experienced early in life remain stable throughout adulthood, confounding is present.

To sum up, self-interest accounts expect a causal relationship between unemployment and political attitudes as well as between unemployment and predispositions even though there is room for confounding by economic risk. In contrast, different versions of the impressionable years hypothesis offer the possibility to see these associations are completely confounded. Finally, both the impressionable years hypothesis and motivated reasoning accounts offer possibilities for heterogeneous causal effects. Keeping in mind these separate mechanisms behind causal and non-causal relations between unemployment and labour market policy attitudes or predispositions is important to be able to theoretically interpret empirical findings of observable or not observable effects after a credible causal design has been applied. The three articles of this 
thesis typically contrast the self-interest-based argument of a causal effect of unemployment with the stratified socialization argument of (potentially pure) confounding (see again 1.2). The same goes for the discussed rest of the literature with a causal inference perspective on the relationship between economic risk or hardship on various political outcomes. It is, therefore, crucial to keep in mind, that there are two versions of stratified early socialization experiences, one including and one excluding the first steps in the labour market. And it is even more crucial to keep in mind that concluding that self-interest does not play a role for non-causal effects of unemployment is only based on the assumption that self-interested people should react to risks and realized risks alike.

\subsubsection{Research Design of the 3 Papers}

The starting point for this thesis question of causality - confounding or causality? - is a counterfactual perspective on causality. This perspective is a rather pessimistic one: there is the fundamental problem of causal inference (Holland, 1986). It is never possible to observe a causal effect. This is due to the definition of a causal effect as the difference in the outcome (dependent variable) between a) a situation where a unit, e.g. a person, has been exposed to the treatment (or independent variable) and b) a situation where the same person did not get exposed to the treatment.

$$
Y_{i=1}^{t_{1}}(T=1)-Y_{i=1}^{t_{1}}(T=0)
$$

One of both situations is never observable - the potential outcome, or counterfactual - since the same person cannot be exposed and not be exposed to the treatment at the same time. A rather fundamental problem indeed.

Practical solutions revolve around assumptions and methods that make causal inference based on comparisons between different persons or based on over-time comparisons plausible. Both solutions are used in the present dissertation project: comparisons between as similar as possible people (between design) and comparisons within the same person over time (within design). Figure 1.3 shows the causal identification strategies applied in the three articles schematically. These different strategies also come with different blind spots.

The biggest difference lies between the within estimation strategy applied to the panel data used in articles 2 and 3 and the between estimation strategy applied to the cross-sectional data in article 1.

Analyses in article 1 (entropy balancing and other re-weighting and matching techniques) rely on a comparison between "treated" and "non-treated" people. In figure 1.3 this equals a comparison between circles and squares. In real life, this means comparing unemployed and employed people, when estimating the effect of unemployment. 

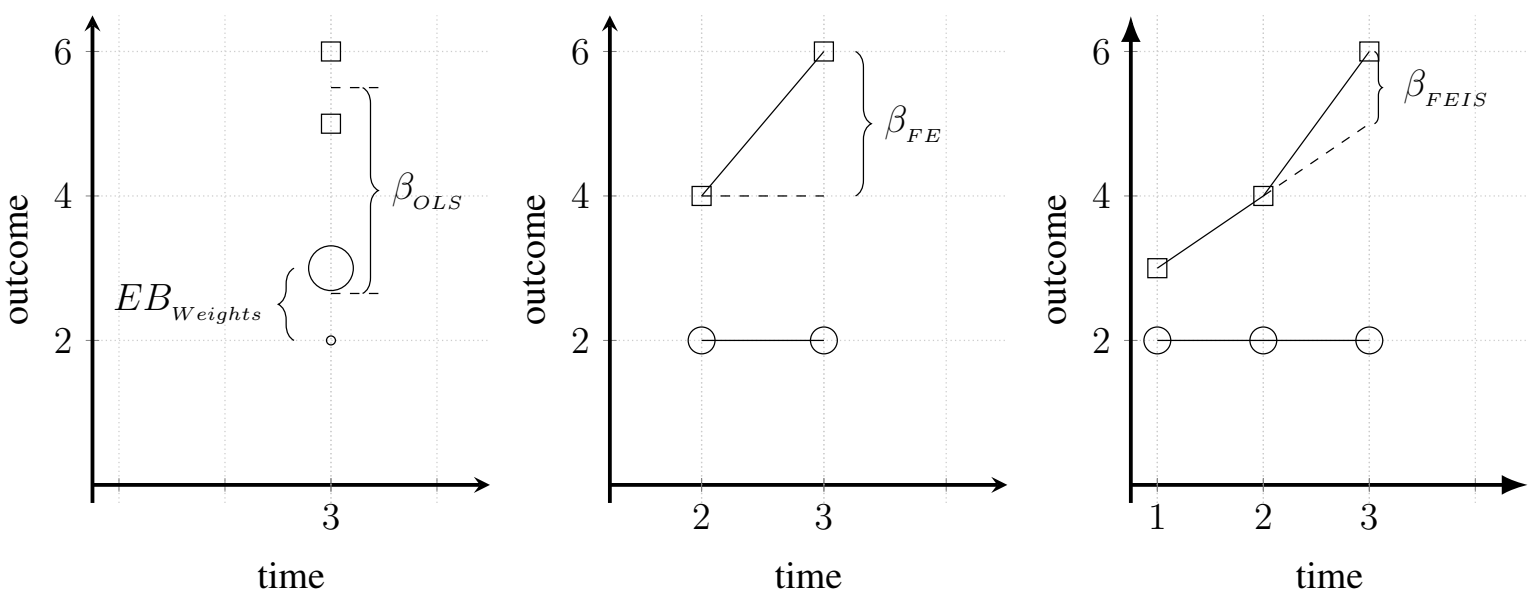

Legend:

$\circ=$ never treated and $\square=$ treated between time points 2 and 3 .

$\mathrm{EB}=$ Entropy Balancing. FE $=$ Fixed Effects. FEIS $=$ FE with Individual Slopes

Figure 1.3: The Causal Identification Strategies of the Three Articles

This comparison is made more plausible by comparing unemployed people with employed people with similar unemployment risk factors. As indicated by the size of the circles in the left panel of figure 1.3 more similar people get a higher weight, more dissimilar people get a lower weight.

Thus, the quality of this comparison crucially hinges on the factors one chooses to determine similarity or dissimilarity between employed and unemployed people. In article 1 I choose a variety of socio-economic and demographic background factors that can be expected to influence selection into unemployment. But unobserved confounders, i.e. factors not included in the entropy balancing analysis, can still bias the comparison between employed and unemployed people.

In particular, this means that confounding by genetic differences, by personality differences, and by non-measured socio-economic differences could still bias the results of article 1 .

Articles 2 and 3 rely on a within-design. The effect of unemployment is estimated by comparing the outcome (labour market policy attitudes in article 2 and left-right ideology in article 3 ) after the person entered unemployment with the outcome of the same person before entering into unemployment. This strategy automatically controls away all stable sources of confounding, like socialization experiences, or previous labour market experiences. It can, however, still be biased, if people who enter unemployment would have anyway (i.e. even in the counterfactual scenario of not entering unemployment) changed their attitudes or their ideology. This is taken into account in the third article. However, while this is a crucial advantage for causal inference, it is possible, that this controls for the risk-based adaption of attitudes or ideology. In this case, extra care (or extra steps like in the third article) is necessary to infer whether a non-causal FEIS estimate means that self-interest does not play a role. 


\subsection{Summary of the 3 Articles}

\subsubsection{Summary Article 1}

Article 1: Wehl, N. (2019): The (ir)relevance of unemployment for labour market policy attitudes and welfare state attitudes, in: European Journal of Political Research 58(1), 141-162.

This article asks whether unemployment effects on labour market policy attitudes and welfare state principles are causal. In theoretical terms, the article starts with doubts about unemployment effects based on the idea of predispositional stability. It continues with developing stratified early socialization as an alternative argument for associations between unemployment and social policy attitudes. This is its main theoretical contribution.

Empirically, the article uses cross-sectional data of the European Social Survey (ESS) and analyses unemployment effects in each of the ESS countries separately. It uses four different dependent variables: 1) respondents' attitude towards government responsibility for active labour market policies, 2) respondents' attitude towards government responsibility for passive labour market policies, 3) respondents' attitudes towards income redistribution by the government, and 4) respondents' belief in the justice principle "equality of outcomes" with regard to living standards. The first two dependent variables are labour market policy attitudes. The last two dependent variables can either be seen as more abstract welfare attitudes or as welfare principles and thus as relatively concrete and probably weak predispositions. The article uses the richness of available socio-economic background characteristics to model different "selection probabilities into treatment", i.e. different unemployment risk factors between the employed and unemployed. It thus answers the question about the causal effect by checking whether the associations between unemployment and the dependent variables remain after the socio-economic confounders are taken into account. The main analyses apply entropy balancing (see again figure 1.3), additional analyses use matching techniques and simple regression adjustment (adding confounders as control variables) to account for these socio-economic confounders.

Its results show that after taking into account socio-economic confounder virtually all associations between unemployment and welfare state principles (dependent variables $3 \& 4$ ) vanish. While in most countries, this is also true for the associations between unemployment and labour market policy attitudes, there is a substantial amount of countries where even after entropy balancing (and similar causal analysis methods), associations remain.

But as discussed in the literature overview, at the time of publishing the article, and even more so at the time of writing the present introductory chapter, raising such doubts was and is not a unique feature of this article. In contrast, by now several articles use a combination of arguments about predispositional stability, stratified socialization experiences, and stratified labour market risks. As a result, they infer doubts about causality between unemployment or other material circumstances and various kinds of political attitudes and behaviour. However, the 
overwhelming majority of these articles are panel studies within a single country (just like the second article of this dissertation).

The main empirical contribution of the article is the test of this causal question in a crossnational context. While the cross-sectional nature of the data leaves room for an unobserved variables bias, the explicit modelling of confounders comes with an additional advantage. In panel studies applying fixed effects, it is only possible to see if, not why, descriptive, bivariate associations are confounded. In contrast, the results of the first article of this dissertation leave no doubt: Socio-economic risk factors are responsible for a huge part of this confounding.

Taken together, the combination of the results' cross-national nature with the comparison of results for different kinds of dependent variables offers a good yardstick for existing and future studies with a smaller scope like single-country panel studies. Furthermore, zooming out from its empirical focus the article shows how future research about relations between any material circumstances and any political outcome variables can apply a more credible causal design.

A clear limitation of the article is that it does not empirically test the mechanisms behind the confounding. While I already acknowledged this in the article, I do see this as an even bigger limitation at the time of writing this introductory chapter. Indeed, a first step aimed at disentangling confounding due to self-interested reactions to economic risk and confounding due to early socialization was already taken in the paper. I checked if most of the confounding is due to the experience of unemployment within the last year (it was not). However, a stepwise approach with a more direct comparison of the confounding due to parental socio-economic variables in comparison to individual socioeconomic variables related to individuals' more recent economic fortunes would certainly have been even more informative. Similarly, while heterogeneities based on prior predispositions are hard to disentangle in cross-sectional data, age heterogeneities could have already been analysed with the ESS data.

\subsubsection{Summary Article 2}

Article 2: Wehl, N. (2020): Going beyond values versus self-interest: whose attitudes change after employment transitions?, in: Political Research Exchange 2(1), 1-23.

The second article asks, whose labour market policy attitudes change after employment transitions. In this context, "whose?" refers to people with various prior political beliefs or predispositions. The answer is crucial for the interpretation of results with respect to the importance of self-interest and predispositions (like values).

Its arguments start, where the first article - together with the biggest part of the literature ends: the dichotomy between self-interest and values/predispositions and related empirical results. Effects of material circumstances on political attitudes and behaviour support self-interest accounts, null-results support predispositional accounts. To go beyond this dichotomy, the article continues with arguments based on motivated reasoning for a moderation of unemployment (risk) effects by prior political predispositions. There are three possibilities for this moderation: 
1) unemployment (risk) reinforces pre-existing beliefs, 2) unemployment (risk) affects people without strong predispositions, and 3) unemployment (risk) effects run opposite to pre-existing beliefs. Only in the third case self-interest and predispositions are truly opposing forces.

The empirical analyses are based on German panel data from the 1997 and 2002 waves of the Socio-Economic Panel study (SOEP). The main dependent variable is a combination of respondents' attitudes towards state responsibility for active and passive labour market policies. Unlike the first article, this second article focuses on the effects of several independent variables: it differs between unemployment and unemployment risk, objective and subjective indicators of unemployment risk, and - given the longitudinal context - positive and negative trajectories of all these indicators. As moderators and indicators for prior beliefs the article uses respondents' party identification and labour market policy attitudes - categorized into left/pro, right/contra, and none/neutral respectively. Analyses are based on fixed effects models (see again figure 1.3), which automatically control for all time-constant confounders.

The results show that job loss simply reinforces pre-existing left tendencies and favourable views of state responsibility. Interestingly and unexpectedly, however, this pattern is not found for the other analysed indicators of unemployment (risk). First, the effects of positive trajectories, especially more decreasing worries about job insecurity, run opposite to pre-existing beliefs. Second, several indicators only affect people without strong partisan ties and/or without a strong view about state responsibility.

The main empirical contribution is to add more evidence about predispositions based heterogeneities in unemployment effects on labour market policy attitudes outside the U.S. context, that Margalit (2013) covered with his study.

Taken together, this second article clearly shows that conclusions about the importance of self-interest vis-à-vis predispositions based on significant "causal" effects of material hardship might not be warranted. Similarly, conclusions about the importance of predispositions compared to self-interest based on insignificant effects of material hardship are probably equally inappropriate. Both kinds of conclusions are only due when the interactions between predispositions and reactions to material circumstances are clear.

A clear limitation of this article is that it remains unclear whether the heterogeneities based on prior predispositions and attitudes are really due to the different predispositions and attitudes. Are they the true moderators? Of course, this article shares this limitation with virtually all research on partisan biases. Nevertheless, only with an answer to that question we could truly understand, whether predispositions-based heterogeneities are due to cognitive biases like motivated reasoning, or whether (socio-economic or age-based) compositional differences drive these heterogeneities. In the latter case, one would move quickly back away from motivated reasoning to risk-based accounts of such heterogeneities. Of course, risk-based accounts of such heterogeneities suffer from the reverse problem. 


\subsubsection{Summary Article 3}

Article 3: Wehl, N. (2021) The dynamics of unemployment, risk, and left-right ideology. Constrained change or changed constraints? (Under review)

This article asks whether unemployment affects political ideology. Thus, it moves beyond the focus on specific policy attitudes of the first two papers of the dissertation, and most of the relevant literature for that matter. Instead, it focuses on unemployment effects on ideology, an important, political predisposition, especially in the European context, as discussed earlier (Rekker et al., 2018).

The starting point for this article are the somewhat mixed findings of the literature (including the first two articles of the dissertation) with regard to "good" estimates of the effects of unemployment on policy attitudes. Many studies find at least a few small effects of unemployment. Both, for effects on support for economically "left" policies (more welfare), and for "culturally" right policies (less immigration). What - if any - is the broader political relevance of such findings? In theoretical terms, the article introduces arguments that point out that even when specific attitudes change, more abstract predispositions change only under rare circumstances. The article continues to identify these circumstances, both on the individual level (young age and - similar to the second article - different prior leanings) and on the macro-level (the salience or importance of the issues that are assumed behind reactions to unemployment). This is its main theoretical contribution.

In empirical terms, the article focuses on middle- to long-run panel data from Switzerland (Swiss Household Panel - SHP), Spain (Political Attitudes Panel - Polat), and the Netherlands (Longitudinal Internet Studies Social Sciences - LISS). The results are based on fixed effects (FE) models and fixed effects models with individual slopes (FEIS). The latter is not only able to account for time-constant confounding, but also for time-varying confounding (see again figure 1.3). The main independent variable is unemployment - its effects can be interpreted as job loss effects given various recodings and sample restrictions. Additional analyses focus on job insecurity feelings before people become unemployed. The dependent variable is respondents' left-right self-placement. (Time-constant!) individual moderator variables are age and left-right ideology measured at the first observed wave for each respondent. Both, the cross-national aspect and the application of FEIS constitute the empirical contribution of the paper.

Its results show no ideological reactions (main effects) to unemployment, except in Spain. Moderation analyses show that the non-existent effect in Switzerland is hidden by polarization after job loss: left-leaning people become more left, right-leaning people become more right. Interestingly, this result fits very well with the result on job loss effects in Germany from the second paper. However, neither in Spain nor in the Netherlands similar heterogeneities are observable. In Spain, however, and only in Spain, only young people react to job loss with a left shift, there is no effect observable for older people. Finally, analyses on the effects of changes in subjective job insecurity restricted to those who do lose their job later find no such effects. 
Taken together, these findings show that ideological reactions to unemployment are the exception rather than the rule and that these exceptions follow known exceptions to predispositional stability. Additionally, the paper suggests that the non-causal associations are not to be understood as a result of risk-based adaptions of ideology. This last point can be seen as a step towards disentangling the mechanisms behind confounding. A point that should probably be more emphasized in the paper is that the effects for young adults in Spain show, that it does indeed make sense to think of the first steps in the labour market as part of the story of stratified early (or not so early) socialization experiences.

A clear limitation of the article is that the reasons for the contextual variation remain poorly understood, even though they are in line with expectations based on issue salience. Since this article is currently under review, I will try to alleviate this issue by comparing unemployment effects on left-right ideology with unemployment effects on economic and migration-related attitudes, if this is in line with the further trajectory of the review process. This way I could at least test the assumption that the Swiss polarization effect is related to migration-related concerns for those with a right-leaning ideology.

\subsection{Conclusion}

In this introductory chapter of the thesis, I summarized the main idea of the thesis. Its main research question is whether there is a causal effect of unemployment on labour market policy attitudes and broader political predispositions. In the section on previous research, I introduced the vast empirical evidence on associations between unemployment and social policy attitudes, including labour market policy attitudes. This literature cannot offer evidence for or against causality in the relationship between unemployment and labour market policy attitudes due to its clear limitations with regard to strategies of causal identification. In contrast, a small literature is emerging that applies more credible causal designs to the question of causality between material circumstances and political attitudes, predispositions, and behaviour. This thesis builds on and contributes to this literature.

In the theoretical section, I identified theoretical expectations and empirical patterns of predispositional stability, attitudinal stability, and predispositional influences on attitudes as a basis for doubts about a causal relationship between unemployment and political attitudes and predispositions. The empirical question of whether unemployment affects labour market policy attitudes causally is thus represented in a similar theoretical question: are there self-interest effects in light of stable predispositions, or are material shocks the exception to the rule of predispositional stability?

In the section on research design, I discussed how this thesis applies research designs that are better suited for observational causal inference than the methods much of the previous literature is based on. Applying these designs, the results of the three articles of this thesis can be summarized as: unemployment often has no causal impact on labour market policy attitudes 
and broader predispositions. But sometimes, even after applying more credible causal designs, effects of unemployment remain.

This is a somewhat unsatisfactory answer as it suggests very different mechanisms of political reasoning to be present - somehow, at the same time. Therefore, a second key concern of this thesis is the identification of factors decisive for the question of causal effects of unemployment on labour market policy attitudes and predispositions. As I discussed in the section on previous research this question is largely ignored in research with a causal perspective on the relationship between material circumstances and political attitudes and behaviour. When focusing on research on the relationship between unemployment and labour market policy attitudes, theoretical treatments of such heterogeneity are completely missing. In empirical terms, one study is a rare exception showing effect heterogeneity by different partisan groups.

The question of heterogeneous effects of unemployment also motivates large parts of the theoretical section. Here I focused on theories about early life socialization and motivated reasoning. I hypothesized that unemployment effects should be more likely when individuals' predispositions are weak or when they already fit well with the self-interest emanating from unemployment. But again, the empirical evidence for such heterogeneities is mixed. While the second and third articles certainly show empirical support for such heterogeneities, there are again - exceptions.

Despite some mixed findings the overall message this thesis and its results can offer is relatively straightforward. The idea of a self-interested, mechanistic adaption of labour market policy attitudes and other political outcomes to unemployment should be overcome. There are simply too many null-results and too many heterogeneities in the effect of unemployment, to uphold this idea.

Of course, this leads to the follow-up question, which alternative idea should serve as a replacement. Where else do associations between unemployment and labour market policy attitudes or other political outcomes come from? In the section on confounding and stratified socialization, I discussed several mechanisms. These alternative stories can now be re-examined in light of the findings of the three articles, even though none of the three articles tested them directly. The theoretical explanation for non-causal associations between unemployment and political attitudes and predispositions I focused on in the three articles are stratified political socialization experiences during adolescence. The effects of unemployment I find after applying credible causal designs suggest that this is not the whole story. Therefore, one could argue that the idea of stratified socialization experiences during the impressionable years should include the first labour market experiences in young adulthood. It is possible, that this is, indeed, the whole story behind associations between unemployment and labour market policy attitudes or other political outcomes. However, the empirical analyses in this thesis did not focus on this question in sufficient detail to provide a conclusive evaluation. Therefore, it is also possible that the following two remaining potential mechanisms operate throughout the whole life course. I suggested that weak predispositions can leave room for self-interest effects and that strong predispositions can interact with self-interest resulting in polarization effects. Since I do find both, supportive evidence and counter-evidence for these arguments, this suggests that these mechanisms do play a role, but they do not tell the whole story. And finally, and to some extent 
in contrast to the arguments of this thesis, one could interpret the results as a sign that people do follow their self-interest but only in the long-term. In this case, individuals would slowly adapt to economic risk. In contrast, material shocks like unemployment would in most cases not affect individuals' attitudes. To give some examples, this could be the case because these shocks are most of the times already anticipated, or because the discussed mechanisms of predispositional stability decelerate such short-term reactions. This argument could be reframed as asking whether the impact of stratified socialization experiences never ceases to play a role. Unfortunately, again, this thesis is ill-equipped to offer a final judgment in this regard. However, the results in the second article suggest that reactions to (perceived) economic risk factors are dependent on individuals' prior predispositions as well.

Future research will hopefully be able to disentangle these mechanisms more systematically. This would not only provide us with a clearer understanding of employment-based gaps (or other risk-based gaps) in social policy attitudes or other political outcomes. It would also help us in identifying which context factors decrease such gaps. If stratified socialization experiences in adolescence play a decisive role, economic inequality present early in life could be such a crucial factor. Additionally, societal institutions that contribute to more or less stratification, like the kind of educational system could play a role here. If additionally, the first labour market experiences in young adulthood play a role, institutions regulating school-to-work transitions are an additional candidate for such context factors. Considering that the strength of predispositions seems to matter, characteristics of the political system that affect predispositional strength, like its polarization, could be added to the list. Finally, if reactions to economic risk in the long-term are a substantial part of the story, policies and institutions that affect this risk should remain on this list, yet with a substantial lag. 


\section{References}

Alesina, Alberto and Eliana La Ferrara (2005). "Preferences for redistribution in the land of opportunities". In: Journal of Public Economics 89 (5-6), 897-931.

Alwin, Duane F. and Jon A. Krosnick (1991). "Aging, Cohorts, and the Stability of Sociopolitical Orientations Over the Life Span”. In: American Journal of Sociology 97 (1), 169-195.

Andreß, Hans-Jürgen and Thorsten Heien (2001). "Four Worlds of Welfare State Attitudes? A Comparison of Germany, Norway, and the United States". In: European Sociological Review 17 (4), 337-356.

Ansolabehere, Stephen, Jonathan Rodden, and James Jr. Snyder (2008). "The Strength of Issues: Using Multiple Measures to Gauge Preference Stability, Ideological Constraint, and Issue Voting”. In: American Political Science Review 102 (2), 215-232.

Armingeon, Klaus and David Weisstanner (2021). "Objective Conditions Count, Political Beliefs Decide: The Conditional Effects of Self-Interest and Ideology on Redistribution Preferences". In: Political Studies (Online First).

Arts, Wil and John Gelissen (2001). "Welfare States, Solidarity and Justice Principles: Does the Type Really Matter?” In: Acta Sociologica 44 (4), 283-299.

Arzheimer, Kai and Harald Schoen (2005). "Erste Schritte auf kaum erschlossenem Terrain. Zur Stabiliter Parteiidentifikation in Deutschland". In: Politische Vierteljahresschrift 46 (4), 629-654.

Baldassarri, Delia and Andrew Gelman (2008). "Partisans without Constraint: Political Polarization and Trends in American Public Opinion". In: American Journal of Sociology 114 (2), 408-446.

Baldassarri, Delia and Amir Goldberg (2014). "Neither Ideologues nor Agnostics: Alternative Voters' Belief System in an Age of Partisan Politic". In: American Journal of Sociology 120 (1), 45-95.

Bartle, John (2000). "Political Awareness, Opinion Constraint and the Stability of Ideological Positions". In: Political Studies 48 (3), 467-484.

Baslevent, Cem and Hasan Kirmanoglu (2011). "Discerning self-interest behaviour in attitudes towards welfare state responsibilities across Europe." In: International Journal of Social Welfare 20 (4), 344-352.

Bauer, Paul C. (2018). "Unemployment, Trust in Government, and Satisfaction with Democracy: An Empirical Investigation”. In: Socius 4, 1-14.

Bisgaard, Martin (2015). "Bias Will Find a Way: Economic Perceptions, Attribution of Blame, and Partisan-Motivated Reasoning during Crisis." In: The Journal of Politics 77 (3), 849860.

Blais, Andr'e (2000). To Vote or Not to Vote. The Merits and Limits of Rational Choice Theory. University of Pittsburgh Press.

Blekesaune, Morten and Jill Quadagno (2003). "Public Attitudes toward Welfare State Policies: A Comparative Analysis of 24 Nations". In: European Sociological Review 19 (5), 415-427.

Brandt, Mark J., Chris G. Sibley, and Danny Osborne (2019). "What Is Central to Political Belief System Networks?" In: Personality and Social Psychology Bulletin 45 (9), 13521364.

Brandt, Mark J. and Willem W. A. Sleegers (2021). "Evaluating Belief System Networks as a Theory of Political Belief System Dynamics". In: Personality and Social Psychology Review (Online First). 
Brooks, Clem and Jeff Manza (2013). "A Broken Public?Americans' Responses to the Great Recession". In: American Sociological Review 78 (5), 727-748.

Campbell, Angus, Philip E. Converse, Warren E. Miller, and Donald E. Stokes (1960). The American Voter. Chicago and London: University of Chicago Press.

Campbell, Colin (2016). "The Formative Years, Economic Hardship, and Beliefs about the Governments Role in Lessening Poverty”. In: Social Problems 63 (2), 244-265.

Carsey, Thomas M. and Geoffrey C. Layman (2006). "Changing Sides or Changing Minds? Party Identification and Policy Preferences in the American Electorate". In: American Journal of Political Science 50 (2), 464-477.

Converse, P. E. (2004). "The nature of belief systems in mass publics". In: Ideology and its discontents. Ed. by John T. Jost and Jim Sidanius. Reprinted Version from 1964. Psychology Press, 181-199.

Cusack, Thomas, Torben Iversen, and Philipp Rehm (2006). "Risks at Work: The Demand and Supply Sides of Government Redistribution". In: Oxford Review of Economic Policy 22 (3), 365-389.

Dancey, Logan and Paul Goren (2010). "Party Identification, Issue Attitudes, and the Dynamics of Political Debate". In: American Journal of Political Science 54 (3), 686-699.

Emmenegger, Patrick (2009). "Barriers to entry: insider/outsider politics and the political determinants of job security regulations". In: Journal of European Social Policy 19 (2), 131146.

Emmenegger, Patrick, Paul Marx, and Dominik Schraff (2017). "Off to a Bad Start: Unemployment and Political Interest during Early Adulthood". In: The Journal of Politics 79 (1), 315-328.

Feldman, Stanley (2003). "Values, Ideology, and the Structure of Political Attitudes". In: $O x$ ford Handbook of Political Psychology. Ed. by David O. Sears, Leonie Huddy, and Robert Jervis. Oxford and New York: Oxford University Press, 477-508.

Fernandez-Albertos, Jose, Alexander Kuo, and Laia Balcells (2013). "Economic Crisis, Globalization, and Partisan Bias: Evidence from Spain”. In: International Studies Quarterly 57 (4), 804-816.

Ferragina, Emanuele and Martin Seeleib-Kaiser (2011). "Thematic Review: Welfare regime debate: past, present, futures?” In: Policy \& Politics 39 (4), 583-611.

Fossati, Flavia (2018). "Who Wants Demanding Active Labour Market Policies? Public Attitudes towards Policies that put Pressure on the Unemployed". In: Journal of Social Policy 47 (1), 77-97.

Freeze, Melanie and Jacob M. Montgomery (2016). "Static Stability and Evolving Constraint: Preference Stability and Ideological Structure in the Mass Public". In: American Politics Research 44 (3), 415-447.

Gelissen, John (2000). "Popular support for institutionalised solidarity: a comparison between European welfare states”. In: International Journal of Social Welfare 9 (4), 285-300.

Gerber, Alan and Donald P. Green (1998). "Rational Learning and Partisan Attitudes". In: American Journal of Political Science 42 (3), 794-818.

Gerber, Alan S., Gregory A. Huber, David Doherty, Conor M. Dowling, and Shang E. Ha (2010). "Personality and Political Attitudes: Relationship across Issue Domains and Political Context". In: American Political Science Review 104 (1), 111-133. 
Gidron, Noam and Jonathan J. B. Mijs (2019). "Do Changes in Material Circumstances Drive Support for Populist Radical Parties? Panel Data Evidence from the Netherlands during the Great Recession, 2007-2015”. In: European Sociological Review 35 (5), 637-650.

Giesecke, Johannes (2009). "Socio-economic Risks of Atypical Employment Relationships: Evidence from the German Labour Market”. In: European Sociological Review 25 (6), 629646.

Gingrich, Jane (2019). "Schools and Attitudes Toward Economic Equality". In: Policy Studies Journal 47 (2), 324-352.

Gingrich, Jane and Ben Ansell (2012). "Preferences in Context: Micro Preferences, Macro Context, and the Demand for Social Policy". In: Comparative Political Studies 45 (12), 16241654.

Goren, Paul (2005). "Party Identification and Core Political Values". In: American Journal of Political Science 49 (4), 881-896.

- (2013). On Voter Competence. Oxford University Press.

Hatemi, Peter K., Sarah E. Medland, Robert Klemmensen, Sven Oskarsson, Levente Littvay, Christopher T. Dawes, Brad Verhulst, Rose McDermott, Asbjørn Sonne Nørgaard, Casey A. Klofstad, Kaare Christensen, Magnus Johannesson, Patrik K. E. Magnusson, Lindon J. Eaves, and Nicholas G. Martin (2014). "Genetic Influences on Political Ideologies: Twin Analyses of 19 Measures of Political Ideologies from Five Democracies and Genome-Wide Findings from Three Populations”. In: Behavior Genetics 44 (3), 282 -294.

Heinemann, Friedrich, Ivo Bischoff, and Tanja Hennighausen (2009). "Choosing from the Reform Menu Card - Individual Determinants of Labour Market Policy Preferences”. In: Journal of Economics and Statistics 229 (2/3), 180-197.

Highton, Benjamin and Cindy D. Kam (2011). "The Long-Term Dynamics of Partisanship and Issue Orientations". In: The Journal of Politics 73 (1), 202-215.

Holland, Paul W. (1986). "Statistics and Causal Inference". In: Journal of the American Statistical Association 81 (396), 945-960.

Jæger, Mads Meier (2006). "Welfare Regimes and Attitudes Towards Redistribution: The Regime Hypothesis Revisited”. In: European Sociological Review 22 (2), 157-170.

Jaime-Castillo, Antonio M. and José L. Sáez-Lozano (2016). "Preferences for tax schemes in OECD countries, self-interest and ideology". In: International Political Science Review 37 (1), 81-98.

Jennings, M. Kent, Laura Stoker, and Jake Bowers (2009). "Politics across Generations: Family Transmission Reexamined”. In: The Journal of Politics 71 (3), 782-799.

Kiley, Kevin and Stephen Vaisey (2020). "Measuring Stability and Change in Personal Culture Using Panel Data". In: American Sociological Review 85 (3), 477-506.

Kitschelt, Herbert and Philipp Rehm (2006). "New social risk and political preferences". In: The Politics of Post-Industrial Welfare States. Adapting post-war social policies to new social risks. Ed. by Klaus Armingeon and Giuliano Bonoli. Routledge, 52-82.

Krosnick, Jon A. (1991). "The Stability of Political Preferences: Comparisons of Symbolic and Nonsymbolic Attitudes". In: American Journal of Political Science 35 (3), 547-576.

Krosnick, Jon A. and Duane F. Alwin (1989). "Aging and Susceptibility to Attitude Change". In: Journal of Personality and Social Psychology 57 (3), 416-425.

Lancee, Bram and Sergi Pardos-Prado (2013). "Group Conflict Theory in a Longitudinal Perspective: Anaylzing the Dynamic Side of Ethnic Competition". In: International Migration Review 47 (1), 106-131. 
Maio, Gregory R., James M. Olson, Mark M. Bernard, and Mechelle A. Luke (2003). "Ideologies, Values, Attitudes, and Behavior". In: Delamater, John. Handbook of Social Psychology. New York: Kluwer Academic/Plenum Publishers.

Margalit, Yotam (2013). "Explaining Social Policy Preferences: Evidence from the Great Recession". In: American Political Science Review 107 (1), 80-103.

Martén, Linna (2019). "Demand for Redistribution: Individuals' Responses to Economic Setbacks". In: The Scandinavian Journal of Economics 121 (1), 225-242.

Meltzer, Allan H. and Scott F. Richard (1981). "A Rational Theory of the Size of Government". In: Journal of Political Economy 89 (5), 914-927.

Munzert, Simon and Paul C. Bauer (2013). "Political Depolarization in German Public Opinion, 1980-2010". In: Political Science Research and Methods 1 (1), 67-89.

Naumann, Elias, Christopher Buss, and Johannes Bähr (2016). "How Unemployment Experience Affects Support for the Welfare State: A Real Panel Approach". In: European Sociological Review 32 (1), 81-92.

Neundorf, Anja and Kaat Smets (2018). "Political Socialization and the Making of Citizens". In: Oxford Handbooks Online. Oxford University Press.

O'Grady, Tom (2019). "How do Economic Circumstances Determine Preferences? Evidence from Long-run Panel Data". In: British Journal of Political Science 49 (4), 1381-1406.

Ojeda, Christopher (2018). “The Two Income-Participation Gaps”. In: American Journal of Political Science 62 (4), 813-829.

Owens, Lindsay A. and David S. Pedulla (2014). "Material Welfare and Changing Political Preferences: The Case of Support for Redistributive Social Policies". In: Social Forces 92 (3), 1087-1113.

Pecoraro, Marco and Didier Ruedin (2016). "A Foreigner Who Does Not Steal My Job: The Role of Unemployment Risk and Values in Attitudes toward Equal Opportunities". In: International Migration Review 50 (3), 628-666.

Peterson, Erik (2016). "The Rich are Different: The Effect of Wealth on Partisanship". In: Political Behavior 38, 33-54.

Powdthavee, Nattavudh and J. Andrew Oswald (2014). "Does Money Make People Right-Wing and Inegalitarian? A Longitudinal Study of Lottery Winners". In: IZA Discussion Papers No. 7934.

Prior, Markus (2010). "You've Either Got It or You Don't? The Stability of Political Interest over the Life Cycle". In: Lournal of Politics 72 (3), 747-766.

Rehm, Philipp (2009). "Risks and Redistribution. An Individual-Level Analysis". In: Comparative Political Studies 42 (7), 855-881.

- (2016). Risk Inequality and Welfare States. Social Policy Preferences, Development, and Dynamics. New York: Cambridge University Press.

Rekker, Roderik, Loes Keijsers, Susan Branje, and Wim Meeus (2015). "Political attitudes in adolescence and emerging adulthood: Developmental changes in mean level, polarization, rank-order stability, and correlates". In: Journal of Adolescence 41, 136-147.

- (2018). "The Formation of Party Preference in Adolescence and Early Adulthood: How and when Does It Occur in the Multiparty Context of the Netherlands?" In: YOUNG 27 (1), 1-21.

Rico, Guillem and M. Kent Jennings (2016). "The Formation of Left-Right Identification: Pathways and Correlates of Parental Influence". In: Political Psychology 37 (2), 237-252.

Rueda, David (2005). "Insider-outsider politics in industrialized democracies: The challenge to social democratic parties”. In: American Political Science Review 99 (1), 61-74. 
Schaffner, Brian F. and Cameron Roche (2017). "Misinformation and Motivated Reasoning. Responses to Economic News in a Politicized Environment". In: Public Opinion Quarterly $81(1), 86-110$.

Schickler, Eric and Donald Philip Green (1997). "The Stability of Party Identification in Western Democracies: Results from Eight Panel Surveys". In: Comparative Political Studies 30 (4), 450-483.

Schmillen, Achim and Matthias Umkehrer (2017). "The scars of youth: Effects of early-career unemployment on future unemployment experience". In: International Labour Review 156 (34), 465-494.

Schraff, Dominik (2018). "Labor market disadvantage and political alienation: a longitudinal perspective on the heterogeneous risk in temporar employment". In: Acta Politica 53 (1), 48-67.

- (2019). "Politically Alienated Through Low-Wage Work? Evidence from Panel Data". In: Swiss Political Science Review 25 (1), 19-39.

Schumann, Siegfried and Harald Schoen (2009). "Muster an Beständigkeit? Zur Stabilität politischer und persönlicher Prädispositionen". In: Vom Interview zur Analyse: Methodische Aspekte der Einstellungs- und Wahlforschung. Ed. by Harald Schoen, Hans Rattinger, and Oscar W. Gabriel. Baden-Baden: Nomos, 13-33.

Schwander, Hanna and Silja Häusermann (2013). "Who is in and who is out? A risk-based conceptualization of insiders and outsiders". In: Journal of European Social Policy 23 (3), 248-269.

Sears, David O. and Carolyn L. Funk (1999). "Evidence of the Long-Term Persistence of Adults' Political Predispositions". In: The Journal of Politics 61 (1), 1-28.

Taber, Charles S. and Milton Lodge (2006). "Motivated Skepticism in the Evaluation of Political Beliefs". In: American Journal of Political Science 50 (3), 755-769.

Tilley, James, Anja Neundorf, and Sara B. Hobolt (2018). "When the Pound in Peoples Pocket Matters: How Changes to Personal Financial Circumstances Affect Party Choice". In: The Journal of Politics 80 (2), 555-569.

Vaisey, Stephen and Kevin Kiley (2021). "A Model-Based Method for Detecting Persistent Cultural Change Using Panel Data”. In: Sociological Science 8 (5), 83-95.

Weber, Wiebke and Willem E. Saris (2014). "The relationship between issues and an individual's left-right orientation". In: Acta Politica 50 (2), 193-213.

Weeden, Jason and Robert Kurzban (2017). "Self-Interest Is Often a Major Determinant of Issue Attitudes". In: Advances in Political Psychology 38 (1), 67-90.

Weinschenk, Aaron C. and Christopher T. Dawes (2017). "The Relationship between Genes, Personality Traits, and Political Interest". In: Political Research Quarterly 70 (3), 467-479.

Wiertz, Dingeman and Toni Rodon (2021). "Frozen or malleable? Political ideology in the face of job loss and unemployment”. In: Socio-Economic Review 19 (1), 307-331. 


\section{Article 1: The (ir)relevance of unemployment for labour market policy attitudes and welfare state attitudes}

This is the accepted version of the article. It is published as:

Wehl, N. (2019): The (ir)relevance of unemployment for labour market policy attitudes and welfare state attitudes, in: European Journal of Political Research 58(1), 141-162.

The published version can be found here:

https://doi.org/10.1111/1475-6765.12274

Acknowledgements This work was supported by the Bamberg Graduate School of Social Sciences which is funded by the German Research Foundation (DFG) under the German Excellence Initiative (GSC1024). An earlier version was presented at the 2016 ECPR Graduate Student Conference in Tartu. I would like to thank the panel participants at this event as well as the anonymous reviewers for helpful feedback. 


\title{
The (ir)relevance of unemployment for labour market policy attitudes and welfare state attitudes
}

\begin{abstract}
Typically, associations between being unemployed and policy attitudes are explained with reference to economic self-interest considerations of the unemployed. Preferences for labour market policies (LMP) and egalitarian preferences are the prime example and the focus of this study. Its aim is to challenge this causal self-interest argument: self-interest consistent associations of unemployment with policy preferences are neither necessarily driven by self-interest nor necessarily causal. To that end this article first confronts the self-interest argument with a broader perspective on attitudes. Given that predispositions (e.g. value orientations) are stable and influence more specific policy attitudes, it is at least questionable whether people change their policy attitudes simply because they get laid off. Second, this article derives a non-causal argument behind associations between unemployment and policy attitudes arguing that these might be spurious associations driven by individuals' socio-economic background. After all, the entire socio-economic background of a person is simultaneously related to both the risk of getting unemployed ("selection into unemployment") and distinct political socialization experiences from early childhood on. Third, this article uses methods inspired by a counterfactual account on causality to test the non-causal claims. Analyses are carried out using the fourth wave of the European Social Survey and applying entropy balancing to control for selection bias. In none but two of the 31 analysed countries unemployment effects on egalitarian orientations remain significant after controlling for selection bias. The same holds for effects on active LMP attitudes with the exception of six countries. Attitudes towards passive LMP are to some degree an exception since here effects remain in one third of the countries. Robustness checks and bayes factor replications showing evidence for the absence of unemployment effects support the general impression from these initial analyses. After discussing this article's results and limitations, broader implications of this article are considered. On the one hand, this article offers a new perspective on the conceptualization and measurement of unemployment risk. On the other hand, this article's theoretical argument, as well as its treatment of the resulting selection bias, can be broadly applied. Thus, this article can contribute to many other research questions regarding the (ir)relevance of individual life events for political attitudes and political behaviour.
\end{abstract}

Keywords: counterfactual causality; political socialisation; economic self-interest; unemployment; policy attitudes 


\subsection{Introduction}

It is old news that the unemployed differ profoundly from the remaining population in terms of their thinking of and acting in the political world. They participate less in politics (Gallego, 2007; Lorenzini and Giugni, 2012), trust less in political institutions (Dotti Sani and Magistro, 2016), feel less efficacious (Marx and Nguyen, 2016), and support more "leftist" political parties and policies (Emmenegger, 2009; Faas, 2010). Whenever such differences in policy attitudes occur, they are explained with reference to the material self-interest of the unemployed ${ }^{1}$. Unemployed people prefer policies they benefit from. Preferences for labour market policies (LMP) are the prime example. The self-interest argument behind unemployment effects goes sometimes explicitly (Cusack et al., 2006), sometimes more implicitly, hand in hand with an assumption of causality. The aim of this article is to challenge this causal self-interest argument. To that end this article first confronts the self-interest argument with a broader perspective on attitudes, second derives a non-causal argument behind associations between unemployment and policy attitudes and third uses methods inspired from a counterfactual account on causality to test the non-causal claims.

The first step simply questions the self-interest argument. The effect of unemployment, or employment status in general, on LMP attitudes, or social policy attitudes in general, is first and foremost discussed in the literature stimulated by Rueda (2005) on labour market dualization and its impact on public opinion (Emmenegger, 2009; Schwander and Häusermann, 2013). However, the broader literature on welfare policy attitudes is typically concerned with two sources of policy attitudes: self-interest and political predispositions, i.e. value orientations, party attachments, etc. (e.g. van Oorschot, 2002; Owens and Pedulla, 2014; Sears et al., 1980). Given the stability of predispositions and their influence on specific policy attitudes (Goren $2005,2013)$, it is at least questionable whether people change their policy attitudes simply because they get laid off.

However, where do all the associations between unemployment and policy attitudes come from, if causality plays no part in it? The second step develops an answer to that question: selection bias. The entire socio-economic background of a person is simultaneously related to both the risk of getting unemployed ("selection into unemployment") and distinct political socialization experiences from early childhood on. One example of an often overlooked socio-economic factor is the social status of the parents that is positively related to both labour market success (Gregg and Machin, 2001) and egalitarian/leftist orientations (Rekker et al., 2015) of the offspring. Given only some degree of social immobility and some degree of stability in individuals' political predispositions, individuals' socio-economic background might be enough to create the non-causal relation between unemployment and LMP attitudes.

The third step combines this theoretical argument with a counterfactually inspired empirical strategy to identify causal, or non-causal, effects. In contrast to the "Y-centred", "causes of effects", "backwards" oriented approaches that focuses on the precise prediction of an outcome, counterfactual approaches focus on the precise estimation of an effect. Thus, these "X-centred", "effects of causes", "forward" oriented approaches focus on the elimination of selection bias by other third variables (Gelman, 2011; Rohlfing, 2012). 
Using such a counterfactual perspective leads to a contrast between the theoretical argument that focuses on socialization dynamics, political predispositions, etc. and the empirical strategy that focuses on the factors that predict unemployment - the selection model in other words. In contrast, existing cross-sectional research regarding unemployment effects on political attitudes and behaviour often uses a limited set of socio-economic variables and/or eventually a limited set of political predispositions ${ }^{2}$. Unemployment effects found with such an empirical strategy are, however, likely to be the result of bias.

To avoid such a selection bias, some recent studies on unemployment and LMP or egalitarian attitudes (Margalit, 2013; Naumann et al., 2016; Owens and Pedulla, 2014; Stegmueller, 2013) rely on panel data to focus on attitude changes within individuals, which gives them a crucial benefit over any study based on non-experimental ${ }^{3}$, cross-sectional data - including the present one. Applying a fixed effects approach (Allison, 2009) or controlling for first wave responses they automatically control for observable and unobservable selection bias by factors that are stable over time. The benefit for causal inferences, however, comes at the price of countrycontext dependence. It is thus not clear whether the results of these four studies that are based on U.S., UK, and Dutch data are generalisable to other countries.

A generalisation based on these results is further limited by differences between them. Thus, in contrast to the other three panel studies Stegmueller does not find unemployment effects on LMP attitudes in the UK context. And while Margalit finds for the U.S. context that reemployment reverses the attitudinal effects of a job loss, Naumann et al. find the opposite for the Dutch context. What does that mean for differences between the unemployed and the employed? And do the differing results emerge due to context differences or due to other differences? Crossnational surveys can easily alleviate this context-specificity problem, but their results are due to the cross-sectional character of the data always endangered by unobservable selection bias. One can, however, still think in theoretical terms about selection bias and try to minimize it in empirical terms, which is what the present article aims at.

In the following I will develop at first a theoretical argument showing the relevance of the socio-economic background for both the risk of unemployment and socialization experiences. The methods section will focus on ways to account for the selection bias, especially entropy balancing (Hainmueller, 2012). The analyses of data from the fourth wave of the European Social Survey generally support the claim of no causality between unemployment and policy attitudes, even though the level of support is a bit lower for passive LMP attitudes. I will close with thoughts on the conceptualization and measurement of unemployment risk and broader applications of this article's theoretical argument and of the handling of the resulting selection bias in cross-sectional data. 


\subsection{Unemployment and Labour Market Policy (LMP) Attitudes: Causal and Non-Causal Mechanisms}

\subsubsection{Self-Interest Driven Attitudes}

Starting point for arguments about an influence of unemployment on political attitudes is a selfinterest driven model of policy preferences (Häusermann et al., 2015). People support those policies most that benefit them most. In the case of unemployment the emphasis is on the need to rely on social security. Thus, David Rueda (2005) proposes an attitudinal gap between labour market insiders and labour market outsiders.

Rueda (2005) believes that labour market outsiders benefit from active (i.e. job creation) and passive LMPs (i.e. unemployment benefits). After all they are unemployed or, in the case of atypical employment ${ }^{4}$, face a high risk of becoming unemployed. Labour market insiders on the other hand do not benefit from these LMPs and have to finance them ultimately via taxes. Hence, according to Rueda labour market outsiders are more supportive of active and passive LMPs than insiders ${ }^{5}$.

The literature discusses whether unemployment and atypical employment have similar selfinterest driven effects on policy attitudes (Emmenegger, 2009; Guillaud and Marx, 2014). Importantly however, regarding the effect of unemployment on political attitudes, there seems to be a clear consensus. This is not only true for LMP attitudes, but also for redistributional preferences (Cusack et al., 2006), or party preferences (Marx and Picot, 2013) among others. And it is even true for the broader welfare state literature - discussed in the following paragraph that does not confine itself to the self-interest argument (Blekesaune and Quadagno, 2003).

\subsubsection{Political Predispositions: Another Look at Attitudes}

The broader literature on welfare state attitudes discusses for a long time two kinds of explanations: self-interest, but also peoples' political predispositions, especially value orientations, ideology, and party attachments (Andreß and Heien, 2001; Blekesaune and Quadagno, 2003; Hasenfeld and Rafferty, 1989 Jæger, 2006). Even some self-interest focused studies explicitly acknowledge predispositions' influence on attitudes, but choose not to focus on it (Häusermann et al., 2015; Rehm, 2016). However, since self-interest consistent effects can be driven by predispositions, as I will argue, it is actually hard to separate between both.

There is ample empirical evidence for associations between political predispositions and attitudes towards specific policies. First and foremost a variety of studies show that orientations towards welfare state related values are predictive of specific social policy attitudes (Borre and Viegas, 1995; Feldman and Steenbergen, 2001; Goren, 2001). The most widespread example is that people who prioritize egalitarian values are more prone to support specific government spending programs for the disadvantaged (e.g. Calzada et al., 2014; Jacoby, 2006). Other ex- 
amples for predictors of social policy attitudes are deservingness beliefs (Petersen et al., 2010) and predispositions that are not so closely related to welfare state principles like party attachments, political ideology (Carsey and Layman, 2006; Gelissen, 2000), or even racism (Harell et al., 2016). Of course, predispositions' predictive power does not suggest anything about the causal direction between predispositions and attitudes. However, a vast amount of literature concerned with individuals' political belief systems does ${ }^{6}$.

That predispositions influence attitudes and not vice versa can be derived theoretically from Converse's (1964) idea of political belief systems, i.e. individuals' "network of interconnected political beliefs" (Baldassarri and Goldberg 2014, p. 54). The elements of a belief system can range from very specific evaluations (e.g. policy attitudes or candidate evaluations) to very abstract ones like political value orientations or political ideologies (Feldman, 2003). For distinguishing these different types of political beliefs, the term "constraint" in Converse's definition becomes crucial. The idea is that the more abstract beliefs (predispositions) "constraint", i.e. shape, the specific attitudes or serve as a heuristic to build the more specific attitudes (Goren, 2013). Empirical research in this tradition seems to support this direction of causality (Goren 2000, 2013, ch.5, 6; Peffley and Hurwitz 1985, 1993)

Apart from that, predispositions are also expected to show high levels of intra-individual stability over time. Indeed, the more a belief is expected to constraint other attitudes, the more stable that belief should be (Converse, 1964). Empirically, considerable high stability levels of party identification, ideology and value orientations are found ${ }^{7}$ (e.g. Feldman 1988; Goren 2005).

Predispositions' influence on attitudes and predispositions' stability do not exclude self-interest effects. Indeed, it has been suggested that in a context of salience self-interest can have an effect despite of stable predispositions. That is, self-interest might prevail, if there are clear and big material gains for the respondents regarding the issue at stake (Chong et al., 2001). However, predispositions' influence on attitudes and predispositions' stability pose a challenge to the selfinterest argument behind unemployment effects on policy attitudes. Imagine a person under a standard employment contract who opposes government spending on unemployment benefits. Now that person gets unemployed. Maybe she will stick to her attitude, simply because it's in line with her other political beliefs.

\subsubsection{Alternative Explanation: Stratified Predispositions and Stratified Unemployment Risks}

If not self-interest, what else can account for the relation between unemployment and LMP attitudes? The answer, that I will suggest in the following, is a combination of two mechanisms: shared socio-economic stratification patterns of unemployment risks and political predispositions, i.e. selection bias.

Thinking of Lipset and Rokkan's (1967) cleavage structures, Campbell et al.'s (1960) funnel of causality, or simply the plethora of studies on the social basis of welfare states (Borre and Scarbrough, 1995; Rehm, 2016) one fact is clear and has been so for long. Unemployment is 
but one of a variety of socio-economic factors associated with political attitudes and predispositions. Men and members of higher social classes are repeatedly shown to lean a bit more to the right side of the political spectrum, identify with more conservative parties and prefer less redistribution and state intervention. People with higher formal education are less fond of redistribution and intervention, as well, even though they are more left in ideological terms (Andreß and Heien, 2001; Dalton, 2010; Linos and West, 2003; Knoke and Hout, 1974). And in recent years, additional socio-economic factors have been focused. The strong redistributive preferences of people with highly specialized vocational skills (Iversen and Soskice, 2001) and of migrants (Reeskens and Oorschot, 2015) are probably the most eminent examples.

Importantly, stratification also occurs on the labour market. Low formal education is often equated with low human capital and/or low signalling power. Therefore, employers are often more prone to offer contracts to people with a higher level of formal education. Low education is a disadvantage in European labour markets (Müller, 2005). Similar arguments and observations are made regarding the (non-)existence of specific vocational skills (Korpi et al., 2003) as well as a persons' specific field of study (Reimer et al., 2008). Once employed, some employees face a higher risk of being fired again, especially if they belong to a lower social class performing low-skill tasks. After all, the employer does not face high costs when firing them - they are easily replaced (Goldthorpe and McKnight, 2006; Lucchini and Schizzerotto, 2010). Furthermore, some face discrimination on top of potentially pre-existing disadvantages due to the already mentioned factors. Women (Rubery et al., 1998) and people with a migratory background or from ethnic minorities (Heath, 2007) are typical examples. Apart from these personal characteristics, parents' socio-economic situation has a huge impact on the labour market chances of their offspring. A big part of this intergenerational transmission or immobility is mediated through the already mentioned individual characteristics. But there seems to be some causal component, as well, especially of parents' unemployment (Gregg et al., 2012; Gregg and Machin, 2001).

Seen from a self-interest perspective all of these relations between socio-economic factors and political predispositions (and attitudes) can be explained with reference to self-interest. Not only the unemployed, but also people with a high risk of unemployment - or of any form of downward mobility for that matter - are said to have an interest in e.g. redistribution, since it serves them as insurance for the likely realization of their economic risks (Alesina and La Ferrara, 2005; Rehm, 2016; Schwander and Häusermann, 2013). Operating under the selfinterest assumption, bivariate associations between unemployment and political preferences are thus highly confounded by socio-economic factors. But unemployment as "realized risk" (Cusack et al., 2006) should still haven an independent, causal effect on political preferences.

However, socio-economic correlates of political predispositions can also be interpreted as relicts from experiences in childhood and adolescence, i.e. as product of political socialization. First, there might be a direct influence of the families' socio-economic situation, an argument especially championed by Inglehart(1977) in the context of the acquisition of materialist and postmaterialist values. Similarly, parental unemployment is found to affect offsprings' right wing party preferences even if controlling for parents' party preferences (Siedler, 2011). But the direct transmission of political predispositions from parents to children seems to be the dominant mechanism. Parents' predisposition outperform socio-economic factors by far in pre- 
dicting offspring predispositions like party identification (Dalton, 1982; Jennings et al., 2009), ideology (Rico and Jennings, 2016), or the aforementioned materialist and postmaterialist value orientations (Kroh, 2009). However, since many children "inherit" 8 not only political beliefs, but also socio-economic status from their parents - the aforementioned intergenerational immobility - the result is in both cases the same: socio-economic stratification in political predispositions is passed down from one generation to another. Thus, for example Rekker et al. (2015) show associations between economic egalitarianism and parental socio-economic status in Dutch youths.

Since this explanation works without any reference to self-interest, in this perspective the causal influence of unemployment on political predispositions and attitudes is at least an open question, if not doubtful. It is possible, that previously found cross-sectional associations between unemployment and political attitudes and predispositions are entirely the product of confounding (see figure 2.1). Consequently, the two hypotheses of this paper are that there are neither causal relations between unemployment and LMP attitudes (H1) nor between unemployment and relevant political predispositions $(\mathrm{H} 2)$. Hypothesis 2 is tested in this paper solely with regard to egalitarian orientations, even though the theoretical argument should be valid for all predispositions that guide LMP attitudes.

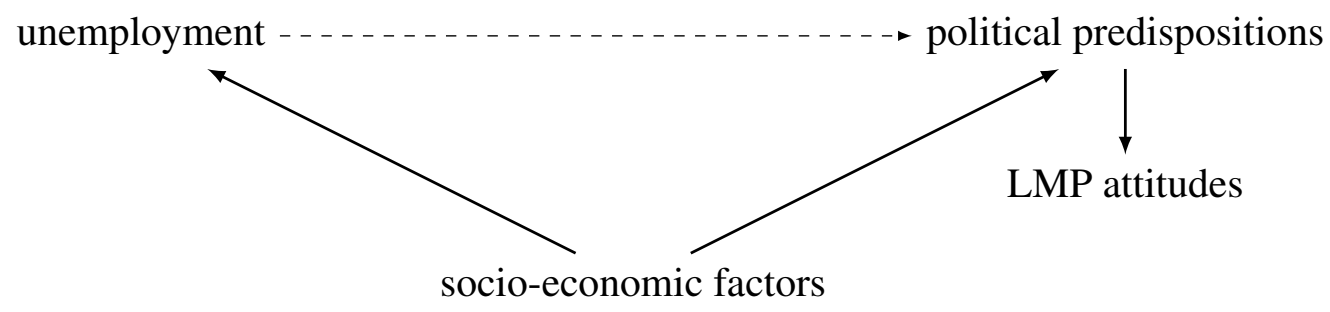

Figure 2.1: (Non)causality in associations between unemployment and LMP attitudes and political predispositions

\subsection{Data and Methods}

\subsubsection{Data}

The analyses in this paper are based on data from the fourth wave of the European Social Survey (ESS), that has been mainly gathered in 2008 and 2009. The fourth ESS wave contains data on 31 countries and questions from a module on welfare state attitudes.

I use four dependent variables (or outcomes): the first two are respondents' attitudes towards passive and active LMPs. Respondents were asked on a 11-point scale how much responsibility the government should have in a) ensuring a reasonable standard of living for the unemployed and $b$ ) in creating new jobs for everyone, who wants one.

Furthermore, I use two items related to egalitarian values as two examples for political predispositions. Respondents are asked on a 5-point scale whether they agree a) that the government 
should reduce differences in income levels and b) that in a fair society, differences in living standards should be small

The independent variable (or treatment condition) is unemployment. I restrict the sample so that only currently employed and currently unemployed people are compared. Non-employed people (in education, doing housework, retired, doing military/community service) are excluded.

I use the following control variables (or Confounders): respondents' age, gender, formal education, field of education, migratory background, previous unemployment. Furthermore, I use several job characteristics as confounders that relate to the current job for employed respondents and the previous job for unemployed respondents: temporary contract, self-employment, firm size, supervisory position, and occupational group. Additionally, I use some parents' characteristics as controls, namely parents' formal education and fathers' employment status and occupational group. For details on variables and recodings see Appendix A.

\subsubsection{Controlling Selection Bias with Entropy Balancing (EB)}

The choice of this distinct set of control variables is based on a counterfactual perspective on causality (Holland, 1986). Causality is inferred by a comparison between similar treatment and control units - at least when dealing with observational, cross-sectional data. "Similar" in this context means similar with respect to the chance to receive the treatment. Other predictors of the outcome, that do not influence treatment assignment, however, do not need to be taken into account (Gangl, 2015; Winship and Sobel, 2004). Furthermore, mediators should not be taken into account, since the lead to post-treatment bias, i.e. an underestimation of the direct causal effect (Rosenbaum, 1984). Applied to the present empirical context this means, that a causal estimate of the effect of unemployment should be based on a comparison between the LMP attitudes of unemployed people and employed people with an equally high risk of getting unemployed. Other political attitudes or predispositions, that are certainly highly correlated with LMP attitudes do not need to be taken into account. Furthermore, other consequences of unemployment, like e.g. financial worries, should not be included, as well (see figure 2.2). Note however, that unlike experiments, that control for observable and unobservable confounding by design, in cross-sectional, observational studies all possible confounders have to be directly modelled (Imai et al., 2008). Thus, omitted variable bias (selection bias by unobservables) is always a danger to causal inference in this case (Ho et al., 2007). The causal estimate is only unbiased, if all confounders are taken into account.

To account for selection of observable variables, I use EB (Hainmueller, 2012) that forces exact balance on all observed confounders. Thus, no standard mean differences between the treated and non-treated units should be detectable for any of the observed confounders. EB is a nonparametric reweighting method. All control group units (here: employed respondents) receive a weight ${ }^{9}$ that is computed by directly specifying balance constraints. Thus, the weighted means of all specified confounders are equal in the treatment and the control group. The weighted sample is perfectly balanced. 
Outcome Predictors unrelated

to treatment selection

here e.g. : egalitarianism

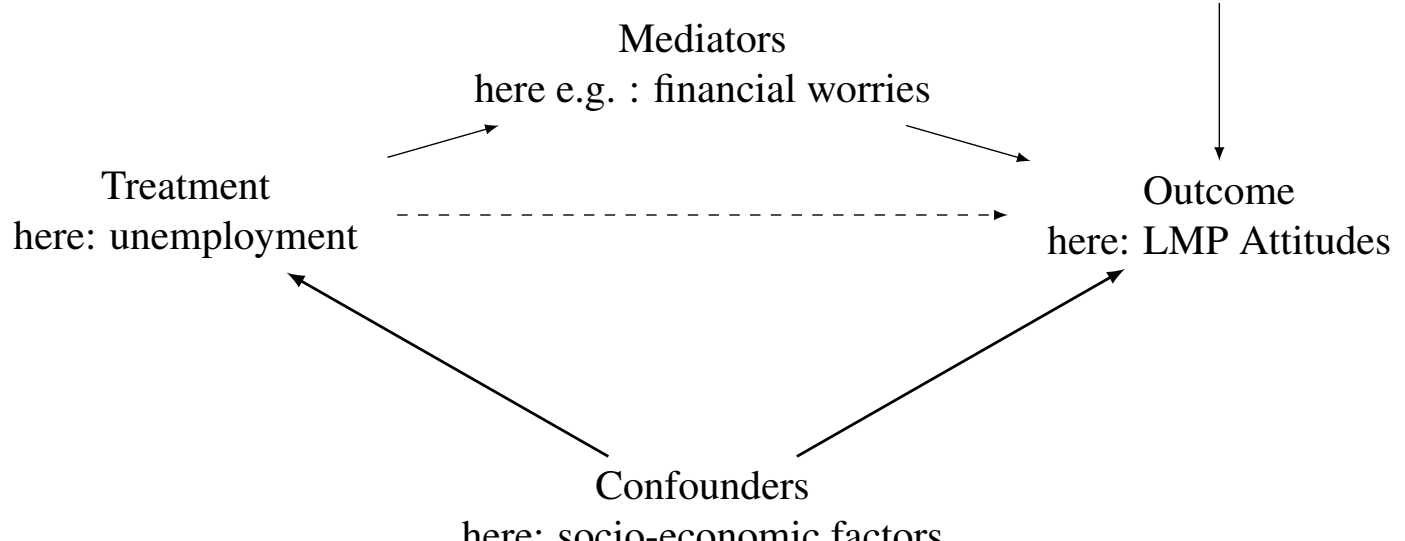

here: socio-economic factors

Figure 2.2: The Problem of Selection Bias

Figure A.2 in the Appendix shows that this works as intended for the present empirical application ${ }^{10}$. In all countries imbalances are virtually non-existent afterwards and for any single confounder below the typical 0.05 threshold (Caliendo and Kopeinig, 2008) of imbalance.

\subsubsection{Outcome Analyses}

Once (observed) selection bias is accounted for the outcome analyses per se are straightforward. For each of the four outcome measures linear regressions are run with an indicator for unemployment and weighted with the EB weights. Inference in presence of the EB weights is done using robust standard errors ${ }^{11}$. To avoid an obvious violation of SUTVA (stable unit treatment value assumption) (Imbens and Rubin, 2015, pp. 10-12) all analyses are done for each country separately. Thus, neither country differences in the selection into unemployment nor country differences in the effect of unemployment need to be modelled directly. Two complications arise, however, due to a) missing data and b) the fact that this article's hypotheses claim the absence, not the presence, of an effect.

Dealing with missing data is especially important in this case, because EB requires fully observed treatment and confounder data. Therefore, I use multiple imputation avoiding the potential of missing data bias by observed variables - assuming MAR - and avoiding the loss of information, i.e. inefficiency, as in the case of listwise deletion (Allison, 2002, ch. 3). Multiple Imputation ( $m=20$ for each country separately) is done using the chained equation's approach (MICE), facilitating the handling of missing data in variables of different scale types (van Buuren, 2012). Missing values occur in the treatment, in the confounders, and in the outcomes. To impute each variable, I include all remaining variables, including the outcome measures as repeatedly suggested (White et al., 2009), in the imputation model. Once outcome regressions are run in each imputed data set, results are combined using Rubin's combining rules (van Buuren, 2012). 
To sum up, in each country I compute for every imputed data set the EB weights, use these weights in treatment on outcome regressions and finally combine the results from the $20 \mathrm{im}$ puted data sets. The final result will be either a significant or an insignificant effect of unemployment. While a significant effect would speak rather clearly against the hypotheses, insignificant effects should not be interpreted as confirmation of the hypotheses. After all, this would mean to equal absence of evidence (an insignificant effect) with evidence of absence (a zero effect) - a practice that is increasingly criticized (Bernardi et al., 2017). To show evidence for the hypotheses of zero effects, I therefore rely on bayes factors (Kass and Raftery, 1995). Bayes factors are able to show the same amount of evidence in favour of the presence of an effect as in favour of the absence of an effect. In contrast, with significance testing it is only possible to reject the hypothesis of the presence of an effect, which does not convey a comparable amount of information about the hypothesis of the absence of an effect (Rouder et al., 2009).

\subsection{Analysis}

Are the unemployed driven by their self-interest when forming their attitudes towards LMPs and egalitarianism? Or are their distinct attitudes mainly the result of third variables that simultaneously influence the risk of becoming unemployed and political socialization experiences, as this article's theoretical argument suggests? To test both arguments empirically I use this article's hypotheses about the absence of unemployment effects as rather extreme observable implications of the socialization argument and the presence of unemployment effects as observable implication of the self-interest argument.

The results of these tests are displayed in figure 2.3 for LMP attitudes and in figure 2.4 for egalitarian orientations. In both figures bivariate associations between individual unemployment and the four attitudinal outcomes are compared to these associations after EB that incorporates confounding variables influencing selection into unemployment while not being influenced by unemployment ${ }^{12}$. The results are divided into three categories. First there are countries with a significant effect of unemployment before, but not after EB. For every outcome approximately one third of the total of 31 analysed countries fall into this result category. The results for all the countries in this first results category clearly challenge the self-interest argument and are in line with this article's hypotheses. After all, these results suggest that given their socio-economic background employed and unemployed persons hold similar LMP attitudes and egalitarian orientations.

Second, there are countries without any significant effect, neither before nor after EB. The number of countries falling into this second results category is higher for the egalitarian items (figure 2.4) than for the LMP attitudes (figure 2.3), and higher for the right panels in each figure, i.e. active LMP attitudes and the item about a fair society. The results for the countries in this second results category challenge the self-interest argument and are in line with this article's hypotheses - just like the results in the first results category. The difference is, however, that here selection bias is not as strong as before. Thus, even without controlling for social background 
variables unemployed and employed people seem not to differ in their LMP attitudes and their egalitarian orientations. In substantive terms this suggests that becoming unemployed, as well as holding certain orientations, is not as strongly influenced by the socio-economic background as in the countries discussed before. The socio-economic background (and thus selection bias) does, however, still play some role, as the comparison of point estimates before and after EB suggests.

And finally, there are countries, where there is a significant effect of unemployment before as well as after EB. While this is the case in only one or two countries for the egalitarian items, it is more common for the LMP attitudes, especially for passive LMP attitudes, where this is the case for one third of all analysed countries. These cases clearly present evidence against the hypotheses and are in line with the self-interest argument. Note however, that even in these countries point estimates are reduced after EB, pointing to the statistical role of selection bias and the substantive role of socio-economic background.

As tentative take away message I suggest that even though results vary across countries and outcomes, the normal case seems to be that there is no causal link between unemployment and LMP attitudes or an egalitarian orientation. But what about the exceptions that still show significant effects after EB? On the one hand, they might be explained with some remaining unobservable selection bias, assuming that for some reason unobservable factors play a bigger role in these cases. On the other hand, these might be special cases, where unemployment has a causal effect on LMP attitudes (or egalitarian orientations in one or two cases).

The logical follow-up question is what special circumstances might lead to (potentially) causal effects for some countries and some outcomes, but not for others? The salience argument that states that self-interest matters when it is very clear (salient) to the respondents (Chong et al., 2001), is in line with the fact that more effects remain for LMP attitudes than for the egalitarian items. After all, the leap from LMPs, especially passive LMPs i.e. the living standard of the unemployed, to the possibility of material gains is arguably not too big. However, it is debatable whether the differences between the results for both LMP attitudes are in line with this argument.

Applied to the cross-country differences the salience argument might suggest that causal effects remain in those contexts, where the individual consequences of unemployment are stronger. To test this possibility empirically, I look at the difference in the share of people worrying about their household income between the employed and unemployed respondents. As figure A.3 in the appendix shows, there is no relevant overlap between the countries, where this difference is the highest, with the countries, where a significant effect remains between unemployment and passive LMP attitudes. Thus, it is not clear, what drives these country differences. 


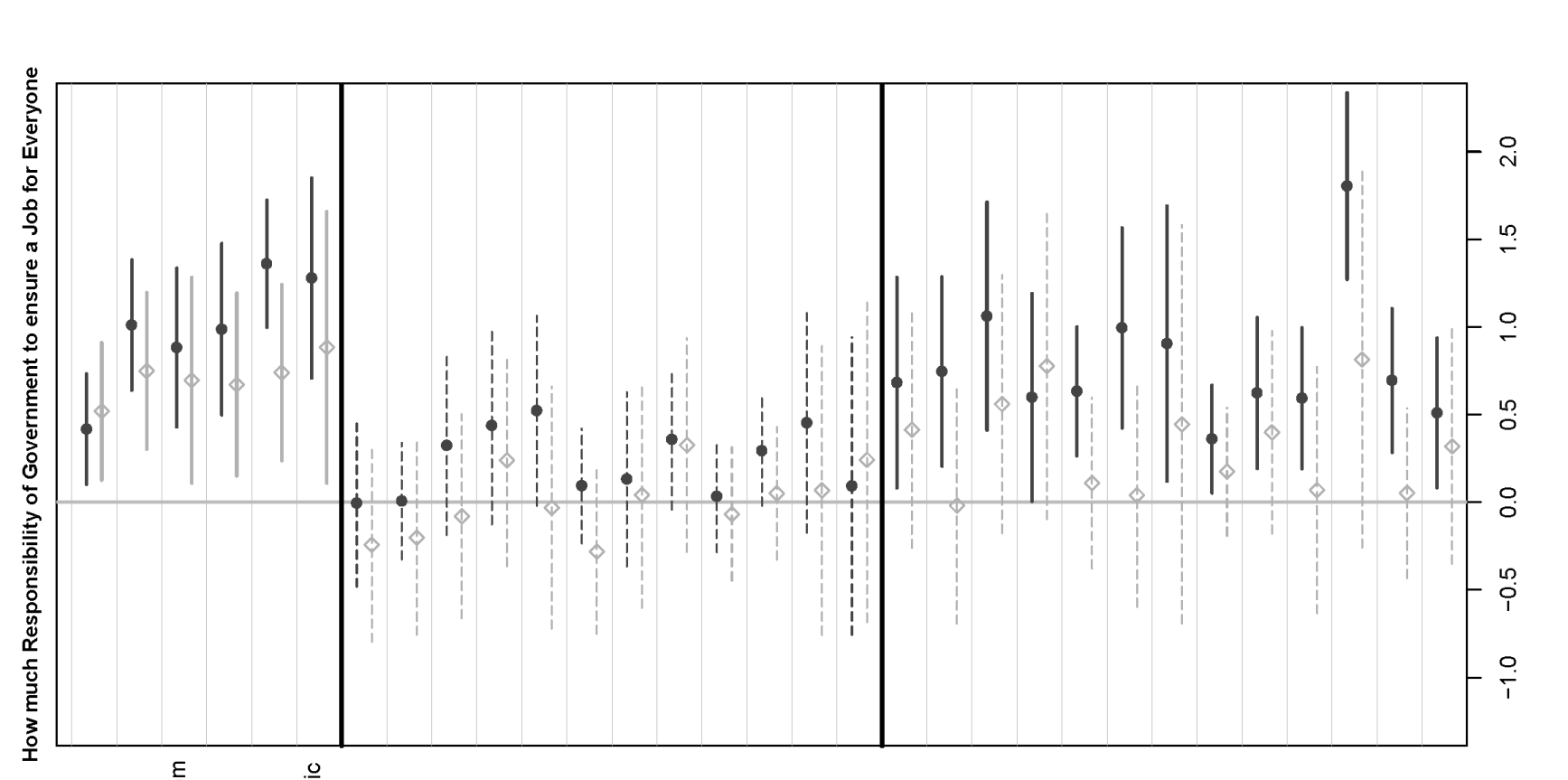

美离

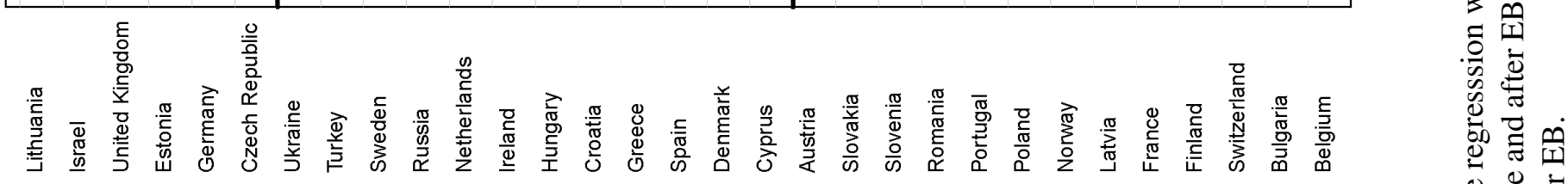
. :

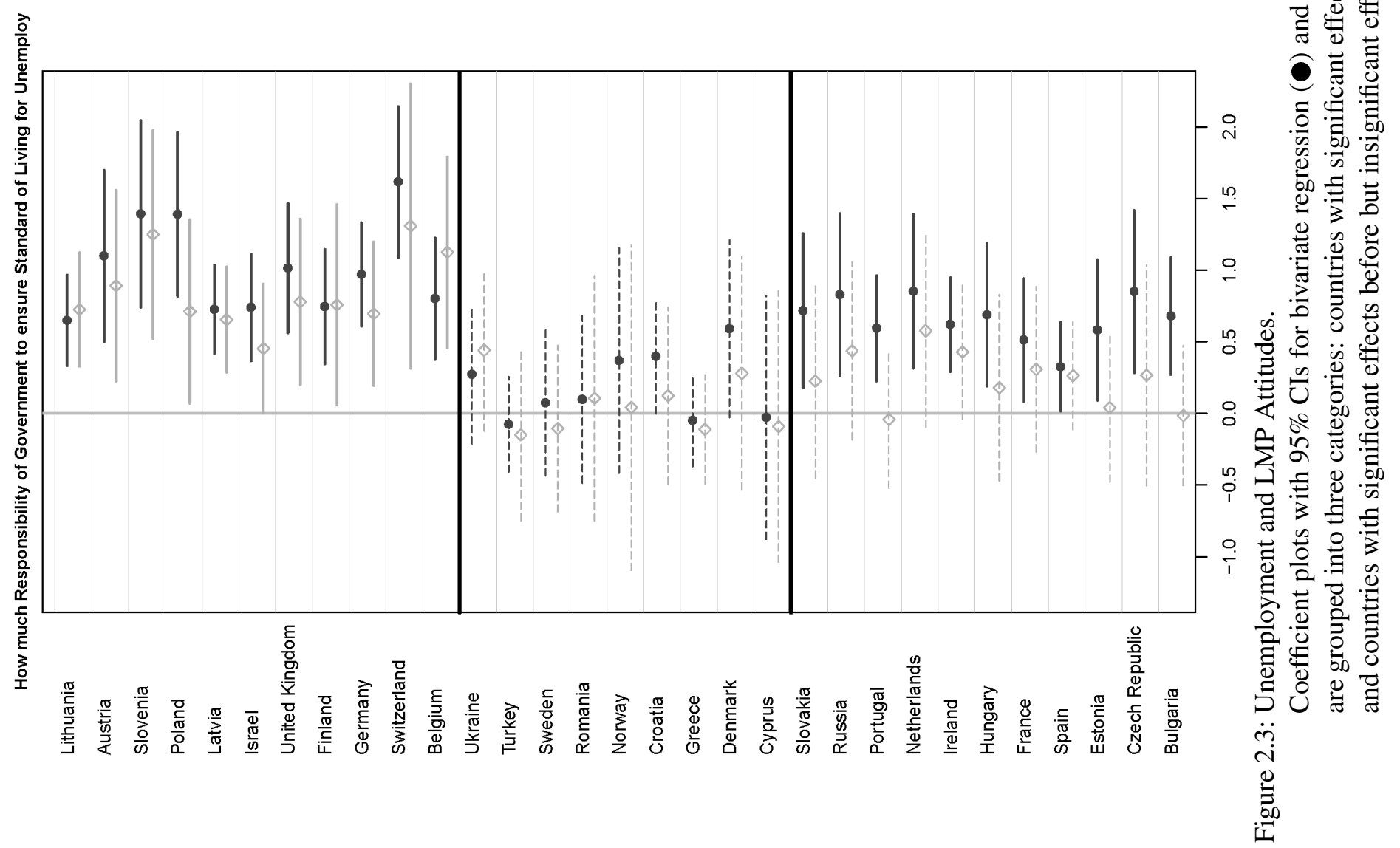




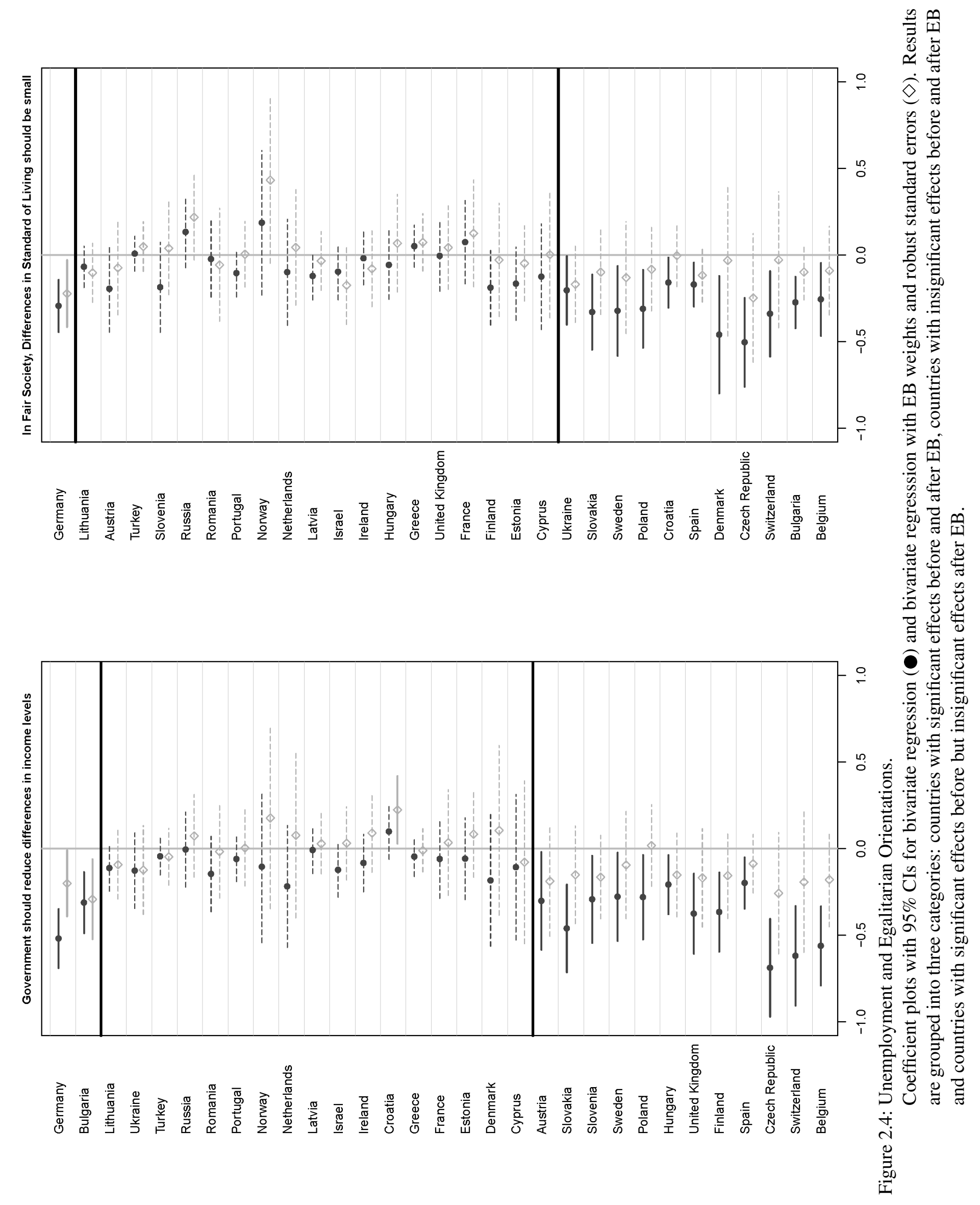




\subsubsection{Robustness Checks and Bayes Factor Replication}

To gauge how robust these initial results are, outcome analyses are replicated with six alternative specifications (see table 2.1 and figures A.4 - A.9 in the appendix for detailed results). The first two specifications potentially increase the quality of EB by A) using trimmed EB weights ${ }^{13}$ and $\mathrm{B}$ ) adding the EB variables to the outcome regression (Lee et al., 2011; Lunceford and Davidian, 2004). The next two replications use potentially less efficient methods to handle selection bias (compared to EB), namely using C) the propensity score ${ }^{14}$ and D) the individual confounders as control variables in the treatment-outcome regression. However, as table 2.1 suggests, the results for all these specifications are very similar to the original results ${ }^{15}$. Under replication A) no country at all remains with significant unemployment effects on the egalitarian item about a fair society. The biggest difference occurs for passive LMP attitudes under check D), where three more countries retain their significant unemployment effects after accounting for selection bias. Thus, the substantive conclusions do not depend on how, but on whether one controls for selection bias.

Furthermore, E) replicates the analyses without controlling for previous unemployment experience. On the one hand, this avoids controlling away unemployment effects by effects of previous unemployment, which might be the result of an attitudinal adaption after reemployment as Naumann et al. (2016) suggest. On the other hand, however, it increases selection bias since previous unemployment is an important predictor for current unemployment and might even act as proxy for other unobservable factors guiding selection into unemployment. Therefore, it emphasizes the robustness of the results that in this replication the results for active LMP attitudes and the egalitarian item about a fair society yield similar numbers of countries where the unemployment effect disappears after EB. In the case of passive LMP attitudes and the egalitarian item about income differences not controlling for previous unemployment results in four or five countries more with remaining significant effects. All in all, however, the results for none of the outcomes are merely based on previous unemployment experiences.

The last replication is based on ESS data from the sixth wave carried out in 2012 and 2013, when unemployment rates were in most European countries increased due to the economic crisis (see figure A.10 in the appendix). This replication is only possible for the egalitarian item on income differences due to data limitations and countries in the sixth ESS wave do not perfectly match the countries in the fourth wave. That said, the 2012 results are perfectly in line with all previous analyses, given the even bigger number of countries that show significant effects before, but insignificant effects after EB. Thus, the results seem to hold for normal as well as for more extreme situations on the labour market.

So far, the shown results only allow us to differ between countries where the hypothesis of an unemployment effect can be rejected and countries where it cannot be rejected. Given this article's hypotheses about the absence of unemployment effects, quantifiable evidence for the absence of these effects would be more informative. Therefore, figure 2.5 shows for all four outcomes bayes factors that compare models including unemployment and models excluding unemployment by showing their odds ratio ${ }^{16}$. 


\begin{tabular}{|c|c|c|c|c|c|}
\hline & & sig/ns & $\mathrm{ns} / \mathrm{ns}$ & sig/sig & $\mathrm{ns} / \mathrm{sig}$ \\
\hline & Original EB & 11 & 9 & 11 & 0 \\
\hline & A) EB with Trimmed Weights & 11 & 9 & 11 & 0 \\
\hline passive & B) EB + Controlling for Confounders & 10 & 9 & 12 & 0 \\
\hline LMP & C) Controlling for Propensity Score & 12 & 9 & 10 & 0 \\
\hline \multirow[t]{2}{*}{ attitudes } & D) Controlling for individual Confounders & 8 & 9 & 14 & 0 \\
\hline & E) EB Without previous unemployment & 7 & 9 & 15 & 0 \\
\hline & Original EB & 13 & 12 & 6 & 0 \\
\hline & A) EB with Trimmed Weights & 13 & 12 & 6 & 0 \\
\hline active & B) $\mathrm{EB}+$ Controlling for Confounders & 12 & 12 & 7 & \\
\hline LMP & C) Controlling for Propensity Score & 12 & 12 & 7 & 0 \\
\hline \multirow[t]{4}{*}{ attitudes } & D) Controlling for individual Confounders & 12 & 12 & 7 & 0 \\
\hline & E) EB Without previous unemployment & 11 & 12 & 8 & 0 \\
\hline & Original EB & 12 & 16 & 2 & 1 \\
\hline & A) EB with Trimmed Weights & 13 & 17 & 1 & 0 \\
\hline egalitarian & B) $\mathrm{EB}+$ Controlling for Confounders & 12 & 16 & 2 & 1 \\
\hline item 1 & C) Controlling for Propensity Score & 12 & 17 & 2 & 0 \\
\hline income & D) Controlling for individual Confounders & 11 & 17 & 3 & 0 \\
\hline \multirow[t]{2}{*}{ differences } & E) EB Without previous unemployment & 7 & 16 & 7 & 1 \\
\hline & F) 2012 Replication & 15 & 10 & 4 & \\
\hline \multirow{6}{*}{$\begin{array}{l}\text { egalitarian } \\
\text { item } 2 \\
\text { fair } \\
\text { society }\end{array}$} & Original EB & 11 & 19 & 1 & 0 \\
\hline & A) EB with Trimmed Weights & 12 & 18 & 0 & 1 \\
\hline & B) $\mathrm{EB}+$ Controlling for Confounders & 11 & 18 & 1 & 1 \\
\hline & C) Controlling for Propensity Score & 11 & 19 & 1 & 0 \\
\hline & D) Controlling for individual Confounders & 11 & 18 & 1 & 1 \\
\hline & E) EB Without previous unemployment & 10 & 19 & 2 & 0 \\
\hline \multicolumn{6}{|c|}{$\begin{array}{l}\text { "sig/ns": unemployment effect significant before, insignificant after controlling selection bias } \\
\text { "ns/ns": unemployment effect insignificant before and after controlling selection bias } \\
\text { "sig/sig": unemployment effect significant before and after controlling selection bias } \\
\text { "ns/sig": unemployment effect insignificant before, significant after controlling selection bias }\end{array}$} \\
\hline
\end{tabular}

Table 2.1: Summary of Robustness Checks 
Most of the insignificant unemployment effects after controlling for selection bias are accompanied by bayes factor values below 0.33 showing moderate evidence for the absence of unemployment effects. There are, however, a few cases, where according to the bayes factor values the vanishing significance after controlling for selection bias does not suggest anything about the absence of unemployment effects. These few cases occur mainly for passive LMP attitudes and overlap mostly with countries that already showed differing results in the robustness checks.

Interestingly, some of the remaining significant effects after controlling for selection bias fall into this grey area of the bayes factors as well, thus questioning, whether the significance suggests anything about the existence of the respective unemployment effects. For active LMP attitudes this, i.e. bayes factor values below 3 , is the case for all but one of the remaining significant effects.

Taken together the robustness and bayes factor replication support on the one hand largely the impression from the initial analyses. On the other hand, however, they show that neither the presence, nor the absence of unemployment effects can be confidently concluded in several cases. In statistical terms this is thus a grey area in need for more evidence, i.e. more data. In substantive terms, however, these non-robust effects pose a bigger challenge for the self-interest based arguments about the relevance of unemployment than for this article's arguments about the possible irrelevance of unemployment. 

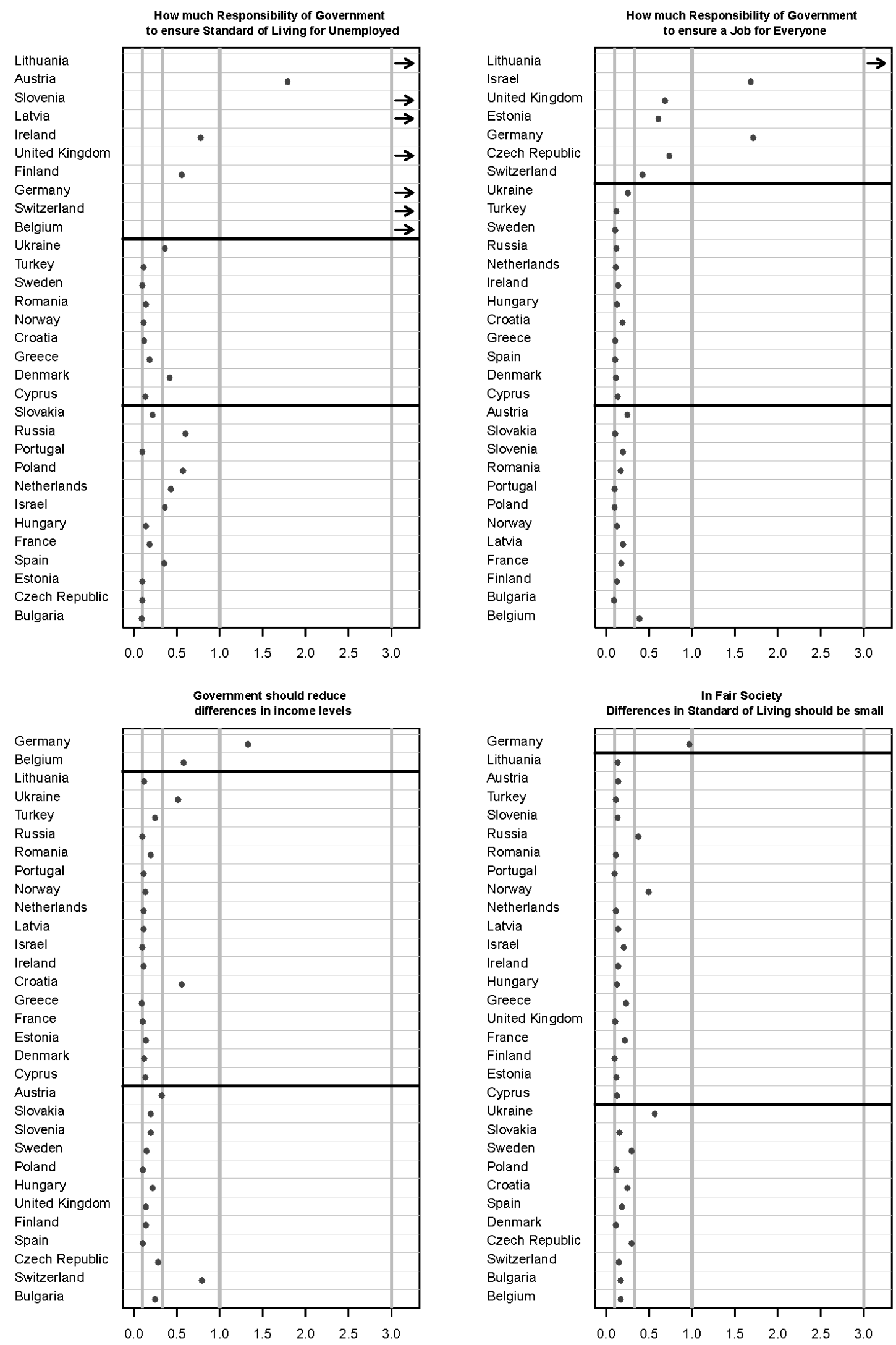

Figure 2.5: Bayes Factors.

Results are grouped into three categories: countries with significant effects before and after Propensity Score Adjustment, countries with insignificant effects before and after Propensity Score Adjustment and countries with significant effects before but insignificant effects after Propensity Score Adjustment. " $\rightarrow$ ": $B F>3$, i.e. evidence for the presence of unemployment effects. Reading example: The bayes factor of 0.35 in Spain for the unemployment effect on passive LMP attitudes in the upper left panel means that the model without unemployment is $\frac{1}{0.35}=2.86$ times more likely than the model with unemployment as a predictor. (see also footnote 16) 


\subsection{Summary and Discussion}

Starting point of this article was to question whether associations between unemployment and LMP attitudes or unemployment and egalitarian orientations are based on self-interest induced causality. In theoretical terms an alternative non-causal argument has been developed. Whenever such associations are observed, this might be the result of several socio-economic factors that shape a) selection into unemployment and b) political predispositions via political socialization from early childhood on. The two hypotheses, that there is no causal influence of unemployment on LMP attitudes and egalitarian orientations have been tested with data from the European Social Survey in 2008/2009 applying entropy balancing (EB) to control for selection bias.

In around one third of the analysed 31 countries significant unemployment effects vanished after EB. Remaining significant effects occurred in one or two countries for egalitarian orientations and for six countries in the case of active LMP attitudes. Compared to that, results for passive LMP attitudes were somehow exceptional with remaining significant unemployment effects in one third of the countries. However, for all four analysed items unemployment effects after taking into account selection bias are the exception rather than the rule. Robustness and bayes factor replications largely supported the impression from this initial analysis. However, these replications cautioned against the interpretation of a few insignificant unemployment effects as absence of unemployment effects. Similarly, these replications showed that some of the remaining significant effects were not robust enough to offer clear evidence for the presence of unemployment effects.

It could be argued that passive LMPs related to the living standard of the unemployed are the most salient or important topic of the four analysed items for the unemployed. But in contrast to the item differences in the results, the salience argument could not help explaining the country differences in the results. Thus, the interpretation of the remaining effects on passive LMP attitudes clearly points to the limitations of the present study. Remaining effects after taking into account observable selection bias can either be interpreted as causal or as result of unobservable selection bias. Furthermore, this article focused exclusively on direct effects from unemployment on political orientations. It is, however, possible that these direct effects are moderated, i.e. that some of the remaining effects are only remaining for some subgroup, or that some of the absent effects are actually present for some special subgroup. And finally, this article could not test any of the proposed theoretical mechanisms - stratified political socialization experiences, predispositions stability, and so on.

Despite these limitations there are three broader implications of this article. First of all, this article offered an alternative to the typical theoretical conceptualization and empirical measurement of (unemployment) risk. In the literature on attitudinal insider-outsider divides several researches have explored the possibility of an unemployment risk based conceptualization of the insider and outsider categories (Rovny and Rovny, 2017; Schwander and Häusermann, 2013). This article's results seem at least superficially to support such a risk-based conceptualization, since the results basically suggest that unemployment risk is predictive of political attitudes while given unemployment risk, unemployment per se, i.e. the realized risk, has no 
or almost no influence on political preferences. However, the risk-based conceptualization of insiders and outsiders is based on the assumption that individuals are aware of their unemployment risk and that the expectations to become unemployed are the causal mechanism by which unemployment risk and political preferences are linked (Schwander and Häusermann, 2013 , p. 249). This article's theoretical argument on the contrary treats unemployment risk as confounding the effect of unemployment and thus does not require respondents' awareness of their unemployment risk.

These different theoretical assumptions about the causal role of unemployment risk are mirrored in the measurement of unemployment risk. Thus, e.g. Schwander and Häusermann (2013) measure unemployment risk with reference to respondents age, gender, and occupation. While the assumption of risk awareness might be more realistic for such a risk measurement, from a counterfactual perspective this is of course an extremely limited account of unemployment risk. Thus, for future research it is of crucial importance what it aims for: descriptive differences, that do not require the elimination of confounding risk factors? Or causal claims, that can only be established after the elimination of confounding risk factors?

However, this article can also offer broader implications that go beyond its empirical focus on unemployment and LMP / egalitarian attitudes. Unemployment is not the only life event that can be predicted by socio-economic risk factors. And the arguments about the stability and causal priority of political predispositions over specific attitudes and socio-economic correlates of political socialization are not limited to LMP attitudes. Therefore, these argumentative steps could be used in future research to question the relevance of other life events / circumstances for other political beliefs or political behaviour. One example that is not too far from this article's empirical focus, is the relation between income and egalitarian attitudes. But not only unemployment and income, but also ill-health or single-parenthood are individual circumstances that can be predicted from socio-economic background variables like individuals' formal education or parents' social class (Pintelon et al., 2013). And all such circumstances can be related to social policy attitudes (Hacker et al., 2013).

The fact that this article's theoretical argument is widely applicable also means that selection bias is a commonly encountered problem, as well. Taking on a counterfactual perspective on causality - like the present article - can help alleviating the problem of selection bias in crosssectional survey data. When estimating the effect of a treatment (an independent variable) on an outcome (a dependent variable) the counterfactual perspective offers clear guidance on how to select control variables: focus on variables that come in a causal and temporal sense before the treatment and leave out variables that are / can be a consequence of the treatment. These recommendations are by no means new (Caliendo and Kopeinig, 2008; Gangl, 2015; Ho et al., 2007), but their implementation in cross-sectional research on political behaviour, political attitudes, and their socio-economic causes (or mere correlates?) could help to improve the quality of causal inferences in future research. 


\section{Notes}

${ }^{1}$ However, not all unemployment effects on political beliefs and behaviour are solely seen as self-interest based, as, for example, the argument about a lower general and political efficacy in the case of the political involvement of the unemployed shows (Marx and Nguyen, 2016)

${ }^{2}$ Examples regarding LMP attitudes include Burgoon and Dekker (2010), Emmenegger (2009), and Heinemann et al. (2009). This is not necessarily a critique of these or other similar studies. As long as conclusions about causality are not the aim of the analysis, a distinction between proper and improper identification strategies of causal effects is irrelevant.

${ }^{3}$ Normative reasons make it hard to imagine an experimental study on unemployment effects. Barr et al. (2016) analyse (and find) unemployment effects on beliefs about earned entitlement in an longitudinal, experimental setting. The experimental setting is, however, not used to randomize treatment but to measure acknowledgement of earned entitlement by inferring it from behavioural tasks. From a causal inference perspective this study is thus comparable with the other panel studies with two caveats about the possibly high context dependency due to the selection of experimental participants and the unclear relation between this article's focus on policy attitudes and the behaviourally inferred acknowledgement of earned entitlement.

${ }^{4}$ Part-time and temporary employment are the main categories of atypical employment (Keller and Seifert, 2013).

${ }^{5}$ Fossati (2018) shows that in the case of highly demanding active LMPs this relation is reverse. Unemployed people show lower support for these policies. Demanding active LMPs like e.g. sanctions against unemployed people, who refuse job offers, are, however, a special case that is not the focus here.

${ }^{6} \mathrm{~A}$ similar idea is found in voting studies in the tradition of Campbell et al.'s The American Voter. Party attachments are seen as "perceptual screen" (1960, p. 133) through which political objects (including policies) are evaluated. More recently, the framework of "motivated reasoning" (Taber and Lodge, 2006) follows as similar logic.

${ }^{7}$ Note that the idea that specific attitudes fluctuate more than predispositions is empirically challenged (Ansolabehere et al., 2008; Freeze and Montgomery, 2016; Krosnick, 1991). However, the take away message from these studies is not that predispositions do fluctuate a lot, but on the contrary that there is considerable temporal stability in specific policy attitudes, as well.

${ }^{8}$ While most political socialization scholars see direct transmission of political beliefs from parents to children through the lens of social learning theory, newer research suggests genetic transmission as additional mechanism (Alford et al., 2005)

${ }^{9}$ Figure A.1 in the appendix shows the maximum EB weights in each country before and after trimming, the latter being part of a sensitivity check.

${ }^{10}$ For some countries (Belgium, Germany, Croatia, Portugal, Turkey, and Austria), EB adjusts additionally for an interaction between unemployment experience and age or between age and one of the field of education dummies (Cyprus). Initial balance checks without adjusting for these interactions yielded insufficient balance in these countries for many variables. After accounting for these interactions only minimal imbalances remain.

${ }^{11}$ Freedman and Berk (2008) show for the case of Propensity Score weighting that the use of weights leads to a substantial underestimation of standard errors in the outcome analysis.

${ }^{12}$ The pre-treatment status of most variables used for EB is obvious. Parental characteristics, characteristics of the last job before unemployment and demographics like age, gender, and migratory status undoubtedly come before 
unemployment in a temporal / causal sense. For formal education variables, the pre-treatment status has to be assumed.

${ }^{13}$ see figure A.1 for the maximum weights before and after trimming

${ }^{14}$ The Propensity Score equals the probability to receive treatment, typically computed by a logit model predicting the treatment with the confounders. Rosenbaum and Rubin (1983) have shown that accounting for the true propensity score - instead of accounting for all confounders separately - yields unbiased treatment effects. However, in contrast to EB propensity score methods can leave or even increase imbalances (King and Nielsen, 2015).

${ }^{15}$ The detailed results in figures A.4 - A.7 further show some cases, where the numbers in table 2.1 keep stable while simultaneously one additional country loses significance after controlling selection bias and one additional other country retains a significant effect compared to the original analyses or to the other robustness specifications.

${ }^{16}$ In general, bayes factors equal the ratio of a) the likelihood of the data given a null hypothesis and b) the likelihood of the data given some alternative hypothesis: $B F_{01}=\frac{p\left(D \mid H_{0}\right)}{p\left(D \mid H_{1}\right)}$. Thus, they can be interpreted with their face values. Here, the bayes factors show the odds ratio between a model that explains an outcome with the Propensity Score plus unemployment and a model that explains the same outcome only with the Propensity Score. It is common practice to interpret only bayes factors below 0.33 as evidence at all and only bayes factors below 0.1 as strong evidence for the absence of an effect. Similarly, support for the presence of an effect is typically claimed when bayes factors exceed 3, and strong evidence, when bayes factors exceed 10. (Jarosz and Wiley, 2014; Masson, 2011). These thresholds are shown in figure 2.5 as grey vertical lines. Since the incorporation of weights into the computation of bayes factors is not straightforward the bayes factor computation relies on the models controlling for selection bias via propensity score adjustment, i.e. robustness check $\mathrm{C}$ (see figure A.6 in the appendix). 


\section{References}

Alesina, Alberto and Eliana La Ferrara (2005). "Preferences for redistribution in the land of opportunities". In: Journal of Public Economics 89 (5-6), 897-931.

Alford, John R., Carolyn L. Funk, and John R. Hibbing (2005). “Are Political Orientations Genetically Transmitted?” In: The American Political Science Review 99 (2), 153-167.

Allison, Paul D. (2002). Missing Data. Thousand Oaks: Sage.

- (2009). Fixed Effects Regression Models. Thousand Oaks: Sage.

Andreß, Hans-Jürgen and Thorsten Heien (2001). "Four Worlds of Welfare State Attitudes? A Comparison of Germany, Norway, and the United States". In: European Sociological Review 17 (4), 337-356.

Ansolabehere, Stephen, Jonathan Rodden, and James Jr. Snyder (2008). "The Strength of Issues: Using Multiple Measures to Gauge Preference Stability, Ideological Constraint, and Issue Voting”. In: American Political Science Review 102 (2), 215-232.

Baldassarri, Delia and Amir Goldberg (2014). "Neither Ideologues nor Agnostics: Alternative Voters' Belief System in an Age of Partisan Politic". In: American Journal of Sociology 120 (1), 45-95.

Barr, Abigail, Luis Miller, and Paloma Ubeda (2016). "Moral consequences of becoming unemployed". In: Proceedings of the National Academy of Sciences of the United States of America 113 (17), 4676-4681.

Bernardi, Fabrizio, Lela Chakhaia, and Liliya Leopold (2017). "'Sing Me a Song with Social Significance': The (Mis)Use of Statistical Significance Testing in European Sociological Research". In: European Sociological Review 33 (1), 1-15.

Blekesaune, Morten and Jill Quadagno (2003). "Public Attitudes toward Welfare State Policies: A Comparative Analysis of 24 Nations". In: European Sociological Review 19 (5), 415-427.

Borre, Ole and Elinor Scarbrough, eds. (1995). The Scope of Government. Oxford: Oxford University Press.

Borre, Ole and José Manuel Viegas (1995). "Government Intervention in the Economy”. In: The Scope of Government. Ed. by Ole Borre and Elenor Scarbrough. Oxford and New York: Oxford University Press, 234-279.

Burgoon, Brian and Fabian Dekker (2010). "Flexible employment, economic insecurity and social policy preferences in Europe". In: Journal of European Social Policy 20 (2), 126-141.

Caliendo, Marco and Sabine Kopeinig (2008). "Some Pratical Guidance for the Implementation of Propensity Score Matching”. In: Journal of Economic Surveys 22 (1), 31-72.

Calzada, Inés, Mariá Gómez-Garrido, Luis Moreno, and Francisco Javier Moreno-Fuentes (2014). "It is not Only About Equality. A Study on the (Other) Values That Ground Attitudes to the Welfare State". In: International Journal of Public Opinion Research 26 (2), 178-201.

Campbell, Angus, Philip E. Converse, Warren E. Miller, and Donald E. Stokes (1960). The American Voter. Chicago and London: University of Chicago Press.

Carsey, Thomas M. and Geoffrey C. Layman (2006). "Changing Sides or Changing Minds? Party Identification and Policy Preferences in the American Electorate". In: American Journal of Political Science 50 (2), 464-477.

Chong, Dennis, Jack Citrin, and Jack Conley (2001). "When Self-Interest Matters”. In: Political Psychology 22 (3), 541-570. 
Converse, P. E. (1964). "The nature of belief systems in mass publics". In: Ideology and its discontents. Ed. by David E. Apter. The Free Press of Glencoe, 206-226.

Cusack, Thomas, Torben Iversen, and Philipp Rehm (2006). "Risks at Work: The Demand and Supply Sides of Government Redistribution". In: Oxford Review of Economic Policy 22 (3), 365-389.

Dalton, Russel J. (1982). “The Pathways of Parental Socialization”. In: American Politics Quarterly 10 (2), 139-157.

- (2010). "Ideology, Partisanship, and Democratic Development". In: Comparing Democracies 3. Elections and Voting in the $21^{\text {st }}$ Century. Ed. by Lawrence LeDuc, Richard G. Niemi, and Pippa Norris. London: Sage, 143-164.

Dotti Sani, Giulia M. and Beatrice Magistro (2016). "Increasingly unequal? The economic crisis, social inequalities and trust in the European Parliament in 20 European countries". In: European Journal of Political Research 55 (2), 246-264.

Emmenegger, Patrick (2009). "Barriers to entry: insider/outsider politics and the political determinants of job security regulations". In: Journal of European Social Policy 19 (2), 131146.

ESS (Round 4). European Social Survey Round 4 Data (2008). Data file edition 4.4. NSD Norwegian Centre for Research Data, Norway - Data Archive and distributor of ESS data for ESS ERIC.

- (Round 6). European Social Survey Round 6 Data (2012). Data file edition 2.3. NSD - Norwegian Centre for Research Data, Norway - Data Archive and distributor of ESS data for ESS ERIC.

Faas, Thorsten (2010). Arbeitslosigkeit und Wählerverhalten. Direkte und indirekte Wirkungen auf Wahlbeteiligung und Parteipräferenzen in Ost- und Westdeutschland. Baden-Baden: Nomos.

Feldman, Stanley (1988). "Structure and Consistency in Public Opinion: the Role of Core Beliefs and Values". In: American Journal of Political Science 32 (2), 416-440.

- (2003). "Values, Ideology, and the Structure of Political Attitudes". In: Oxford Handbook of Political Psychology. Ed. by David O. Sears, Leonie Huddy, and Robert Jervis. Oxford and New York: Oxford University Press, 477-508.

Feldman, Stanley and Marco Steenbergen (2001). "The Humanitarian Foundation of Public Support for Social Welfare”. In: American Journal of Political Science 45 (3), 658-677.

Fossati, Flavia (2018). "Who Wants Demanding Active Labour Market Policies? Public Attitudes towards Policies that put Pressure on the Unemployed". In: Journal of Social Policy 47 (1), 77-97.

Freedman, David A. and Richard A. Berk (2008). "Weighting Regressions by Propensity Scores". In: Evaluation Review 32 (4), 392-409.

Freeze, Melanie and Jacob M. Montgomery (2016). "Static Stability and Evolving Constraint: Preference Stability and Ideological Structure in the Mass Public". In: American Politics Research 44 (3), 415-447.

Gallego, Aina (2007). "Unequal Political Participation in Europe". In: International Journal of Sociology 37 (4), 10-25.

Gangl, Markus (2015). "Matching Estimators for treatment effects". In: The SAGE Handbook of Regression Analysis and Causal Inference. Ed. by Henning Best and Christof Wolf. London, et al.: Sage Publications, 251-276. 
Gelissen, John (2000). "Popular support for institutionalised solidarity: a comparison between European welfare states". In: International Journal of Social Welfare 9 (4), 285-300.

Gelman, Andrew (2011). "Causality and Statistical Learning". In: American Journal of Sociology 117 (3), 955-966.

Goldthorpe, John H. and Abigail McKnight (2006). "The Economic Basis of Social Class.” In: Mobility and Inequality. Frontiers of Research in Sociology and Economics. Ed. by Stephen L. Morgan, David B. Grusky, and Gary S. Fields. Stanford: Stanford University Press, 109136.

Goren, Paul (2000). "Political Expertise and Principled Political Thought". In: Political Research Quarterly, 117-136.

- (2001). "Core Principles and Policy Reasoning in Mass Publics: A Test of Two Theories". In: British Journal of Political Science 31 (1), 159-177.

- (2005). "Party Identification and Core Political Values". In: American Journal of Political Science 49 (4), 881-896.

- (2013). On Voter Competence. Oxford University Press.

Gregg, Paul and Stephen Machin (2001). "Childhood experiences, education attainment and adult labour market performance". In: Child Well-Being, Child Poverty and Child Policy in Modern Nations. What do we know? Ed. by Koen Vleminckx and Timothy M. Smeeding. Bristol: The Policy Press, 129-150.

Gregg, Paul, Lindsey Macmillan, and Bilal Nasim (2012). "The Impact of Fathers' Job Loss during the Recession of the 1980 on their Children's Education Attainment and Labour Market Outcomes". In: Fiscal Studies 33 (2), 237-264.

Guillaud, Elvire and Paul Marx (2014). "Preferences for Employment Protection and the InsiderOutsider Divide: Evidence from France". In: West European Politics 37 (5), 1177-1185.

Hacker, Jacob S., Phlipp Rehm, and Mark Schlesinger (2013). "The Insecure American: Economic Experiences, Financial Worries, and Policy Attitudes". In: Perspectives on Politics $11(1), 23-49$.

Hainmueller, Jens (2012). "Entropy Balancing for Causal Effects: A Multivariate Reweighting Method to Produce Balanced Samples in Observational Studies". In: Political Analysis 20, 25-46.

Harell, Allison, Stuart Soroka, and Shanto Iyengar (2016). "Race, prejudice and attitudes toward redistribution: A comparative experimental approach". In: European Journal of Political Research 55, 723-744.

Hasenfeld, Yeheskel and Jane A. Rafferty (1989). "The Determinants of Public Attitudes toward the Welfare State”. In: Social Forces 67 (4), 1027-1048.

Häusermann, Silja, Thomas Kurer, and Hanna Schwander (2015). "High-skilled outsiders? Labor market vulnerability, education and welfare state preferences". In: Socio-Economic Review 13 (2), 235-258.

Heath, Anthony (2007). "Crossnational Patterns and Processes of Ethnic Disadvantage". In: Unequal Chances. Ethnic Minorities in Western Labour Markets. Ed. by Anthony F. Heath, Sin Yi Cheung, and Shawna N. Smith. New York: Oxford University Press, 639-689.

Heinemann, Friedrich, Ivo Bischoff, and Tanja Hennighausen (2009). "Choosing from the Reform Menu Card - Individual Determinants of Labour Market Policy Preferences”. In: Journal of Economics and Statistics 229 (2/3), 180-197. 
Ho, Daniel E., Kosuke Imai, Gary King, and Elizabeth A. Stuart (2007). "Matching as Nonparametric Preprocessing for Reducing Model Dependence in Parametric Causal Inference". In: Political Analysis 15 (3), 199-236.

Holland, Paul W. (1986). "Statistics and Causal Inference". In: Journal of the American Statistical Association 81 (396), 945-960.

Imai, Kosuke, Gary King, and Elizabeth A. Stuart (2008). "Misunderstandings between experimentalists and observationalists about causal inference". In: Journal of the Royal Statistical Society. Series A 171 (2), 481-502.

Imbens, Guido W. and Donald B. Rubin (2015). Causal Inference for Statistics, Social, and Biomedical Sciences. An Introduction. New York: Cambridge University Press.

Inglehart, Ronald (1977). The Silent Revolution. Changing Values and Political Styles Among Western Publics. Princeton: Princeton University Press.

Iversen, Torben and David Soskice (2001). "An Asset Theory of Social Policy Preferences". In: American Political Science Review 95 (4), 875-893.

Jacoby, William G. (2006). "Value Choices and American Public Opinion". In: American Journal of Political Science 50 (3), 706-723.

Jæger, Mads Meier (2006). "What Makes People Support Public Responsibility for Welfare Provision: Self-interest or Political Ideology?” In: Acta Sociologica 49 (3), 321-338.

Jarosz, Andrew F. and Jennifer Wiley (2014). "What are the Odds? A Practical Guide to Computing and Reporting Bayes Factors". In: Journal of Problem Solving 7, 2-9.

Jennings, M. Kent, Laura Stoker, and Jake Bowers (2009). "Politics across Generations: Family Transmission Reexamined". In: The Journal of Politics 71 (3), 782-799.

Kass, Robert E. and Adrian E. Raftery (1995). "Bayes Factors". In: Journal of the American Statistical Association 90 (430), 773-795.

Keller, Berndt and Hartmut Seifert (2013). "Atypical employment in Germany. Forms, development, patterns". In: European Review of Labour and Research 19 (4), 457-474.

King, Gary and Richard Nielsen (2015). Why Propensity Scores Should Not Be Used for Matching.

Knoke, David and Michael Hout (1974). "Social and Demographic Factors in American Party Affiliations, 1952-72”. In: American Sociological Review 39 (5), 700-713.

Korpi, Thomas, Paul de Graaf, John Hendrickx, and Richard Layte (2003). "Vocational Training and Career Employment Precariousness in Great Britain, the Netherlands and Sweden". In: Acta Sociologica 46 (1), 17-30.

Kroh, Martin (2009). "The preadult origins of postmaterialism: A longitudinal sibling study". In: European Journal of Political Research 48 (5), 598-621.

Krosnick, Jon A. (1991). "The Stability of Political Preferences: Comparisons of Symbolic and Nonsymbolic Attitudes”. In: American Journal of Political Science 35 (3), 547-576.

Lee, Brian K., Justin Lessler, and Elizabeth A. Stuart (2011). "Weight Trimming and Propensity Score Weighting". In: PLoS ONE 6 (3), 1-6.

Linos, Katerina and Martin West (2003). "Self-Interest, Social Beliefs, and Attitudes to Redistribution. Re-adressing the Issue of Cross-national Variation". In: European Sociological Review 19 (4), 393-409.

Lipset, Seymour M. and Stein Rokkan (1967). Party System and Voter Alignments. The Free Press. 
Lorenzini, Jasmine and Marco Giugni (2012). "Employment Status, Social Capital, and Political Participation: A Comparison of Unemployed and Employed Youth in Geneva". In: Swiss Political Science Review 18 (3), 332-351.

Lucchini, Mario and Antonio Schizzerotto (2010). "Unemployment risks in four EU countries". In: Social Class in Europe. An introduction to the European Socio-economic Classification. Ed. by David Rose and Eric Harrison. New York: Routledge, 235-244.

Lunceford, Jared K. and Marie Davidian (2004). "Stratification and weighting via the propensity score in estimation of causal treatment effects: a comparative study". In: Statistics in Medicine 23, 2937-2960.

Margalit, Yotam (2013). "Explaining Social Policy Preferences: Evidence from the Great Recession". In: American Political Science Review 107 (1), 80-103.

Marx, Paul and Christoph Nguyen (2016). "Are the Unemployed Less Politically Involved? A Comparative Study of Internal Political Efficacy". In: European Sociological Review 32 (5), 634-648.

Marx, Paul and Georg Picot (2013). "The party preferences of atypical workers in Germany". In: Journal of European Social Policy 23 (2), 164-178.

Masson, Michael E. J. (2011). "A tutorial on a practical Bayesian alternative to null-hypothesis significance testing". In: Behavioral Research 43, 679-690.

Müller, Walter (2005). "Education and Youth Integration into European Labour Markets". In: International Journal of comparative Sociology 46 (5-6), 461-485.

Naumann, Elias, Christopher Buss, and Johannes Bähr (2016). "How Unemployment Experience Affects Support for the Welfare State: A Real Panel Approach”. In: European Sociological Review 32 (1), 81-92.

Owens, Lindsay A. and David S. Pedulla (2014). "Material Welfare and Changing Political Preferences: The Case of Support for Redistributive Social Policies". In: Social Forces 92 (3), 1087-1113.

Peffley, Mark A. and Jon Hurwitz (1985). "A Hierarchical Model of Attitude Constraint". In: American Journal of Political Science 29 (4), 871-890.

- (1993). "Models of Attitude Constraint in Foreign Affairs". In: Political Behavior 15 (1), 61-90.

Petersen, Michael Bang, Rune Slothuus, Rune Stubager, and Lise Togeby (2010). "Deservingness versus values in public opinion on welfare: The automaticity of the deservingness heuristic.” In: European Journal of Political Research 50, 24-52.

Pintelon, Olivier, Bea Cantillon, Karel Van den Bosch, and Christopher T. Whelan (2013). "The Social Stratification of Social Risks: The Relevance of class for ssocial investment strategies". In: Journal of European Social Policy 23 (1), 52-67.

Reeskens, Tim and Wim van Oorschot (2015). "Immigrants' Attitudes towards Welfare Redistribution. An Exploration of Role of Government Preferences among Immigrants and Natives across 18 European Welfare States". In: European Sociological Review 31 (4), 433-445.

Rehm, Philipp (2016). Risk Inequality and Welfare States. Social Policy Preferences, Development, and Dynamics. New York: Cambridge University Press.

Reimer, David, Clemens Noelke, and Aleksander Kucel (2008). "Labor Market Effects of Field of Study in Comparative Perspective. An Analysis of 22 European Countries". In: International Journal of Comparative Sociology 49 (4-5), 233-256. 
Rekker, Roderik, Loes Keijsers, Susan Branje, and Wim Meeus (2015). "Political attitudes in adolescence and emerging adulthood: Developmental changes in mean level, polarization, rank-order stability, and correlates". In: Journal of Adolescence 41, 136-147.

Rico, Guillem and M. Kent Jennings (2016). "The Formation of Left-Right Identification: Pathways and Correlates of Parental Influence". In: Political Psychology 37 (2), 237-252.

Rohlfing, Ingo (2012). Case Studies and Causal Inference. Basingstoke: Palgrave Macmillan.

Rosenbaum, Paul R. (1984). "The Consequences of Adjustment for a Concomitant Variable That Has Been Affected by the Treatment". In: Journal of the Royal Statistical Society. Series A 147 (5), 656-666.

Rosenbaum, Paul R. and Donald B. Rubin (1983). "The central role of the propensity score in observational studies for causal effects". In: Biometrica 70 (1), 41-55.

Rouder, Jeffrey N., Paul L. Speckman, Dongchu Sun, Richard D. Morey, and Geoffrey Iverson (2009). "Bayesian t tests for accepting and rejecting the null hypothesis". In: Psychonomic Bulletin \& Review 16 (2), 225-237.

Rovny, Allison E. and Jan Rovny (2017). "Outsiders at the ballot box: operationalizations and political consequences of the insider-outsider dualism”. In: Socio-Economic Review 15 (1), 161-185.

Rubery, Jill, Mark Smith, Colette Fagan, and Damian Grimshaw (1998). Women and European Employment. London: Routledge.

Rueda, David (2005). "Insider-outsider politics in industrialized democracies: The challenge to social democratic parties". In: American Political Science Review 99 (1), 61-74.

Schwander, Hanna and Silja Häusermann (2013). "Who is in and who is out? A risk-based conceptualization of insiders and outsiders". In: Journal of European Social Policy 23 (3), 248-269.

Sears, David O., Richard R. Lau, Tom R. Tyler, and Harris M. Jr. Allen (1980). "Self-Interest vs. Symbolic Politics in Policy Attitudes and Presidential Voting”. In: The American Political Science Review 74 (3), 670-684.

Siedler, Thomas (2011). "Parental unemployment and young people's extreme right-wing party affinity: evidence from panel data". In: Journal of the Royal Statistical Society. Series A 174 (3), 737-758.

Stegmueller, Daniel (2013). "Modeling Dynamic Preferences: A Bayesian Robust Dynamic Latent Ordered Probit Model". In: Political Analysis 21 (3), 314-333.

Taber, Charles S. and Milton Lodge (2006). "Motivated Skepticism in the Evaluation of Political Beliefs". In: American Journal of Political Science 50 (3), 755-769.

van Buuren, Stef (2012). Flexible Imputation of Missing Data. CRC Press.

van Oorschot, Wim (2002). "Individual motives for contributing to welfare benefits in the Netherlands". In: Policy \& Politics 30 (1), 31-46.

White, Ian R., Patrick Royston, and Angela M. Wood (2009). "Multiple Imputation using chained equations: Issues and guidance for practice". In: Statistics in Medicine 30 (4), 377399.

Winship, Christopher and Michael Sobel (2004). "Causal Inference in Sociological Studies". In: Handbook of Data Analysis. Ed. by Melissa Hardy and Alan Bryman. London, et al.: Sage Publications, 481-503. 


\section{Article 2: Going beyond values versus self-interest. Whose attitudes change after employment transitions?}

This is the accepted version of the article. It is published as:

Wehl, N. (2020): Going beyond values versus self-interest: whose attitudes change after employment transitions?, in: Political Research Exchange 2(1), 1-23

The published version can be found here:

https://doi.org/10.1080/2474736X.2020.1809473

Acknowledgements This work was supported by the Bamberg Graduate School of Social Sciences which is funded by the German Research Foundation (DFG) under the German Excellence Initiative (GSC1024).

I am grateful for comments received at the 3rd Leuven-Montreal Winter School on Elections, where an earlier version of this work was presented. Furthermore I would like to thank the anonymous reviewers of the manuscript as well as Kattalina Berriochoa, Nona Bledow, Sebastian Jungkunz, Katja Pomianowicz, Femke Roosma, and Gundula Zoch for their helpful feedback and suggestions. 


\title{
Going beyond values versus self-interest. Whose attitudes change after employment transitions?
}

\begin{abstract}
Are self-interest or presumably stable value orientations and other predispositions the main drivers behind social policy attitudes? This article aims at contributing to this debate by moving away from the binary discussion of this question. It does so by differentiating between attitude changes driven by self-interest that are in line with pre-existing predispositions and those that are not. Empirically, this article focuses on changes of labour market policy attitudes after employment transitions and job insecurity changes. More precisely, this article differentiates between attitude changes within three subgroups of people. A) People whose self-interest after the employment transitions reinforces their prior predispositions. B) People without strong prior predispositions, who are thus unconstrained by them. And C) people whose self-interest after the employment transitions contradicts their prior predispositions. Panel analyses with fixed effects use German data from SOEP waves in 1997 and 2002. Analyses of main effects show significant attitudinal reactions after most of the transitions and perception changes. Thus, they suggest an important role for self-interest. However, subgroup analyses result in a somewhat mixed picture since there is evidence for attitude change within different subgroups after different transitions and perception changes. In theoretical terms, however, this mixed empirical picture suggests caution when interpreting attitudinal change or stability after changing material circumstances as a sign for the relative importance of self-interest or value orientations and other predispositions.
\end{abstract}

Keywords: self-interest - values - social policy attitudes - panel fixed effects - labour market insider/outsider 


\subsection{Introduction}

Why do we want what we want or do what we do? To answer this question, a large part of the literature on political attitudes and behaviour centers on the influence of self-interest vis-á-vis presumably stable predispositions. Examples for such predispositions are value orientations (Calzada et al., 2014; van Oorschot, 2002), ideology (Jæger, 2006; Wiertz and Rodon, 2021), or party identification (Lau and Heldman, 2009) among others. This debate is also highly relevant for social policy attitudes (Owens and Pedulla, 2014) including this article's empirical focus on labour market policy (LMP) attitudes (Margalit, 2013). To be more precise, I focus on attitudes towards job creation policies (active LMPs) and unemployment benefits helping the unemployed financially (passive LMPs).

This article focuses on the question whether LMP attitudes change after employment transitions and changes of perceived job insecurity. Self-interest based arguments expect growing support for LMPs after job loss and other subjective or objective deteriorations of the individual employment situation. Arguments emphasizing the role of values, in contrast, are typically associated with the expectation of attitudinal stability. To move away from this binary 'selfinterest versus values' discussion, this article contributes by differentiating between attitude changes that are consistent with pre-existing value orientations and other predispositions and those that are not. Thus, this article does not only infer the relation between self-interest and value orientations and other predispositions. Instead, this article observes their relation more directly.

By doing so, this article answers recent calls to better understand "how prior leanings condition the response to the [economic] shock" (Margalit, 2019, p. 290). More precisely, this article differentiates between three subgroups of people, who might experience self-interest driven attitude changes after employment transitions and job insecurity changes. These are A) people whose predispositions already agree with those LMPs that serve their self-interest after these employment changes. B) people who do not hold strong prior predispositions and thus are not constrained by these prior predispositions C) people whose prior predispositions contradict their later self-interest after these employment changes.

Empirically, I use German panel data from the Socio-Economic Panel (SOEP) from 1997 and 2002. The SOEP has not yet been used for analyses of dynamics between employment and LMP attitudes. Its advantage is that it allows for the observation of a sufficient number of employment transitions and job insecurity changes even when splitting the sample according to measures of prior predispositions.

When focusing on the whole sample most transitions and changes of perceived job insecurity are followed by attitudinal responses consistent with self-interest accounts. However, the subgroup analyses show a mixed picture. While a few attitudinal responses counteract pre-existing predispositions, many actually do not, as they reinforce pre-existing predispositions or happen in absence of strong predispositions. 
In the following, I address accounts of welfare attitudes and specifically of labour market policy (LMP) attitudes that focus on self-interest and accounts that focus on value orientations and other predispositions. After delineating the arguments for attitudinal responses within the three subgroups I discuss the SOEP data and variables and the panel fixed effects models used for the analyses. After that, the results will be discussed including a descriptive overview as well as several robustness checks. The article concludes with a summary and lessons for future research. The mixed findings caution against inferring the relation between self-interest and predispositions from (in)significant main effects of changing material circumstances on attitudes. Furthermore, they caution against generalizing attitudinal reactions to one kind of changing material circumstances to reactions to other kinds of material circumstances.

\subsection{Values versus Self-Interest and Beyond}

The basic assumption of self-interest based arguments regarding policy attitudes is that people support a policy because they benefit from it. This includes people who 1) objectively benefit from that policy now, 2) are objectively expected to benefit from that policy in the future, and 3) people who subjectively believe they will benefit from that policy in the future. These three versions of the self-interest argument are typically applied to the relation between social policy attitudes and income (Alesina and La Ferrara, 2005) or unemployment. In the latter case this application includes 1) those who are currently unemployed, 2) those who are in an objectively insecure employment situation like fixed-term employment (Marx, 2015) or employment in an occupation with a high unemployment rate (Rehm, 2016), and 3) those who subjectively worry about their job security for whatever ${ }^{17}$ reason (Burgoon and Dekker, 2010). All three groups of labour market 'outsiders' (Rueda, 2005; Schwander and Häusermann, 2013) are thus expected to demand government action for financial help during unemployment (passive LMPs) and measures to reduce unemployment (active ${ }^{18}$ LMPs) among other things.

The rival argument par excellence comes from the "values perspective", as it is referred to in the literature on attitudes towards social policies, redistribution, and the welfare state. Here, social policy attitudes are seen as determined by egalitarian value orientations, justice principles like equality, need, or equity, and other value orientations not so closely linked with redistribution (Andreß and Heien, 2001; Calzada et al., 2014). However, zooming out from the literature on social policy attitudes to policy attitudes in general goes hand in hand with a stronger focus on other examples of predispositions besides value orientations. The most widespread examples are party identification (Harteveld et al., 2017) and political left-right ideology ${ }^{19}$ (Jæger, 2006; Pardos-Prado, 2011). And to give some empirical examples from Germany with relation to LMP attitudes, research shows that spending less on LMPs is more acceptable for people who generally believe in everyone's own responsibility for their economic fate. Similarly, such cuts are less acceptable for people who believe the needy should to be supported by the state (Heinemann et al., 2009). Also, identifiers with left parties are shown to support state responsibility for different social policies more than identifiers with conservative parties (Dageförde, 2013). 
Whether focusing on value orientations, ideology, or party identification, all these different kinds of predispositions share several functions and characteristics especially in comparison to policy attitudes. Most importantly, they are assumed to be far more stable over time than policy attitudes and they are assumed to causally influence policy attitudes, not vice versa (Maio et al., 2003). Whether these assumptions are true is of course an empirical question and part of a longstanding debate. But these assumptions have certainly received too much empirical credit to ignore them (Carsey and Layman, 2006; Weber and Saris, 2014). Also, different predispositions can of course impact each other, as well, as e.g. Goren (2005) shows with regard to core values and party identification.

The self-interest perspective does not necessarily contradict such predispositional determinants of policy attitudes. Indeed, theoretical arguments relying on a self-interest logic often discuss the "values perspective" before choosing to derive hypotheses from the self-interest mechanism (Häusermann et al., 2015; Rehm, 2016). Thus, if self-interest measures and value orientations were independent of each other the values versus self-interest controversy could be solved by simply acknowledging the existence of two different sets of predictors for political attitudes. However, they are not independent. Take the examples of attitudinal gaps based on age (Sears et al., 1980), formal education (Sears and Funk, 1990), or employment related variables like subjective job insecurity (O'Grady, 2019) or unemployment (Wehl, 2019). On the one hand, these can be interpreted as a result of diverging interests of the young and old, the highly and low educated, or of labour market insiders and outsiders. On the other hand, however, they can be interpreted as a result of different socialization experiences of these groups in different school contexts, different political contexts (cohort socialization), or in more or less affluent parental households (O'Grady, 2019; Sears et al., 1980; Sears and Funk, 1990; Wehl, 2019). Should we thus stop interpreting any socio-economic or demographic gaps in attitudes as evidence for self-interest (Chong et al., 2001)? Or should we rather start to interpret all predispositional effects on attitudes as additional evidence for self-interest (Weeden and Kurzban, 2017)? For some it basically becomes a matter of taste.

In contrast, a clear observational difference between self-interest based and value-based arguments emerges in a dynamic context where people move into unemployment, fixed-term employment, etc. and others move out of these insecure situations. The straightforward selfinterest expectation is that people will support LMPs more strongly after their employment situation deteriorates. Similarly, their support for LMPs will decrease after their employment situation improves (Margalit, 2013; O'Grady, 2019). In contrast, the "values perspective" emphasizes predispositional, and thus attitudinal, stability. Value orientations and other predispositions acquired during socialization are seen as rather stable afterwards in adulthood (Chong et al., 2001; Sears et al., 1980). This focus on attitudinal change or stability after changing material situations including employment transitions is an increasingly used strategy against the self-interest versus values conundrum. The big advantage that comes with the focus on employment and attitudinal dynamics is that it eliminates potential confounding by past socialization experiences.

Studies applying such a dynamic focus to the U.S. context (Margalit, 2013; Owens and Pedulla, 2014) and to the Dutch context (Naumann et al., 2016) find that job loss is related to higher demands for unemployment benefits, higher demands for assistance (including training) to the 
poor and the unemployed, and higher demands for general redistributive measures. On the contrary, Stegmueller (2013) finds no evidence for relations between changes in unemployment and attitudes towards government responsibility for job creation in the U.K. context. Margalit additionally looks at changes of subjective job insecurity and finds evidence for higher demands for government assistance to the poor and unemployed after increasing worries about job insecurity. On the contrary, O'Grady (2019), looks at job insecurity changes in the Swiss context and finds a small increase in demands for social benefits but no increase in demands for taxing the rich. And while Margalit (2013) finds decreasing demands for assistance to the poor and unemployed after reemployment, Naumann et al. (2016) find no evidence for attitudinal change after reemployment. However, they find even higher demands for unemployment benefits after temporary unemployment than after to job loss. Thus, not only the theoretical expectations from self-interest based arguments and arguments emphasizing values or other predispositions are contradicting. Empirical results are contradicting as well.

\subsubsection{Who experiences self-interest based attitude changes?}

The theoretical and empirical ambivalence surrounding the self-interest versus values debate already led to some theoretical combinations of both. The starting point is to ask "when selfinterest matters', as Chong et al. (2001) suggest - not just 'whether' self-interest matters. These authors argue that individuals' attitude changes are guided by material self-interest when their stakes are clear and high. Another example is the study by van Oorschot (2002) that asked people directly why they pay for social security and found that people are motivated by both, self-interest and value orientations.

Following these attempts to go beyond the simple dichotomy of self-interest versus value orientations, I suggest asking whose attitudes change after employment transitions and changes of job insecurity. More precisely, I suggest differentiating between three groups of people whose attitudes might change after such transitions as depicted in figure 3.1. A) People whose self-interest after the employment transitions reinforces their prior predispositions, B) people without strong prior predispositions, who are thus unconstrained by them and C) people whose self-interest after the employment transitions contradicts their prior predispositions. Of course, it is not possible to exclude that attitudinal reactions are observable in all three subgroups. That would be clear evidence for pure self-interest arguments.

Why should there be attitude changes in the first subgroup, where prior predispositions already fit together with later self-interest? The literature offers at least two arguments for attitude changes after employment transitions or changes of subjective job insecurity in this subgroup. On the one hand, it is argued that self-interest affects how much someone cares about an issue, i.e. attitude importance (Boninger et al., 1995). Attitude importance in turn is related to attitude extremity (Boninger et al., 2009). On the other hand, this subgroup of people might experience attitude changes because they engage in some form of motivated reasoning (Taber and Lodge, 2006). When confronted with new information (here rather experiences) people tend to incorporate information that is in line with their prior value orientations and other predispositions in 
their belief system as support for these predispositions and thereby strengthen these prior value orientations even more.

Several findings on the role of party identification in shaping attitudinal dynamics point to this direction. Thus, Brooks and Manza's (2013) study shows in the U.S. context that after the great recession identifiers with the Democrats increased their demands for social policies, while identifiers with the Republicans even decreased such demands. The same is true for Peterson's (2016) finding that after winning the lottery Republican identifiers are less likely to move away from their Republican identification. Note that in this subgroup, attitude changes simply strengthen or reinforce individuals' prior predispositions. Thus, in this case, expectations from self-interest based arguments and arguments emphasizing the role of predispositions do not contradict each other but complement each other.

Hypothesis 1a: An attitude change in the direction predicted by self-interest arguments is observable after employment transitions and changes of perceived job insecurity for people whose predispositions already agree with those LMPs that serve their self-interest after these employment changes.

The second possibility is attitude change experienced by people who do not hold strong prior predispositions and thus are not constrained by these prior predispositions to borrow from the belief system terminology (Converse, 1964). Or to put it differently, without strong values there is more room for self-interest effects.

Several varieties of this argument are well known in political science. People without strong predispositions - especially without a partisan identity - are often seen as the prototype of a good citizen, as e.g. Dalton (2012) argues when evoking the concept of cognitive mobilization. After all, they are assumed to be able to build their opinions and behave politically without reliance on their partisan identities as cues. Thus, e.g. de la Calle and Roussias (2012) show that Spanish independent voters were more likely than there counterparts - partisan identifiers - to engage in retrospective voting. Similarly, Lachat (2007) shows that people with weaker predispositions are more prone to attitudinal changes. A somewhat similar argument is made in the context of motivated reasoning by Taber and Lodge (2006), who argue that weaker attitudes induce smaller biases when evaluating new information. Also, Peterson's findings focusing on selfinterest based effects on party ID are in line with this reasoning. Peterson shows that winning the lottery increases the likelihood of a Republican identification for previous non-identifiers. Note that in this case expectations from predispositional arguments and self-interest based arguments again do not contradict each other. However, in contrast to the first subgroup, this is neither a case supporting nor questioning the role of value orientations or other predispositions. After all, according to this hypothesis, the other two subgroups specified in H1a and H1c do not show attitudinal reactions precisely because of the predispositional influences.

Hypothesis 1b: An attitude change in the direction predicted by self-interest arguments is observable after employment transitions and changes of perceived job insecurity for people who do not hold strong prior predispositions. 
Finally, attitude changes might also be experienced by people whose prior values and other predispositions do not agree with what serves their self-interest after the employment changes. In this subgroup, the contrast between previous value orientations or predispositions and later self-interest is sharpest. In that sense, this scenario could be seen as most likely case from a self-interest perspective (or vice versa as least likely case from predispositional accounts). Furthermore, it is quite likely that employment status changes induce experiences, that do not fit so well to the rest of people's belief system. I.e. employment status changes might induce cognitive dissonance (Festinger, 1957). Attitude change in turn is a typical way to solve dissonances. Attitude reversal is in line with Margalit's (2013) result from the U.S. context that the increase in social policy demands after experiencing an economic shock is higher for Republican than for Democratic identifiers. Note that in this case expectations from the "values perspective" and the self-interest perspective clearly contradict each other. Effects occurring for this group of people would clearly highlight the importance of self-interest effects and question the role of pre-existing values and other predispositions in light of changing material circumstances.

Hypothesis 1c: An attitude change in the direction predicted by self-interest arguments is observable after employment transitions and changes of perceived job insecurity for people whose prior predispositions do not agree with those LMPs that serve their self-interest after these employment changes. 

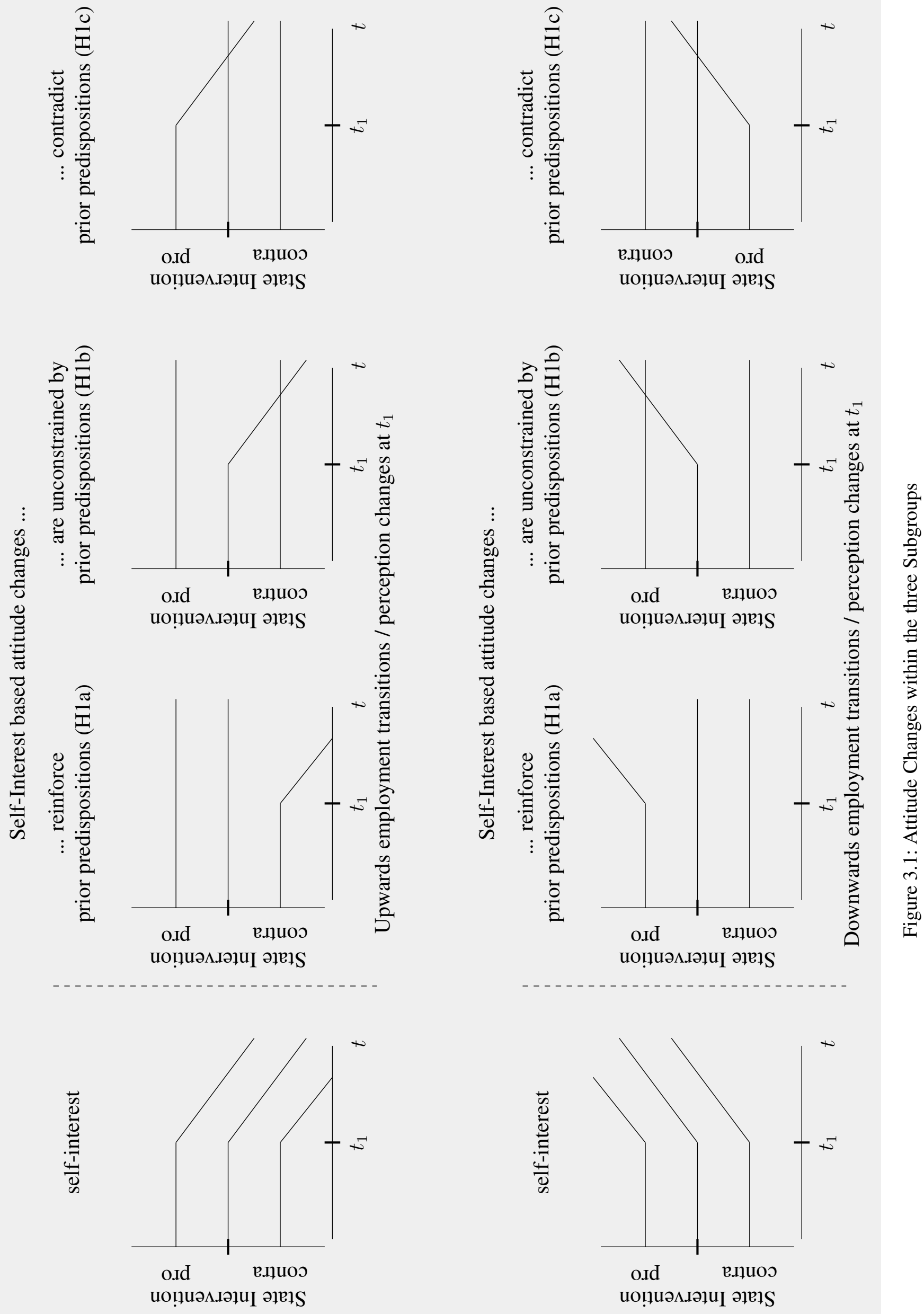


\subsection{Data and Methods}

German data ${ }^{20}$ from the SOEP, the German Socio-Economic Panel (Wagner et al., 2007) are analysed relying on fixed effects models. In addition to the following discussion of data and methods, detailed question wordings and recodings can be found in the appendix.

\subsubsection{Measurement}

Labour market policy (LMP) attitudes are the dependent variable in all analyses. The SOEP includes such items only in 1997 and 2002. Thus, despite the existence of yearly data from 1984 onwards, only those two waves are used for the analyses excluding respondents with missing values on the dependent variable in at least one of the waves. The SOEP items on LMP attitudes ask respondents for their position on government or state responsibility for LMPs. While government responsibility items are widely used, they are only sub-optimal. Spending preference items could show an even closer link to respondents' material self-interest, especially when combined with trade-offs with cuts for other policy areas or higher taxes (Cavaillé and Trump, 2015; Gallego and Marx, 2017). The SOEP includes two items, one on passive LMPs and one on active LMPs (job creation), both measured on a 5-point scale. As discussed in the theory section, both kinds of LMPs can be assumed to be in the interest of unemployed persons and those with a high unemployment risk. Therefore, both LMP attitude items are averaged and jointly analysed ${ }^{21}$. A robustness check analyses them separately, however.

The main independent variables are employment status transitions and changing levels of job insecurity. First, these are transitions in and out of unemployment, i.e. job loss, reemployment, and temporary unemployment. Job loss and reemployment do not cover all transitions in or out of unemployment since transitions in or out of non-employment, like e.g. school-to-work transitions or retiring, are excluded. Temporary unemployment refers to persons employed in both analysed waves who went through an episode ( $\geq 1$ month) of unemployment in between, which is measured using monthly employment records from the SOEP. Second, changes from a fixed-term contract to a permanent contract and vice versa are observable. These transitions between permanent and fixed-term contracts are only observable for employees and do not include transitions from or to self-employment or employment without a contract. As discussed below, due to the low number of respondents experiencing such employment transitions - especially when splitting analyses by first wave attitudes or party ID -, job loss and switching from a permanent to a fixed-term contract are combined to "deteriorations". Similarly, reemployment and switching from a fixed-term to a permanent contract are combined to "improvements". Again, a robustness check analyses them separately.

Changing subjective perceptions of the employment situation are measured with items on job insecurity. SOEP respondents are asked on two 3-point scales how much they are concerned about their job security. The SOEP data additionally contains an item about respondents' subjective reemployment chances also measured on a 3-point scale. Each of these perception 
changes is converted into two binary variables indicating whether respondents worry more (or less) than in the first wave.

To differentiate between attitude changes within the three subgroups, analyses are split by respondents' first wave LMP attitudes and their first wave party identification. In the case of LMP attitudes 3 groups are built, namely a 'pro', a neutral, and a 'contra' government responsibility category. Thus, using the combined ${ }^{22}$ measure of LMP attitudes, respondents with a score value between 1 and 2.5 are categorized as 'contra', respondents with a score values of 3 as 'neutral', and respondents with a score value between 3.5 and 5 as 'pro'. Also in the case of party identification three groups are built, namely identifiers with a "left" party, i.e. social democratic, green, and far left identifiers, non-identifiers, and identifiers with a right party, i.e. christian-democratic, liberal, and far right identifiers. These three groups of party identifiers are built using the typical two-step survey-question about party identification asking respondents first, whether they feel close to any party, and in a second step, if so, to which one.

\subsubsection{Analytical Strategy}

To analyse the dynamics of employment transitions, job insecurity changes, and LMP attitudes, linear $^{23}$ fixed effects panel models (Allison, 2009; Brüderl and Ludwig, 2015) with cluster robust standard errors are applied. Such fixed effects estimators rely solely on intra-individual comparisons. Thus, all constant sources of heterogeneity like gender or past life course events are automatically controlled for - a considerable advantage over results based on cross-sectional data (Brüderl and Ludwig, 2015).

While it is not possible to include time constant variables as predictors, they can be included as moderator variables, as hypotheses 1a-1c suggest. For most analyses this is done by subgroup analyses with subgroups defined by respondents' first wave LMP attitudes or party attachments. However, these subgroup analyses are complemented with interaction models. These interaction models are used to test for significant differences in the effects of employment transitions and perception changes. Note that both modelling strategies can be exactly equivalent when all interactions which the subgroup analyses implicitly represent are explicitly modelled.

Importantly, results from fixed effects models are still threatened by omitted variable bias from time-varying variables. Therefore, indicators for further training, childbirth as well as changes of subjective health after the first analysis wave are added and thus factors, that might influence both, employment transitions and attitude changes. However, since the causal role of these time-varying variables is not clear and post-treatment bias is a danger their influence is considered in a robustness check only. One special case of a time-varying variable is time itself. In line with e.g. Owens and Pedulla (2014) time fixed effects (i.e. survey wave dummies) are added to control for general time trends or shocks in the political attitude measures that are independent of employment transitions or perception changes. 
In the following analyses, I interpret effects for employment transitions or changing feelings of job insecurity in the direction expected by self-interest arguments as signs for self-interest effects. Beyond that self-interest is not observed. Similarly, I interpret attitudinal stability after employment transitions or changing feelings of job insecurity as evidence for the relevance of values and other predispositions. Both interpretations are in line with the relevant discussed literature (O'Grady, 2019; Owens and Pedulla, 2014).

Predispositions, however, are observed beyond that, namely in the subgroup analyses. As discussed above, the different subgroups are based on respondents' first wave party ID and respondents' first wave LMP attitudes. Both measures have advantages and disadvantages. Party ID is one of the strongest political predispositions - especially in comparison to LMP attitudes. The literature on motivated reasoning shows definitive evidence for that (Bisgaard, 2015). However, the link between a left party ID and e.g. egalitarian values is weakened by the multidimensionality of political conflict. Non-economic issues obviously can and do play a role as well for individual predispositions like party ID or ideology (de Vries et al., 2013). Therefore, subgroups are also built using respondents' first wave LMP attitudes. As discussed above, policy attitudes are seen as functionally different from predispositions. However, supporters of LMPs are likely to be general supporters of social policies due to their underlying (not measured) value orientations (Jæger, 2011).

\subsection{Results}

\subsubsection{Descriptive Overview}

Figure 3.2 gives an overview of the three analysed subgroups. In the left panel we see that the overwhelming majority of respondents does not identify with a political party. In the middle panel we see that an even bigger majority supports state responsibility for LMPs. In the right panel we see the combination of both. As one would expect, within those who are sceptical about LMPs there are more identifiers with parties of the right side of the political spectrum than identifiers with left parties. For those who support LMPs it is the other way round - there are more identifiers with left parties. However, probably the most obvious pattern is that in each of the three subgroups split by first wave LMP attitudes those without a party ID are the most frequent group.

So, on the one hand, party ID and LMP attitudes are related as one would expect. On the other hand, the overlap between support for LMPs and left party identifiers, scepticism about LMPs and right party identifiers, and being neutral about LMPs and not identifying with any party is clearly limited. Therefore, a crucial question for the following analyses is, whether the findings hold simultaneously for the subgroups split by LMP support and for the subgroups split by party ID.

Figure 3.3 shows the employment transitions and perception changes that are observable in the SOEP data ( $1^{\text {st }}$ column of both figures $)$ and their frequencies broken down by respondents' first 
SOEP: Descriptives on Party ID and LMP Attitudes

Total Frequencies and Party ID (Right (R), No, Left(L)) by First Wave LMP Attitudes Subgroups ('-', '+/-', '+')

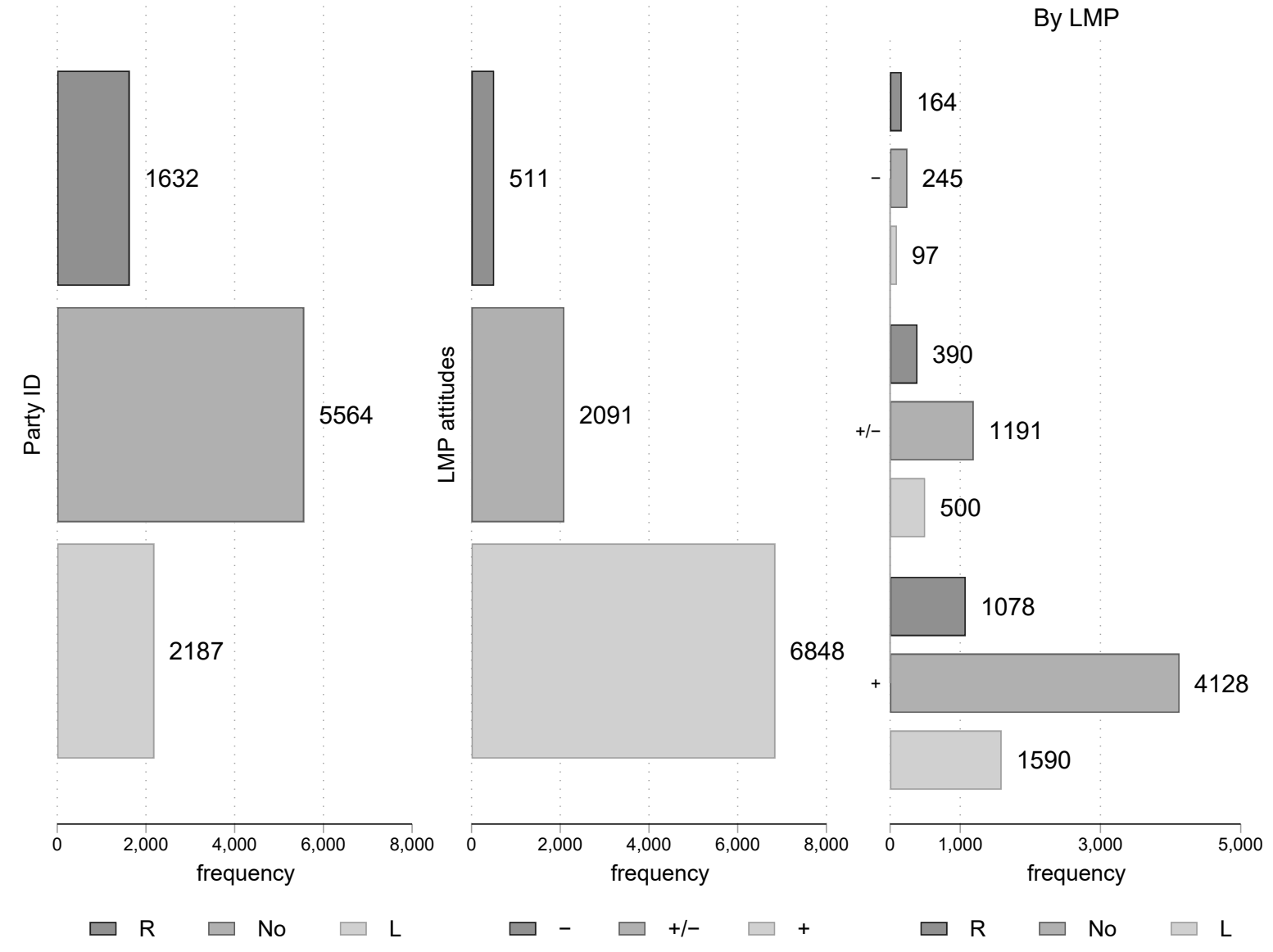

Figure 3.2: SOEP: Descriptive Overview: The 3 Subgroups 
wave LMP attitudes ( $2^{\text {nd }}$ column of figure 3.3: sceptics '-' , neutrals ' \pm ' , and supporters '+' ) and their party identification ( $3^{\text {rd }}$ column of figure 3.3 : left ' $L$ ', no, right ' $R$ ' identifiers ). 


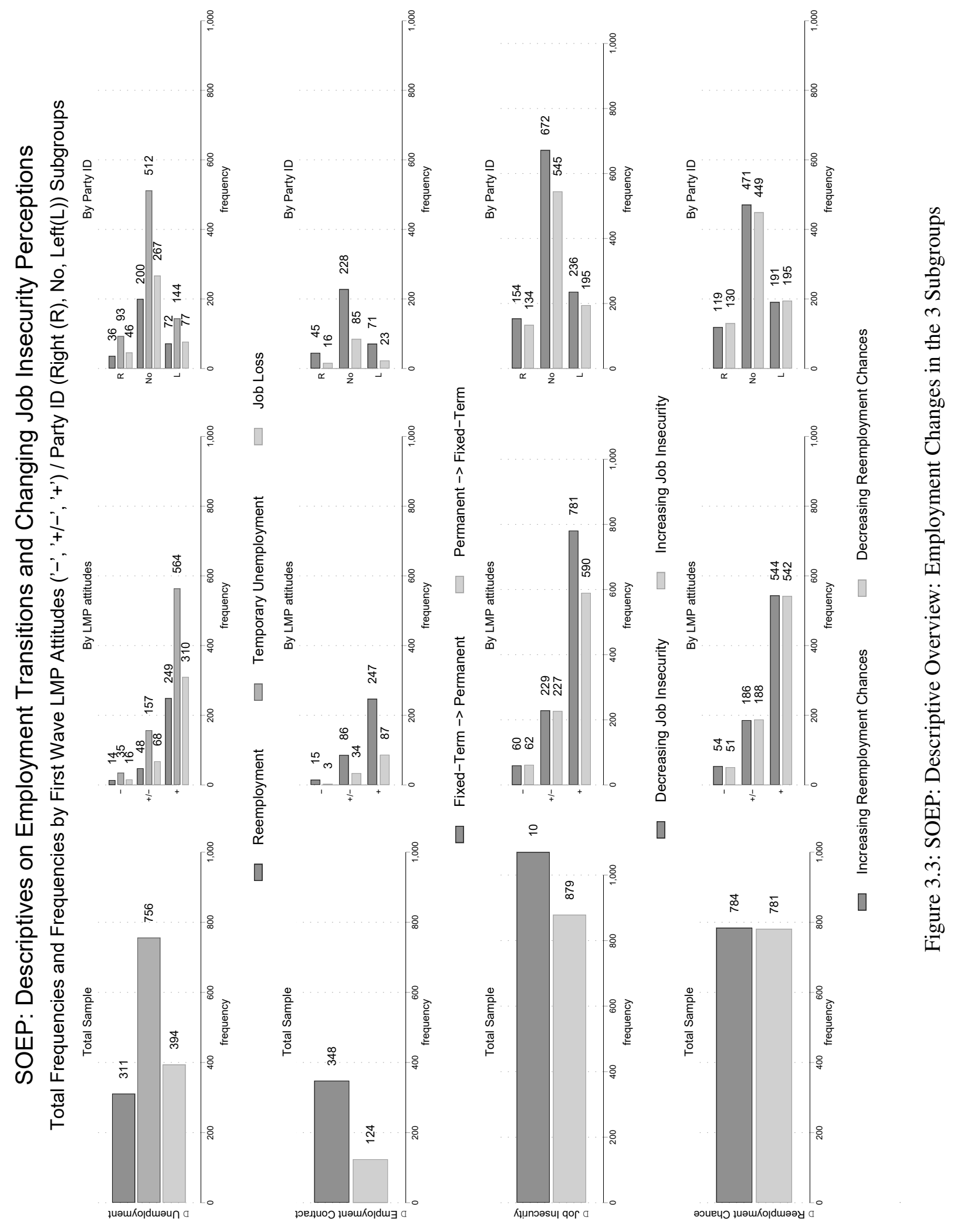


Furthermore, the prevalence of support for LMPs, that was shown already in figure 3.2, also becomes obvious when splitting the number of employment transitions and perception changes according to respondents' first wave LMP attitudes. For every employment transition and for every perception change positive first wave LMP attitudes outweigh neutral or sceptic attitudes and by far. Given those numbers statistically significant effects supporting hypothesis 1a (1c) might be more likely to observe for employment and perception deteriorations (improvements).

Again, as before in figure 3.2, the situation is very different when splitting the number of employment transitions and perception changes according to respondents' first wave party ID. Now, employment transitions and perceptions changes for people without a party ID clearly outweigh employment transitions and perception changes for party supporters. Given those numbers effects supporting hypothesis $1 \mathrm{~b}$ could be more likely to observe when analysing party ID subgroups. These different descriptives for the numbers of transitions and perception changes within party ID and LMP attitude subgroups again lead to an emphasis on results of the following analyses that can be observed for both kinds (LMP and party ID based) of subgroups simultaneously.

Finally, there are extremely small numbers for some of the employment transitions - especially for sceptics of state responsibility for LMPs. Therefore, I combine job loss and the transitions from a permanent to a fixed-term contract within the category of employment deteriorations in the following analyses. Similarly, reemployment and the transition from a fixed-term to a permanent contract are combined in the category of employment improvements.

\subsubsection{Main Effects}

Before looking at the effects of employment transitions and perception changes within the different subgroups and thus testing hypotheses 1a-1c, figure 3.4 (for tabular results see appendix table A1) shows the respective main effects on LMP attitude changes. All positive subjective or objective changes (employment improvements, decreasing job insecurity, increasing reemployment chances) are accompanied by negative, significant coefficients. Thus, respondents withdraw to some degree their support for LMPs after such positive events or perception changes. Similarly, negative subjective perception changes - but not objective employment deteriorations or temporary unemployment - are accompanied by positive significant coefficients. Thus, respondents increase their support for LMPs when they worry more about their job insecurity or their reemployment chances.

The results so far firmly support the self-interest perspective and raise doubts about the relevance of arguments emphasizing the role of values or other predispositions. After all, respondents' attitudes seem to respond to employment transitions and worries exactly like the selfinterest account predicts it. Respondents might nevertheless possess stable value orientations and other predispositions. These do, however, not stop respondents' attitudes from reacting to the employment changes. 


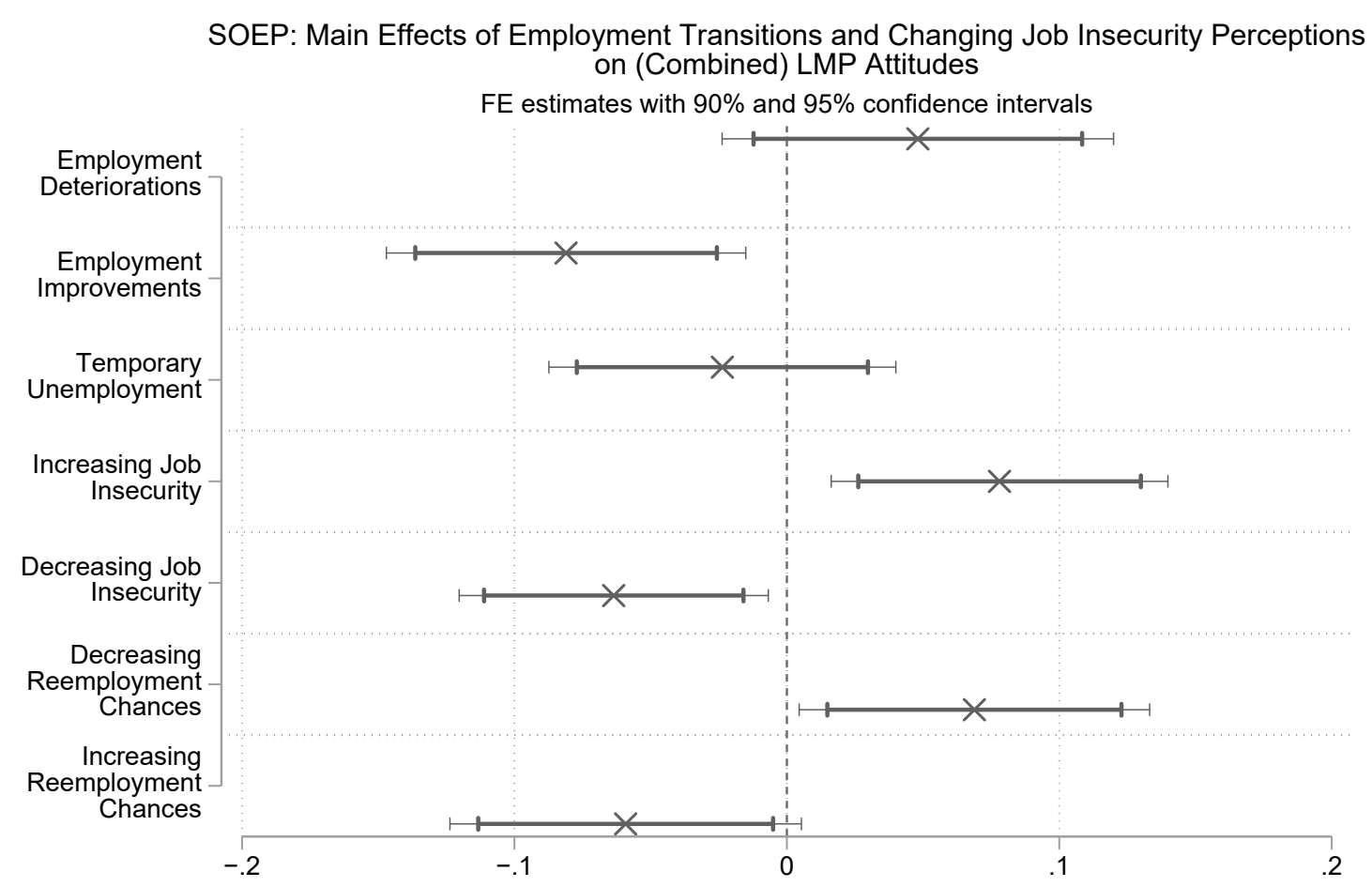

Figure 3.4: SOEP: Main Effects (FE-estimates with $90 \%$ and $95 \%$ Confidence Intervals)

One concern with such an interpretation is the question whether these coefficients actually represent causal effects and thus "reactions" 24 . The concern I want to focus on here, however, is that - depending on who changes their attitudes - these changes do not necessarily as clearly contradict the idea behind the long-lasting impact of values and other predispositions as this interpretation suggests.

\subsubsection{Subgroup Analyses}

Figures 3.5 and 3.6 display the results of the analyses testing this articles' three hypotheses and answering the question who changes their LMP attitudes after employment transitions and job security perception changes. Tabular results are displayed in appendix tables A2 to A7. Both figures display again the main effects that have been shown already in figure 3.4. Below these main effects, the effects of the employment transitions and perceptions changes within three subgroups defined by individuals' first wave LMP attitudes and party ID are shown. 


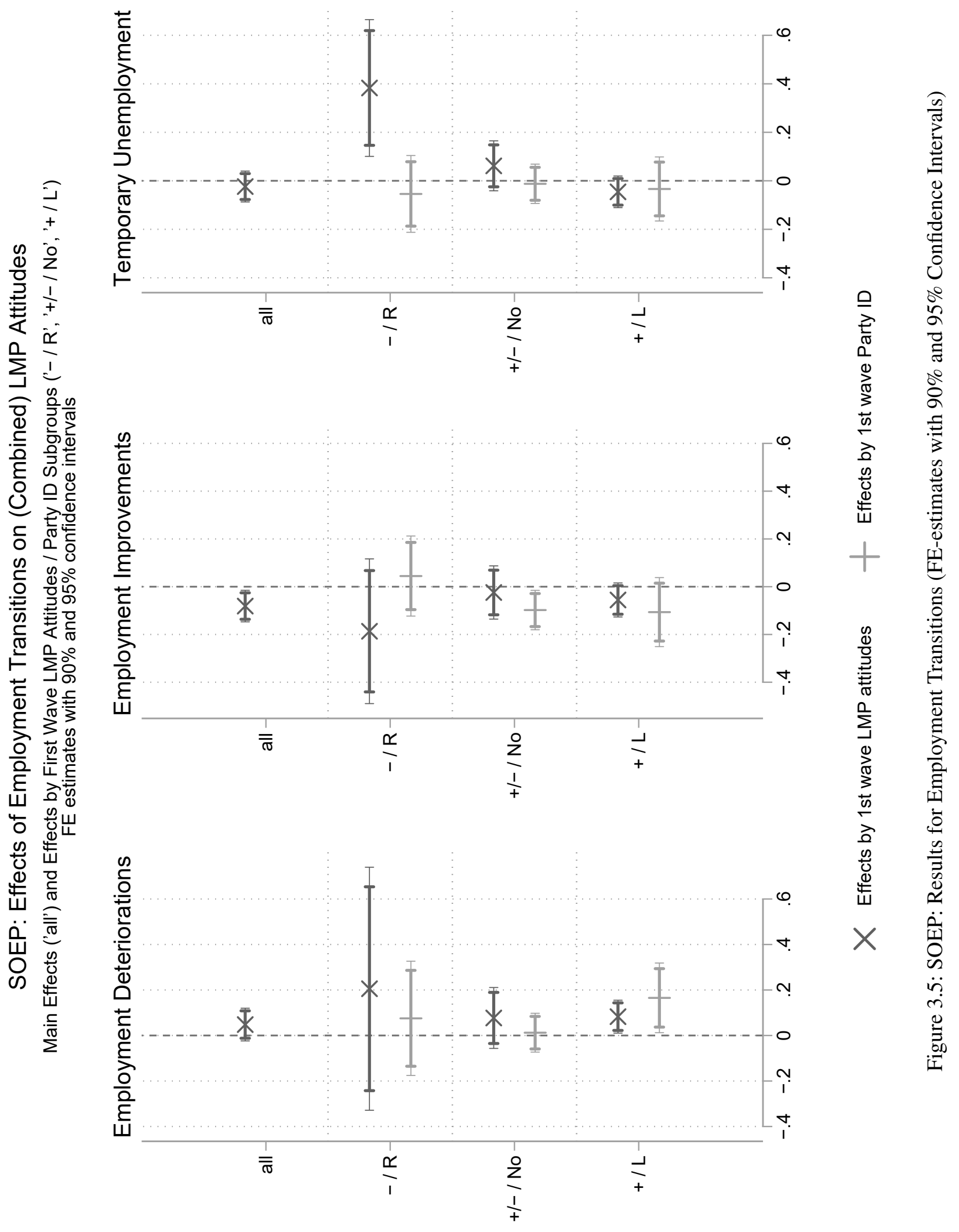



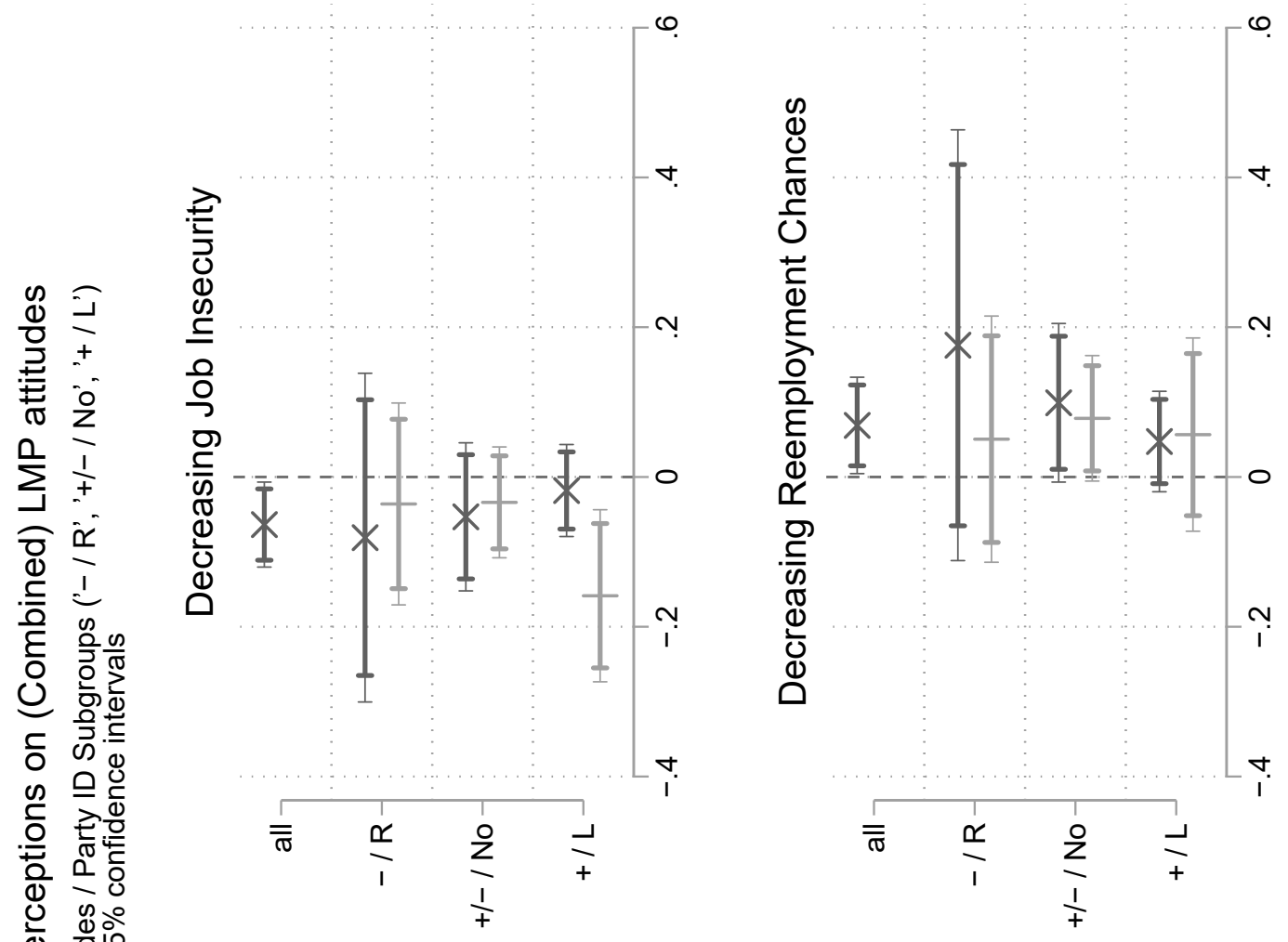

(1) 응

要辛

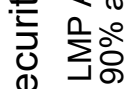

要产产

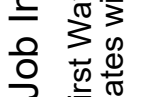

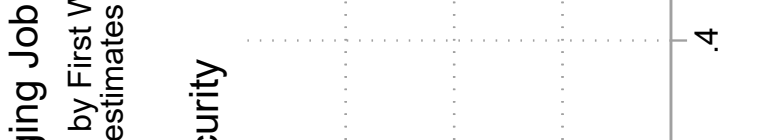
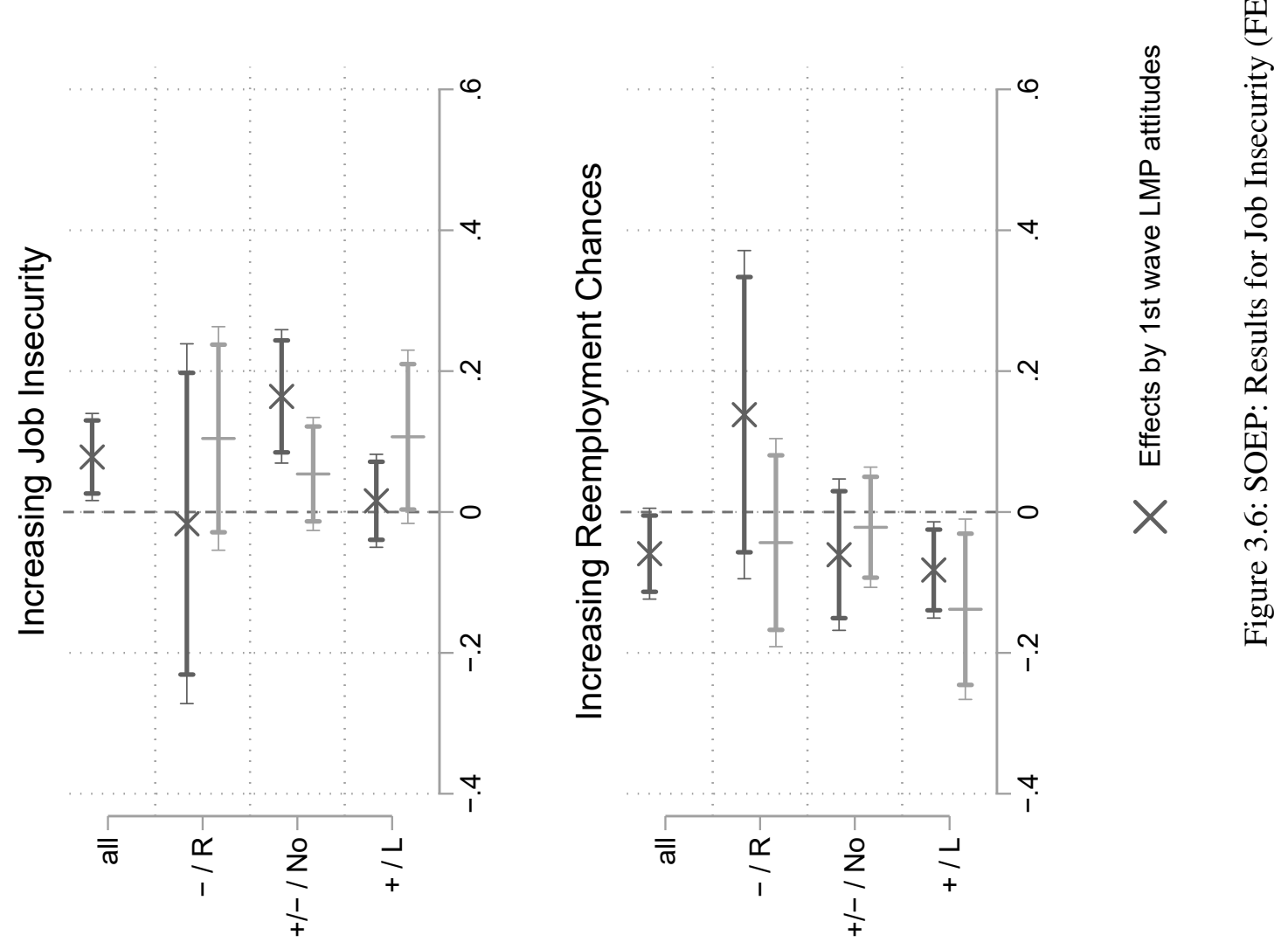
Looking at the left panel in figure 3.5 we see that only those people, who already supported LMPs or adhered to a left party in the first wave, further increased their support for LMPs after employment deteriorations. Interestingly this kind of attitude change, which simply reinforces pre-existing beliefs, occurs even though no main effect was observable. This attitude change among those who identified with left parties and supported LMPs is driven by the experience of a job loss as figure A1 in the appendix shows. Thus, this result directly contradicts the evidence for the U.S. context presented by Margalit (2013) who showed that Republicans, but not Democrats, increased their support for social policies after a job loss. A similar increased support for LMPs among left party identifiers can be observed in the upper left panel in figure 3.6 after an increased level of job insecurity. In contrast to the attitude changes after employment deteriorations, however, this effect only occurs when splitting respondents according to their party identification, not to their previous LMP support. Furthermore, left party supporters are not the only ones who increase their support for LMPs after perceiving higher levels of job insecurity.

As can be seen in the upper left panel in figure 3.6, increasing job insecurity leads to increased LMP support for those who are unconstrained by their prior predispositions, at least when judging from their previous LMP attitudes. Similarly, those - and only those - without a party attachment react to employment improvements by decreasing their support for LMPs. But the strongest support for attitude changes among those unconstrained comes from attitude changes in response to less optimistically perceived reemployment chances. Here, both those without a party attachment and those with a neutral LMP attitude in the first wave increase their LMP support.

Finally, there is also evidence for attitude changes that contradict individuals' prior predispositions. In contrast to decreasing perceptions of reemployment chances, increasing perceptions of reemployment chances go hand in hand with lower support for LMPs among those who previously supported LMPs and those who previously identified with left parties. A similar drop in support among those who previously supported LMPs can be observed in response to decreasing worries about job insecurity. And a temporary episode of unemployment between the first and the second wave increased support for LMPs among those who did not support LMPs in the first wave.

\subsubsection{Results Summary and Robustness Checks}

Figure 3.7 summarizes the results presented in figures 3.4 - 3.6. Overall, there is some evidence for attitude changes in each of the subgroups and thus for each of the three hypotheses. However, for most of the employment transitions and perception changes there is only one subgroup for which an attitudinal reaction is observable. Thus, it is not possible to identify any constellation between pre-existing predispositions and self-interest as more likely than any other constellation to lead to self-interest based attitudinal reactions ${ }^{25}$.

Furthermore, an interesting pattern emerges for employment improvements compared to employment deteriorations (and similar perception changes). It appears that attitude changes that 
simply reinforce predispositions are only present after employment deteriorations and more pessimistic perceptions. In contrast, attitude changes that challenge predispositions are present only after employment improvements and more optimistic perceptions. To be clear, this pattern was not expected for any theoretical reasons. It will thus be interesting to see, whether future research will be able to replicate it.

The presented and summarized results so far show in which subgroups significant effects of employment transitions and perception changes occur. An even harder test is, however, whether these effects differ significantly between the subgroups. After all the difference between a significant and insignificant effect might itself not be significant (Gelman and Stern, 2006). Most confidence intervals shown in figures 3.4 - 3.6 are overlapping. But overlapping confidence intervals are not a definitive sign regarding the (in)significance of the difference of effects (Austin and Hux, 2002). Therefore, the shown subgroup analyses were replicated via interaction models including interactions between the subgroups and the employment transitions or perception changes (see appendix tables A8 to A14). Based on these models the differences between the average marginal effects of the transitions and perception changes between the subgroups are formally tested (see appendix tables A15 and A16).

Doing so, it turns out that indeed the majority of the effect differences between subgroups are not significant with three notable exceptions. The first is the effect of employment deteriorations among left party identifiers, which is significantly bigger than the effect for people without a party identification (in ine with hypothesis 1a). The second is the effect of increasing job insecurity among people with neutral LMP attitudes in the first wave, which is significantly bigger than for LMP supporters (in line with hypothesis 1b). And finally, all differences based on LMP subgroups are significant for effects of a temporary unemployment episode (in line with hypothesis 1c). Taken together, these tests thus corroborate the mixed picture of the results.

In the following, it will be tested how robust these results are, when time-varying covariates are included, when each employment transition is analysed separately (compared to the combined analysis of improvements and deteriorations), or when active and passive LMP attitudes are analysed separately. 


\begin{tabular}{|c|c|c|c|c|c|}
\hline & $\begin{array}{l}\text { By } 1^{s t} \\
\text { Wave }\end{array}$ & $\begin{array}{c}\text { Main } \\
\text { Effects }\end{array}$ & $\begin{array}{l}\text { Subgrou } \\
\text { Hyp 1a }\end{array}$ & $\begin{array}{l}\text { Effects } \\
\text { Hyp } 1 b\end{array}$ & $\begin{array}{l}\text { line with } \\
\text { Hyp 1c }\end{array}$ \\
\hline Employment Deteriorations & $\begin{array}{l}\text { Attitudes } \\
\text { PID }\end{array}$ & & $\begin{array}{l}\checkmark \\
\checkmark\end{array}$ & & \\
\hline Employment Improvements & $\begin{array}{l}\text { Attitudes } \\
\text { PID }\end{array}$ & $\checkmark$ & & $\checkmark$ & \\
\hline Temporary Unemployment & $\begin{array}{l}\text { Attitudes } \\
\text { PID }\end{array}$ & & & & $\checkmark$ \\
\hline$\nearrow$ Job Insecurity & $\begin{array}{l}\text { Attitudes } \\
\text { PID }\end{array}$ & $\checkmark$ & $\checkmark$ & $\checkmark$ & \\
\hline$\searrow$ Job Insecurity & $\begin{array}{l}\text { Attitudes } \\
\text { PID }\end{array}$ & $\checkmark$ & & & $\checkmark$ \\
\hline$\searrow$ Reemployment Chances & $\begin{array}{l}\text { Attitudes } \\
\text { PID }\end{array}$ & $\checkmark$ & & $\begin{array}{l}\checkmark \\
\checkmark\end{array}$ & \\
\hline$\nearrow$ Reemployment Chances & $\begin{array}{l}\text { Attitudes } \\
\text { PID }\end{array}$ & $\checkmark$ & & & $\begin{array}{l}\checkmark \\
\checkmark\end{array}$ \\
\hline
\end{tabular}

Figure 3.7: Results Summary $(\checkmark$ Significant Effects with $\mathrm{p}<0.1$ ) 
Appendix tables A1 to A7 display the discussed results in tabular form and replicate all analyses adding controls for further education, childbirth, and subjective health changes. This does not visibly alter the overwhelming majority of results ${ }^{26}$. The only exception are effects of employment improvements. After adding the time-varying controls it appears that both, first wave sceptics and first wave supporters of LMPs, become more sceptical about LMPs. This puts two findings to some degree into perspective. On the one hand, this is the first evidence for hypothesis 1a after "positive" employment or perception changes with LMP sceptics becoming even more sceptical of LMPs. On the other hand, together with the robust effect for people without a party ID after employment improvements this actually amounts to evidence supporting all three hypotheses simultaneously. This, however, is not true for both kinds (PID and LMP) of subgroups.

In a next step appendix figure A1 compares the results for the combined analyses of improvements and deteriorations of the employment situation with results for job loss, reemployment, and transitions between permanent and fixed-term contracts. As already mentioned above this shows that the growing support for LMPs of left party supporters and LMP supporters after employment deteriorations is actually only observable after job loss. However, effects of employment improvements are not heavily dominated by either reemployment or changes from a fixed to a permanent contract. Thus, the decreasing support for LMPs among people without a party ID after employment improvements is only observable after changing into a permanent contract. Contrarily, a new, i.e. now significant, effect becomes observable after reemployment when previous left party supporters grow more sceptical about LMPs.

And finally, I test whether attitudes towards active or passive LMPs heavily dominate the results and if a focus on the separate attitudes would lead to different conclusions regarding the hypotheses. Both concerns, however, seem unsubstantiated when looking at appendix figures A2 and A3. First of all, separate analyses of active and passive LMP attitudes result in a similar mix of support for hypotheses 1a-1c. And while the main effects are largely driven by changes in active LMP attitudes, subgroup results are not heavily driven by either active or passive LMP attitudes.

\subsection{Conclusion}

This article started with contradicting theoretical expectations and empirical findings from the self-interest and the "values perspective": attitudinal change and attitudinal stability. Applied to the empirical context of the paper this lead to the question: do labour market policy (LMP) attitudes change after employment transitions and changed job insecurity perceptions?

The main theoretical contribution of the article was to overcome this dichotomy from selfinterest based and value-based arguments. Therefore, this article suggested to move away from empirical implications and to focus on empirical observations regarding the relation between self-interest and predispositions. To do so, I asked whose attitudes change in response to employment transitions and perception changes. To answer this question, the article differenti- 
ated between three subgroups of respondents. These subgroups were based on respondents' predispositions to support or question LMPs. More precisely, the article asked whether selfinterest based attitude changes are more likely for respondents a) with predispositions fitting that self-interest $b$ ) without strong predispositions or $\mathrm{c}$ ) with predispositions contradicting that self-interest.

The answer to that question is crucial for connecting empirical results to the values versus selfinterest debate. Scenario a) would suggest that it is not "values versus self-interest" but rather that self-interest effects only occur when they are "supported" by predispositional influences. Scenario b) would suggest that self-interest effects occur only for people whose attitudes are only weakly influenced by predispositions. And scenario c) would suggest that values and predispositions are indeed challenged by self-interest effects.

The analyses were based on German panel data from the SOEP in 1997 and 2002 and applied panel fixed effects models. Applying these analyses to the whole sample showed clear evidence in favour of self-interest based accounts of social policy attitudes. Respondents withdrew some of their support for LMPs after transitions improving respondents' employment situation and after worrying less about their employment situation. Similarly, respondents increased their support for LMPs after worrying more about their employment situation. Interestingly, this increased support could not be observed in the whole sample after transitions deteriorating respondents' employment situation like job loss.

However, the results of the subgroup analyses turned out mixed. Thus, while crucial for the interpretation of the effects, none of the three combinations between self-interest and predispositions turned out to be a condition for or against self-interest effects. More precisely, some self-interest effects were observed for people with predispositions supporting that self-interest. Other attitudinal reactions to employment transitions or changed feelings of job insecurity only affected people without strong predispositions. And yet other attitudinal reactions were only observed for people whose self-interest and whose predispositions pointed in opposing directions.

Even though the findings of the present article were mixed, they offer important lessons for future research and for interpreting existing findings. First of all, they show that evidence in favor of self-interest effects after employment changes as e.g. by Naumann et al. (2016) or Owens and Pedulla (2014) is not simultaneously evidence against the role of predispositions. Similarly, failures to find main effects of unemployment or other objective or subjective employment risks on social policy attitudes as in the case of O'Grady (2019) or Wehl (2019) are not necessarily a sign for the absence of self-interest driven effects. Additionally, the presented findings show that the interplay between prior predispositions and self-interest is not always as straightforward as the U.S. based results from Margalit (2013) suggest. This study found that increased social policy support after job loss is especially pronounced for Republicans, which challenges the influence of their party ID.

Second, the mixed findings also caution against generalizing findings on attitudinal reactions from one employment transition to another employment transition, perception change, or completely different changes in material circumstances. On the one hand, transitions and perception 
changes assumed to have similar self-interest effects turn out to result in different relations between self-interest and prior predispositions. Thus, to give an example, different subgroups adjusted their LMP attitudes to job loss and to increasing worries about job loss. On the other hand, the present article found that employment improvements lead to attitudinal changes challenging prior predispositions. On the contrary, employment and perception deteriorations lead to attitudinal reactions for people with supporting predispositions or without strong predispositions.

Finally, the question should be considered how context dependent the results of the present article might be. Keeping in mind the speculative nature of possible answers such speculations can go in two directions: the strength of predispositions in guiding policy attitudes and the material consequences of an employment transition.

Regarding the strength of predispositions, the literature on party identification has shown that its effects increase under high polarization (Druckman et al., 2013). Germany at the turn of the century, however, has undergone a decline in polarization (Munzert and Bauer, 2013) as well as a decline of the number of people identifying with a party and of the strength of party identification (Ohr et al., 2009). The only moderate overlap between party identification and LMP attitudes shown in the descriptive findings fits rather well with this picture.

Regarding the material consequences of unemployment, the Hartz reforms introduced major changes to the German labour market. Given their implementation between 2003 and 2005 these changes all happened after the analysis period of the current paper. Among other things the Hartz laws shortened the period for income-dependent unemployment benefits $(60 \%$ of prior income) to twelve months and introduced several sanctions i.e. possibilities to cut unemployment benefits (Kemmerling and Bruttel, 2006). Thus, during the period of analysis in this article unemployment (or the risk thereof) was still less hurtful than afterwards. Interestingly, the mentioned findings from Margalit (2013) from the U.S occur in a context of increasing polarization (Druckman et al., 2013) and higher costs of job loss given the weaker social safety of a typical liberal welfare state (Ferragina and Seeleib-Kaiser, 2011).

Analysing the role of these different context effects in driving changes of LMP attitudes after employment transitions is certainly an interesting avenue for future research. However, this article's basic idea is neither limited to employment transitions nor to LMP attitudes, but can be transferred to other changes of individual material circumstances (e.g. income changes) or attitudes (e.g. redistributive attitudes or immigration related attitudes). In these (and similar) cases it is possible and necessary for a sound judgement about the relevance of self-interest vis-á-vis predispositions to answer the question: whose attitudes change? 


\section{Notes}

${ }^{17}$ Subjective worries about job insecurity can result from objective unemployment risks and from certain personality factors (Debus et al., 2014; DeWitte, 2005). Thus, it is not necessarily the case that people in an objectively insecure employment situation - e.g. in fixed-term employment - perceive that situation as insecure (Schraff, 2018).

${ }^{18}$ Throughout the paper the terms passive LMPs and unemployment benefits or financial help for the unemployed as well as the terms active LMPs and job creation measures are used interchangeably. Note, however, that especially active LMPs include many more measures. In cases of 'demanding' active LMP measures that e.g. implement sanctions against unsatisfactory efforts for job search one might even expect less support by labour market outsiders, as argued and shown by Fossati (2018). Such demanding active LMPs are, however, neither theoretically nor empirically the focus of the present article.

${ }^{19}$ Of course this is not to say that party identification or political ideology are not used in social policy attitudes research, as evidenced by Jæger (2006).

${ }^{20}$ The SOEP data that support the findings of this study are available at doi:10.5684/soep.v31.1 after signing a user contract.

${ }^{21}$ Using this combined measure of LMP attitudes additionally comes with the benefit that this measures allows for more potential changes than the original 5-point scale.

${ }^{22}$ Building these subgroups could lead to ceiling or floor effects for the 'pro' and 'contra' subgroups. This problem is reduced to some degree by using the combined measure of LMP attitudes with its higher number of scale points to build the subgroups.

${ }^{23}$ Given the subgroup analyses in presence of a dependent variable measured on a 5-point scale the choice of linear fixed effects models might seem odd especially in comparison to e.g. tobit models built to deal with ceiling / flooring effects. However, no established solution exists to implement these models with fixed effects, as estimators face the so called "incidental parameters problem" resulting in biased point estimators or standard errors (Greene 2004;Cameron and Trivedi 2005, ch.23.5)

${ }^{24}$ To address these concerns, all analyses are repeated using several additional time-varying covariates. In the case of the main effects shown in figure 3.4 this does not alter the results with the exception of more optimistically perceived reemployment chances. This negative main effect loses its significance after adding the time-varying controls.

${ }^{25}$ The fact that the results are so mixed also reduces to some degree the concern, that results are affected by ceiling or floor effects. Of course, this does not exclude the possibility, that they are still present in the findings.

${ }^{26}$ I control for these time-varying variables in two different ways. On the one hand these control variables are added to the subgroup analyses. On the other hand, these control variables are added to the interaction models mimicking the subgroup analyses. Both modelling solutions are not exactly equivalent, as the interaction models do not include interactions between the control variables and the subgroup indicators, i.e. respondents' first wave party ID or LMP attitudes. As fewer parameters are estimated in the interaction models, this could increase the efficiency of the estimates (of employment transitions and job insecurity changes). In fact, however, differences between both ways of including the control variables are hard to spot. In any way, both modelling solutions yield exactly the same conclusions as discussed here. 


\section{References}

Alesina, Alberto and Eliana La Ferrara (2005). "Preferences for redistribution in the land of opportunities". In: Journal of Public Economics 89 (5-6), 897-931.

Allison, Paul D. (2009). Fixed Effects Regression Models. Thousand Oaks: Sage.

Andreß, Hans-Jürgen and Thorsten Heien (2001). "Four Worlds of Welfare State Attitudes? A Comparison of Germany, Norway, and the United States". In: European Sociological Review 17 (4), 337-356.

Austin, Peter C. and Janet E. Hux (2002). "A brief note on overlapping confidence intervals". In: Journal of Vascular Surgery 36 (1), $194-195$.

Bischof, Daniel (2017). "New graphic schemes for Stata: plotplain and plottig". In: The Stata Journal 17 (3), 748-759.

Bisgaard, Martin (2015). "Bias Will Find a Way: Economic Perceptions, Attribution of Blame, and Partisan-Motivated Reasoning during Crisis." In: The Journal of Politics 77 (3), 849860.

Boninger, David S., Matthew K. Berent, and Jon A. Krosnick (1995). "Origins of Attitude Importance: Self-Interest, Social Identificaiton, and Value Relevance”. In: Journal of Personality and Social Psychology 68 (1), 61-80.

Boninger, David S., Jon A. Krosnick, Matthew K. Berent, and Leandre R. Fabrigar (2009). "The Causes and Consequences of Attitude Importance". In: Attitude Strength. Antecedents and Consequences. Ed. by Richard E. Petty and Jon A. Krosnick. New York: Psychology Press.

Brooks, Clem and Jeff Manza (2013). "A Broken Public?Americans' Responses to the Great Recession”. In: American Sociological Review 78 (5), 727-748.

Brüderl, Josef and Volker Ludwig (2015). "Fixed-effects panel regression". In: Regression Analysis and Causal Inference. Ed. by Henning Best and Christof Wolf. Sage, 327-357.

Burgoon, Brian and Fabian Dekker (2010). "Flexible employment, economic insecurity and social policy preferences in Europe". In: Journal of European Social Policy 20 (2), 126-141.

Calzada, Inés, Mariá Gómez-Garrido, Luis Moreno, and Francisco Javier Moreno-Fuentes (2014). "It is not Only About Equality. A Study on the (Other) Values That Ground Attitudes to the Welfare State". In: International Journal of Public Opinion Research 26 (2), 178-201.

Cameron, A. Colin and Pravin K. Trivedi (2005). Microeconometrics. Methods and Applications. Cambridge et al.: Cambridge University Press.

Carsey, Thomas M. and Geoffrey C. Layman (2006). "Changing Sides or Changing Minds? Party Identification and Policy Preferences in the American Electorate". In: American Journal of Political Science 50 (2), 464-477.

Cavaillé, Charlotte and Kris-Stella Trump (2015). "The Two Facets of Social Policy Preferences". In: The Journal of Politics 77 (1), 146-160.

Chong, Dennis, Jack Citrin, and Jack Conley (2001). "When Self-Interest Matters". In: Political Psychology 22 (3), 541-570.

Converse, P. E. (1964). "The nature of belief systems in mass publics". In: Ideology and its discontents. Ed. by David E. Apter. The Free Press of Glencoe, 206-226.

Cox, Nicholas J. (2003). CATPLOT: Stata module for plots of frequencies, fractions or percents of categorical data. Statistical Software Components, Boston College Department of Economics. 
Dageförde, Mirjam (2013). "Ideologische Kongruenz, Parteiidentifikation und Policy-Präferenzen. Das Beispiel der Gesundheitspolitik der 16. Legislaturperiode". In: Reformen des Sozialstaates in Deutschland. Ed. by Eva-Maria Trüdinger and Oscar W. Gabriel. Nomos.

Dalton, Russel J. (2012). “Apartisans and the changig German electorate”. In: Electoral Studies 31, 35-45.

de la Calle, Luis and Nasos Roussias (2012). "How Do Spanish Independents Vote? Ideology vs performance". In: South European Society and Politics 17 (3), 411-425.

de Vries, Catherin, Armen Hakhverdian, and Bram Lancee (2013). "The Dynamics of Voters' Left/Right Identification: The Role of Economic and Cultural Attitudes". In: Political Science Research and Methods 1 (2), 223-238.

Debus, Maike E., Cornelius J. König, and Martin Kleinmann (2014). "The building blocks of job insecurity: The impact of environmental and person-related variables on job insecurity perceptions”. In: Journal of Occupational and Organizational Psychology 87 (2), 329-351.

DeWitte, Hans (2005). "Job Insecurity: Review of the International Literature on Definitions, Prevalence, Antecedents and Consequences”. In: Journal of Industrial Psychology 31 (4), $1-6$.

Druckman, James N., Erik Peterson, and Rune Slothuus (2013). "How Elite Partisan Polarization Affects Public Opinion Formation". In: American Political Science Review 107 (1), 5779.

Ferragina, Emanuele and Martin Seeleib-Kaiser (2011). "Thematic Review: Welfare regime debate: past, present, futures?” In: Policy \& Politics 39 (4), 583-611.

Festinger, Leon (1957). A Theory of Cognitive Dissonance. Stanford Univeristy Press.

Fossati, Flavia (2018). "Who Wants Demanding Active Labour Market Policies? Public Attitudes towards Policies that put Pressure on the Unemployed". In: Journal of Social Policy 47 (1), 77-97.

Gallego, Aina and Paul Marx (2017). "Multi-dimensional preferences for labour market reforms: a conjoint experiment". In: Journal of European Public Policy 24 (7), 1027-1047.

Gelman, Andrew and Hal Stern (2006). "The Difference Between "Significant" and "Not Significant" is not Itself Statistically Significant". In: The American Statistician 60 (4), 328331.

Goren, Paul (2005). "Party Identification and Core Political Values". In: American Journal of Political Science 49 (4), 881-896.

Greene, William (2004). "Fixed Effects and Bias Due to the Incidental Parameters Problem in the Tobit Model". In: Econometric Reviews 23 (2), 125-147.

Harteveld, Eelco, Andrej Kokkonen, and Stefan Dahlberg (2017). "Adapting to party lines: the effect of party affiliation on attitudes to immigration". In: West European Politics 40 (6), 1177-1197.

Häusermann, Silja, Thomas Kurer, and Hanna Schwander (2015). "High-skilled outsiders? Labor market vulnerability, education and welfare state preferences". In: Socio-Economic Review 13 (2), 235-258.

Heinemann, Friedrich, Ivo Bischoff, and Tanja Hennighausen (2009). "Choosing from the Reform Menu Card - Individual Determinants of Labour Market Policy Preferences". In: Journal of Economics and Statistics 229 (2/3), 180-197.

Jæger, Mads Meier (2006). "What Makes People Support Public Responsibility for Welfare Provision: Self-interest or Political Ideology?” In: Acta Sociologica 49 (3), 321-338. 
Jæger, Mads Meier (2011). "Do we all (dis)like the same welfare state? Configurations of public support for the welfare state in comparative perspective". In: Changing Social Equality: The Nordic Welfare Model in the 21 st Century. Ed. by Jon Kvist, Johan Fritzell, Bjorn Hvinden, and Olli Kangas. Policy Press, 45-68.

Jann, Ben (2014). "Plotting regression coefficients and other estimate." In: The Stata Journal 14 (4), 708-737.

Kemmerling, Achim and Oliver Bruttel (2006). “'New politics' in German labour market policy? The implications of the recent Hartz reforms for the German welfare state". In: West European Politics 29 (1), 90-112.

Kohler, Ulrich (2010). CM2IN: Stata module to provide conversion between inch/cm and others. Statistical Software Components, Boston College Department of Economics.

Lachat, Romain (2007). A heterogeneous electorate. Nomos.

Lau, Richard R. and Caroline Heldman (2009). "Self-Interest, Symbolic Attitudes, and Support for Public Policy: A Multilevel Analysis”. In: Political Psychology 30 (4), 513-537.

Maio, Gregory R., James M. Olson, Mark M. Bernard, and Mechelle A. Luke (2003). "Ideologies, Values, Attitudes, and Behavior". In: Delamater, John. Handbook of Social Psychology. New York: Kluwer Academic/Plenum Publishers.

Margalit, Yotam (2013). "Explaining Social Policy Preferences: Evidence from the Great Recession”. In: American Political Science Review 107 (1), 80-103.

- (2019). "Political Responses to Economic Shocks". In: Annual Review of Political Science 22 (1), 277-295.

Marx, Paul (2015). The Political Behaviour of Temporary Workers. Palgrave Macmillan.

Munzert, Simon and Paul C. Bauer (2013). "Political Depolarization in German Public Opinion, 1980-2010". In: Political Science Research and Methods 1 (1), 67-89.

Naumann, Elias, Christopher Buss, and Johannes Bähr (2016). "How Unemployment Experience Affects Support for the Welfare State: A Real Panel Approach". In: European Sociological Review 32 (1), 81-92.

O’Grady, Tom (2019). "How do Economic Circumstances Determine Preferences? Evidence from Long-run Panel Data". In: British Journal of Political Science 49 (4), 1381-1406.

Ohr, Dieter, Hermann Dülmer, and Markus Quandt (2009). "Kognitive Mobilisierung oder nicht-kognitive De-Mobilisierung? Eine längsschnittliche Analyse der deutschen Wählerschaft für die Jahre 1976 bis 2005". In: Wahlen und Wähler: Analysen aus Anlass der Bundestagswahl 2005. Ed. by O.W. Gabriel, B Weßels, and J.W. Falter. VS Verlag für Sozialwissenschaften, 536-558.

Owens, Lindsay A. and David S. Pedulla (2014). "Material Welfare and Changing Political Preferences: The Case of Support for Redistributive Social Policies". In: Social Forces 92 (3), 1087-1113.

Pardos-Prado, Sergi (2011). "Framing Attitudes Towards Immigrants in Europe: When Competition Does Not Matter". In: Journal of Ethnic and Migration Studies 37 (7), 999-1015.

Peterson, Erik (2016). "The Rich are Different: The Effect of Wealth on Partisanship". In: Political Behavior 38, 33-54.

Rehm, Philipp (2016). Risk Inequality and Welfare States. Social Policy Preferences, Development, and Dynamics. New York: Cambridge University Press.

Rueda, David (2005). "Insider-outsider politics in industrialized democracies: The challenge to social democratic parties”. In: American Political Science Review 99 (1), 61-74. 
Schraff, Dominik (2018). "Labor market disadvantage and political alienation: a longitudinal perspective on the heterogeneous risk in temporar employment". In: Acta Politica 53 (1), 48-67.

Schwander, Hanna and Silja Häusermann (2013). "Who is in and who is out? A risk-based conceptualization of insiders and outsiders". In: Journal of European Social Policy 23 (3), 248-269.

Sears, David O. and Carolyn L. Funk (1990). "The Limited Effect of Economic Self-interest on the Political Atittudes of the Mass Public". In: The Journal of Behavioral Economics 19 (3), 247-271.

Sears, David O., Richard R. Lau, Tom R. Tyler, and Harris M. Jr. Allen (1980). "Self-Interest vs. Symbolic Politics in Policy Attitudes and Presidential Voting". In: The American Political Science Review 74 (3), 670-684.

SOEP (2016). Socio-Economic Panel (SOEP), data for years 1984-2014, version 31.1.

Stegmueller, Daniel (2013). "Modeling Dynamic Preferences: A Bayesian Robust Dynamic Latent Ordered Probit Model”. In: Political Analysis 21 (3), 314-333.

Taber, Charles S. and Milton Lodge (2006). "Motivated Skepticism in the Evaluation of Political Beliefs". In: American Journal of Political Science 50 (3), 755-769.

van Oorschot, Wim (2002). "Individual motives for contributing to welfare benefits in the Netherlands". In: Policy \& Politics 30 (1), 31-46.

Wagner, Gert G., Joachim R. Frick, and Jürgen Schupp (2007). "The German Socio-Economic Panel Study (SOEP) - Scope, Evolution and Enhancements". In: Schmollers Jahrbuch 127 (1), 139-169.

Weber, Wiebke and Willem E. Saris (2014). "The relationship between issues and an individual's left-right orientation”. In: Acta Politica 50 (2), 193-213.

Weeden, Jason and Robert Kurzban (2017). "Self-Interest Is Often a Major Determinant of Issue Attitudes". In: Advances in Political Psychology 38 (1), 67-90.

Wehl, Nadja (2019). "The (ir)relevance of unemployment for labour market policy attitudes and welfare state attitudes". In: European Journal of Political Research 58 (1), 141-162.

Wiertz, Dingeman and Toni Rodon (2021). "Frozen or malleable? Political ideology in the face of job loss and unemployment”. In: Socio-Economic Review 19 (1), 307-331. 


\section{Article 3: The dynamics of unemployment, risk, and left-right ideology. Constrained change or changed constraints?}

This manuscript has been sent for peer-review by an international, peer-reviewed journal.

\section{Acknowledgements:}

Funding:

This work received funding by the German Research Foundation (DFG) under the German Excellence Initiative (GSC1024).

Acknowledgements:

I would like to thank Leo Ahrens and Svenja Krauss for constructive feedback on the manuscript.

Data:

This study has been realized using the data collected by the Swiss Household Panel (SHP), which is based at the Swiss Centre of Expertise in the Social Sciences FORS. The project is financed by the Swiss National Science Foundation. Furthermore, I would like to express gratitude to Eva Anduiza for sharing the POLAT data. Finally, in this paper use is made of data of the LISS (Longitudinal Internet Studies for the Social sciences) panel administered by CentERdata (Tilburg University, The Netherlands). 


\title{
The Dynamics of Unemployment, Risk, and Left-Right Ideology. Constrained Change or Changed Constraints?
}

\begin{abstract}
Are generally stable political predispositions equally stable after unemployment? Swiss, Spanish, and Dutch panel analyses on ideological reactions to unemployment extend the limited evidence on this question. These different contexts and interactions with age and prior ideology are used to test the relevance of known factors behind predispositional instability for this question. To account for factors that increase both, the chances to be unemployed and to hold left political views (time-constant selection bias), analyses follow current practices and use fixed effects. Furthermore, I contribute by developing and adequately testing arguments for time-varying selection biases (with fixed effects with individual slopes). Results show high ideological stability after unemployment but also predicted exceptions. In Spain, left-shifts after unemployment occur only for the young, there are nearly no ideological reactions in the Netherlands, and polarization is observable in Switzerland. Some of these country differences could be interpreted as resulting from different salient topics.
\end{abstract}




\subsection{Introduction}

There is an emerging literature investigating how material shocks like job loss affect changes in attitudes towards specific social (Margalit, 2013; Naumann et al., 2016; Owens and Pedulla, 2014) and migration-related policies (Lancee and Pardos-Prado, 2013). Are deeper, more stable, (pre)dispositions like left-right ideology similarly affected? And if so, in which direction? We do not yet know - with one notable exception: a recent study showed ideological left-shifts after transitions in and out of unemployment in the Netherlands (Wiertz and Rodon, 2021). Therefore, I aim at broadening this limited empirical evidence. Doing so I add several new perspectives on this question. First, I use a comparative perspective focusing not only on the Netherlands, but also on Switzerland and Spain (with data from the Dutch Longitudinal Internet Study for the Social Sciences (LISS) from 2008 to 2019 (Scherpenzeel and Das, 2010), data from the Spanish Political Attitudes panel dataset (POLAT) from 2010 - 2014 (Anduiza et al., 2015), and data from the Swiss Household Panel Study (SHP) from 1999 to 2018 (Voorpostel et al., 2015)). Second, I identify individual (age and prior ideological leanings) and contextual (issue salience) factors known to influence predispositional (in)stability and test if they moderate ideological reactions to unemployment. And third, I base these analyses on panel methods that are not only able to account for time-constant, but also for time-varying selection into unemployment (fixed effects with individual slopes).

Extending our knowledge about predispositional dynamics after unemployment helps by providing a bigger picture for results regarding specific attitudinal reactions. Do such attitudinal reactions "spill over" into predispositional reactions ("changed constraints"), or is predispositional change itself "constrained"? Thus, there are two scenarios. One, if not only attitudes but also predispositions were affected, this could be the basis for long-lasting changes in the way people think and act politically. Two, if only specific attitudes but no predispositions were affected, the broader relevance of such attitudinal reactions would be somewhat questionable. In that latter case, it is not clear whether people would keep their new preferences or whether their political attitudes and behaviour would sooner or later (re-)adjust to their unaffected political dispositions.

Several studies on the link between material circumstances and political attitudes and behaviour have already pointed out that such associations are likely to be not (only) the result of direct (causal) reactions to these material circumstances. In contrast, these associations can at least partly be explained by stratified early socialization, i.e. by several, mostly socio-economic, background factors, that influence both: individuals' labour market risks in adulthood and individuals' political socialization experiences in childhood and adolescence. One way to tackle this challenge is to focus on changes in material circumstances and political attitudes and behaviour by using panel data and fixed effects estimators that control for time-constant selection biases (Gidron and Mijs, 2019; O'Grady, 2019; Wehl, 2020; Wiertz and Rodon, 2021). However, the validity of these fixed effects estimates, depends on the non-existence of time-varying selection biases. As this is not a plausible assumption, I apply fixed effects with individualspecific slopes (FEIS), that are valid even in presence of dynamic selection biases (Brüderl and Ludwig, 2015; Rüttenauer and Ludwig, 2020). 
I develop two arguments for such time-varying selection biases. First, they can be expected given self-interest based arguments about the consequences of unemployment risks. Thus, dynamic selection bias could arise from people experiencing an increasing unemployment risk and adapting their left-right ideology accordingly before they become unemployed. Second, similar conclusions could be drawn from arguments about stratified socialization experiences that continue in adult life. I add analyses on ideological reactions to increasing job insecurity (i.e. subjective unemployment risk) to directly test the first potential mechanism behind timevarying confounding.

Furthermore, changes of left-right ideology in response to unemployment are likely heterogeneous. First, prior ideological leanings might moderate how and in which direction people adapt their left-right position. Furthermore, young people have more volatile predispositions (Kiley and Vaisey, 2020). Thus, also their ideological reactions to unemployment might be stronger. And finally, Switzerland, Spain, and the Netherlands differ considerably with respect to the salience of the topics of unemployment and migration. Given that the salience of a topic increases the chances for corresponding predispositional reactions (Dancey and Goren, 2010), stronger left-shifts unemployment should be observable when unemployment is more salient.

In the following, I will review theoretical arguments for ideological left-shifts, that are based on arguments about social policy and redistributive attitudes, and for ideological right-shifts, that are based on arguments about migration-related attitudes. I contrast both arguments on ideological reactions, i.e. "changed constraints", with arguments about no ideological changes, i.e. "constrained change", in response to unemployment (risk). Next, I discuss how stratified socialization poses challenges for causal inference (time-constant and time-varying selection bias) when analysing the political consequences of material shocks. Finally, I focus on individual (prior leanings and age) and contextual (salience) heterogeneities in ideological reactions to unemployment. Heterogeneities based on individuals' prior predispositions are especially relevant in the case of left-right ideology, as "left" and "right" can have different meanings for people on the left and right.

After that, I discuss in detail the data, coding, and the FEIS estimation strategy I use. The results section covers the main effects of unemployment and unemployment risk, interactions by age and prior ideological leanings, and country differences in the results.

These results show left-shifts after unemployment in Spain but no ideological reactions in the Netherlands and Switzerland when looking at the main effects of unemployment. Further analyses of heterogeneities show that the effect in Spain is driven by young people, that a polarization effect is the reason for the non-existent main effect in Switzerland, and that there is barely any evidence for ideological reactions in the Netherlands - contrary to the results from Wiertz and Rodon (2021).

This suggests that factors conducive for general predispositional change are also relevant for ideological reactions to unemployment. Additionally, these results suggest an interesting interaction between individual and contextual factors in determining the direction of political reactions to unemployment. It seems like self-interest is not strong enough to always lead to 
ideological reactions and that the public discourse (salience) and prior leanings can condition how individuals interpret their self-interest.

\subsection{Labour Market Transitions and Ideology}

Starting point for arguments for a left-shift in response to transitions into unemployment is the assumption that individuals are at least partially driven by economic self-interest. Unemployment is supposed to lead to higher support for policies, that benefit unemployed people, especially active and passive labour market policies and general redistributive measures. The same type of arguments is brought forward regarding the political consequences of unemployment risk (Cusack et al., 2006; Rehm, 2016; Schwander and Häusermann, 2013).

Several studies already tested these claims in a dynamic context, i.e. with panel data and fixed effects models, and showed that apart from unemployed people supporting these policies more, becoming unemployed also increases the support for such social policies or redistribution (Naumann et al., 2016; Owens and Pedulla, 2014). Additional analyses reported in Gidron and Mijs (2019) and Wiertz and Rodon (2021) further support that claim. The study by O'Grady (2019) on the effects of job insecurity on redistributive attitudes, however, shows - depending on the exact attitudinal item - minimal or even no support for this dynamic version.

Based on these effects on social policy attitudes, several studies argue in a next step that individuals adapt their voting behaviour (Emmenegger et al., 2015), their party preference or identification (Cusack et al., 2006; Marx and Picot, 2013), and their ideological position (Corbetta and Colloca, 2013; Visser et al., 2014) accordingly. However, this has barely been tested in a dynamic context. Martén (2019) tests if unemployment leads to vote switching to the left, and finds that it does not. And Wiertz and Rodon (2021) find ideological left-shifts after transitions into unemployment.

However, one could also assume a shift to the right in response to unemployment based on arguments focusing on migration-related attitudes. Not only social policy attitudes but also migration-related attitudes are said to be rooted in economic self-interest, at least when one shares the perspective of theories about ethnic threat and competition (Billiet et al., 2014; Pecoraro and Ruedin, 2016). The basic idea is that individuals feel threatened by migration if they perceive migrants as competition in the labour market. The strictest version of this argument has been challenged by experimental findings. Natives are not more critical towards migrants with the same skill set (Hainmueller et al., 2015; Valentino et al., 2017). In contrast, economic or labour market vulnerability is suggested to lead to a higher perceived threat from migrants in general (Billiet et al., 2014), which is also the lesson from the mentioned experimental evidence.

This second version of the argument also has been put to scrutiny in a dynamic context. Indeed Lancee and Pardos-Prado (2013) found increased worries about migration after involuntary job loss in the German context. However, additional analyses reported in Gidron and Mijs 
(2019) and Wiertz and Rodon (2021) do not support this claim for the Dutch case. Neither are ideological right-shifts found in the Dutch case (Wiertz and Rodon, 2021).

Taken together, opposing ideological reactions to transitions into unemployment can be expected: an ideological left-shift (hypothesis 1a) and an ideological right-shift (hypothesis 1b).

\subsubsection{Constraining Change or Changing Constraints}

Arguments for both, for a left- and a right-shift, are based on the assumption that changes in policy attitudes translate into changes in ideology or other political (pre)dispositions like party identification. Or in other words: changes in policy attitudes are assumed to update predispositions (Gerber and Green, 1998).

In contrast, proponents of the perspective that party ID influences policy attitudes conceptually differ between specific policy attitudes and political predispositions, including party identification, but also ideology or (core) value orientations (Sears and Funk, 1999). Political predispositions are seen as "perceptual screen" through which political objects (including policies) are evaluated or as "central heuristics" that affect other (policy) attitudes (Campbell et al., 1960; Goren, 2013). In a more dynamic sense, political predispositions are supposed to "constraint" or limit individuals more specific political/policy attitudes and thereby give (ideological) structure to individuals' political "belief systems" (Converse, 1964). Adopting the concept of predispositions thus casts doubt on the idea of a spillover from attitudes sensitive to labour market transitions to left-right ideology or other predispositions. In contrast to hypotheses $1 \mathrm{a}$ and $1 \mathrm{~b}$, this argument leads to the expectation of no ideological shift in response to transitions into unemployment (hypothesis 1c).

\subsubsection{Stratified Socialization: Two Challenges for Causal Inference}

Given the abundance of findings on links between unemployment and political attitudes, behaviour, and predispositions arguments about the stability of political predispositions might seem irrelevant for such associations. However, there is an alternative story behind links between unemployment (or other material circumstances) and political attitudes that has been elaborated elsewhere (Lancee and Pardos-Prado, 2013; O'Grady, 2019; Wehl, 2019). To reiterate, such links can also be explained by stratified early socialization, i.e. by several (mostly socio-economic) background factors, that influence both: individuals' labour market risks in adulthood and individuals' political socialization experiences in childhood and adolescence. Similarly, personality traits are known to influence individuals' political attitudes and predispositions (Gerber et al., 2010) as well as their chances on the labour market (Gnambs, 2017; Viinikainen and Kokko, 2012). This dual influence on political predispositions and labour market risks creates an issue of time-constant confounding (see left part of figure 4.1). 

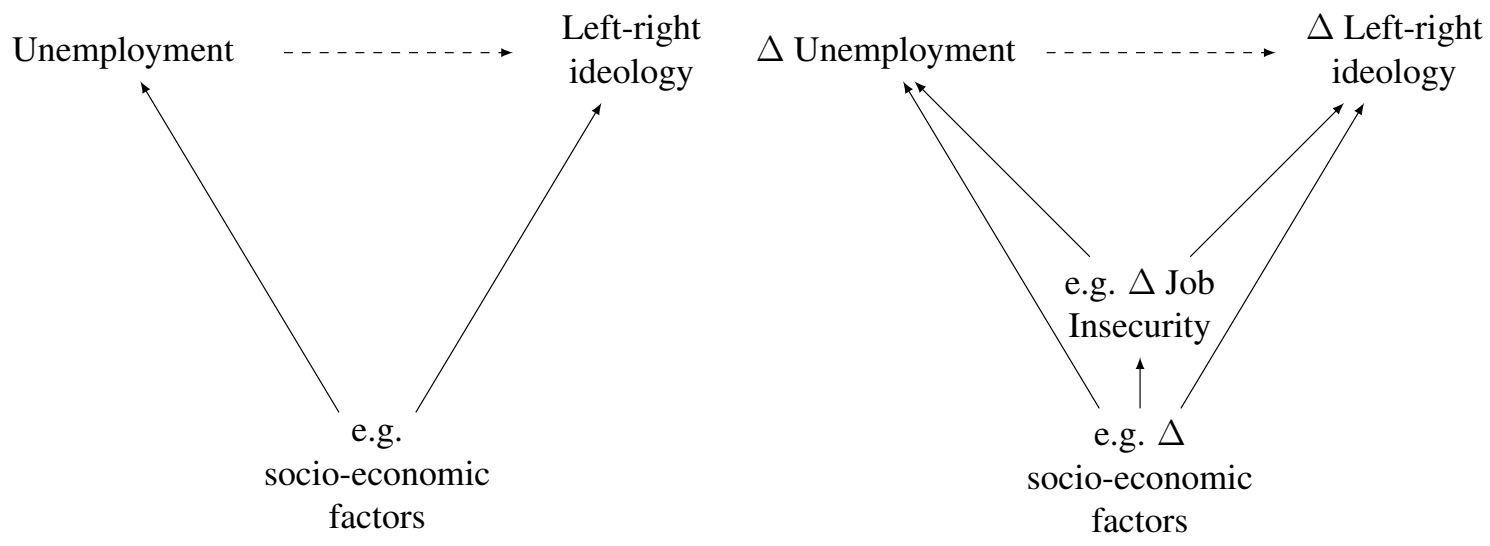

Figure 4.1: Time-Constant (left) and Time-Varying (right) Confounding of Relations between Unemployment and Ideology

Studies examining the political consequences of unemployment or other material circumstances in a panel context with fixed-effects do account for time-constant confounding. However, timevarying confounding can bias the results from such panel studies. Unfortunately, it is not very hard to think of factors or situations that could lead to an increasing unemployment risk as well as to ideological left shifts. The right part of figure 4.1 depicts two theoretical possibilities for such time-varying confounding.

The first possibility focuses on the already mentioned extension of the self-interest based argument regarding the political consequences of unemployment to political consequences of unemployment risk. Similar attitudinal reactions to the ones after unemployment are expected when unemployment risk is changing (Rehm, 2016). If people who at some point will become unemployed experience some change affecting their objective unemployment risk, realize their increased job insecurity, and adjust their left-right ideology accordingly this might lead to an overestimation of the relation between unemployment and left-right ideology. As an example we can think of mobility between social classes or occupational mobility. Both can be associated with a changing unemployment risk and both have been shown in a dynamic context to affect "economic preferences" (among others: labour market policy attitudes) and party preferences (Ares, 2020; Kurer, 2020). However, should this explanation be true, this overestimation would not change conclusions about self-interest. After all, the mechanism behind this first explanation for time-varying confounding is self-interest. Neither would it change conclusions about ideological (in)stability as the explanation focuses on ideological change in response to changing unemployment risk.

But it is equally possible to imagine time-varying confounding without a self-interest driven mechanism. The literature mentions several mechanisms, that are basically variants of arguments of adult-life socialization and do not refer to (narrowly defined) self-interest. Starting with an example there are many different changes in individuals' work life, that objectively affect their unemployment risk, e.g. a new occupation or a new position within one's occupation. Even if such a change does not affect individuals' subjective job insecurity, it could be enough to change their political preferences and finally their ideology simply due to exposure to a more insecure context, with which one increasingly communicates and identifies. In more abstract 
terms, this is essentially what has been put forward for long in the literature on economic voting as sociotropic considerations (Lewis-Beck and Stegmaier, 2000). More recently, similar thoughts have been developed under the term "linked fate" (Donnelly, 2021).

With regard to ideological reactions to unemployment, both explanations for time-varying confounding are observationally equivalent. However, only the first, self-interest driven explanation, is based on reactions to job insecurity. This argument leads to the expectation that changes in job insecurity perceptions trigger ideological left-shifts (hypothesis 2a) or rightshifts (hypothesis $2 \mathrm{~b}$ ) for people who later become unemployed. To differentiate between the two possible mechanisms behind time-varying confounding, hypothesis $2 \mathrm{c}$ expects no ideological reaction to job insecurity for people who later become unemployed.

\subsubsection{Effect Heterogeneity}

If and how people adapt their left-right ideology in response to unemployment likely depends on the groups and contexts analysed. Indeed, previous studies already pointed to heterogeneity in the effects of unemployment or other material shocks on political attitudes, predispositions, and behaviour. However, such arguments were mostly based on the idea that attitudinal or predispositional reactions should be stronger for people or groups who are hit harder by an economic shock, e.g. low income groups (Gidron and Mijs, 2019; Wiertz and Rodon, 2021). In contrast, I discuss in the following that factors known to influence predispositional (in)stabiliity in light of attitudinal changes should moderate the relation between unemployment and ideology. In particular, I focus on previous ideological leanings, age, and contextual salience.

Starting point for different effects for people with different ideological leanings is the often raised criticism that "left" and "right" can mean different things for different people. This starts with the discussion about the two- or multi-dimensionality of ideology (de Vries et al., 2013) and extends to the discussion which belief objects (politicians, parties, policies, values) are mostly associated with the understanding of "left" and "right" and the positioning on the left-right scale (Knutsen, 1997; Bauer et al., 2017). These ambiguities include the possibility that different issues are related to variation on the two sides of individuals' left-right placement. Economic concerns are more important for the question of how extreme or central people locate themselves on the left side. In contrast, socio-cultural concerns are more important for the difference between extreme and centrist locations on the right side of the left-right axis (Lachat, 2018). This leads to the expectation that previously left-leaning people react with a left-shift to unemployment and previously right-leaning people react with a right-shift (hypothesis $3 \mathrm{a}$ )

Hypothesis 3a suggests that ideological instability after unemployment ultimately strengthens or reinforces (Wehl, 2020) pre-existing ideological leanings. However, the opposite might be true as well. Margalit (2013) shows for the U.S. context that job loss leads to a strong increase for social policy attitudes among Republican identifiers, but not so much among Democrats. And while Wiertz and Rodon (2021) do not find strong heterogeneities in ideological reactions to unemployment, they find that people with a previously right ideology are likely to show 
a left-shift in ideology. This leads to the expectation that right-leaning people react with an especially strong left-shift to unemployment (hypothesis 3b).

Finally, Wehl (2020) argues with regard to party ties that people without party ties can be expected to show strong attitudinal change since they are unconstrained and shows this with regard to attitudinal reactions after increasing unemployment risks. This leads to the expectation that people with a central ideological position show especially strong ideological reactions to unemployment (hypothesis 3c).

Apart from individuals' prior ideological position the timing of employment transitions is likely to matter for ideological responses, as well. After all, political predispositions are considerably stable over the life course, but only to a lesser degree so during the formative years of adolescence and early adulthood, as research following the "impressionable years" hypothesis holds and shows (Dinas, 2013; Krosnick and Alwin, 1989). First, young people do have more instable (political) attitudes and predispositions (Kiley and Vaisey, 2020). And second, young people update their predispositions more often when their attitudes change, as Rekker et al. (2017) show regarding the relation between issue attitudes and left-right orientation. The argument about "constrained change" thus might be less relevant for younger people. Indeed, Emmenegger et al. (2017) argue similarly and find in their analyses of political interest strong reactions to unemployment only among young people. Accordingly, I expect that ideological reactions to unemployment are stronger for younger people (hypothesis 4).

Finally, the salience of a topic has been established as a crucial condition for the question of whether attitudes update predispositions or predispositions constraint attitudes. Thus, Carsey and Layman (2006) showed in the U.S. context that updating of party identification is only happening for attitudes on issues that are perceived to be important. Weber and Saris (2014) show something similar in the Dutch context for updating of left-right ideology. Finally, Dancey and Goren (2010) reformulated this individual-level argument about salience as a contextual argument focusing on media coverage of disputed issues. They argue that party identification changes in response to attitude changes are more likely for salient topics. After all, these are widely discussed in the media, which provides citizens with information about parties' positions and possible differences between those. The results from Highton and Kam (2011) point into a similar direction. They show - like Dancey and Goren (2010) for the U.S. context - that the direction of causality between party identification and attitudes can change over time, which they suggest to be associated with varying societal level salience of issues. Therefore, I expect stronger ideological left-shifts in response to unemployment, when the (contextual) salience of economic issues is higher (hypothesis 5).

\subsection{Data and Methods}

The individual-level analyses are based on data from the Swiss Household Panel Study (SHP) from 1999 to 2018 (Voorpostel et al., 2015), the Dutch Longitudinal Internet Study for the Social Sciences (LISS) from 2008 to 2019 (Scherpenzeel and Das, 2010), and the Spanish 
Political Attitudes panel (POLAT) from 2010 - 2014 (Anduiza et al., 2015). The SHP is a yearly household panel survey with approximately 7000 interviewed respondents per wave conducted each year since 1999 (Voorpostel et al., 2015).

The LISS is a probability-based internet panel, meaning that even though data collection is administered online, a random sample of respondents is drawn from a population register (Scherpenzeel and Das, 2010). The approximately 8.000 LISS respondents are (at least) yearly contacted since 2007. A peculiarity of the LISS data is, however, its "modular" character with different fieldwork periods throughout a year for different modules. In contrast, the POLAT data, currently ranging from 2010-2014, is an online panel with the typical problems of online surveys like excluding people without internet access, or the underrepresentation of older people. Each wave consists of approximately 2.000 respondents (Anduiza et al., 2015). In contrast to the SHP and LISS data, the POLAT waves show a less regular timing e.g. with two waves in $2011^{27}$

\subsubsection{Measurement of Ideology, Unemployment, and Job Insecurity}

The main dependent variable is respondents' left-right self-placement. Left-right ideology is measured in all three data sets on an 11-point scale ranging from 0 to 10 . However, in the Swiss and Dutch data, the scale endpoints are "left" and "right", while in the Spanish data, they are "extreme left" and "extreme right". While this might reduce the comparability of absolute leftright scale values between the three countries it should not matter (much) for relative changes on the left-right scale - this article's main focus.

The main independent variables of this study are unemployment and unemployment risk. In all three data sets, I identify unemployed respondents by differentiating them from non-employed and employed respondents. To do so I rely in the SHP data on a constructed indicator that contains exactly that differentiation. In the Dutch and Spanish data, I rely on direct respondents' answers. In the Dutch case, monthly information on respondents' employment situation is available. I only use the employment information from exactly that month in which Dutch respondents are interviewed about their left-right ideology and combine both data modules accordingly. A robustness check uses another yearly measure of labour force status to identify unemployed people in the LISS data. ${ }^{28}$

Job insecurity, or the subjective unemployment risk within the next 12 months, is asked in the Swiss and Dutch, but not the Spanish, data. In the SHP this is a 10-point scale, in the LISS a 100-point scale. I round answers to the Dutch job insecurity scale to steps of 10 for better comparability of the Dutch and Swiss results. Unfortunately, Dutch respondents indicate their job insecurity feelings mostly in June and July of a given year, while their left-right ideology is typically observed in January of that year or December of the previous year. This could lead to some undetected dynamics between job insecurity and left-right ideology. To reduce that risk, I replicate all Dutch analyses of job insecurity effects using a lagged measure of job insecurity. In the main analyses, I focus on the experience of increasing job insecurity with a dummy variable, analyses in the appendix replicate all job insecurity analyses with a continuous measure. 
The original variables and survey questions can be found in the online appendix. ${ }^{29}$

\subsubsection{Moderators: Prior Left-Right Ideology, Age, and Salience}

To analyse effect heterogeneities based on respondents' prior ideological position (hypotheses 3a-c), I run models including interactions between unemployment and prior left-right ideology. To account for systematic differences between centre and extreme ideological positions and to account for further non-linearities on the left side and the right side of the ideological spectrum I add interactions with the squared term and the cubic term of the left-right scale. A robustness check uses an interaction with a categorical variable that differentiates between a left, a right, and a centre (5 and 4-6 respectively) position on the left-right scale.

To analyse age-based effect heterogeneities (hypothesis 4) I run models with interactions between unemployment and age. I add interactions with a squared and cubic form of age to account for peculiarities of middle-aged people and further non-linearities within young and old people. A robustness check uses an interaction with a categorical variable that differentiates young, middle aged and elderly respondents. As this is somewhat arbitrary, I use three versions, where I define middle-aged people as those between 25-45,30-50, and 35-55 respectively.

Finally, to judge contextual salience of unemployment (hypothesis 5) I rely on countries' unemployment rates based on World Development Indicators and aggregated measures of subjective issue importance, i.e. mentions of the most important problem(s), based on yearly Eurobarometer data and for Switzerland based on post-electoral Selects (Swiss Election Study) data. Mentions of unemployment (Eurobarometer) and the labour market (Selects) are used and compared to mentions of migration-related issues. These salience measures are used for a description of the contexts and not added to any models. All models are run for each country separately.

\subsubsection{Fixed Effects (FE) \& Fixed Effects with Individual Specific Slopes (FEIS)}

Standard fixed effects (FE) models and fixed effects models with individual specific slopes (FEIS) are applied (Brüderl and Ludwig, 2015; Ludwig, 2019; Ludwig and Brüderl, 2018; Rüttenauer and Ludwig, 2020). with cluster robust standard errors.

In panel data it is always possible to distinguish between two sources of selection bias: timeconstant and time-varying selection bias. This is illustrated in figure 4.2. After receiving a treatment (between $t_{2}$ and $t_{3}$ ) the outcome changes. But even at $t_{1}$ before any unit receives a treatment there are differences between those who are never treated (o) and those, who will be treated $(\square)$. The latter already have a higher outcome level than the former. There is constant selection bias. Equation 4.1 shows a fixed effects estimator, that captures this stable difference by the individual constants $\alpha_{i}$ (next to the time-varying outcome $Y_{i t}$, the time-varying treatment $x_{i t}$ and a time-varying error term $\epsilon_{i t}$ ) and thus eliminates all stable sources of selection bias. 

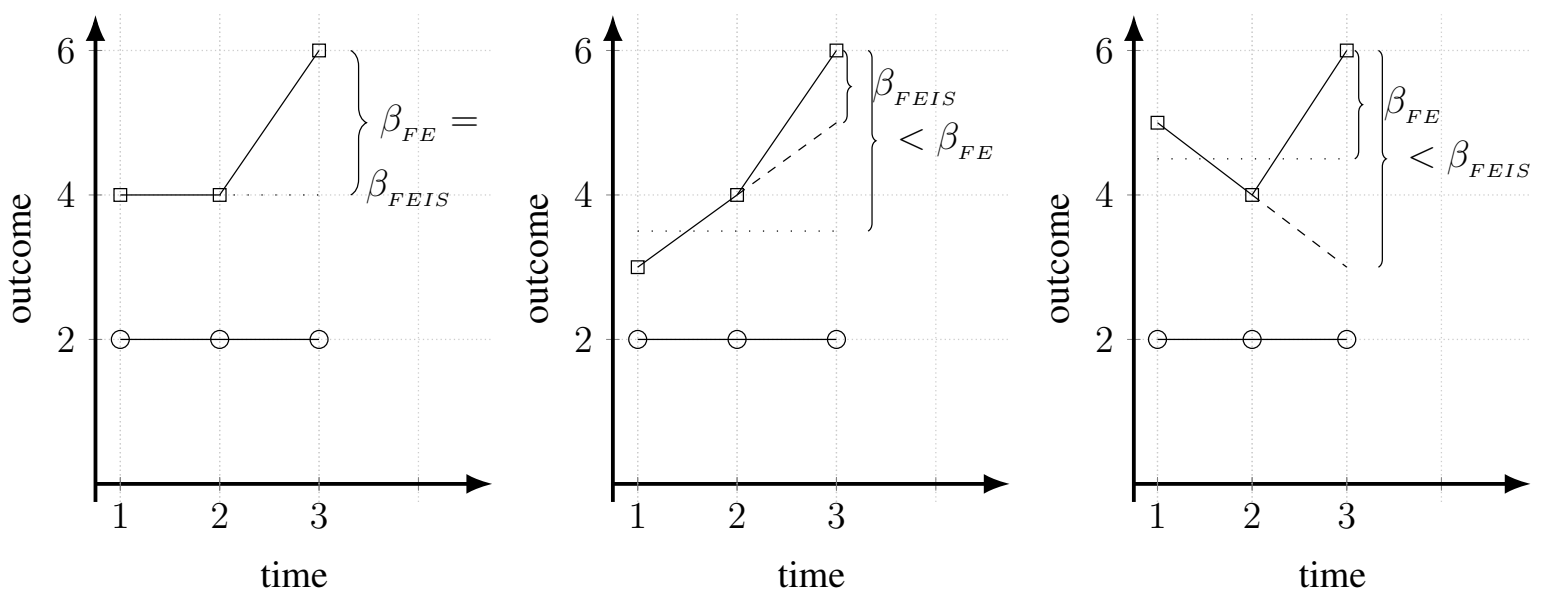

Legend:
$\circ$ and $\square$ observed at time points 1,2 , and 3 with $\circ=$ never treated and $\square=$ treated between
time points 2 and 3 .
Left graph: Selection into Outcome Level $\rightarrow$ unbiased estimation by FE.
Center graph: Selection into Outcome Level and Growth $\rightarrow$ Overestimation by FE.
Right Graph: Selection into Outcome Level and (reverse) Selection on Growth $\rightarrow$ Underesti-
mation by FE.

Figure 4.2: Comparing the Logic of Fixed Effects Estimates with and without Individual Slopes

This can be seen in figure 4.2 where the fixed effects estimators are only based on those units who do receive treatment.

$$
Y_{i t}=\alpha_{i}+\beta_{F E} x_{i t}+\epsilon_{i t}
$$

But, the standard fixed effects estimator is biased by dynamic selection into treatment. This is illustrated in the center and right panel of figure 4.2. Now differences in outcome levels are accompanied by differences in the outcome trajectories between those who will be treated and those who are never treated. If equation 4.2 is the true model, only accounting for $\alpha_{i}$ will result in a biased fixed effects estimator $\beta_{F E} x_{i t}$ (unless $\beta_{F E} x_{i t}$ and $\alpha_{i} z_{i t}$ are independent). In contrast, equation 4.2 gives the fixed effects estimator $\beta_{F E I S}$ with individual specific slopes $\alpha_{i} z_{i t}$ representing an interaction between the individual constants $\alpha_{i}$ and a time-varying "slope" variable $z_{i t}$.

$$
Y_{i t}=\alpha_{i}+\alpha_{i} z_{i t}+\beta_{F E I S} x_{i t}+\epsilon_{i t}
$$

I use time as slope variable meaning that the individual specific slopes are $\alpha_{i} t_{t}$. Thus, the results could potentially still be biased by non-linear trends that are related to selection into unemployment and dynamics of left-right ideology. Note that the FEIS estimation with one slope variable that I use requires a minimum of three observations per panel member (Brüderl 
and Ludwig, 2015, p.336-339). An advantage of time as slope variable is that it excludes the danger of post-treatment bias that other slope variable could create (Rüttenauer and Ludwig, 2020, p. 31). A similar issue of post-treatment bias or overcontrolling can arise when the treatment effect operates over a longer time period, but the specified model only contains a contemporaneous treatment effect (Rüttenauer and Ludwig, 2020, p. 31). Thus, to avoid an underestimation of the effect of unemployment, a robustness check adds lagged measures of unemployment.

To further illustrate the logic FE and FEIS estimators the appendix contains a short Stata code creating artificial data mimicking the examples in figure 4.2 with the FEIS Stata routine (Ludwig, 2019) and an equivalent "manual" OLS solution directly applying formulas 4.1 and 4.2.

\subsubsection{Applied Methodological Considerations: Sample Restrictions and Interactions}

To avoid pitfalls of interactions in longitudinal settings (Giesselmann and Schmidt-Catran, 2020) and more than obvious sources of treatment heterogeneity and selection biases I 1) use time-constant moderator variables and 2) apply several sample restrictions

On the one hand, the use of constant moderator variables has methodical advantages. Giesselmann and Schmidt-Catran (2020) have recently shown that standard interaction effects between two time-varying variables in a fixed effects framework are biased. This bias does not occur for interactions between a time-constant and a time-varying variable. On the other hand, this is perfectly in line with the theoretical arguments behind the moderator variables (prior left-right position and age suggested in hypotheses 4 and 5. Young age, not aging, and prior left-right position, not left-right dynamics were suggested as a source of potential heterogeneity in ideological reactions to unemployment (risk). Thus, these moderator variables are artificially created as constants (within persons) by using respondents' age and their left-right position at the first time they are observed in the analysis sample.

I apply several sample restrictions which all aim at two goals: 1) observing a homogenous treatment 2) focusing on only one treatment experience per person. The second point avoids the risk that past treatment (unemployment, increased job insecurity) influences and thus confounds the relation between current treatment and current outcome (Imai and Kim, 2019).

First, I exclude all observations (person-years) older than 65 years to exclude most of the transitions into retirement. The Spanish data, however, does not contain respondents older than 52 . Furthermore, I exclude observations before their first employment episode, especially to exclude transitions out of school. Of those, I furthermore exclude all observations once they enter nonemployment. This excludes all transitions into retirement (also early retirement), transitions between unemployment and nonemployment, but also other employment interruptions in between the career. Finally, for those who do become unemployed, all observations after their (potential) reemployment are excluded. Given all these sample restrictions, the effect of unemployment captures solely the effect of the transition from employment to unemployment. 
The analyses of job insecurity are based on the same analysis sample, but some more restrictions are applied. First of all, I restrict these analyses to those people who experience an unemployment episode. Furthermore, I exclude this unemployment episode from the sample. Finally, I restrict this sample to only one (the first) experience of increased job insecurity. Given these further sample restrictions, the effect of job insecurity solely captures the effect of increased job insecurity for people who later become unemployed. The analyses in the online appendix using the continuous versions of job insecurity use the same restricted sample without the last restriction on only one job insecurity experience.

Additionally, I exclude respondents with less than two observations of left-right ideology, employment status, or job insecurity, as they anyway could not contribute to the within variation used in FE and FEIS models. Table C.6 in the appendix shows, that these criteria limit the sample quite drastically and leave 822 observations in unemployment for the Swiss data, 428 observations in unemployment in the Spanish data, and 951 observations in unemployment for the Dutch data.

\subsection{Analysis}

I start by discussing the results from main effects analyses on the effect of unemployment and subjective job insecurity before unemployment on left-right ideology. The OLS, fixed effects (FE) and fixed effects with individual slopes (FEIS) estimates are shown in figure 4.3. I continue with a discussion of ideology-based, age-based, and country heterogeneities of the effects of unemployment.

\subsubsection{Main Effects}

Focusing at first on the effects of unemployment (hypotheses 1a-c) the OLS estimates are informative for a descriptive overview of these associations. In Switzerland and the Netherlands, unemployed people place themselves more often on the left side of the left-right scale. Looking at the FE and FEIS estimates for unemployment, it becomes clear that all these Swiss and Dutch associations result from confounding. The Swiss results are very clear. Neither the FE nor the FEIS models show any effects of unemployment on left-right ideology. Thus, in the Swiss case, it even would have been sufficient to account for time-constant selection with traditional FE models. In the Dutch case, the difference between the OLS and FE effect sizes is notable. Yet, the small FE estimate for unemployment is still significant (with $\mathrm{p}<0.1$ ). People who become unemployed move slightly to the left. Thus, time-constant confounding is part of the story but not the whole story behind the significant associations between unemployment and left-right self-placement in the Dutch case. Time-varying confounding, however, explains the rest of the story, as the insignificant, almost nil Dutch FEIS estimate shows. Using the alternative unemployment measure in the Dutch data shows the same pattern of a significant FE estimate (this time with $\mathrm{p}<0.05$ ) and an insignificant FEIS estimate. In both cases, the 
size of the FE estimates fit well with the effect sizes reported by Wiertz and Rodon (2021). ${ }^{30}$. Finally, these Swiss and Dutch results are not resulting from overcontrolling. Including lagged effects of unemployment does not alter the conclusions in any particular way as figure C.1 in the appendix shows. 


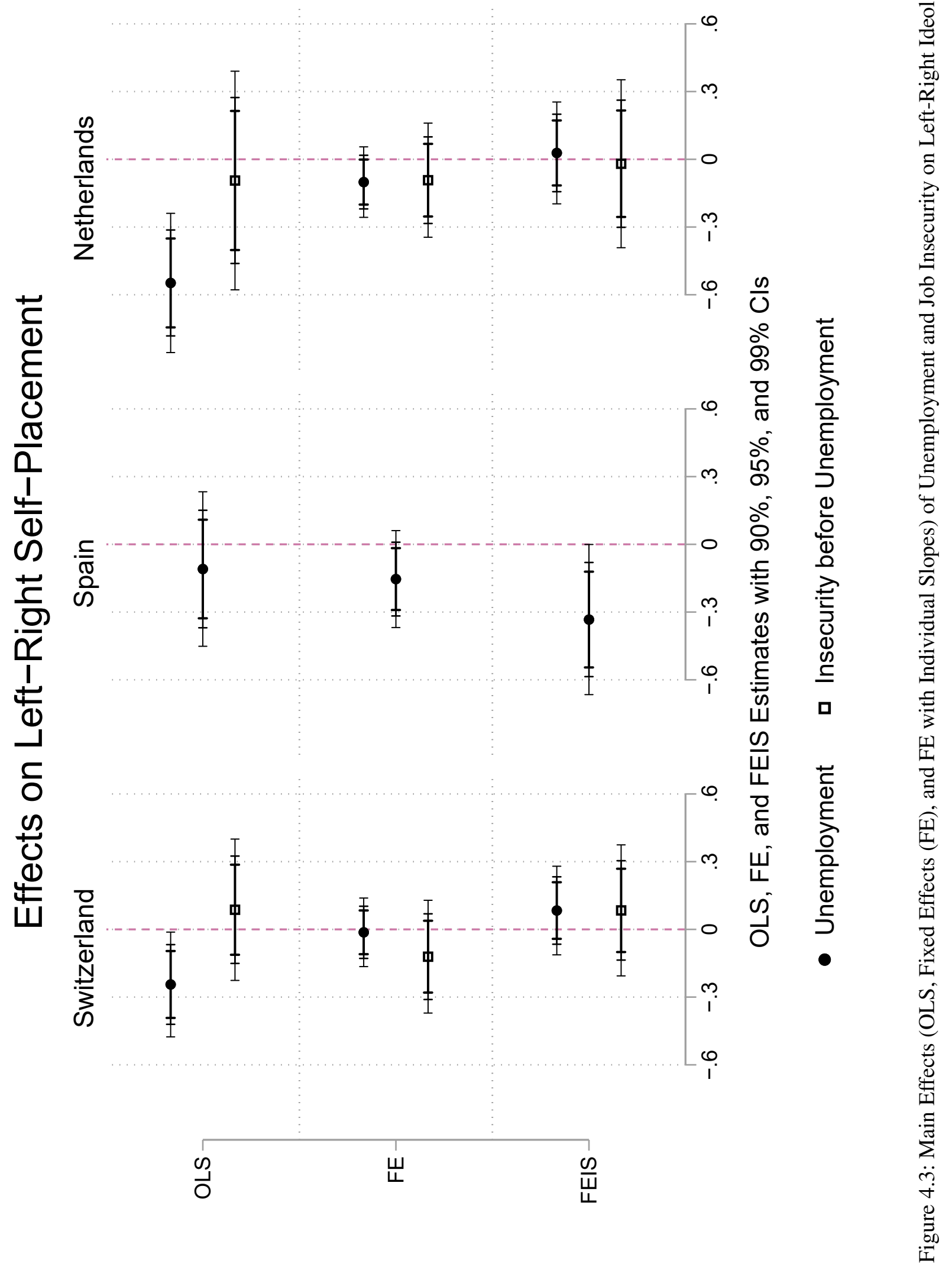


Interestingly, the Spanish results point in the opposite direction. On the one hand, FEIS estimates for Spain show ideological left-shifts after unemployment. However, the FE estimate for Spain is smaller than the FEIS estimate and only significant with $\mathrm{p}<0.1$. The OLS estimate is even smaller and does not meet any significance threshold. This suggests, that in the Spanish case confounding did not lead to an overestimation but an underestimation of the effect of unemployment in the OLS and FE models. One way to interpret this is to remember that the Spanish data starts during the economic crisis. Thus, people who start in the Spanish sample in employment and experience unemployment at some point are a positive selection, or a more advantaged subsample, of all Spanish people who lost their job during the economic crisis. They "survived" longer with employment.

To summarize, selection bias is everything there is in the Swiss and Dutch case so that hypotheses $1 \mathrm{a}$ and $1 \mathrm{~b}$ of left and right-shifts after unemployment have to be rejected and hypothesis $1 \mathrm{c}$ of no ideological reaction cannot be rejected in the Swiss and Dutch data. The opposite is true for Spain, where hypothesis 1a of left-shifts is supported.

However, at least for the Dutch results, time-varying confounding plays some role. To understand better the mechanisms behind this result research question 2 asks if people adapt their left-right ideology to a perception of increased unemployment risk before they become unemployed. Unfortunately, such results are not available for Spain, since the Spanish data does not contain (regular) measures of job insecurity. The results for Switzerland and the Netherlands can be seen as well in figure 4.3. In both, the Swiss and the Dutch case, there are no significant FEIS estimates and thus no ideological reactions to job insecurity observable. In the Swiss case, that means that neither people who become unemployed, nor people who experience increased job insecurity at some time before they become unemployed adapt their left-right placement. From a theoretical perspective, the Dutch case is more interesting. Here, the results for the effects of unemployed showed a difference between the Dutch FE and FEIS estimates and thus some dynamics in left-shifts before unemployment. However, the insignificant results for job insecurity before unemployment suggest that these dynamics are not responses to unemployment risk. Other explanations than (narrowly defined) self-interest based ones seem to be more suitable.

Additional robustness checks support these results and conclusions about job insecurity. These Swiss and Dutch results hold when analyses include additional lagged measures of insecurity to avoid an underestimation of contemporaneous effects (see appendix figure C.1). Similarly, these results hold when continuous measures of job insecurity are used that capture more job insecurity changes (see appendix figure C.2). In the Dutch case, two further robustness checks are necessary. They show similar results when using the alternative measure of labour force status (see appendix figure C.6), which does not refer to a different job insecurity measure, but to a slightly different sample. Finally, given the different timing of the LISS modules including left-right ideology and job insecurity, the Dutch analyses are repeated with a lagged measure of insecurity (see C.3. In contrast to the models including contemporaneous and two lagged effects that avoid the problem of overcontrolling, this model including no contemporaneous and only one lagged effect of job insecurity only tries to address the different fieldwork times. When looking at this lagged measure of job insecurity in the Dutch case, no left-shift, but a rightshift after increasing worries about job insecurity is observable. While interesting on its own, 
this should not affect the conclusion about the lesser explanatory power of self-interest based explanations compared to adult life socialization dynamics for time-varying confounding. After all, these right-shifts after job insecurity give even more support to the idea that the reason for people moving slightly to the left before they become unemployed is not a reaction to unemployment risk.

To summarize, hypotheses $2 \mathrm{a}$ and $2 \mathrm{~b}$ about ideological left and right-shifts have to be rejected, hypothesis $2 \mathrm{c}$ about no ideological reactions to job insecurity before unemployment cannot be rejected. One robustness check in the Netherlands gives slight support for hypothesis $2 \mathrm{~b}$.

\subsubsection{Effect Heterogeneity}

The remaining results on hypotheses 3-4 show if and how prior ideological leanings and age moderate the presented effects of unemployment on left-right ideology.

Figure 4.4 starts with the marginal effects of unemployment by respondents' prior ideological position. The results are very different for the three countries. In Switzerland respondents' prior ideological leaning does moderate the effects of unemployment on left-right ideology. People on the left react with a left-shift, while people with a center or right positions react with a right-shift to unemployment. The resulting polarization can also be seen when one uses a categorical grouping of previously left, center, and right people. Only the marginal effect for those on the left misses conventional significance levels (see appendix figure C.4). These Swiss results thus support hypothesis $3 \mathrm{a}$ and clearly contradict hypothesis $3 \mathrm{~b}$ (left-shifts for those on the right). While there are effects for those with a previous center position, this is neither the only group nor the group with the strongest effects contradicting hypothesis $3 \mathrm{c}$. 


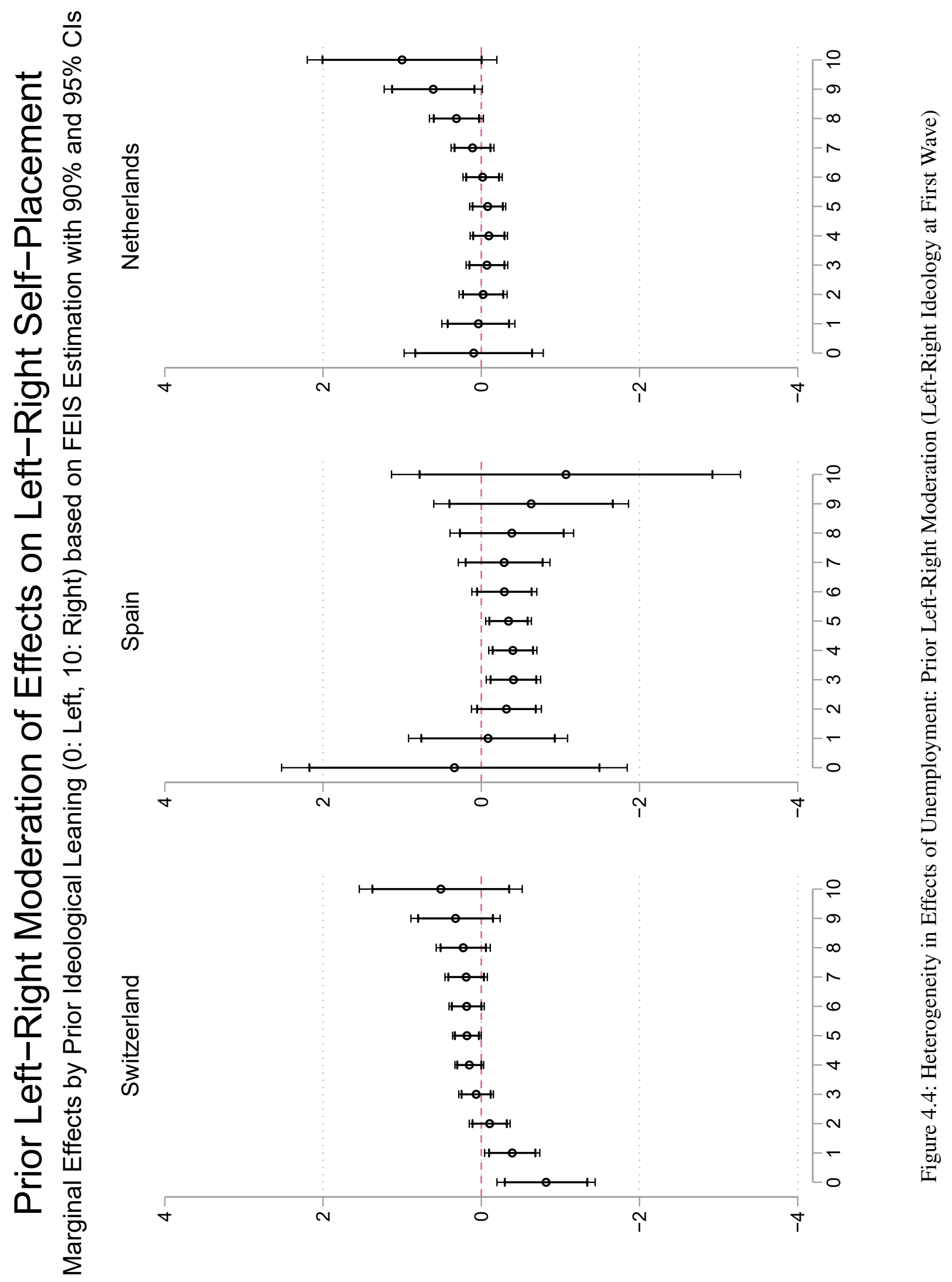


In Spain and the Netherlands, there is no clear moderation. In Spain, everyone (except those farthest to the left) reacts with a left-shift. This left-shift, however, is not significant for everyone. The results in figure 4.4 suggest that only for those with a prior moderate left or a prior center ideological position there is a significant left-shift. Using the categorical interaction instead (see appendix figure C.4) clearly supports the effect for those with a previous center position. However, the marginal effect for those with a previously left position is insignificant, the marginal effect for those on the right is significant with $\mathrm{p}<0.1$. In the Netherlands, nearly no-one except those on the far-right reacts with any ideological changes. But also the evidence for these right-shifts for those on the right is weak. The marginal effects in figure 4.4 are only significant with $\mathrm{p}<0.1$. Furthermore, they do not show up when using the categorical interaction in appendix figure C.4, nor when replicating figure 4.4 with the alternative measure of unemployment in the LISS data (see appendix figure C.7). Thus, in Spain, the clearest support is for hypothesis 3c. Further evidence for left-shifts on the left (part of hypothesis 3a) and left-shifts on the right (hypothesis 3b) exists but is not robust. In the Netherlands, there is only partial, non-robust support for hypothesis $3 \mathrm{a}$ (right-shifts on the right).

Figure 4.5 continues with age-based heterogeneities. Again, the results depend heavily on the country-context. In Switzerland, no age-based heterogeneity is observable. This is true as well when one looks at interactions with categorical age groups (see appendix figure C.5) with the exception of elderly people. This exception, however, is non-robust on its own, as this marginal effect showing a left-shift only appears as significant with $p<0.1$, when defining elderly people as those over 50, not when defining them as over 45 or over 55 . The Spanish results show a very different picture. Here, a clear moderation of the unemployment effect by age is apparent. Younger people do react with left-shifts to unemployment, middle-aged people do not. This finding is equally clear when looking at figure 4.5 as when looking at interactions with categorical age groups in appendix figure C.5. This holds for all definitions (i.e. thresholds) for young people. However, given the restricted age coverage of the Spanish online sample, the Spanish results cannot say anything about the ideological reactions of elderly people. In the Netherlands no systematic age heterogeneities are observable. Figure 4.5 does show right-shifts for a few middle-aged people. And using the interaction with the categorical age variable, there is a left-shift observable for young people in the Netherlands, but only when using the lowest of the three age thresholds (see appendix figure C.5).

To summarize, there is clear evidence for hypothesis 4, which expected stronger ideological reactions for young people, from the Spanish data. There is no support for hypothesis 4 from the Swiss and Dutch data. However, since the Swiss and Dutch results do not show systematic ideological reactions for middle-aged or elderly people, this is not a reason to doubt the theoretical idea behind hypothesis 4: higher predispositional stability during adulthood. 


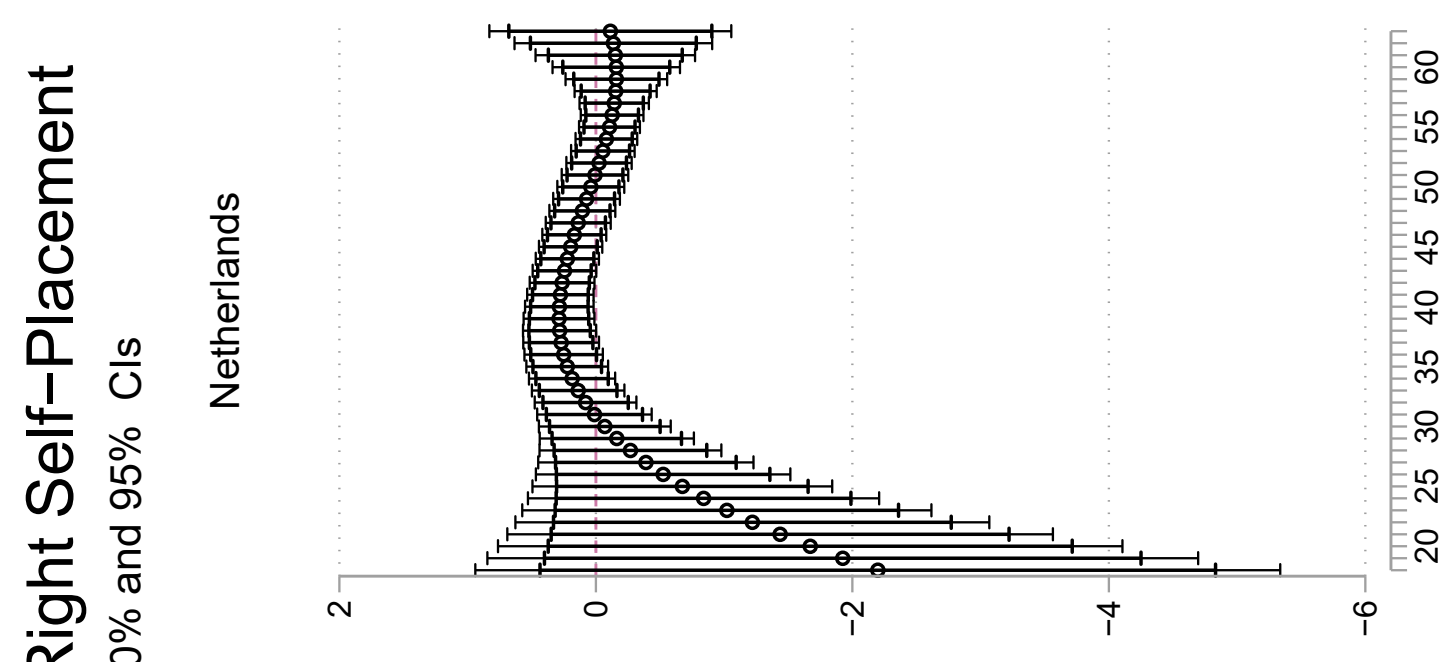




\subsubsection{Country Differences in Context}

Finally, hypothesis 5 asks directly about country differences in the results. Can these be interpreted as a function of the salience of unemployment in a context (hypothesis 5)? To be clear, the comparison between these three countries can show whether or not the idea that salience drives these country differences is plausible. However, it cannot single out salience as the factor driving these differences.

Appendix figures C.9 and C.10 start by displaying descriptive evidence on the spread and salience of unemployment in the three countries. Spain during the study period is clearly the context with the highest rate of unemployment and the highest salience of unemployment during the study period. Also, migration is not an important issue during the whole study period. Of course, all that is not surprising given that the study period coincides with the economic crisis. In contrast, Switzerland is the country with the lowest unemployment rate, and with a continuously higher salience of migration than of labour market issues. Finally, the Netherlands occupies a middle ground. There are some peaks in its official unemployment rate and in subjective issue salience of unemployment. There are also some peaks in the issue salience of migration especially in and after 2015. But there are also times where neither topic is particularly salient.

The country differences in the main effects, i.e. visible left-shifts in Spain but not in the Netherlands and Switzerland, fit very well with the idea that ideological left-shifts are stronger in contexts with a high salience of unemployment. Similarly, the polarization effect in Switzerland could be interpreted as a sign that salience matters, yet with a more nuanced mechanism. It might not only be contextual salience of economic issues that matters for the strength of the ideological reaction. It might be the salience of both, economic (labour market) and cultural (migration) issues, that matters for the direction of the ideological reaction. Especially the comparison between Spanish and Swiss respondents with a prior central position highlight this point: the former react with a left-shift, while the latter react with a right-shift. And finally, missing robust evidence in the Netherlands for any particular ideological reaction to unemployment fits with the middle ground the Netherlands occupy with regard to the salience of both, labour market and migration issues.

However, the salience argument cannot explain, why we observe different individual-level moderators in the different countries. In particular: why do Swiss left-leaning respondents react with a left-shift while Dutch left-leaning respondents do not? And why are only young people in Spain but not in Switzerland and the Netherlands more likely to change their ideology? Both cannot be explained with differences in contextual salience of labour market issues and migration.

Finally, the salience dynamics in the Dutch case allow for an additional test of the salience argument. Are effects in the Netherlands different in the period between 2009 and 2014, which includes peaks of the unemployment rate and the salience of unemployment and excludes peaks of the salience of migration (see appendix figures figures C.11 to C.13)? The short answer is no. 
There are still no significant main effects of unemployment (risk) judging from the FEIS estimates. There are neither effects for any ideological subgroup. ${ }^{31}$ While there is now somewhat stronger evidence for age heterogeneity in the effects of unemployment, this does not support the idea that higher salience leads to more or stronger left-shifts, as this heterogeneity suggests right-shifts for middle-aged people.

\subsection{Summary}

Are peoples' predispositions stable even in the face of a major material shock? Or are people adapting their predispositions mechanically to new economic considerations? After analysing changes in left-right ideology after transitions into unemployment with Swiss SHP, Spanish POLAT, and Dutch LISS panel data applying fixed effects with individual slopes the answer is clear: Neither.

In Switzerland no main effect of transitions into unemployment on left-right ideology was observable. Yet the absence of such an effect was only hidden by a polarization effect: left-shifts from left-leaning people and right-shifts from central- and right-leaning people. While this is a clear instance of ideological instability after unemployment, this instability results in strengthening pre-existing leanings. In Spain, left-shifts after unemployment were observed, which were driven by young people. Again, this is a clear case of ideological instability, however, only for a known exception to predispositional stability: young age. Finally, Dutch analyses found barely any evidence for ideological reactions in the Netherlands - a clear case of ideological stability.

To some degree, these country differences could be interpreted as a result of salience, i.e. the different importance of labour market and migration-related issues in these countries' public discourse. The clearest evidence for left-shifts comes from Spain, where labour market issues were most salient during the economic crisis. In contrast, in Switzerland with its high salience of migration-related issues, at least some people reacted to unemployment with a right-shift. And there is no clear evidence for ideological reactions in the Netherlands, where the salience of migration-related issues and labour market issues differs in both absolute and relative terms over time. However, this salience argument cannot explain the country differences in heterogeneities by age and ideological moderation.

Generally speaking, the presence of both, left-shifts and right-shifts, suggests an interesting new way to think about arguments for both, left-shifts and right-shifts. Regarding voting behaviour, Rovny and Rovny (2017) argue that it depends on the exact kind of labour market risk (occupation-based or status-based), whether the political consequence is voting for the radical left or radical right. In contrast, the present results show that the same kind of material shock can have opposite consequences, depending on individual and contextual factors.

In particular, the results suggest that context and prior leanings together can determine, how people react to unemployment. Arguments about left-shifts after unemployment focus on re- 
distribution and social security and on how both speak to the self-interest of unemployed people. Arguments about right-shifts after unemployment focus on migration and on how reduced competition from migrants speaks to the self-interest of unemployed people. Therefore, future research could directly test, whether context and prior leanings similarly condition whether social policy or migration-related attitudes are responsive to material shocks. If so, this would together with the empirical results of this paper - suggest that context and prior leanings act as a frame for individuals' interpretation of their self-interest. Or in other words, it would suggest a logic of "frame selection" (Kroneberg et al., 2010; Mehlkop and Neumann, 2012). Furthermore, future research is hopefully able to test more directly how contextual and/or individual salience matters for political reactions to material shocks.

Finally, previous research on political reactions to material shocks applied (some sort of) standard fixed effects that can account for stable confounding influences. In contrast, this articles' conclusions are based on fixed effects with individual slopes that can additionally account for time-varying confounding factors (Brüderl and Ludwig, 2015; Rüttenauer and Ludwig, 2020). The relevance of this choice between different fixed effects estimators is highlighted in the comparison between the Dutch FE and FEIS estimates. The former suggests small left-shifts after unemployment, just like the study by Wiertz and Rodon (2021). Even though the present study did not aim at a one-to-one replication, this suggests that these findings on unemployment and ideology were based on time-varying selection bias. It is thus not unlikely, that also other published findings on political reactions to material shocks include some time-varying bias. Future research should certainly consider applying FEIS or other methods that can account not only for time-constant but also for time-varying confounding. Nevertheless, the Swiss results are a clear example of a case where the conclusions about the main effects are similar for traditional fixed effects and FEIS estimates. Thus, only exact replications of published studies could tell, if the conclusions of these studies depend on the modelling of time-varying confounding. 


\section{Notes}

${ }^{27}$ Exact fieldwork times are: Wave 1: Nov/Dec 2010; Wave 2: May 2011; Wave 3: Nov. 2011; Wave 4: May 2012; Wave 5: May-Oct 2013; Wave 6: May 2014.

${ }^{28}$ This measure is only used for robustness reasons, as it captures individuals' labour market situation several months after they participate in the politics module. Nevertheless, it is used, since there are inexplicable discrepancies between people who are unemployed according to both measures, even when one compares their info in the same month.

${ }^{29}$ Replication materials and information about data access can be found at OSF:

https://osf .io/zmnkq/?view_only=d64ec122febe41a7a5edf cf9ae421c06

(link anonymized for peer-review)

${ }^{30}$ Their study reports fixed effects estimates for the effect of unemployment on left-right self-placement between -0.13 and -0.2 depending on the exact model specification (Wiertz and Rodon, 2021).

${ }^{31}$ To be precise, that means that the previously weak and non-robust evidence for right-shifts for right-leaning people does not appear here. Yet given the weakness and non-robustness of these effects, it is far from clear, whether this results from the lower salience of migration issues in the analysis period used by this additional analysis. Furthermore, the analyses during this "high salience" period of unemployment does show right-shifts for those in the center, that miss all conventional levels of statistical significance, yet do so very narrowly. Thus, there is neither new evidence for left-shifts nor "less" evidence for right-shifts during this period of high salience of unemployment. 


\section{References}

Anduiza, Eva, Carolina Galais, Maria J. Hierro, Jordi Muñoz, Sergi Pardos, Guillem Rico, and Roser Rifá (2015). Political Attitudes Panel Dataset (version 6 waves, December 2015). Tech. rep.

Ares, Macarena (2020). "Changing classes, changing preferences: how social class mobility affects economic preferences”. In: West European Politics 43 (6), 1211-1237.

Bauer, Paul C., Pablo Barbera, Kathrin Ackermann, and Aaron Venetz (2017). "Is the LeftRight Scale a Valid Measure of Ideology? Individual-Level Variation in Associations with "Left" and "Right" and Left-Right Self-Placement". In: Political Behavior 39, 553-583.

Billiet, Jaak, Bart Meuleman, and Hans De Witte (2014). "The relationship between ethnic threat and economic insecurity in times of economic crisis: Analysis of European Social Survey Data." In: Migration Studies 2 (2), 135-161.

Brüderl, Josef and Volker Ludwig (2015). "Fixed-effects panel regression". In: Regression Analysis and Causal Inference. Ed. by Henning Best and Christof Wolf. Sage, 327-357.

Campbell, Angus, Philip E. Converse, Warren E. Miller, and Donald E. Stokes (1960). The American Voter. Chicago and London: University of Chicago Press.

Carsey, Thomas M. and Geoffrey C. Layman (2006). "Changing Sides or Changing Minds? Party Identification and Policy Preferences in the American Electorate". In: American Journal of Political Science 50 (2), 464-477.

Converse, P. E. (1964). "The nature of belief systems in mass publics". In: Ideology and its discontents. Ed. by David E. Apter. The Free Press of Glencoe, 206-226.

Corbetta, Piergiorgio and Pasquale Colloca (2013). "Job Precariousness and Political Orientations: The Case of Italy". In: South European Society and Politics 18 (3), 333-354.

Cusack, Thomas, Torben Iversen, and Philipp Rehm (2006). "Risks at Work: The Demand and Supply Sides of Government Redistribution". In: Oxford Review of Economic Policy 22 (3), 365-389.

Dancey, Logan and Paul Goren (2010). "Party Identification, Issue Attitudes, and the Dynamics of Political Debate". In: American Journal of Political Science 54 (3), 686-699.

de Vries, Catherin, Armen Hakhverdian, and Bram Lancee (2013). "The Dynamics of Voters' Left/Right Identification: The Role of Economic and Cultural Attitudes". In: Political Science Research and Methods 1 (2), 223-238.

Dinas, Elias (2013). "Opening "Openness to Change". Political Events and the Increased Sensitivity of Young Adults". In: Political Research Quarterly 66 (4), 868-882.

Donnelly, Michael J. (2021). "Material Interests, Identity and Linked Fate in Three Countries." In: British Journal of Political Science 51, 1119-1137.

Emmenegger, Patrick, Paul Marx, and Dominik Schraff (2015). "Labour market disadvantage, political orientations and voting: how adverse labour market experiences translate into electoral behaviour". In: Socio-Economic Review 13 (2), 189-213.

- (2017). "Off to a Bad Start: Unemployment and Political Interest during Early Adulthood". In: The Journal of Politics 79 (1), 315-328.

Gerber, Alan and Donald P. Green (1998). "Rational Learning and Partisan Attitudes". In: American Journal of Political Science 42 (3), 794-818.

Gerber, Alan S., Gregory A. Huber, David Doherty, Conor M. Dowling, and Shang E. Ha (2010). "Personality and Political Attitudes: Relationship across Issue Domains and Political Context”. In: American Political Science Review 104 (1), 111-133. 
Gidron, Noam and Jonathan J. B. Mijs (2019). "Do Changes in Material Circumstances Drive Support for Populist Radical Parties? Panel Data Evidence from the Netherlands during the Great Recession, 2007-2015”. In: European Sociological Review 35 (5), 637-650.

Giesselmann, Marco and Alexander W. Schmidt-Catran (2020). "Interactions in Fixed Effects Regression Models". In: Sociological Methods \& Research (Online First), 0049124120914934. Gnambs, Timo (2017). "Human Capital and Reemployment Success: The Role of Cognitive Abilities and Personality". In: Journal of Intelligence 5 (1).

Goren, Paul (2013). On Voter Competence. Oxford University Press.

Hainmueller, Jens, Michael J. Hiscox, and Yotam Margalit (2015). "Do concerns about labor market competition shape attitudes toward immigration? New evidence". In: Journal of International Economics 97, 193-207.

Highton, Benjamin and Cindy D. Kam (2011). "The Long-Term Dynamics of Partisanship and Issue Orientations". In: The Journal of Politics 73 (1), 202-215.

Imai, Kosuke and In Song Kim (2019). "When Should We Use Unit Fixed Effects Regression Models for Causal Inference with Longitudinal Data?" In: American Journal of Political Science 63 (2), 467-490.

Kiley, Kevin and Stephen Vaisey (2020). "Measuring Stability and Change in Personal Culture Using Panel Data". In: American Sociological Review 85 (3), 477-506.

Knutsen, Oddbjørn (1997). "The Partisan and the Value-based Component of Left-Right Selfplacement: A Comparative Study". In: International Political Science Review 18 (2), 191235.

Kroneberg, Clemens, Meir Yaish, and Volker Stock'e (2010). "Norms and Rationality in Electoral Participation and in the Rescue of Jews in WWII: An Application of the Model of Frame Selection". In: Rationality and Society 22 (1), 3-36.

Krosnick, Jon A. and Duane F. Alwin (1989). "Aging and Susceptibility to Attitude Change". In: Journal of Personality and Social Psychology 57 (3), 416-425.

Kurer, Thomas (2020). "The Declining Middle: Occupational Change, Social Status, and the Populist Right”. In: Comparative Political Studies 53 (10-11), 1798-1835.

Lachat, Romain (2018). "Which way from left to right? On the relation between voters' issue preferences and left-right orientation in West European democracies." In: International Political Science Review 39 (4), 419-435.

Lancee, Bram and Sergi Pardos-Prado (2013). "Group Conflict Theory in a Longitudinal Perspective: Anaylzing the Dynamic Side of Ethnic Competition”. In: International Migration Review 47 (1), 106-131.

Lewis-Beck, Michael S. and Mary Stegmaier (2000). "Economic Determinants of Electoral Outcomes". In: Annual Review of Political Science 3 (1), 183-219.

Ludwig, Volker (2019). XTFEIS: Stata module to estimate linear Fixed-Effects model with Individual-specific Slopes (FEIS).

Ludwig, Volker and Josef Brüderl (2018). "Is There a Male Marital Wage Premium? New Evidence from the United States”. In: American Sociological Review 83 (4), 744-770.

Margalit, Yotam (2013). "Explaining Social Policy Preferences: Evidence from the Great Recession”. In: American Political Science Review 107 (1), 80-103.

Martén, Linna (2019). "Demand for Redistribution: Individuals' Responses to Economic Setbacks". In: The Scandinavian Journal of Economics 121 (1), 225-242.

Marx, Paul and Georg Picot (2013). "The party preferences of atypical workers in Germany". In: Journal of European Social Policy 23 (2), 164-178. 
Mehlkop, Guido and Robert Neumann (2012). "Explaining preferences for redistribution: A unified framework to account for institutional approaches and economic self-interest for the case of monetary transfers for families and children". In: European Journal of Political Research 51 (3), 350-381.

Naumann, Elias, Christopher Buss, and Johannes Bähr (2016). "How Unemployment Experience Affects Support for the Welfare State: A Real Panel Approach". In: European Sociological Review 32 (1), 81-92.

O’Grady, Tom (2019). "How do Economic Circumstances Determine Preferences? Evidence from Long-run Panel Data". In: British Journal of Political Science 49 (4), 1381-1406.

Owens, Lindsay A. and David S. Pedulla (2014). "Material Welfare and Changing Political Preferences: The Case of Support for Redistributive Social Policies”. In: Social Forces 92 (3), 1087-1113.

Pecoraro, Marco and Didier Ruedin (2016). "A Foreigner Who Does Not Steal My Job: The Role of Unemployment Risk and Values in Attitudes toward Equal Opportunities". In: International Migration Review 50 (3), 628-666.

Rehm, Philipp (2016). Risk Inequality and Welfare States. Social Policy Preferences, Development, and Dynamics. New York: Cambridge University Press.

Rekker, Roderik, Loes Keijsers, Susan Branje, and Wim Meeus (2017). "The dynamics of political identity and issue attitudes in adolescence and young adulthood". In: Electoral Studies 46, 101-111.

Rovny, Allison E. and Jan Rovny (2017). "Outsiders at the ballot box: operationalizations and political consequences of the insider-outsider dualism”. In: Socio-Economic Review 15 (1), 161-185.

Rüttenauer, Tobias and Volker Ludwig (2020). "Fixed Effects Individual Slopes: Accounting and Testing for Heterogeneous Effects in Panel Data or Other Multilevel Models". In: Sociological Methods \& Research (Online First).

Scherpenzeel, A.C. and M. Das (2010). ""True" Longitudinal and Probability-Based Internet Panels: Evidence From the Netherlands". In: Social and Behavioral Research and the Internet: Advances in Applied Methods and Research Strategies. Ed. by M. Das, P. Ester, and L. Kaczmirek. Taylor \& Francis, 77-104.

Schwander, Hanna and Silja Häusermann (2013). "Who is in and who is out? A risk-based conceptualization of insiders and outsiders". In: Journal of European Social Policy 23 (3), 248-269.

Sears, David O. and Carolyn L. Funk (1999). "Evidence of the Long-Term Persistence of Adults' Political Predispositions". In: The Journal of Politics 61 (1), 1-28.

Valentino, Nicholas A., Stuart N. Soroka, Shanto Iyengar, Toril Aalberg, Raymond Duch, Marta Fraile, Kyu S. Hahn, Kasper M. Hansen, Allison Harell, Marc Helbling, Simon D. Jackman, and Tetsuro Kobayashi (2017). "Economic and Cultural Drivers of Immigrant Support Worldwide". In: British Journal of Political Science 49 (4), 1201-1226.

Viinikainen, Jutta and Katja Kokko (2012). "Personality traits and unemployment: Evidence from longitudinal data”. In: Journal of Economic Psychology 33 (6), 1204 -1222.

Visser, Mark, Marcel Lubbers, Gerbert Kraaykamp, and Eva Jaspers (2014). "Support for radical left ideologies in Europe". In: European Journal of Political Research 53 (3), 541-558.

Voorpostel, M., R Tillmann, F. Lebert, U. Kuhn, O. Lipps, V.-A. Ryser, F. Schmid, E. Antal, G.-A. Monsch, and B. Wernli (2015). Swiss Household Panel Userguide (1999-2014), Wave 16, December 2015. Lausanne. 
Weber, Wiebke and Willem E. Saris (2014). "The relationship between issues and an individual's left-right orientation". In: Acta Politica 50 (2), 193-213.

Wehl, Nadja (2019). "The (ir)relevance of unemployment for labour market policy attitudes and welfare state attitudes". In: European Journal of Political Research 58 (1), 141-162.

- (2020). "Going beyond values versus self-interest: whose attitudes change after employment transitions?" In: Political Research Exchange 2 (1), 1-23.

Wiertz, Dingeman and Toni Rodon (2021). "Frozen or malleable? Political ideology in the face of job loss and unemployment”. In: Socio-Economic Review 19 (1), 307-331. 



\section{A Appendix for Article 1}

Supporting Information for:

Wehl, Nadja (2019): The (ir)relevance of unemployment for labour market policy attitudes and welfare state attitudes. European Journal of Political Research

A similar version of this supporting info can be found at the journal homepage:

https://doi.org/10.1111/1475-6765.12274

\section{Contents}

A.1 Appendix A: Variables \& Recodings . . . . . . . . . . . . . . . . 138

A.2 Appendix B: Additional Figures . . . . . . . . . . . . . . . . 142

\section{Figures}

A.1 Maximum EB Weights . . . . . . . . . . . . . . . 143

A.2 Balance . . . . . . . . . . . . . . . . . . 144

A.3 Worries . . . . . . . . . . . . . . . . 145

A.4 Sensitivity Check: Results with trimmed EB weights . . . . . . . . . . 146

A.5 Sensitivity Check: Results with Confounders in Outcome Regression with EB Weights . . . . . . . . . . . . . . . . . 147

A.6 Sensitivity Check: Controlling Selection Bias with Propensity Score Adjustment . . . . . . . . . . . . . . . . . . . 148

A.7 Sensitivity Check: Controlling Selection Bias with Confounders in Outcome Regression . . . . . . . . . . . . . . . . . . 149

A.8 Sensitivity Check: Results without controlling for previous unemployment experience . . . . . . . . . . . . . . 150

A.9 Sensitivity Check: 2012 Replication _ . . . . . . . . . . . . . . . 151

A.10 Unemployment Rate . . . . . . . . . . . . . . . . . . . . . 152 


\section{A.1 Appendix A: Variables \& Recodings}

\section{DEPENDENT VARIABLES (OUTCOMES): No recodings}

- labour market policy attitudes: (11-point scales)

"People have different views on what the responsibilities of governments should or should not be. For each of the tasks I read out please tell me on a score of 0-10 how much responsibility you think governments should have. 0 means it should not be governments' responsibility at all and 10 means it should be entirely governments' responsibility. "

- active LMP attitude:

"ensure a job for everyone who wants one?"

- passive LMP attitude

" ensure a reasonable standard of living for the unemployed"

- egalitarianism items (5-point scales)

- "Using this card, please say to what extent you agree or disagree with each of the following statements."

"The government should take measures to reduce differences in income levels."

- "Now some questions about the way society works. Using this card, please say how much you agree or disagree with each of the following statements. For a society to be fair, differences in people's standard of living should be small."

INDEPENDENT VARIABLE (TREATMENT): Recoding into binary unemployment indicator

"And which of these descriptions best describes your situation (in the last seven days)? Please select only one."

1. "in paid work (or away temporarily) (employee, self-employed, working for your family business)" $\rightarrow$ recoded as employed

2. "in education,(not paid for by employer) even if on vacation" $\rightarrow$ excluded from analyses

3. "unemployed and actively looking for a job" $\rightarrow$ recoded as unemployed

4. "unemployed wanting a job but not actively looking for a job" $\rightarrow$ recoded as unemployed

5. "permanently sick or disabled" $\rightarrow$ excluded from analyses

6. "retired" $\rightarrow$ excluded from analyses

7. "in community or military service" $\rightarrow$ excluded from analyses

8. "doing housework, looking after children or other persons" $\rightarrow$ excluded from analyses

9. "(other)" $\rightarrow$ excluded from analyses

\section{CONTROL VARIABLES (CONFOUNDERS)}


- Gender (no recoding)

- Age (no recoding)

- formal education (ISCED): recoded into 3 categories / dummies

"What is the highest level of education you have achieved? Please use this card."

0 . "Not completed primary education" $\rightarrow$ recoded as low education

1. "Primary or first stage of basic" $\rightarrow$ recoded as low education

2. "Lower secondary or second stage of basic" $\rightarrow$ recoded as low education

3. "Upper secondary" $\rightarrow$ recoded as middle level education

4. "Post secondary, non tertiary" $\rightarrow$ recoded as middle level education

5. "First stage of tertiary" $\rightarrow$ recoded as high education

6. "Second stage of tertiary" $\rightarrow$ recoded as high education

- Field of Education: recoded into 8 categories / dummies (following mostly the coding from Reimer et al. (2008, p.238))

"In which one of these fields or subjects is your highest qualification?"

1. General or no specific field $\rightarrow$ recoded as Field 1

2. Art - fine or applied $\rightarrow$ recoded as Field 2

3. Humanities - languages, classics, history, theology, etc $\rightarrow$ recoded as Field 2

4. Technical \& engineering, including architecture and planning, industry, craft, building trades, etc $\rightarrow$ recoded as Field 3

5. Agriculture \& forestry $\rightarrow$ recoded as Field 4

6. Teacher training or education $\rightarrow$ recoded as Field 5

7. Science, mathematics, computing, etc $\rightarrow$ recoded as Field 3

8. Medical, health services, nursing, etc $\rightarrow$ recoded as Field 6

9. Economics, commerce, business administration, accountancy, etc $\rightarrow$ recoded as Field 7

10. Social \& behavioural studies, public administration, media, culture, sport and leisure studies, etc $\rightarrow$ recoded as Field 7

11. Law and legal services $\rightarrow$ recoded as Field 7

12. Personal care services - catering, domestic science, hairdressing, etc $\rightarrow$ recoded as Field 6

13. Public order and safety - police, army, fire services, etc $\rightarrow$ recoded as Field 8

14. Transport and telecommunications $\rightarrow$ recoded as Field 8

- immigrant background: Recoded into binary indicator

- "Where you born in [COUNTRY]?" $\rightarrow$ "no" recoded as immigrant background

- "Was your father born in [COUNTRY]?" $\rightarrow$ "no" recoded as immigrant background

- "Was your mother born in [COUNTRY]?" $\rightarrow$ "no" recoded as immigrant background 
- previous unemployment: No recoding

"Have you ever been unemployed and seeking work for a period of more than three months?"

1. Yes

2. No

- Temporary Contract: Recoded into binary indicator

"Do/did you have a work contract of..."

1. "unlimited duration" $\rightarrow$ recoded as permanent

2. "or, limited duration," $\rightarrow$ recoded as temporary

3. "or, do/did you have no contract?" $\rightarrow$ recoded as permanent

- Self-employment: Recoded into binary indicator

"In your main job are/were you..."

1. An employee $\rightarrow$ recoded as not self-employed

2. Self-employed $\rightarrow$ recoded as self-employed

3. Working for your own family's business $\rightarrow$ recoded as self-employed

- firm size: Recoded into three categories / dummies

"Including yourself, about how many people are/were employed at the place where you usually work/worked?"

1. under $10 \rightarrow$ recoded as small firm

2. 10 to $24 \rightarrow$ recoded as small firm

3. 25 to $99 \rightarrow$ recoded as medium sized firm

4. 100 to $499 \rightarrow$ recoded as big firm

5. or, 500 or more? $\rightarrow$ recoded as big firm

- supervisory position: No recoding

"In your main job, do/did you have any responsibility for supervising the work of other employees?"

1. Yes

2. No

- Occupational Group: ISCO88 codes recoded into dummies representing 1-digit ISCO groups

"What is/was the name or title of your main job? In your main job, what kind of work do/did you do most of the time? What training or qualifications are/were needed for the job?" 
- Parents formal education (ISCED): Recoded into three categories / dummies

"What is the highest level of education your father achieved?" "What is the highest level of education your mother achieved?"

1. Less than lower secondary education (ISCED 0-1) $\rightarrow$ recoded as low parents education if present for father or mother (and neither with higher educational level)

2. Lower secondary education completed (ISCED 2) $\rightarrow$ recoded as low parents education if present for father or mother (and neither with higher educational level)

3. Upper secondary education completed (ISCED 3) $\rightarrow$ recoded as middle parents education if present for father or mother (and neither with higher educational level)

4. Post-secondary non-tertiary education completed (ISCED 4) $\rightarrow$ recoded as middle parents education if present for father or mother

5. Tertiary education completed (ISCED 5-6) $\rightarrow$ recoded as high parents education if present for father or mother

- Father's employment status: Recoded into binary indicator

"When you were 14, did your father work as an employee, was he self-employed, or was he not working then?"

1. Employee $\rightarrow$ recoded as employed

2. Self-employed $\rightarrow$ recoded as not employed

3. Not working $\rightarrow$ recoded as not employed

4. Father dead/absent when respondent was $14 \rightarrow$ recoded as not employed

- Father's occupational group: Recoded into three categories / dummies according to ISCO skill levels (ILO, 2012, p. 12-14), while combining skill level three and four due to low case numbers

"What was the name or title of his main job?"

1. "Professional and technical occupations such as: doctor - teacher - engineer - artist - accountant" $\rightarrow$ recoded as high skill level

2. "Higher administrator occupations such as: banker - executive in big business high government official - union official" $\rightarrow$ recoded as high skill level

3. "Clerical occupations such as: secretary - clerk - office manager - book keeper" $\rightarrow$ recoded as high skill level

4. "Sales occupations such as: sales manager - shop owner - shop assistant - insurance agent" $\rightarrow$ recoded as medium skill level

5. "Service occupations such as: restaurant owner - police officer - waiter - caretaker - barber - armed forces" $\rightarrow$ recoded as medium skill level

6. "Skilled worker such as: foreman - motor mechanic - printer - tool and die maker - electrician" $\rightarrow$ recoded as medium skill level

7. "Semi-skilled worker such as: bricklayer - bus driver - cannery worker - carpenter - sheet metal worker - baker" $\rightarrow$ recoded as medium skill level

8. "Unskilled worker such as: labourer - porter - unskilled factory worker" $\rightarrow$ recoded as medium skill level 
9. "Farm worker such as: farmer - farm labourer- tractor driver- fisherman" $\rightarrow$ recoded as low skill level

\section{A.2 Appendix B: Additional Figures}




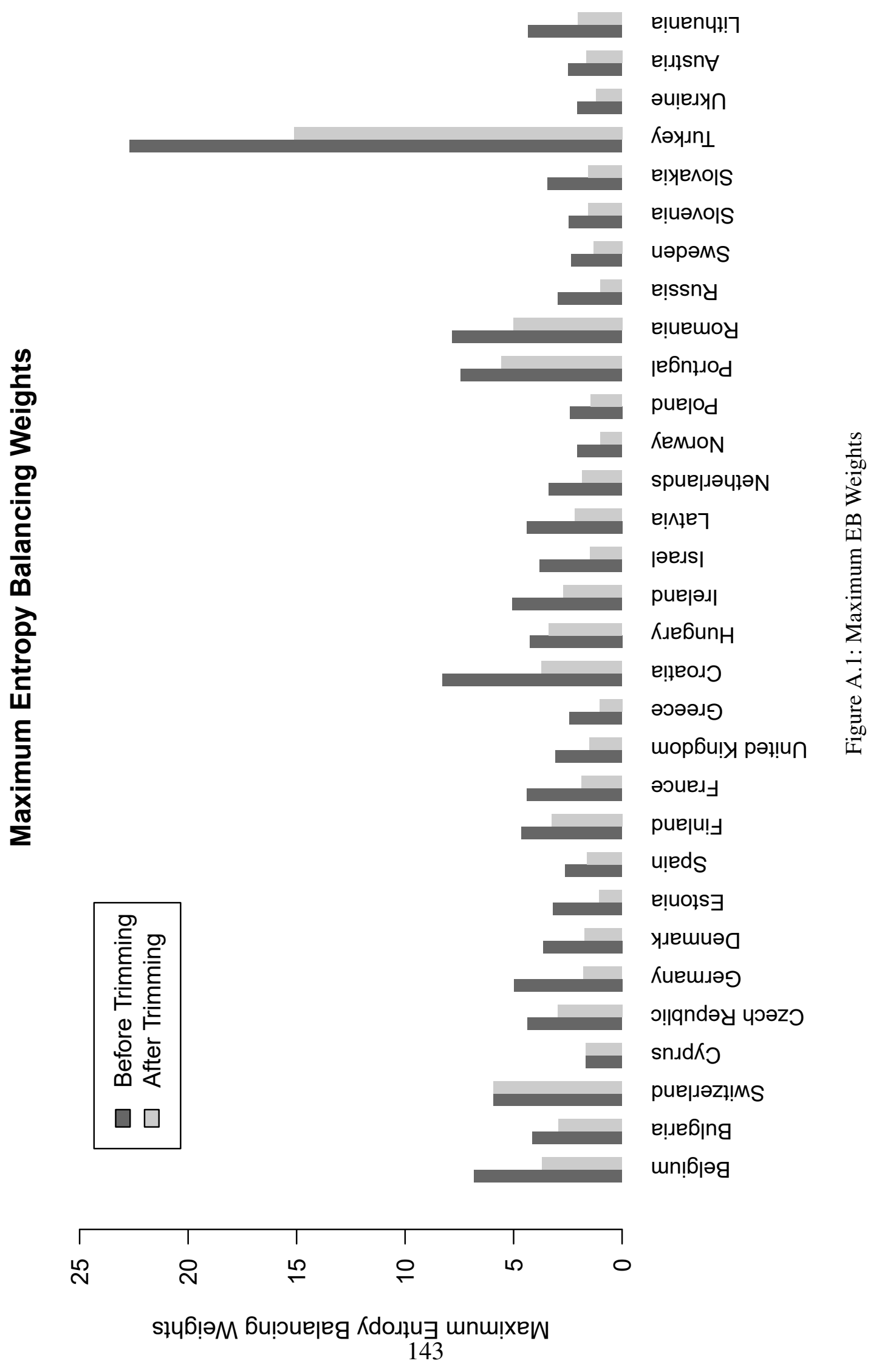




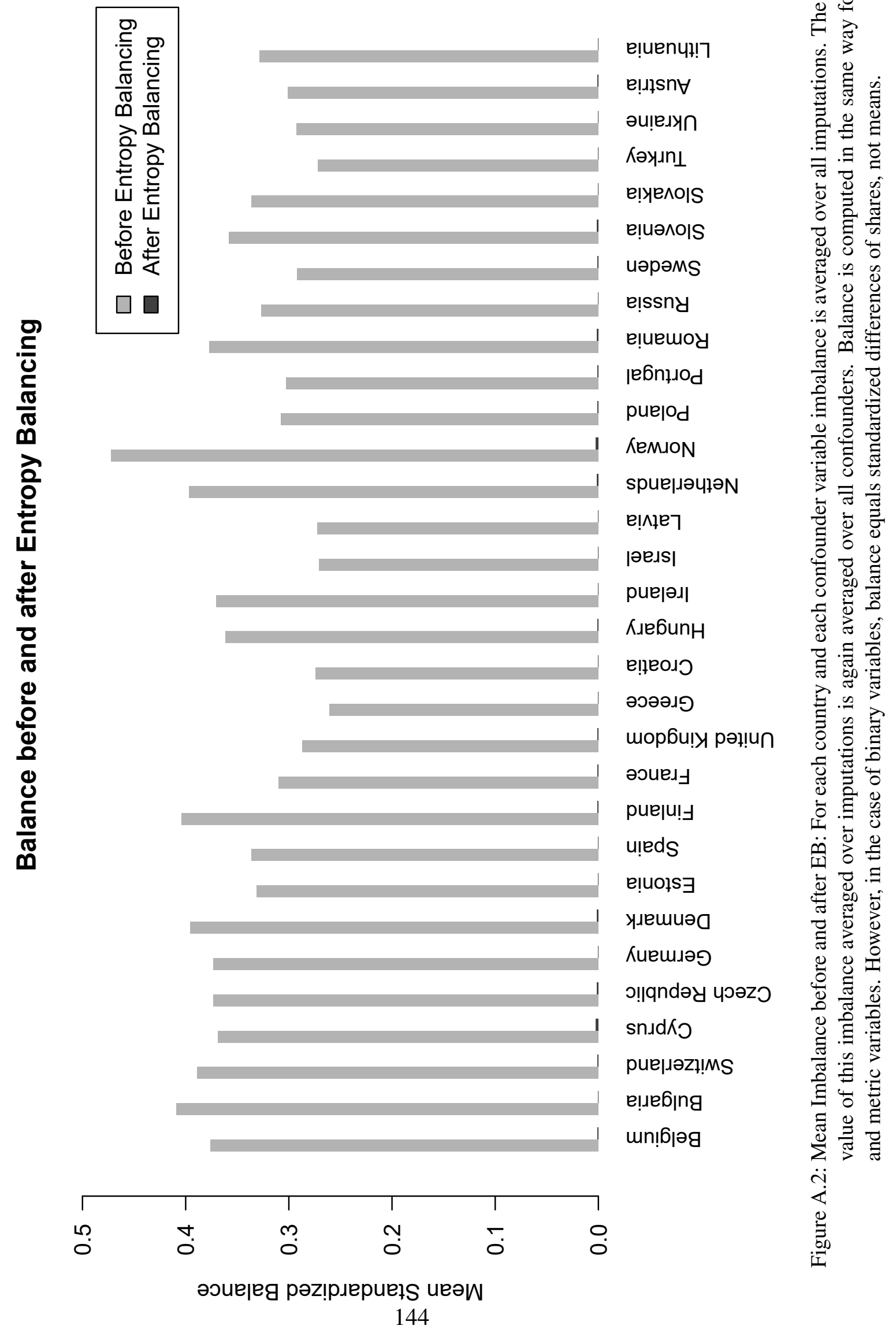



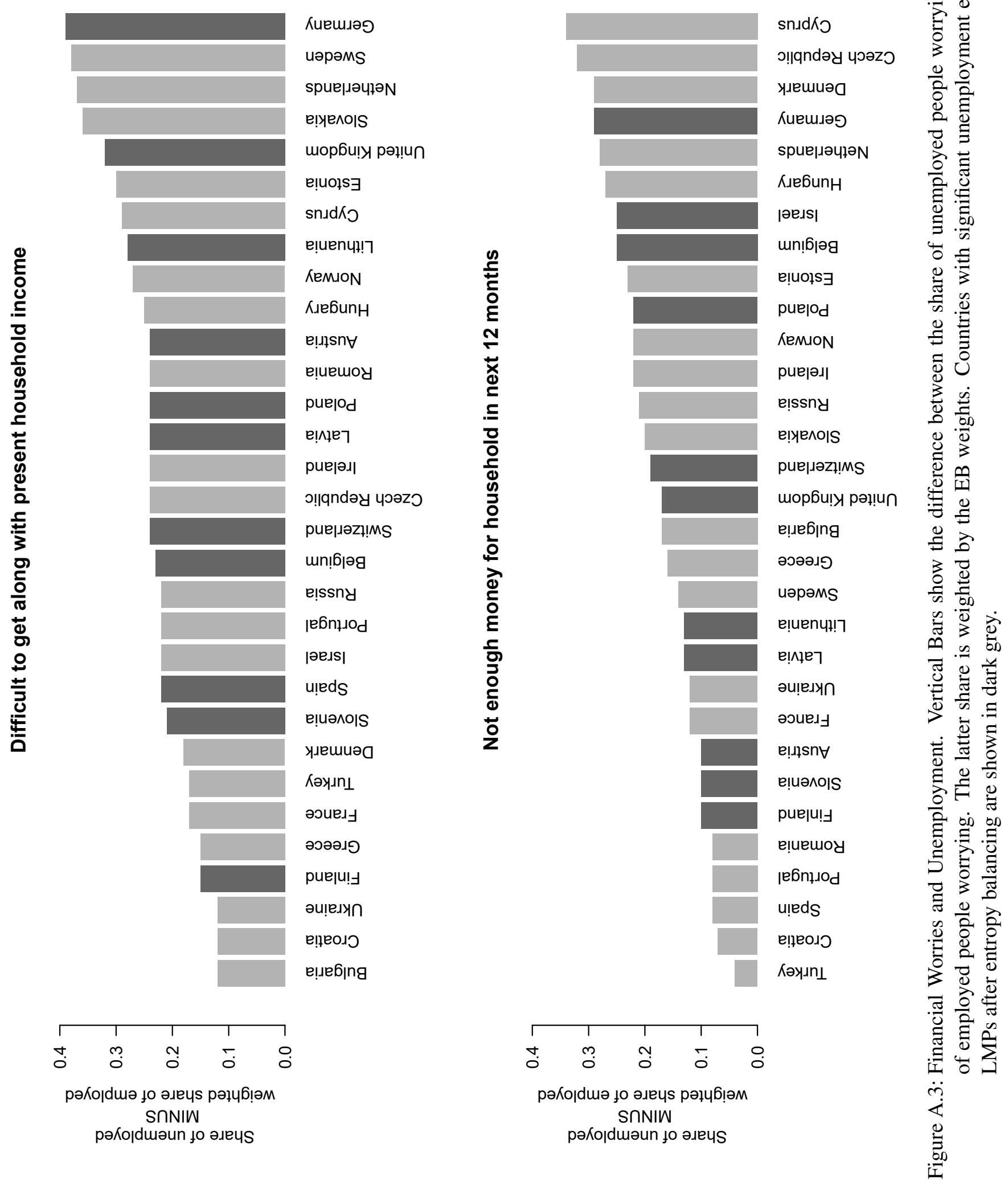


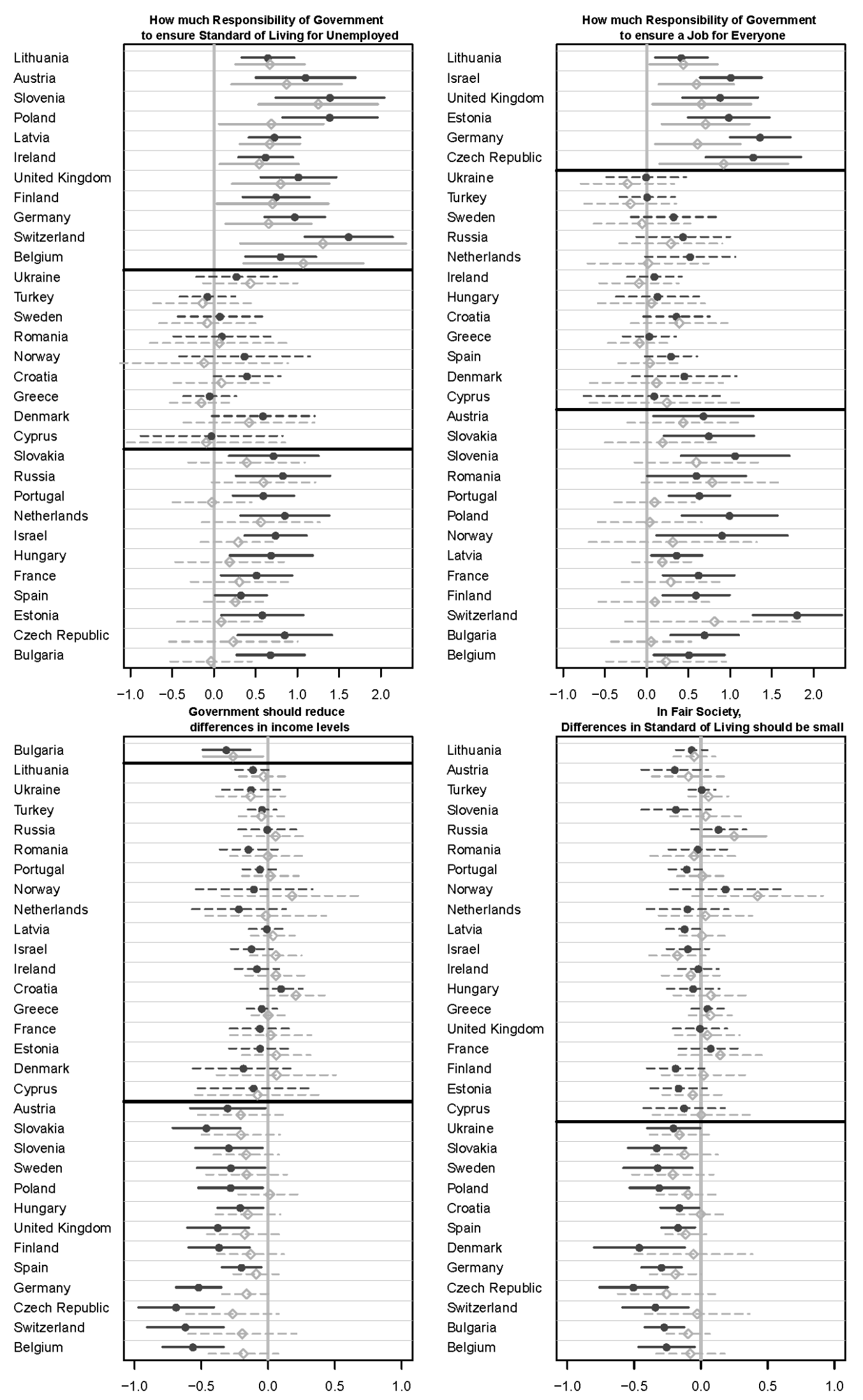

Figure A.4: Sensitivity Check: Results with trimmed EB weights: coefficient plots with $95 \%$ CIs for bivariate regression $(\bullet)$ and bivariate regresssion with trimmed EB weights and robust standard errors $(\diamond)$.

Results are grouped into three categories: countries with significant effects before and after EB, countries with insignificant effects before and after EB and countries with significant effects before but insignificant effects after EB. 


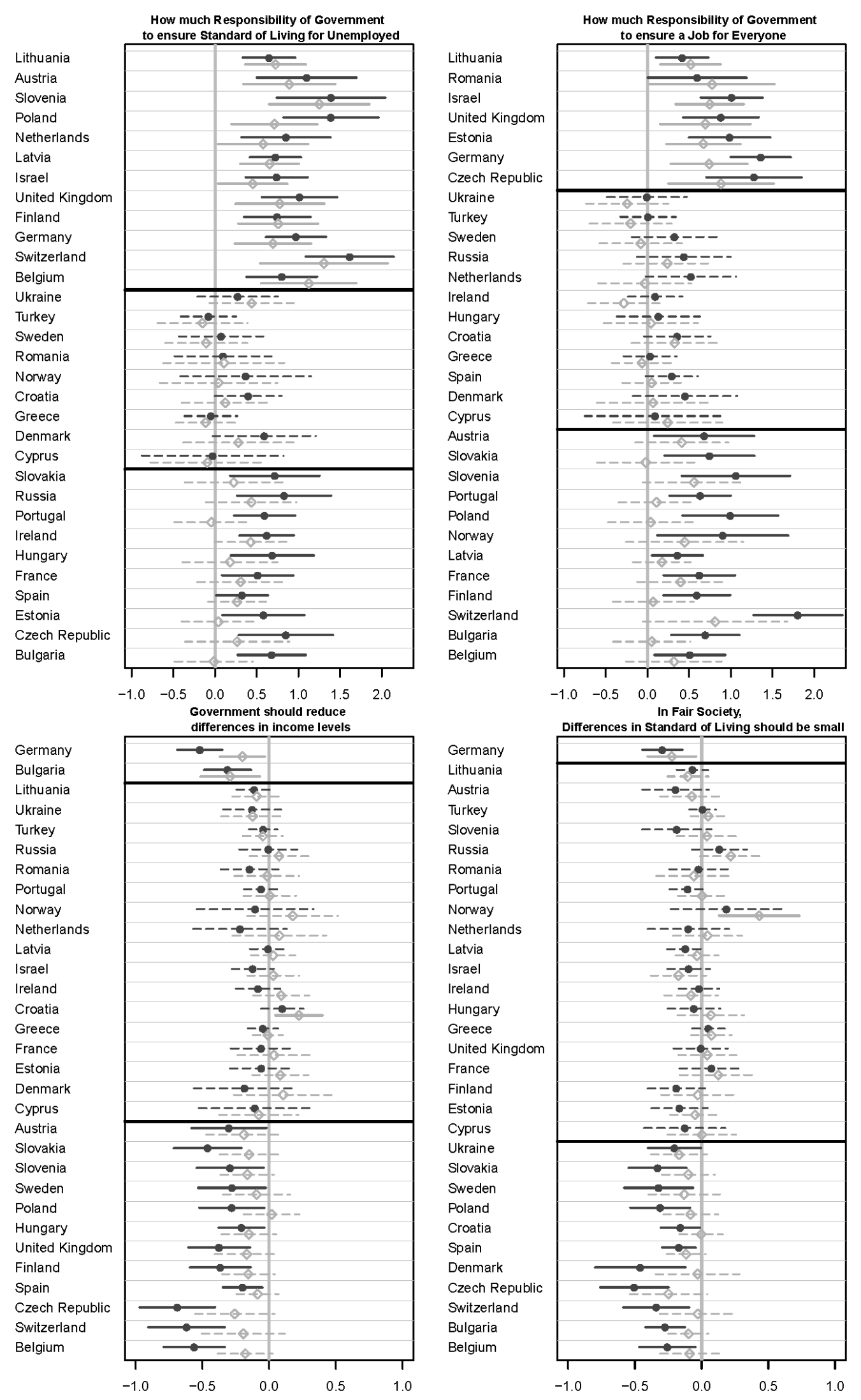

Figure A.5: Sensitivity Check: Results with Confounders in Outcome Regression with EB Weights: coefficient plots with $95 \%$ CIs for bivariate regression $(\bullet)$ and multivariate regresssion with EB weights, confounders, and robust standard errors $(\diamond)$.

Results are grouped into three categories: countries with significant effects before and after EB, countries with insignificant effects before and after EB and countries with significant effects before but insignificant effects after EB. 


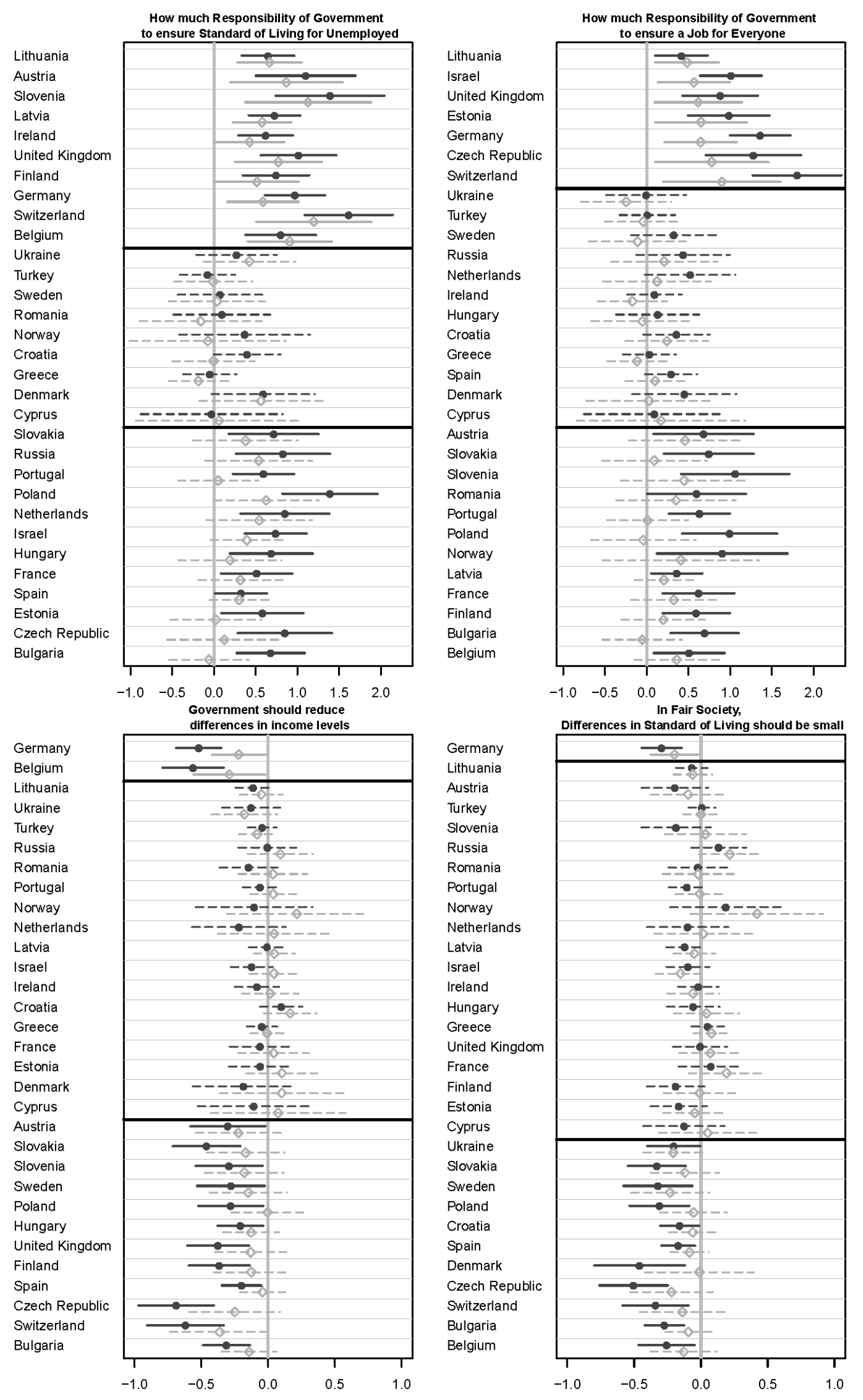

Figure A.6: Sensitivity Check: Controlling Selection Bias with Propensity Score Adjustment: coefficient plots with $95 \%$ CIs for bivariate regression $(\bullet)$ and multivariate regresssion with the Propensity Score as additional control $(\diamond)$.

Results are grouped into three categories: countries with significant effects before and after Propoensity Score Adjustment, countries with insignificant effects before and after Propensity Score Adjustment and countries with significant effects before but insignificant effects after Propensity Score Adjustment. 


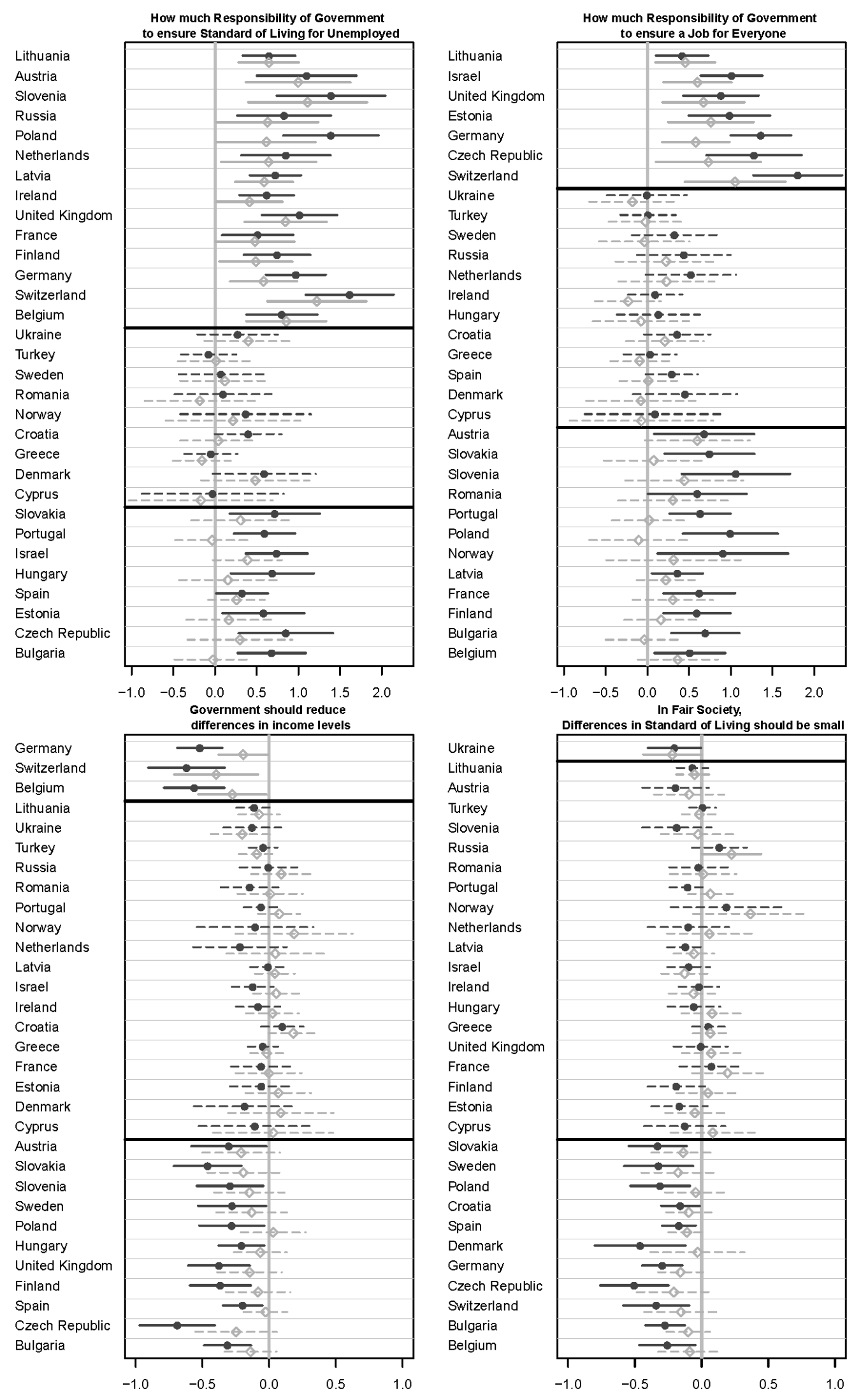

Figure A.7: Sensitivity Check: Controlling Selection Bias with Confounders in Outcome Regression: coefficient plots with $95 \%$ CIs for bivariate regression $(\bullet)$ and multivariate regresssion with Confounders as Controls $(\diamond)$.

Results are grouped into three categories: countries with significant effects before and after controlling for confounders, countries with insignificant effects before and after controlling for confounders and countries with significant effects before but insignificant effects after controlling for confounders. 


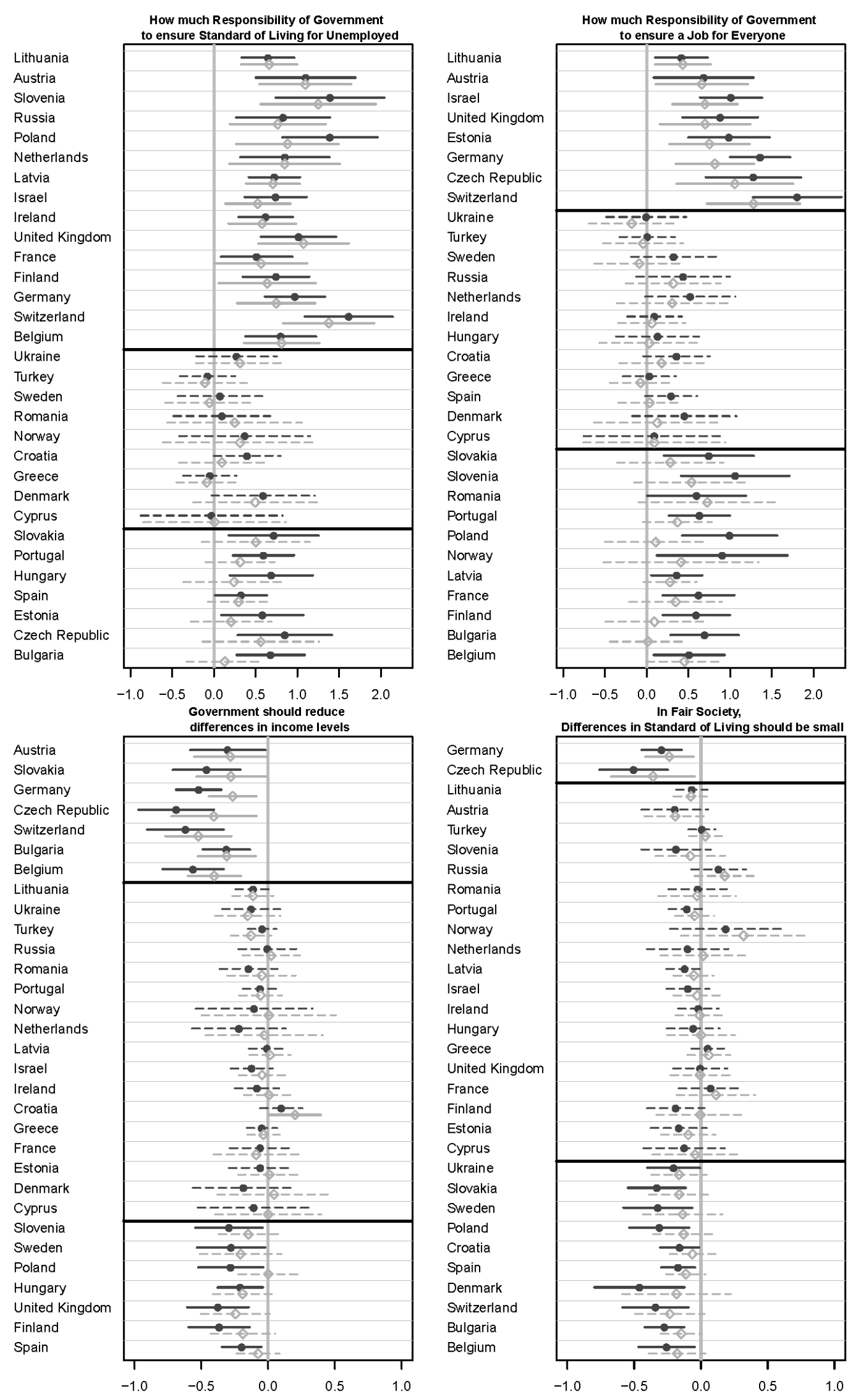

Figure A.8: Sensitivity Check: Results without controlling for previous unemployment experience: coefficient plots with $95 \%$ CIs for bivariate regression $(\bullet)$ and bivariate regresssion with EB weights and robust standard errors $(\diamond)$.

Results are grouped into three categories: countries with significant effects before and after EB, countries with insignificant effects before and after EB and countries with significant effects before but insignificant effects after EB. 


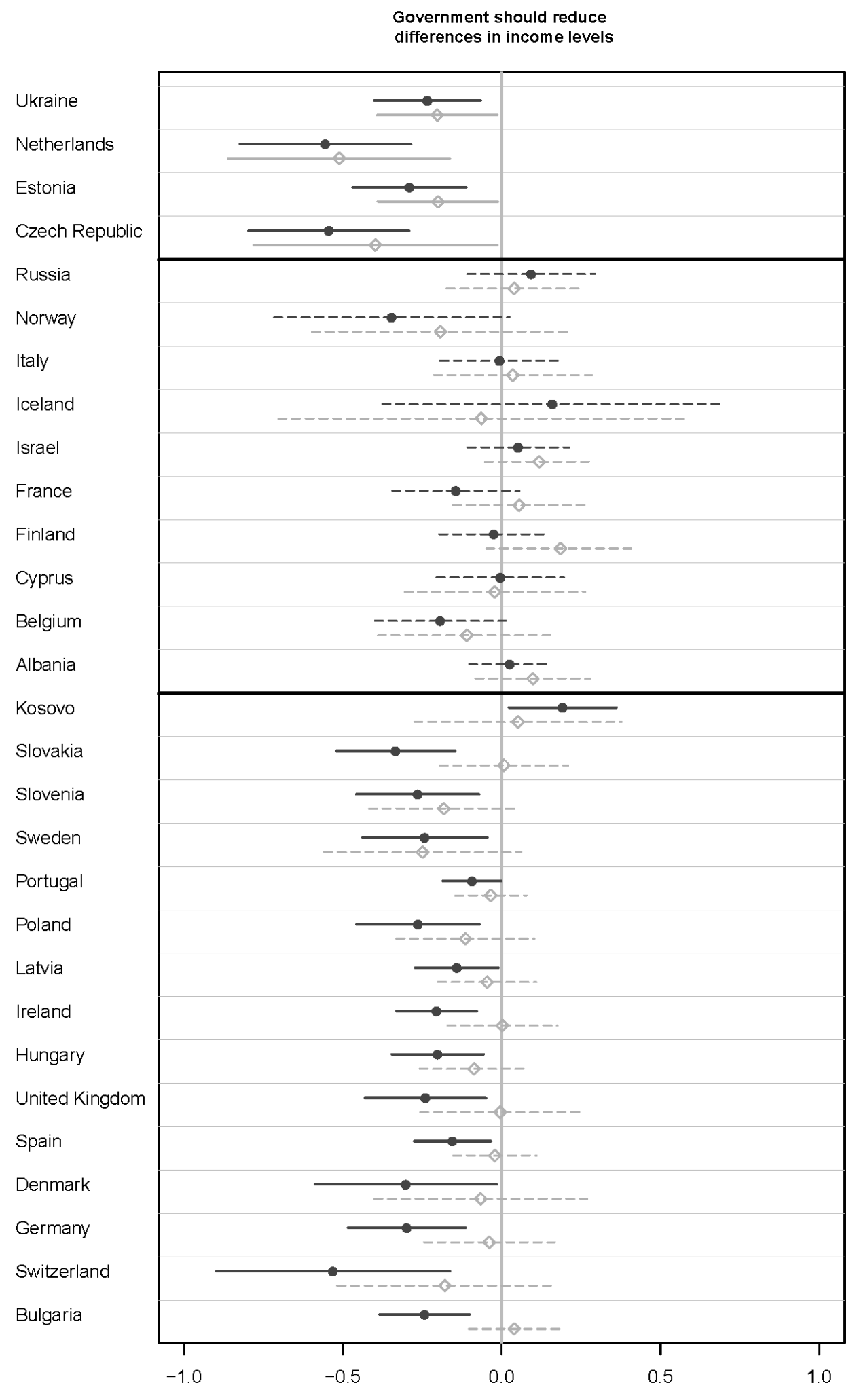

Figure A.9: Sensitivity Check: 2012 Replication: coefficient plots with 95\% CIs for bivariate regression $(\bullet)$ and bivariate regresssion with EB weights and robust standard errors $(\diamond)$.

Results are grouped into three categories: countries with significant effects before and after EB, countries with insignificant effects before and after EB and countries with significant effects before but insignificant effects after EB. 


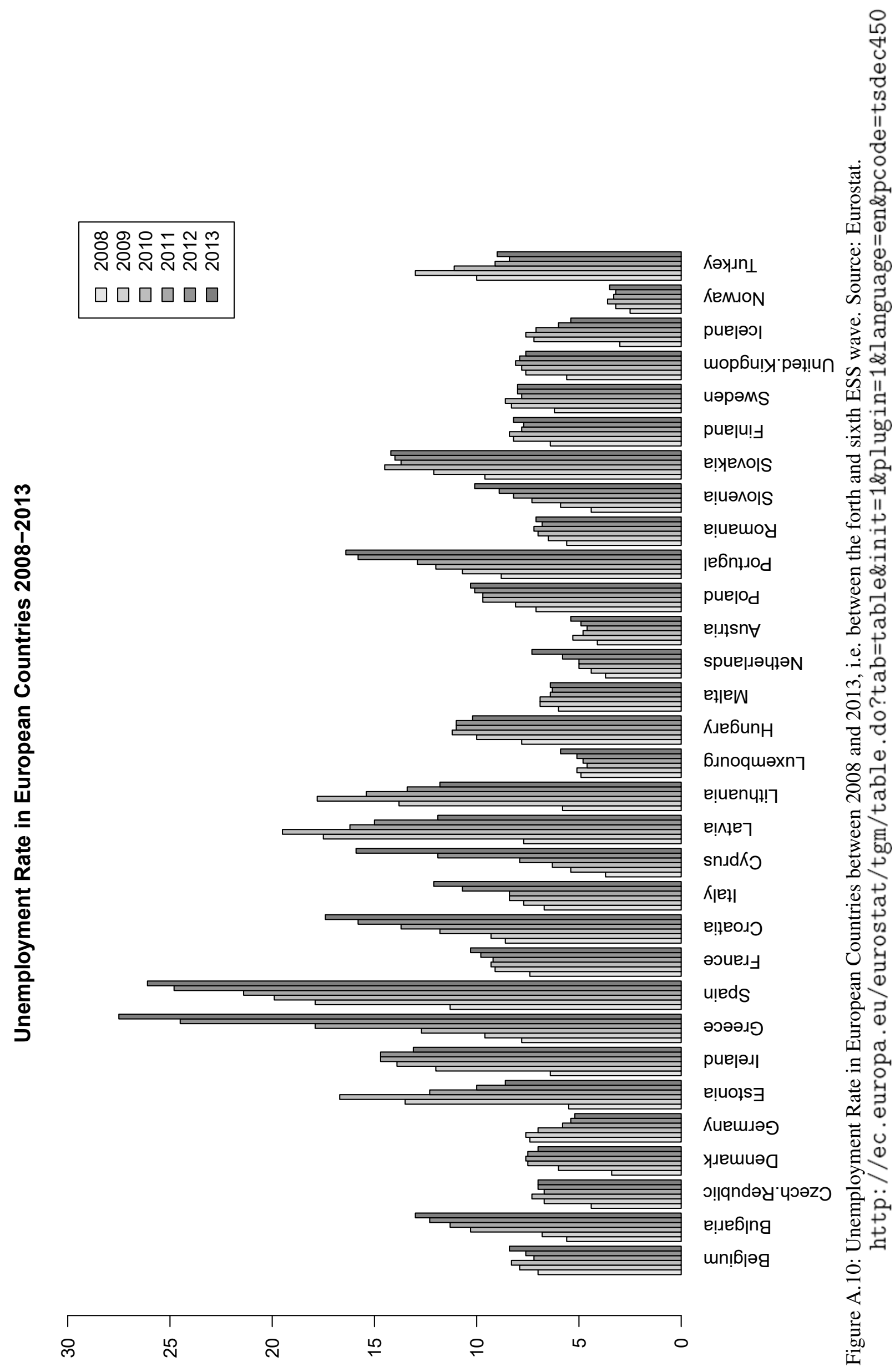

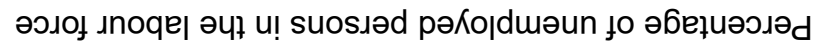




\section{Bibliography}

ILO, International Labour Office (2012). International Standard Classification of Occupations. ISCO-08. Geneva.

Reimer, David, Clemens Noelke, and Aleksander Kucel (2008). "Labor Market Effects of Field of Study in Comparative Perspective. An Analysis of 22 European Countries". In: International Journal of Comparative Sociology 49 (4-5), 233-256. 


\section{B Appendix for Article 2}

Appendix for Wehl, Nadja (2020)“Going beyond values versus self-interest. Whose attitudes change after employment transitions?"Political Research Exchange

A similar version of this supporting info can be found at the journal homepage:

https://doi.org/10.1080/2474736X.2020.1809473

The Stata-Code for the analyses can be found at OSF:

https://osf.io/mhu2n/?view_only=edea3038805d4c0087cf70644c8c200f

\section{Contents}

B.1 Tabular SOEP Results . . . . . . . . . . . . . . . . . . . . . 155

B.1.1 Main Effects . . . . . . . . . . . . . . . . . . . 155

B.1.2 Subgroup Analyses _ . . . . . . . . . . . . . 157

B.1.3 Interaction Models . . . . . . . . . . . . . . . . . . . . 164

B.2 SOEP robustness checks . . . . . . . . . . . . . . . . . . 181

B.3 Coding . . . . . . . . . . . . . . . . . . . 185 


\section{B.1 Tabular SOEP Results}

\section{B.1.1 Main Effects}

Tabular form of the main effects displayed in figure 3.4 of the article. 


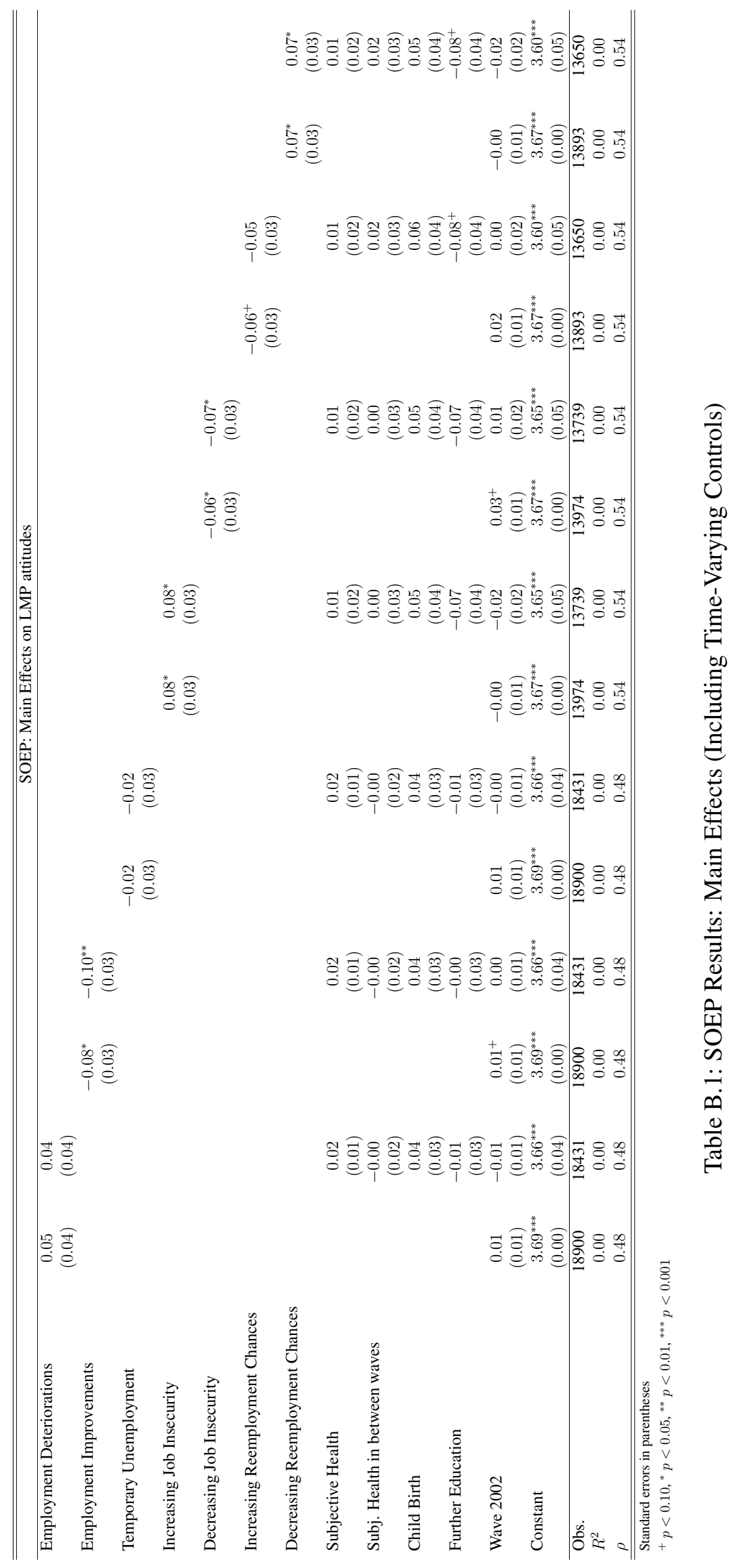




\section{B.1.2 Subgroup Analyses}

Tabular form of the subgroup analyses displayed in figures 3.5 and 3.6 in the article.

Additionally, tabular results for robustness checks including time-varying control variables are displayed. 


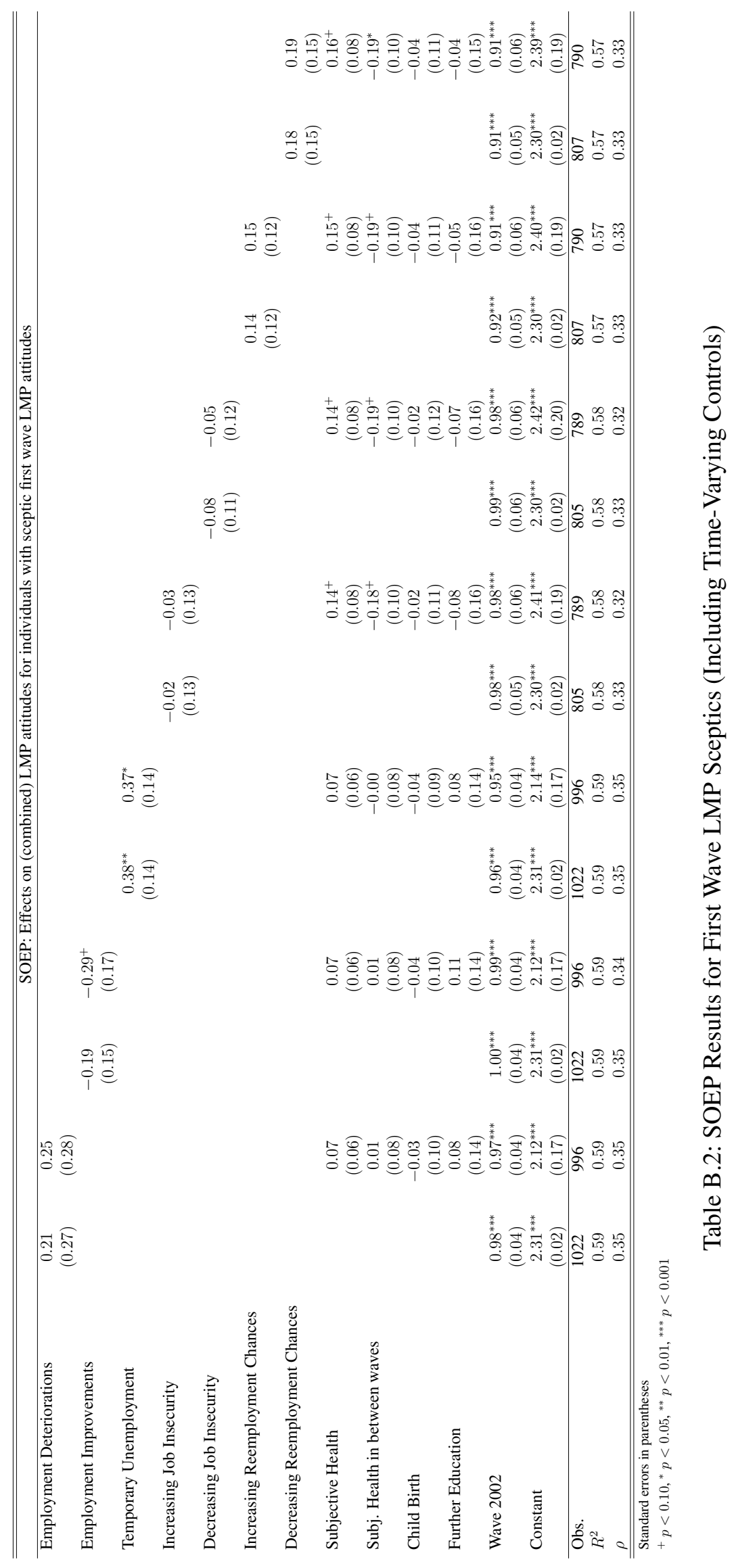




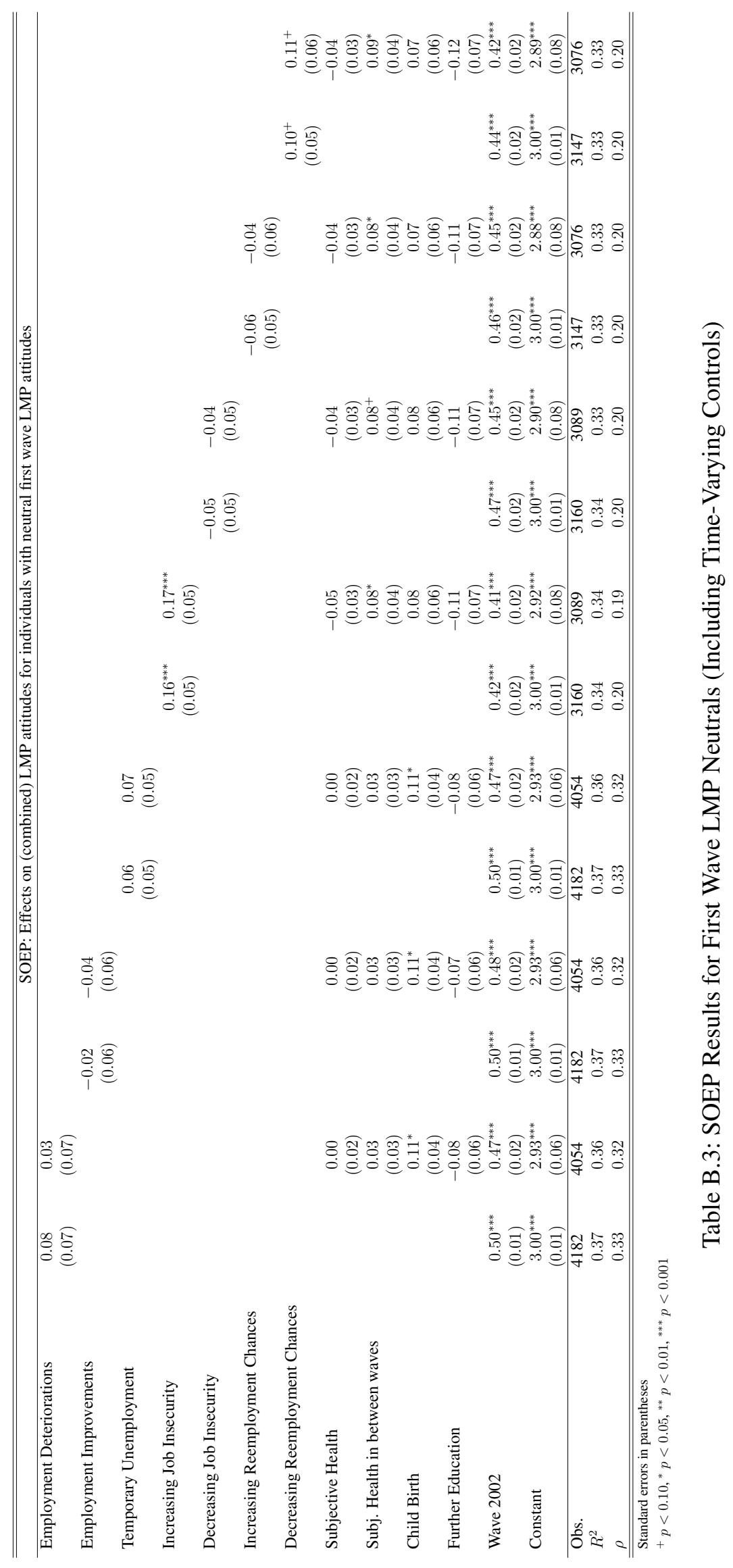




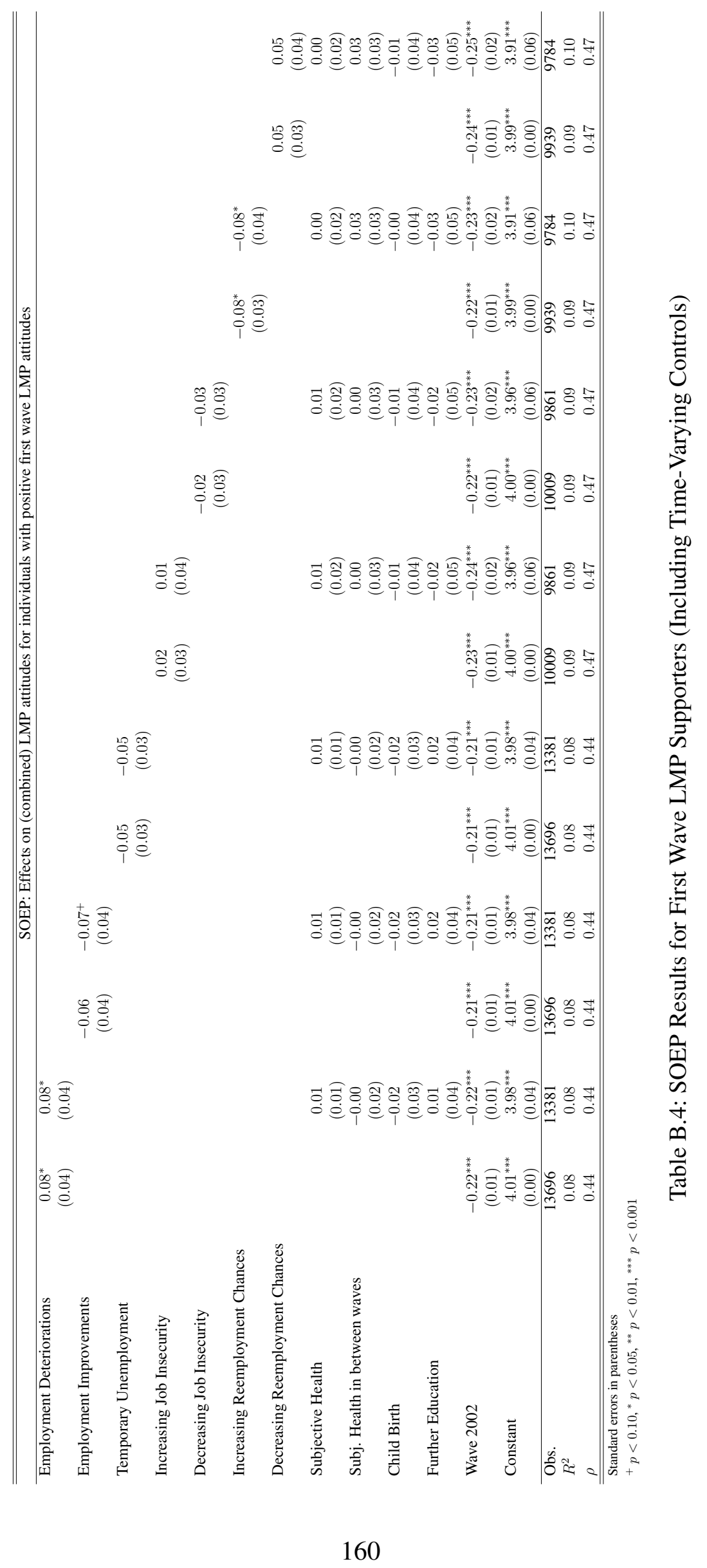




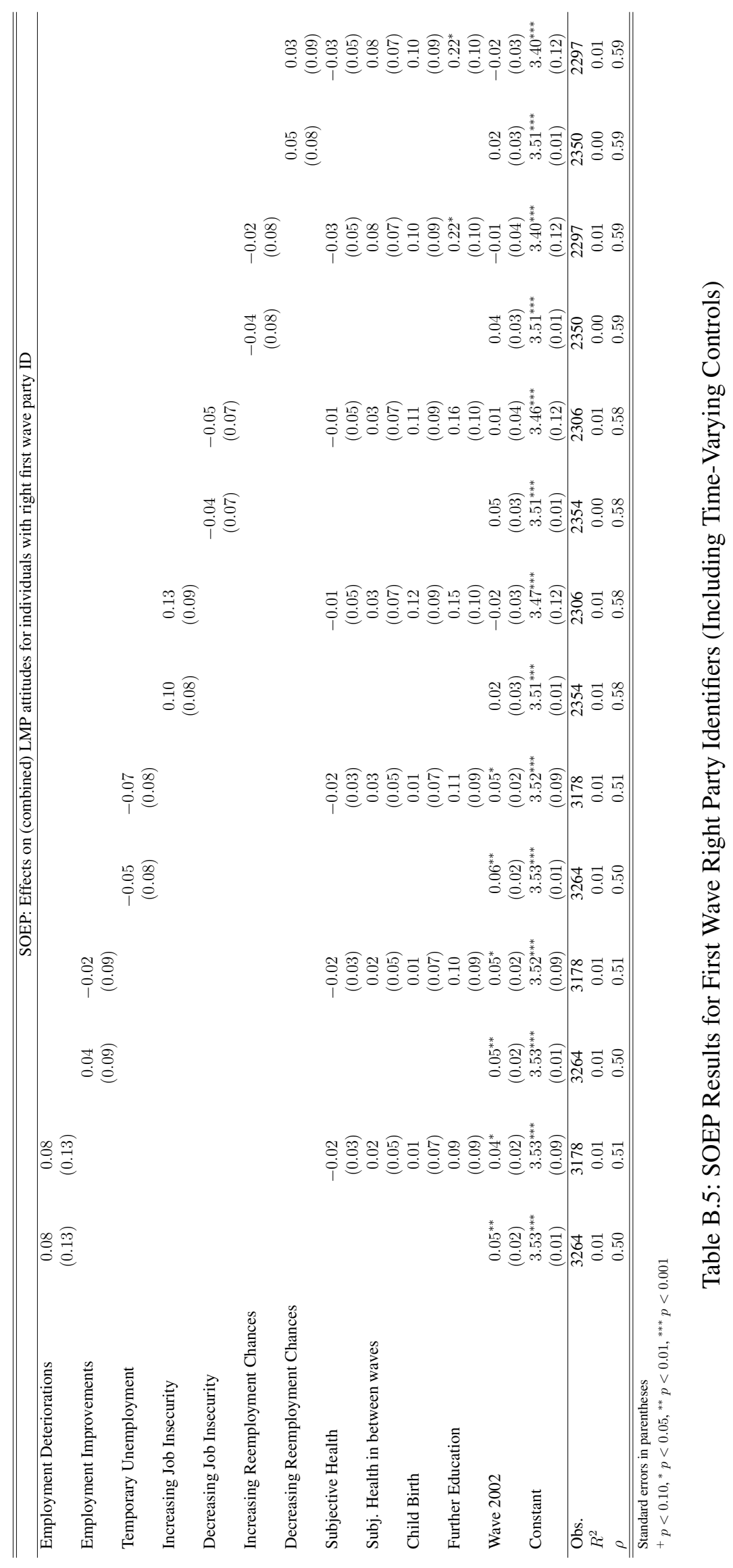




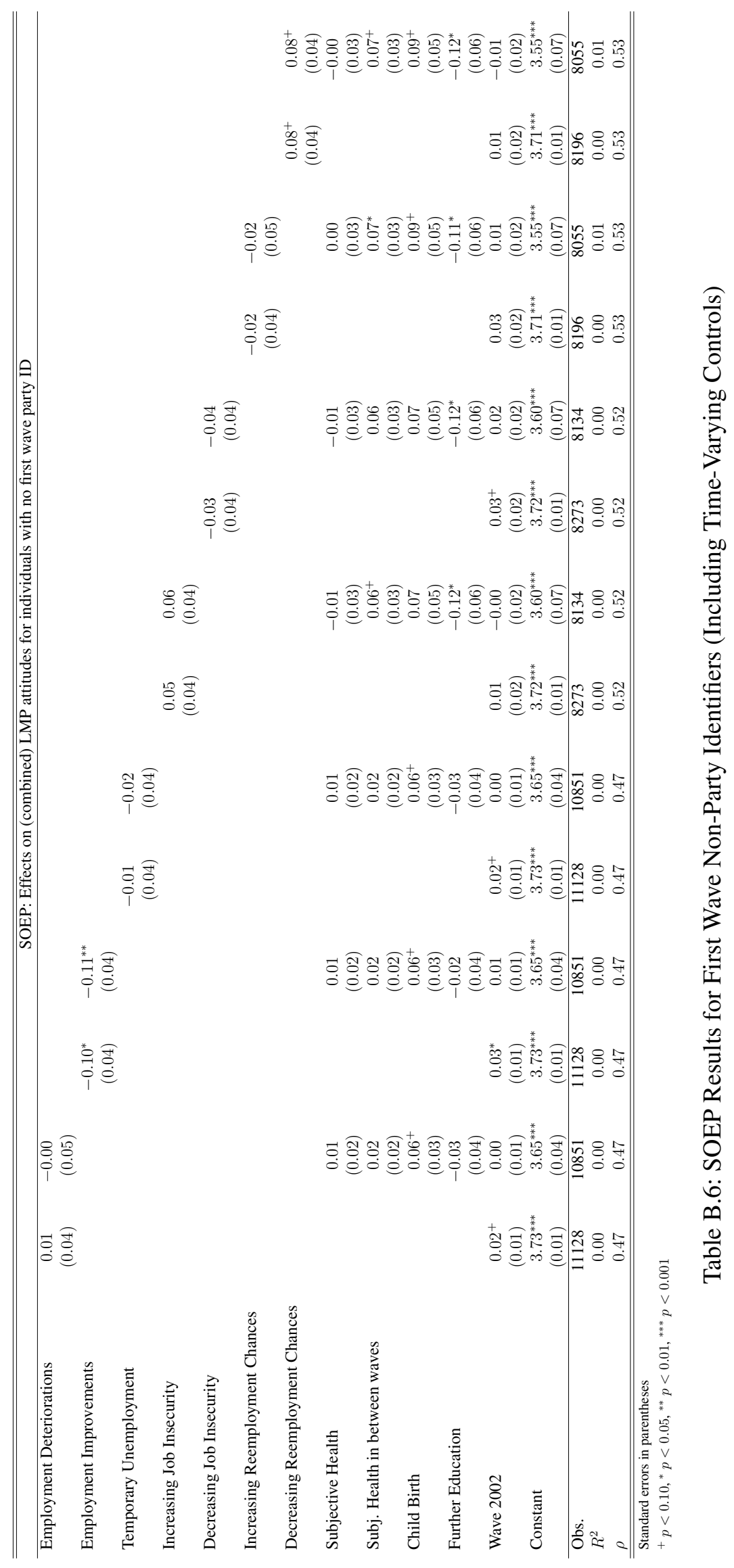




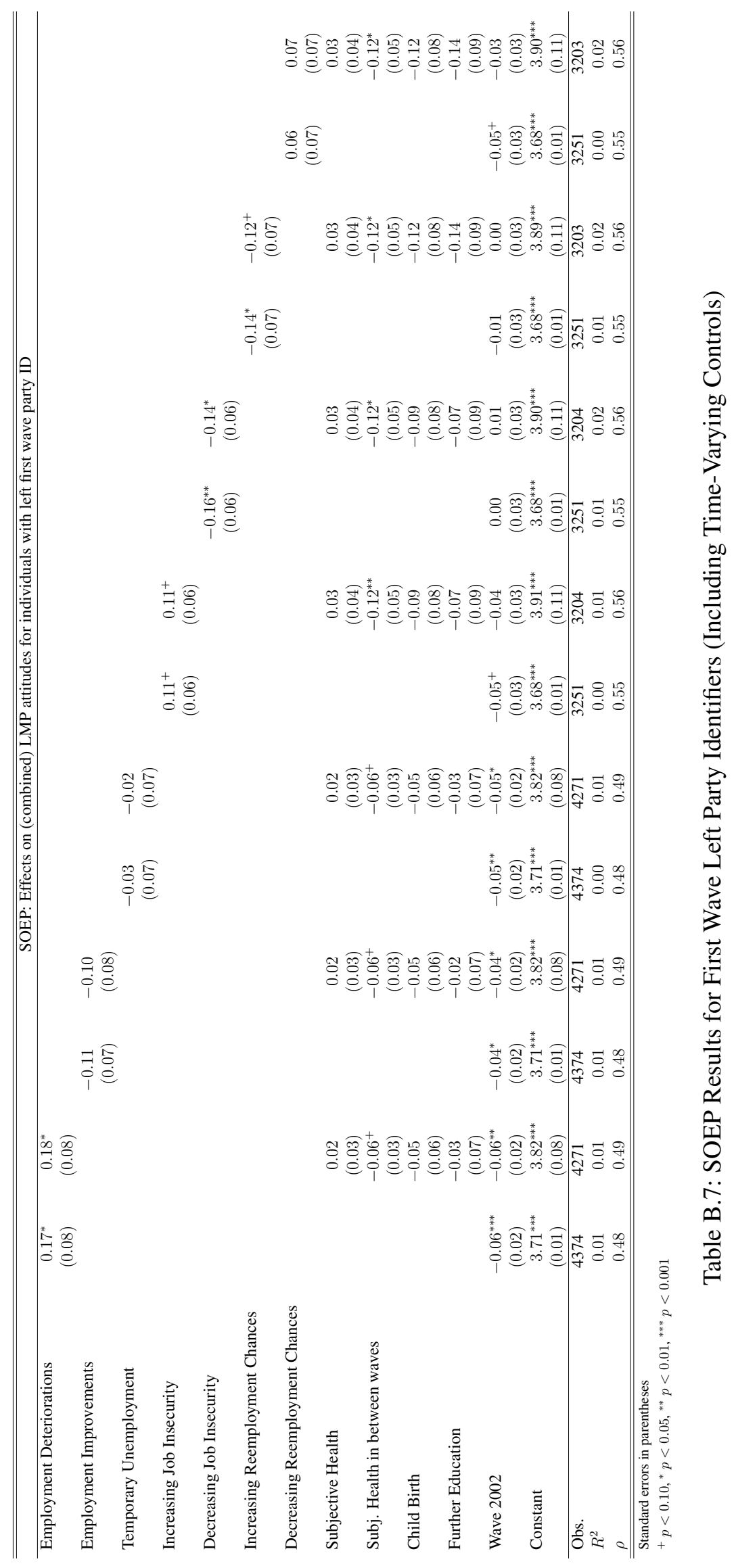


B.1.3 Interaction Models 


\begin{tabular}{|c|c|c|c|c|}
\hline Employment Deteriorations & $\begin{array}{c}0.21 \\
(0.27)\end{array}$ & $\begin{array}{c}0.24 \\
(0.28)\end{array}$ & $\begin{array}{c}0.08 \\
(0.13)\end{array}$ & $\begin{array}{c}0.09 \\
(0.13)\end{array}$ \\
\hline Employment Deteriorations $\times$ neutral LMP & $\begin{array}{c}-0.13 \\
(0.28)\end{array}$ & $\begin{array}{c}-0.21 \\
(0.29)\end{array}$ & & \\
\hline Employment Deteriorations $\times$ pro LMP & $\begin{array}{c}-0.12 \\
(0.27)\end{array}$ & $\begin{array}{c}-0.16 \\
(0.29)\end{array}$ & & \\
\hline Employment Deteriorations $\times$ No PID & & & $\begin{array}{c}-0.06 \\
(0.14)\end{array}$ & $\begin{array}{c}-0.09 \\
(0.14)\end{array}$ \\
\hline Employment Deteriorations $\times$ Left PID & & & $\begin{array}{c}0.09 \\
(0.15)\end{array}$ & $\begin{array}{c}0.09 \\
(0.16)\end{array}$ \\
\hline Subjective Health & & $\begin{array}{c}0.01 \\
(0.01)\end{array}$ & & $\begin{array}{c}0.01 \\
(0.01)\end{array}$ \\
\hline Subj. Health in between waves & & $\begin{array}{c}0.00 \\
(0.02)\end{array}$ & & $\begin{array}{c}-0.00 \\
(0.02)\end{array}$ \\
\hline Child Birth & & $\begin{array}{c}0.01 \\
(0.02)\end{array}$ & & $\begin{array}{c}0.03 \\
(0.03)\end{array}$ \\
\hline Further Education & & $\begin{array}{c}-0.01 \\
(0.03)\end{array}$ & & $\begin{array}{c}-0.01 \\
(0.03)\end{array}$ \\
\hline Wave 2002 & $\begin{array}{l}0.98^{* * *} \\
(0.04)\end{array}$ & $\begin{array}{l}0.98^{* * *} \\
(0.04)\end{array}$ & $\begin{array}{l}0.05^{* *} \\
(0.02)\end{array}$ & $\begin{array}{r}0.04^{*} \\
(0.02)\end{array}$ \\
\hline Wave $2002 \times$ neutral LMP & $\begin{array}{c}-0.48^{* * *} \\
(0.04)\end{array}$ & $\begin{array}{c}-0.49^{* * *} \\
(0.04)\end{array}$ & & \\
\hline Wave $2002 \times$ pro LMP & $\begin{array}{c}-1.20^{* * *} \\
(0.04)\end{array}$ & $\begin{array}{c}-1.20^{* * *} \\
(0.04)\end{array}$ & & \\
\hline Wave $2002 \times$ No PID & & & $\begin{array}{c}-0.03 \\
(0.02)\end{array}$ & $\begin{array}{c}-0.04 \\
(0.02)\end{array}$ \\
\hline Wave $2002 \times$ Left PID & & & $\begin{array}{c}-0.11^{* * *} \\
(0.03)\end{array}$ & $\begin{array}{c}-0.11^{* * *} \\
(0.03)\end{array}$ \\
\hline Constant & $\begin{array}{c}3.69^{* * *} \\
(0.00) \\
\end{array}$ & $\begin{array}{c}3.65^{* * *} \\
(0.03) \\
\end{array}$ & $\begin{array}{c}3.69^{* * *} \\
(0.00) \\
\end{array}$ & $\begin{array}{c}3.67^{* * *} \\
(0.04) \\
\end{array}$ \\
\hline Observations & 18900 & 18431 & 18766 & 18300 \\
\hline
\end{tabular}

Table B.8: SOEP Results: Interaction Models for Employment Deteriorations 


\begin{tabular}{|c|c|c|c|c|}
\hline Employment Improvements & $\begin{array}{c}-0.19 \\
(0.15)\end{array}$ & $\begin{array}{r}-0.28^{+} \\
(0.17)\end{array}$ & $\begin{array}{c}0.04 \\
(0.09)\end{array}$ & $\begin{array}{c}-0.01 \\
(0.09)\end{array}$ \\
\hline Employment Improvements $\times$ neutral LMP & $\begin{array}{c}0.16 \\
(0.16)\end{array}$ & $\begin{array}{c}0.24 \\
(0.18)\end{array}$ & & \\
\hline Employment Improvements $\times$ pro LMP & $\begin{array}{c}0.13 \\
(0.16)\end{array}$ & $\begin{array}{c}0.21 \\
(0.17)\end{array}$ & & \\
\hline Employment Improvements $\times$ No PID & & & $\begin{array}{r}-0.14 \\
(0.10)\end{array}$ & $\begin{array}{r}-0.10 \\
(0.10)\end{array}$ \\
\hline Employment Improvements $\times$ Left PID & & & $\begin{array}{c}-0.15 \\
(0.11)\end{array}$ & $\begin{array}{c}-0.09 \\
(0.12)\end{array}$ \\
\hline Subjective Health & & $\begin{array}{c}0.01 \\
(0.01)\end{array}$ & & $\begin{array}{c}0.01 \\
(0.01)\end{array}$ \\
\hline Subj. Health in between waves & & $\begin{array}{c}0.00 \\
(0.02)\end{array}$ & & $\begin{array}{c}-0.00 \\
(0.02)\end{array}$ \\
\hline Child Birth & & $\begin{array}{c}0.01 \\
(0.02)\end{array}$ & & $\begin{array}{c}0.03 \\
(0.03)\end{array}$ \\
\hline Further Education & & $\begin{array}{c}0.00 \\
(0.03)\end{array}$ & & $\begin{array}{c}-0.00 \\
(0.03)\end{array}$ \\
\hline Wave 2002 & $\begin{array}{l}1.00^{* * *} \\
(0.04)\end{array}$ & $\begin{array}{l}1.00^{* * *} \\
(0.04)\end{array}$ & $\begin{array}{l}0.05^{* *} \\
(0.02)\end{array}$ & $\begin{array}{c}0.05^{*} \\
(0.02)\end{array}$ \\
\hline Wave $2002 \times$ neutral LMP & $\begin{array}{c}-0.50^{* * *} \\
(0.04)\end{array}$ & $\begin{array}{c}-0.51^{* * *} \\
(0.04)\end{array}$ & & \\
\hline Wave $2002 \times$ pro LMP & $\begin{array}{c}-1.21^{* * *} \\
(0.04)\end{array}$ & $\begin{array}{c}-1.21^{* * *} \\
(0.04)\end{array}$ & & \\
\hline Wave $2002 \times$ No PID & & & $\begin{array}{c}-0.03 \\
(0.02)\end{array}$ & $\begin{array}{c}-0.03 \\
(0.02)\end{array}$ \\
\hline Wave $2002 \times$ Left PID & & & $\begin{array}{c}-0.10^{* * *} \\
(0.03)\end{array}$ & $\begin{array}{c}-0.10^{* * *} \\
(0.03)\end{array}$ \\
\hline Constant & $\begin{array}{c}3.69^{* * *} \\
(0.00)\end{array}$ & $\begin{array}{c}3.65^{* * *} \\
(0.03)\end{array}$ & $\begin{array}{c}3.69^{* * *} \\
(0.00)\end{array}$ & $\begin{array}{l}3.67^{* * *} \\
(0.04)\end{array}$ \\
\hline Observations & 18900 & 18431 & 18766 & 18300 \\
\hline
\end{tabular}

Table B.9: SOEP Results: Interaction Models for Employment Improvements 


\begin{tabular}{|c|c|c|c|c|}
\hline Temporary Unemployment & $\begin{array}{c}0.38^{* *} \\
(0.14)\end{array}$ & $\begin{array}{c}0.38^{* *} \\
(0.14)\end{array}$ & $\begin{array}{c}-0.05 \\
(0.08)\end{array}$ & $\begin{array}{c}-0.05 \\
(0.08)\end{array}$ \\
\hline Temporary Unemployment $\times$ neutral LMP & $\begin{array}{r}-0.32^{*} \\
(0.15)\end{array}$ & $\begin{array}{c}-0.31^{*} \\
(0.15)\end{array}$ & & \\
\hline Temporary Unemployment $\times$ pro LMP & $\begin{array}{c}-0.43^{* *} \\
(0.15)\end{array}$ & $\begin{array}{c}-0.43^{* *} \\
(0.15)\end{array}$ & & \\
\hline Temporary Unemployment $\times$ No PID & & & $\begin{array}{c}0.04 \\
(0.09)\end{array}$ & $\begin{array}{c}0.03 \\
(0.09)\end{array}$ \\
\hline Temporary Unemployment $\times$ Left PID & & & $\begin{array}{c}0.02 \\
(0.11)\end{array}$ & $\begin{array}{c}0.04 \\
(0.11)\end{array}$ \\
\hline Subjective Health & & $\begin{array}{c}0.01 \\
(0.01)\end{array}$ & & $\begin{array}{c}0.01 \\
(0.01)\end{array}$ \\
\hline Subj. Health in between waves & & $\begin{array}{c}0.00 \\
(0.02)\end{array}$ & & $\begin{array}{c}0.00 \\
(0.02)\end{array}$ \\
\hline Child Birth & & $\begin{array}{c}0.01 \\
(0.02)\end{array}$ & & $\begin{array}{c}0.03 \\
(0.03)\end{array}$ \\
\hline Further Education & & $\begin{array}{c}0.00 \\
(0.03)\end{array}$ & & $\begin{array}{c}-0.01 \\
(0.03)\end{array}$ \\
\hline Wave 2002 & $\begin{array}{l}0.96^{* * *} \\
(0.04)\end{array}$ & $\begin{array}{l}0.96^{* * *} \\
(0.04)\end{array}$ & $\begin{array}{l}0.06^{* *} \\
(0.02)\end{array}$ & $\begin{array}{c}0.05^{*} \\
(0.02)\end{array}$ \\
\hline Wave $2002 \times$ neutral LMP & $\begin{array}{c}-0.46^{* * *} \\
(0.04)\end{array}$ & $\begin{array}{c}-0.48^{* * *} \\
(0.04)\end{array}$ & & \\
\hline Wave $2002 \times$ pro LMP & $\begin{array}{c}-1.17^{* * *} \\
(0.04)\end{array}$ & $\begin{array}{c}-1.17^{* * *} \\
(0.04)\end{array}$ & & \\
\hline Wave $2002 \times$ No PID & & & $\begin{array}{c}-0.04^{+} \\
(0.02)\end{array}$ & $\begin{array}{c}-0.04^{+} \\
(0.02)\end{array}$ \\
\hline Wave $2002 \times$ Left PID & & & $\begin{array}{c}-0.11^{* * *} \\
(0.03)\end{array}$ & $\begin{array}{c}-0.11^{* * *} \\
(0.03)\end{array}$ \\
\hline Constant & $\begin{array}{l}3.69^{* * *} \\
(0.00)\end{array}$ & $\begin{array}{l}3.65^{* * *} \\
(0.03)\end{array}$ & $\begin{array}{l}3.69^{* * *} \\
(0.00)\end{array}$ & $\begin{array}{l}3.67^{* * *} \\
(0.04)\end{array}$ \\
\hline Observations & 18900 & 18431 & 18766 & 18300 \\
\hline
\end{tabular}

Standard errors in parentheses

${ }^{+} p<0.10,{ }^{*} p<0.05,{ }^{* *} p<0.01,{ }^{* * *} p<0.001$

Table B.10: SOEP Results: Interaction Models for Temporary Unemployment 


\begin{tabular}{|c|c|c|c|c|}
\hline Increasing Job Insecurity & $\begin{array}{c}-0.02 \\
(0.13)\end{array}$ & $\begin{array}{c}-0.02 \\
(0.13)\end{array}$ & $\begin{array}{c}0.10 \\
(0.08)\end{array}$ & $\begin{array}{c}0.13 \\
(0.09)\end{array}$ \\
\hline Increasing Job Insecurity $\times$ neutral LMP & $\begin{array}{c}0.18 \\
(0.14)\end{array}$ & $\begin{array}{c}0.19 \\
(0.14)\end{array}$ & & \\
\hline Increasing Job Insecurity $\times$ pro LMP & $\begin{array}{c}0.03 \\
(0.13)\end{array}$ & $\begin{array}{c}0.03 \\
(0.14)\end{array}$ & & \\
\hline Increasing Job Insecurity $\times$ No PID & & & $\begin{array}{c}-0.05 \\
(0.09)\end{array}$ & $\begin{array}{c}-0.07 \\
(0.10)\end{array}$ \\
\hline Increasing Job Insecurity $\times$ Left PID & & & $\begin{array}{c}0.00 \\
(0.10)\end{array}$ & $\begin{array}{c}-0.04 \\
(0.11)\end{array}$ \\
\hline Subjective Health & & $\begin{array}{c}0.01 \\
(0.02)\end{array}$ & & $\begin{array}{c}0.00 \\
(0.02)\end{array}$ \\
\hline Subj. Health in between waves & & $\begin{array}{c}0.01 \\
(0.02)\end{array}$ & & $\begin{array}{c}0.01 \\
(0.03)\end{array}$ \\
\hline Child Birth & & $\begin{array}{c}0.01 \\
(0.03)\end{array}$ & & $\begin{array}{c}0.05 \\
(0.04)\end{array}$ \\
\hline Further Education & & $\begin{array}{c}-0.04 \\
(0.04)\end{array}$ & & $\begin{array}{r}-0.06 \\
(0.04)\end{array}$ \\
\hline Wave 2002 & $\begin{array}{c}0.98^{* * *} \\
(0.05)\end{array}$ & $\begin{array}{l}0.97^{* * *} \\
(0.06)\end{array}$ & $\begin{array}{c}0.02 \\
(0.03)\end{array}$ & $\begin{array}{c}0.00 \\
(0.03)\end{array}$ \\
\hline Wave $2002 \times$ neutral LMP & $\begin{array}{c}-0.55^{* * *} \\
(0.06)\end{array}$ & $\begin{array}{c}-0.56^{* * *} \\
(0.06)\end{array}$ & & \\
\hline Wave $2002 \times$ pro LMP & $\begin{array}{c}-1.21^{* * *} \\
(0.05)\end{array}$ & $\begin{array}{c}-1.21^{* * *} \\
(0.06)\end{array}$ & & \\
\hline Wave $2002 \times$ No PID & & & $\begin{array}{c}-0.00 \\
(0.04)\end{array}$ & $\begin{array}{c}-0.00 \\
(0.04)\end{array}$ \\
\hline Wave $2002 \times$ Left PID & & & $\begin{array}{c}-0.07^{+} \\
(0.04)\end{array}$ & $\begin{array}{c}-0.06 \\
(0.04)\end{array}$ \\
\hline Constant & $\begin{array}{c}3.67^{* * *} \\
(0.00)\end{array}$ & $\begin{array}{c}3.64^{* * *} \\
(0.04)\end{array}$ & $\begin{array}{l}3.67^{* * *} \\
(0.00)\end{array}$ & $\begin{array}{c}3.66^{* * *} \\
(0.05)\end{array}$ \\
\hline Observations & 13974 & 13739 & 13878 & 13644 \\
\hline
\end{tabular}

Table B.11: SOEP Results: Interaction Models for Increasing Job Insecurity 


\begin{tabular}{|c|c|c|c|c|}
\hline Decreasing Job Insecurity & $\begin{array}{c}-0.08 \\
(0.11)\end{array}$ & $\begin{array}{c}-0.05 \\
(0.12)\end{array}$ & $\begin{array}{c}-0.04 \\
(0.07)\end{array}$ & $\begin{array}{c}-0.05 \\
(0.07)\end{array}$ \\
\hline Decreasing Job Insecurity $\times$ neutral LMP & $\begin{array}{c}0.03 \\
(0.12)\end{array}$ & $\begin{array}{c}0.02 \\
(0.13)\end{array}$ & & \\
\hline Decreasing Job Insecurity $\times$ pro LMP & $\begin{array}{c}0.06 \\
(0.12)\end{array}$ & $\begin{array}{c}0.02 \\
(0.12)\end{array}$ & & \\
\hline Decreasing Job Insecurity $\times$ No PID & & & $\begin{array}{c}0.00 \\
(0.08)\end{array}$ & $\begin{array}{c}0.00 \\
(0.08)\end{array}$ \\
\hline Decreasing Job Insecurity $\times$ Left PID & & & $\begin{array}{c}-0.12 \\
(0.09)\end{array}$ & $\begin{array}{c}-0.10 \\
(0.09)\end{array}$ \\
\hline Subjective Health & & $\begin{array}{c}0.01 \\
(0.02)\end{array}$ & & $\begin{array}{c}0.00 \\
(0.02)\end{array}$ \\
\hline Subj. Health in between waves & & $\begin{array}{c}0.01 \\
(0.02)\end{array}$ & & $\begin{array}{c}0.01 \\
(0.03)\end{array}$ \\
\hline Child Birth & & $\begin{array}{c}0.01 \\
(0.03)\end{array}$ & & $\begin{array}{c}0.04 \\
(0.04)\end{array}$ \\
\hline Further Education & & $\begin{array}{c}-0.04 \\
(0.04)\end{array}$ & & $\begin{array}{c}-0.06 \\
(0.04)\end{array}$ \\
\hline Wave 2002 & $\begin{array}{l}0.99^{* * *} \\
(0.06)\end{array}$ & $\begin{array}{l}0.98^{* * *} \\
(0.06)\end{array}$ & $\begin{array}{c}0.05 \\
(0.03)\end{array}$ & $\begin{array}{c}0.04 \\
(0.03)\end{array}$ \\
\hline Wave $2002 \times$ neutral LMP & $\begin{array}{c}-0.52^{* * *} \\
(0.06)\end{array}$ & $\begin{array}{c}-0.53^{* * *} \\
(0.06)\end{array}$ & & \\
\hline Wave $2002 \times$ pro LMP & $\begin{array}{c}-1.21^{* * *} \\
(0.06)\end{array}$ & $\begin{array}{c}-1.21^{* * *} \\
(0.06)\end{array}$ & & \\
\hline Wave $2002 \times$ No PID & & & $\begin{array}{c}-0.01 \\
(0.04)\end{array}$ & $\begin{array}{c}-0.02 \\
(0.04)\end{array}$ \\
\hline Wave $2002 \times$ Left PID & & & $\begin{array}{c}-0.04 \\
(0.04)\end{array}$ & $\begin{array}{c}-0.05 \\
(0.04)\end{array}$ \\
\hline Constant & $\begin{array}{c}3.67^{* * *} \\
(0.00) \\
\end{array}$ & $\begin{array}{l}3.63^{* * *} \\
(0.04)\end{array}$ & $\begin{array}{l}3.67^{* * *} \\
(0.00)\end{array}$ & $\begin{array}{l}3.65^{* * *} \\
(0.05)\end{array}$ \\
\hline Observations & 13974 & 13739 & 13878 & 13644 \\
\hline
\end{tabular}

Table B.12: SOEP Results: Interaction Models for Decreasing Job Insecurity 


\begin{tabular}{|c|c|c|c|c|}
\hline Decreasing Reemployment Chances & $\begin{array}{c}0.18 \\
(0.15)\end{array}$ & $\begin{array}{c}0.16 \\
(0.15)\end{array}$ & $\begin{array}{c}0.05 \\
(0.08)\end{array}$ & $\begin{array}{c}0.03 \\
(0.09)\end{array}$ \\
\hline Decreasing Reemployment Chances $\times$ neutral LMP & $\begin{array}{c}-0.08 \\
(0.16)\end{array}$ & $\begin{array}{r}-0.06 \\
(0.16)\end{array}$ & & \\
\hline Decreasing Reemployment Chances $\times$ pro LMP & $\begin{array}{c}-0.13 \\
(0.15)\end{array}$ & $\begin{array}{c}-0.11 \\
(0.15)\end{array}$ & & \\
\hline Decreasing Reemployment Chances $\times$ No PID & & & $\begin{array}{c}0.03 \\
(0.09)\end{array}$ & $\begin{array}{c}0.06 \\
(0.10)\end{array}$ \\
\hline Decreasing Reemployment Chances $\times$ Left PID & & & $\begin{array}{c}0.01 \\
(0.11)\end{array}$ & $\begin{array}{c}0.03 \\
(0.11)\end{array}$ \\
\hline Subjective Health & & $\begin{array}{c}0.00 \\
(0.02)\end{array}$ & & $\begin{array}{c}0.00 \\
(0.02)\end{array}$ \\
\hline Subj. Health in between waves & & $\begin{array}{c}0.03 \\
(0.02)\end{array}$ & & $\begin{array}{c}0.02 \\
(0.03)\end{array}$ \\
\hline Child Birth & & $\begin{array}{c}0.01 \\
(0.03)\end{array}$ & & $\begin{array}{c}0.05 \\
(0.04)\end{array}$ \\
\hline Further Education & & $\begin{array}{c}-0.05 \\
(0.04)\end{array}$ & & $\begin{array}{c}-0.07 \\
(0.04)\end{array}$ \\
\hline Wave 2002 & $\begin{array}{l}0.91^{* * *} \\
(0.05)\end{array}$ & $\begin{array}{l}0.91^{* * *} \\
(0.05)\end{array}$ & $\begin{array}{c}0.02 \\
(0.03)\end{array}$ & $\begin{array}{c}0.01 \\
(0.03)\end{array}$ \\
\hline Wave $2002 \times$ neutral LMP & $\begin{array}{l}-0.48^{* * *} \\
(0.05)\end{array}$ & $\begin{array}{c}-0.49^{* * *} \\
(0.06)\end{array}$ & & \\
\hline Wave $2002 \times$ pro LMP & $\begin{array}{l}-1.15^{* * *} \\
(0.05)\end{array}$ & $\begin{array}{l}-1.16^{* * *} \\
(0.05)\end{array}$ & & \\
\hline Wave $2002 \times$ No PID & & & $\begin{array}{c}-0.01 \\
(0.03)\end{array}$ & $\begin{array}{c}-0.01 \\
(0.04)\end{array}$ \\
\hline Wave $2002 \times$ Left PID & & & $\begin{array}{r}-0.07^{+} \\
(0.04)\end{array}$ & $\begin{array}{c}-0.07^{+} \\
(0.04)\end{array}$ \\
\hline Constant & $\begin{array}{l}3.67^{* * *} \\
(0.00)\end{array}$ & $\begin{array}{l}3.59^{* * *} \\
(0.05)\end{array}$ & $\begin{array}{l}3.67^{* * *} \\
(0.00)\end{array}$ & $\begin{array}{l}3.61^{* * *} \\
(0.05)\end{array}$ \\
\hline Observations & 13893 & 13650 & 13797 & 13555 \\
\hline
\end{tabular}

Standard errors in parentheses

${ }^{+} p<0.10,{ }^{*} p<0.05,{ }^{* *} p<0.01,{ }^{* * *} p<0.001$

Table B.13: SOEP Results: Interaction Models for Decreasing Reemployment Chances 


\begin{tabular}{|c|c|c|c|c|}
\hline Increasing Reemployment Chances & $\begin{array}{c}0.14 \\
(0.12)\end{array}$ & $\begin{array}{c}0.14 \\
(0.12)\end{array}$ & $\begin{array}{c}-0.04 \\
(0.08)\end{array}$ & $\begin{array}{c}-0.01 \\
(0.08)\end{array}$ \\
\hline Increasing Reemployment Chances $\times$ neutral LMP & $\begin{array}{c}-0.20 \\
(0.13)\end{array}$ & $\begin{array}{c}-0.19 \\
(0.13)\end{array}$ & & \\
\hline Increasing Reemployment Chances $\times$ pro LMP & $\begin{array}{c}-0.22^{+} \\
(0.12)\end{array}$ & $\begin{array}{c}-0.23^{+} \\
(0.13)\end{array}$ & & \\
\hline Increasing Reemployment Chances $\times$ No PID & & & $\begin{array}{c}0.02 \\
(0.09)\end{array}$ & $\begin{array}{c}-0.02 \\
(0.09)\end{array}$ \\
\hline Increasing Reemployment Chances $\times$ Left PID & & & $\begin{array}{r}-0.09 \\
(0.10)\end{array}$ & $\begin{array}{r}-0.12 \\
(0.10)\end{array}$ \\
\hline Subjective Health & & $\begin{array}{c}0.00 \\
(0.02)\end{array}$ & & $\begin{array}{c}0.00 \\
(0.02)\end{array}$ \\
\hline Subj. Health in between waves & & $\begin{array}{c}0.03 \\
(0.02)\end{array}$ & & $\begin{array}{c}0.02 \\
(0.03)\end{array}$ \\
\hline Child Birth & & $\begin{array}{c}0.01 \\
(0.03)\end{array}$ & & $\begin{array}{c}0.05 \\
(0.04)\end{array}$ \\
\hline Further Education & & $\begin{array}{c}-0.05 \\
(0.04)\end{array}$ & & $\begin{array}{r}-0.07 \\
(0.04)\end{array}$ \\
\hline Wave 2002 & $\begin{array}{l}0.92^{* * *} \\
(0.05)\end{array}$ & $\begin{array}{l}0.91^{* * *} \\
(0.06)\end{array}$ & $\begin{array}{c}0.04 \\
(0.03)\end{array}$ & $\begin{array}{c}0.02 \\
(0.03)\end{array}$ \\
\hline Wave $2002 \times$ neutral LMP & $\begin{array}{c}-0.45^{* * *} \\
(0.06)\end{array}$ & $\begin{array}{c}-0.46^{* * *} \\
(0.06)\end{array}$ & & \\
\hline Wave $2002 \times$ pro LMP & $\begin{array}{c}-1.14^{* * *} \\
(0.06)\end{array}$ & $\begin{array}{c}-1.14^{* * *} \\
(0.06)\end{array}$ & & \\
\hline Wave $2002 \times$ No PID & & & $\begin{array}{c}-0.01 \\
(0.04)\end{array}$ & $\begin{array}{c}-0.00 \\
(0.04)\end{array}$ \\
\hline Wave $2002 \times$ Left PID & & & $\begin{array}{c}-0.05 \\
(0.04)\end{array}$ & $\begin{array}{c}-0.05 \\
(0.04)\end{array}$ \\
\hline Constant & $\begin{array}{c}3.67^{* * *} \\
(0.00)\end{array}$ & $\begin{array}{c}3.59^{* * *} \\
(0.05)\end{array}$ & $\begin{array}{c}3.67^{* * *} \\
(0.00)\end{array}$ & $\begin{array}{c}3.61^{* * *} \\
(0.05)\end{array}$ \\
\hline Observations & 13893 & 13650 & 13797 & 13555 \\
\hline
\end{tabular}

Table B.14: SOEP Results: Interaction Models for Increasing Reemployment Chances 


\section{Pairwise Comparisons of Average Marginal Effects}

The following tables show the differences in average marginal effects computed based on the interaction models in tables B.8 to B.14. 


\begin{tabular}{llccc}
\hline \hline & & $\begin{array}{c}\text { Employment } \\
\text { Deteriorations }\end{array}$ & $\begin{array}{c}\text { Employment } \\
\text { Improvements }\end{array}$ & $\begin{array}{c}\text { Temporary } \\
\text { Unemployment }\end{array}$ \\
\hline \hline \multirow{2}{*}{ first wave } & Neutrals vs Sceptics & -0.13 & 0.16 & $-0.32^{*}$ \\
LMP attitude & $(0.28)$ & $(0.16)$ & $(0.15)$ \\
& Supporters vs Sceptics & -0.12 & 0.13 & $-0.43^{* *}$ \\
& & $(0.27)$ & $(0.16)$ & $(0.15)$ \\
& Supporters vs neutral & 0.01 & -0.03 & $-0.11^{+}$ \\
& & $(0.08)$ & $(0.07)$ & $(0.06)$ \\
first wave & No PID vs Right PID & -0.06 & -0.14 & 0.04 \\
party ID & & $(0.14)$ & $(0.10)$ & $(0.09)$ \\
& & 0.09 & -0.15 & 0.02 \\
& Left PID vs Right PID & $(0.15)$ & $(0.11)$ & $(0.11)$ \\
& & $0.15^{+}$ & -0.01 & -0.02 \\
& & $(0.09)$ & $(0.08)$ & $(0.08)$ \\
\hline \hline
\end{tabular}

Standard errors in parentheses

${ }^{+} p<0.10,{ }^{*} p<0.05,{ }^{* *} p<0.01,{ }^{* * *} p<0.001$

Table B.15: SOEP Results: Pairwise Comparison of Average Marginal Effects for Employment Transitions

\begin{tabular}{|c|c|c|c|c|c|}
\hline & & $\begin{array}{c}\text { Increasing } \\
\text { Job Insecurity }\end{array}$ & $\begin{array}{l}\text { Decreasing } \\
\text { Job Insecurity }\end{array}$ & $\begin{array}{c}\text { Increasing } \\
\text { Reemployment Chances }\end{array}$ & $\begin{array}{c}\text { Decreasing } \\
\text { Reemployment Chances }\end{array}$ \\
\hline \multirow{4}{*}{$\begin{array}{l}\text { first wave } \\
\text { LMP attitude }\end{array}$} & Neutrals vs Sceptics & $\begin{array}{c}0.18 \\
(0.14)\end{array}$ & $\begin{array}{c}0.03 \\
(0.12)\end{array}$ & $\begin{array}{r}-0.20 \\
(0.13)\end{array}$ & $\begin{array}{c}-0.08 \\
(0.16)\end{array}$ \\
\hline & Supporters vs Sceptics & 0.03 & 0.06 & $-0.22^{+}$ & -0.13 \\
\hline & & $(0.13)$ & $(0.11)$ & $(0.12)$ & $(0.15)$ \\
\hline & Supporters vs neutral & $\begin{array}{r}-0.15^{*} \\
(0.06)\end{array}$ & $\begin{array}{c}0.04 \\
(0.06)\end{array}$ & $\begin{array}{r}-0.02 \\
(0.06)\end{array}$ & $\begin{array}{r}-0.05 \\
(0.06)\end{array}$ \\
\hline \multirow{3}{*}{$\begin{array}{l}\text { first wave } \\
\text { party ID }\end{array}$} & No PID vs Right PID & $\begin{array}{c}-0.05 \\
(0.09)\end{array}$ & $\begin{array}{c}0.02 \\
(0.07)\end{array}$ & $\begin{array}{c}0.02 \\
(0.09)\end{array}$ & $\begin{array}{c}0.03 \\
(0.09)\end{array}$ \\
\hline & Left PID vs Right PID & $\begin{array}{c}0.00 \\
(0.19)\end{array}$ & $\begin{array}{r}-0.12 \\
(0.09)\end{array}$ & $\begin{array}{c}-0.09 \\
(0.10)\end{array}$ & $\begin{array}{c}0.01 \\
(0.11)\end{array}$ \\
\hline & Left PID vs No PID & $\begin{array}{c}0.05 \\
(0.08)\end{array}$ & $\begin{array}{r}-0.12^{+} \\
(0.07)\end{array}$ & $\begin{array}{c}-0.12 \\
(0.08)\end{array}$ & $\begin{array}{c}-0.02 \\
(0.08)\end{array}$ \\
\hline
\end{tabular}

Standard errors in parentheses

$+p<0.10,{ }^{*} p<0.05,{ }^{* *} p<0.01,{ }^{* * *} p<0.001$

Table B.16: SOEP Results: Pairwise Comparison of Average Marginal Effects for Job Insecurity Perceptions 
Comparison between results from subgroup analyses and average marginal effects from interaction models

The following tables show the effects of the transitions and perception changes from the subgroup analyses ("S.G.") that are already displayed in tables B.2 to B.7. The following tables compare these results to the average marginal effects ("AME") computed based on the interaction models in tables B.8 to B.14. 


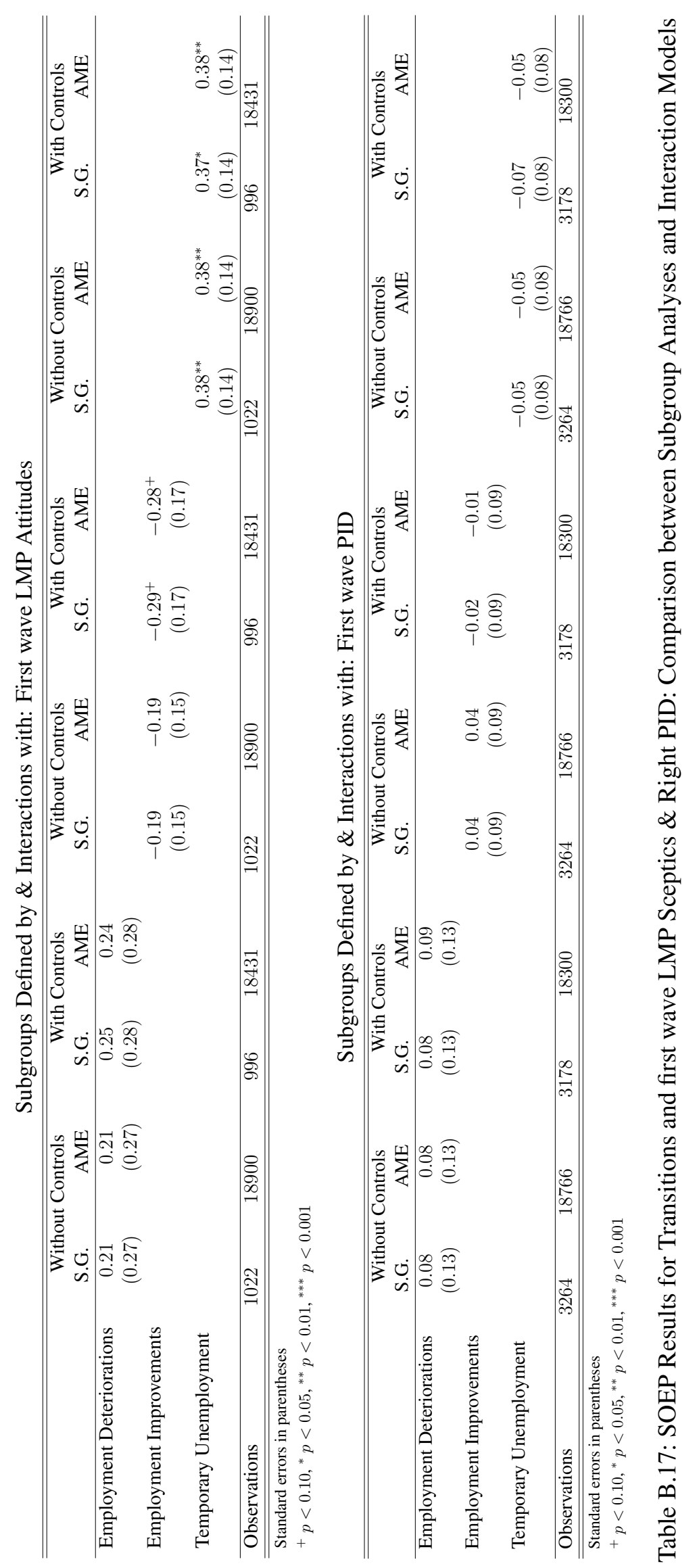




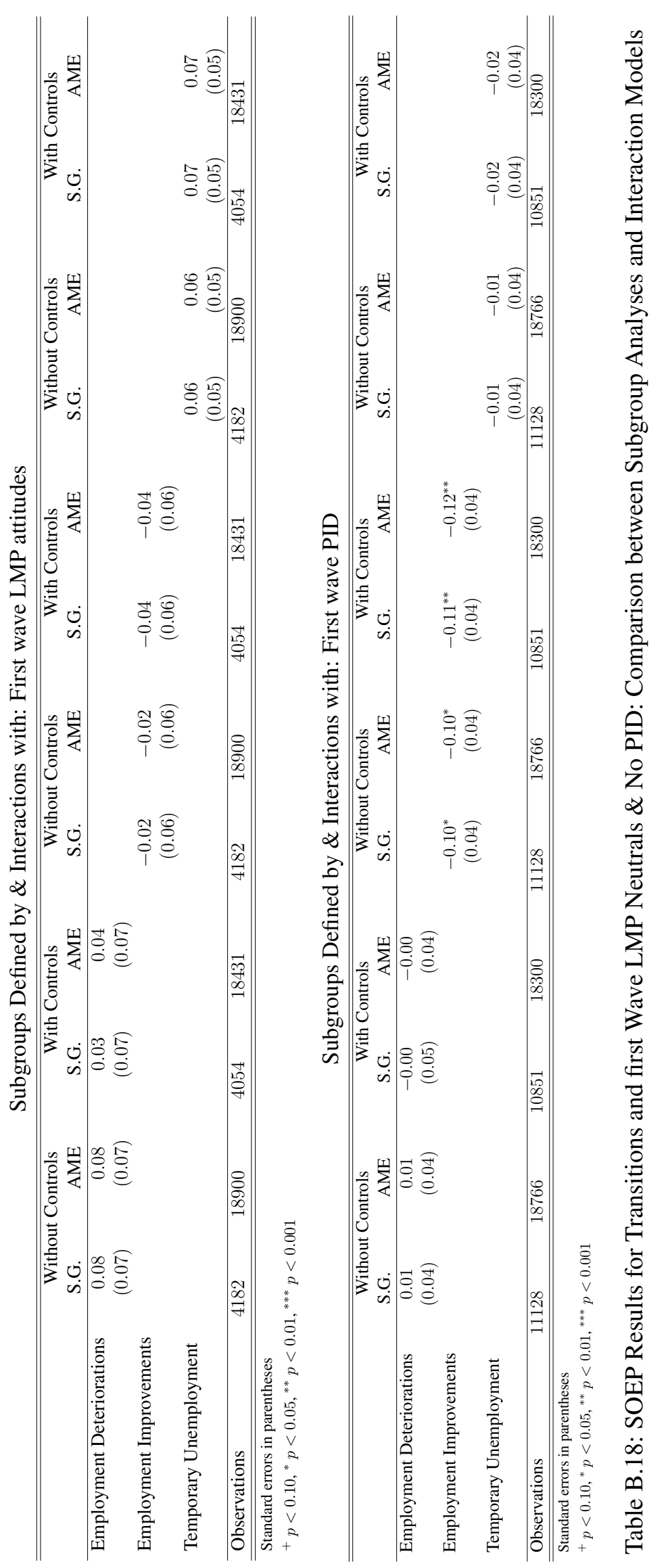




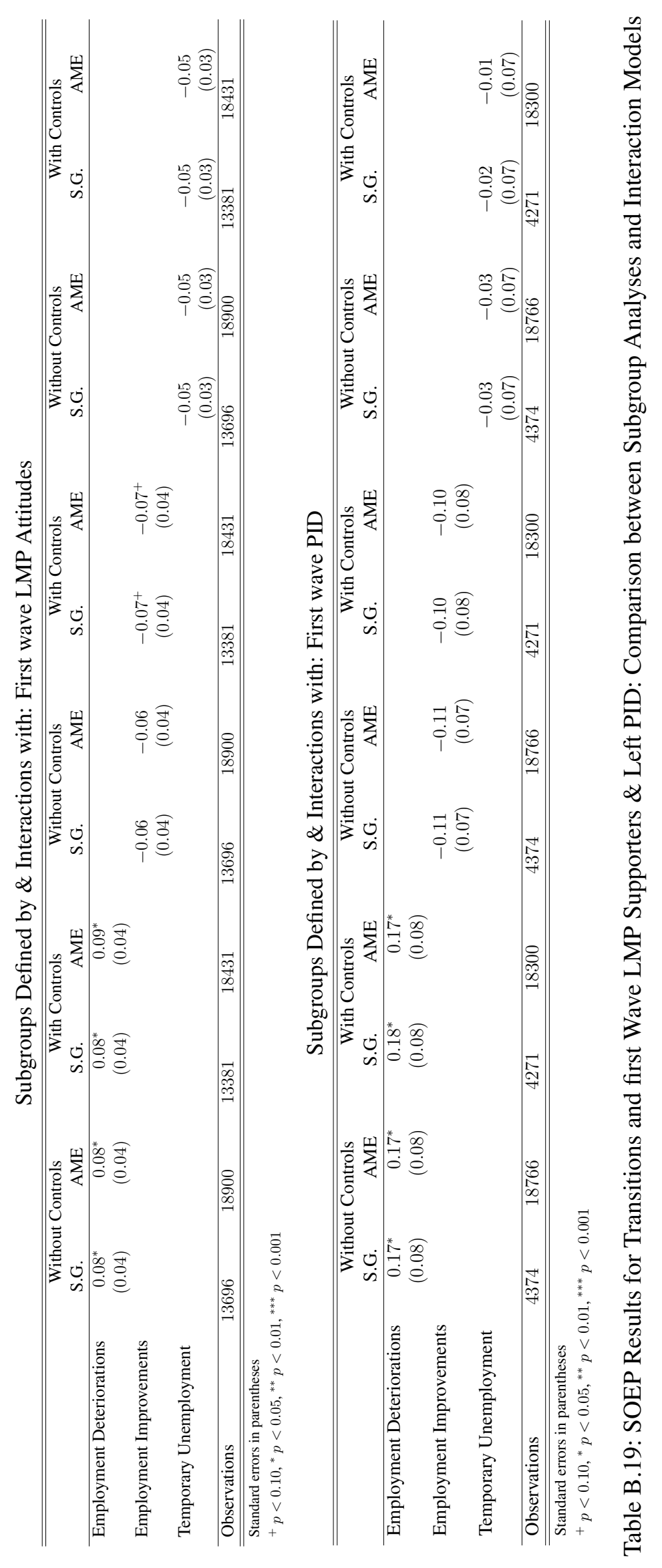




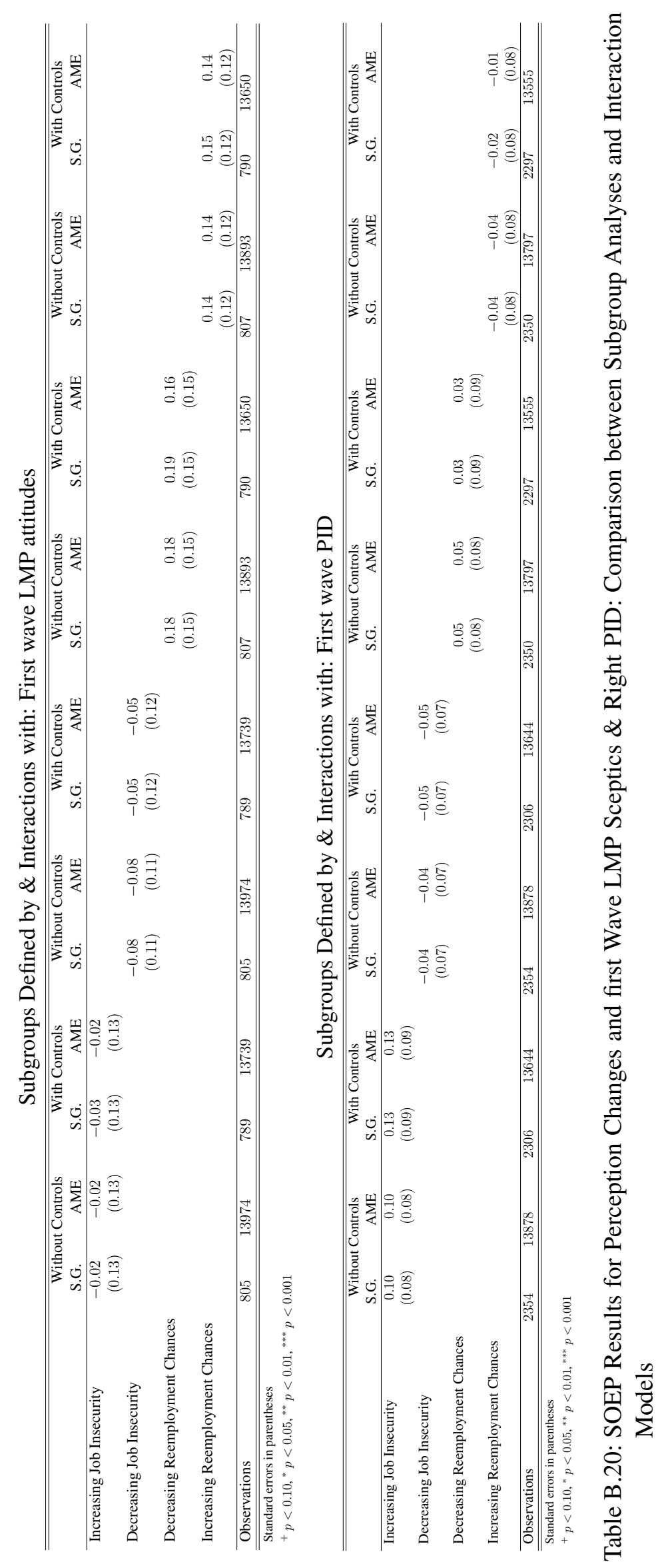




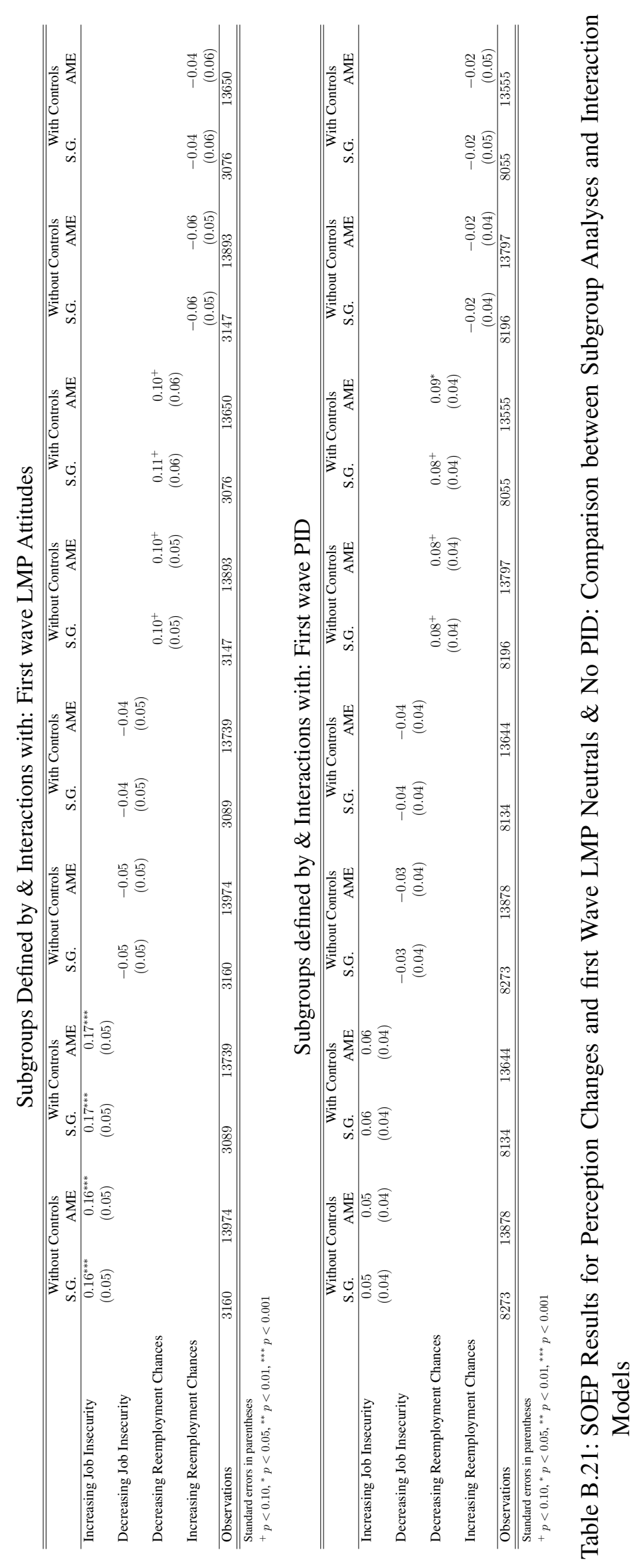




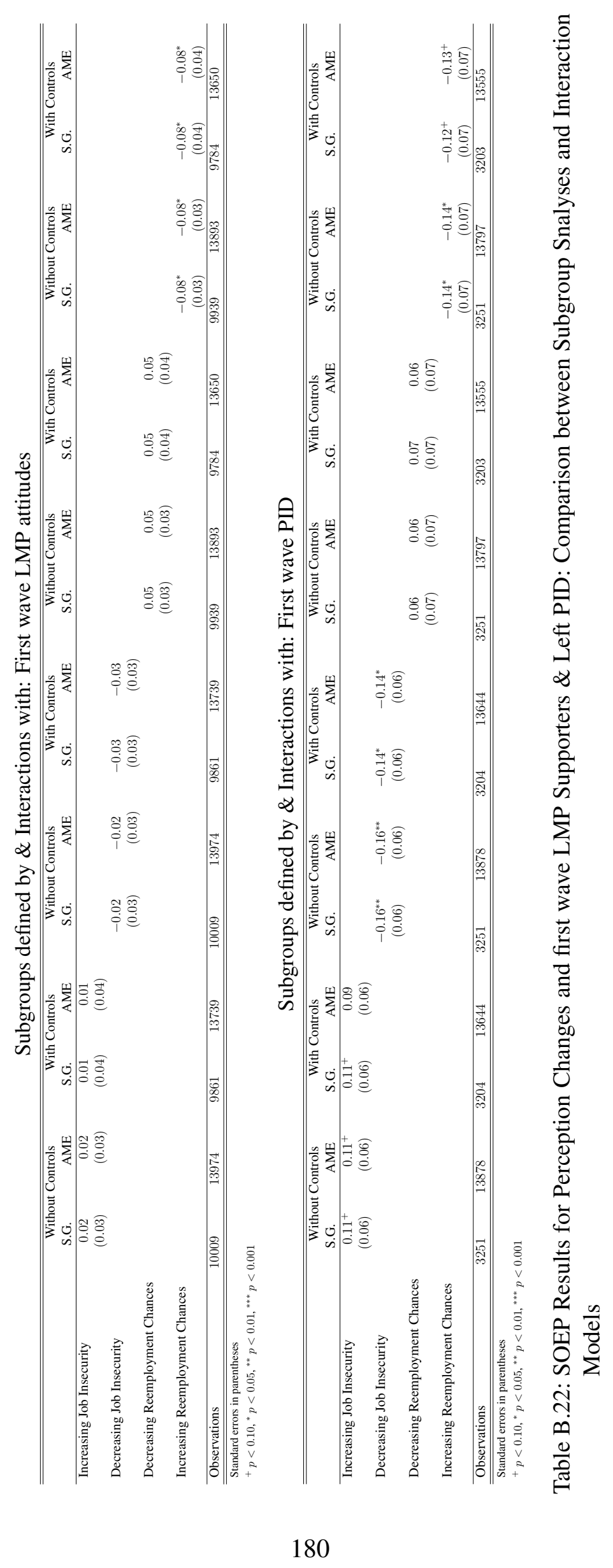


B.2 SOEP robustness checks 


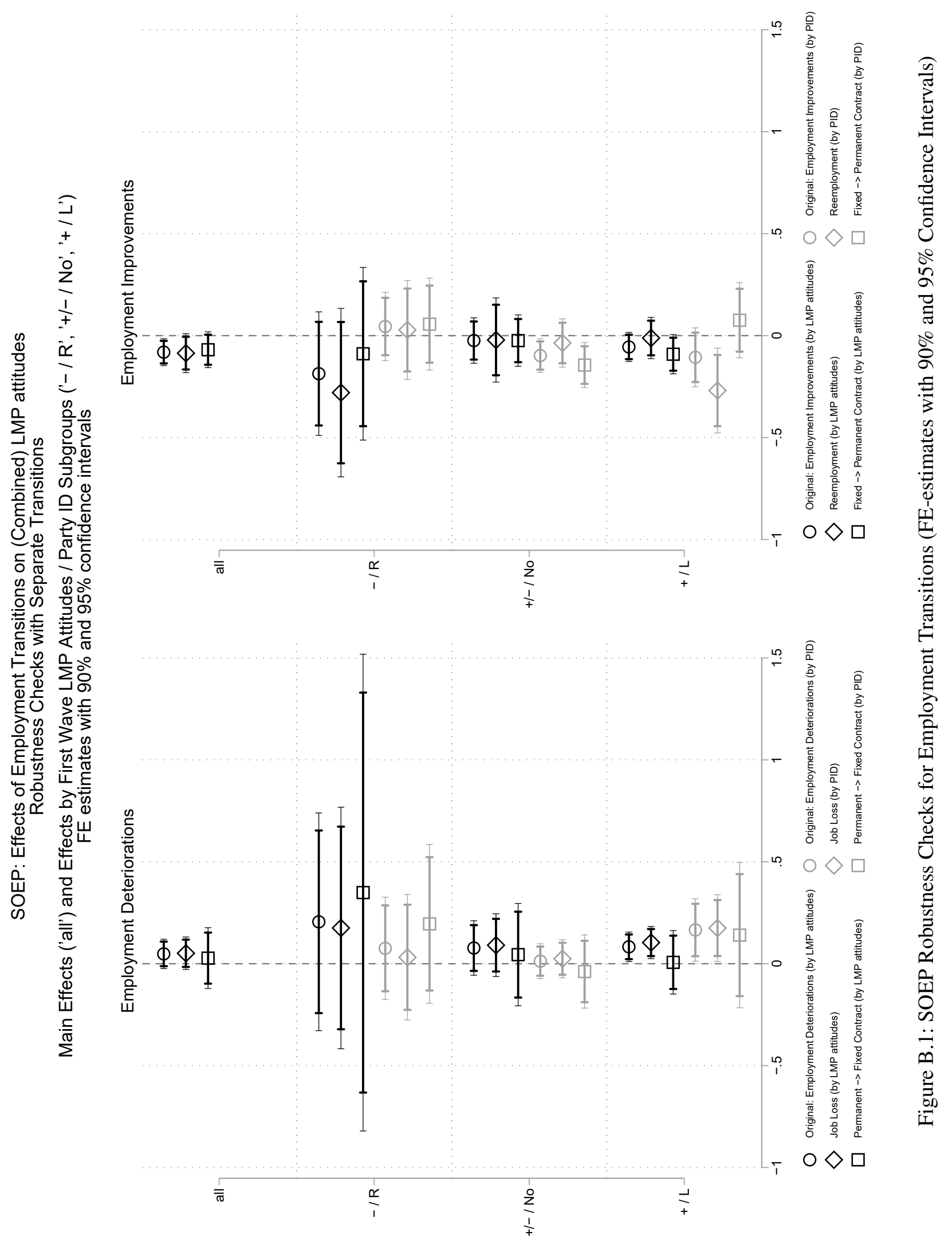




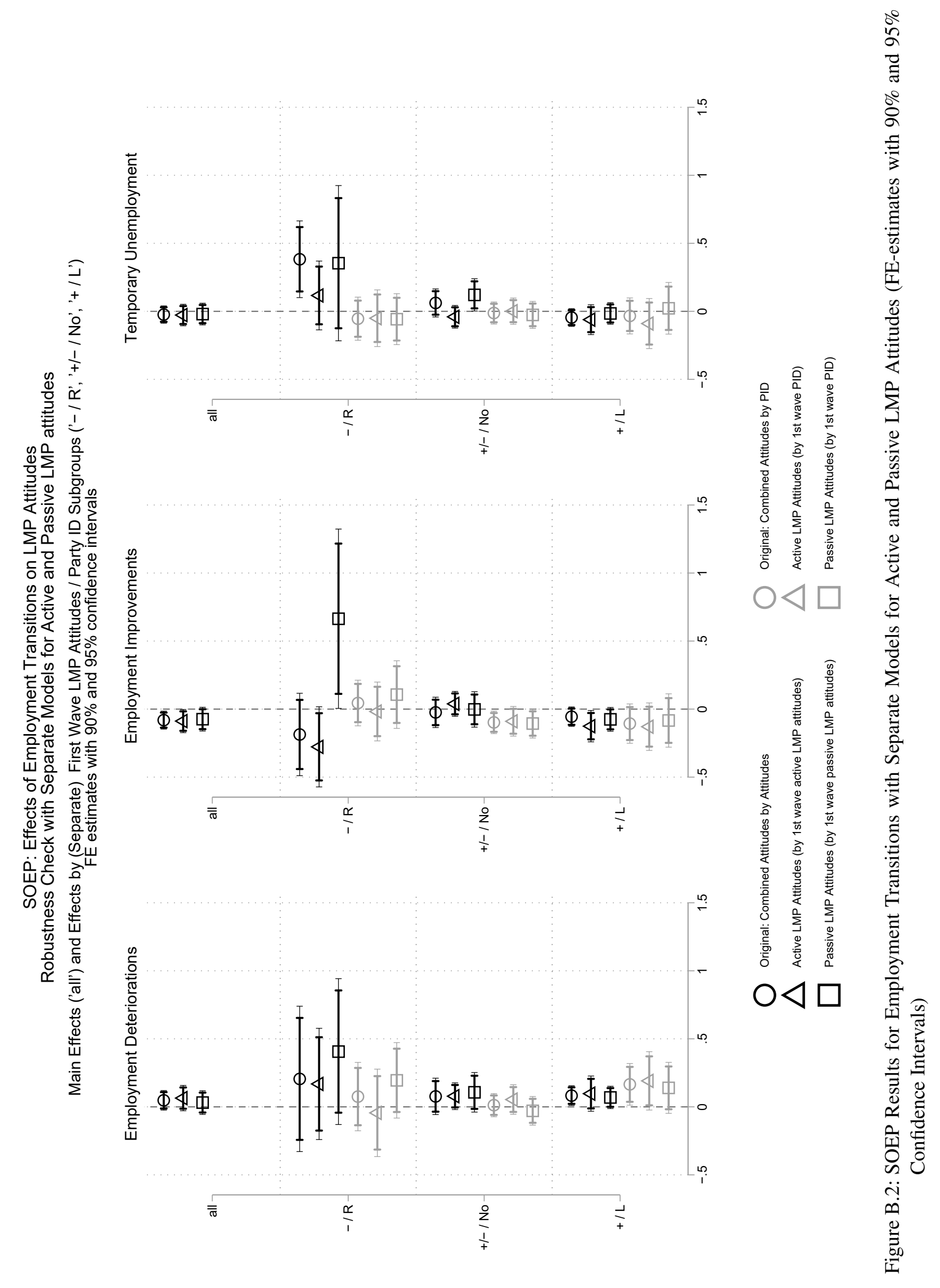


SOEP: Effects of Perception Changes on LMP Attitudes

Robustness Check with Separate Models for Active and Passive LMP attitudes

Main Effects ('all') and Effects by (Separate) First Wave LMP Attitudes / Party ID Subgroups ('- / R', '+/- / No', '+ / L')

FE estimates with $90 \%$ and $95 \%$ confidence intervals
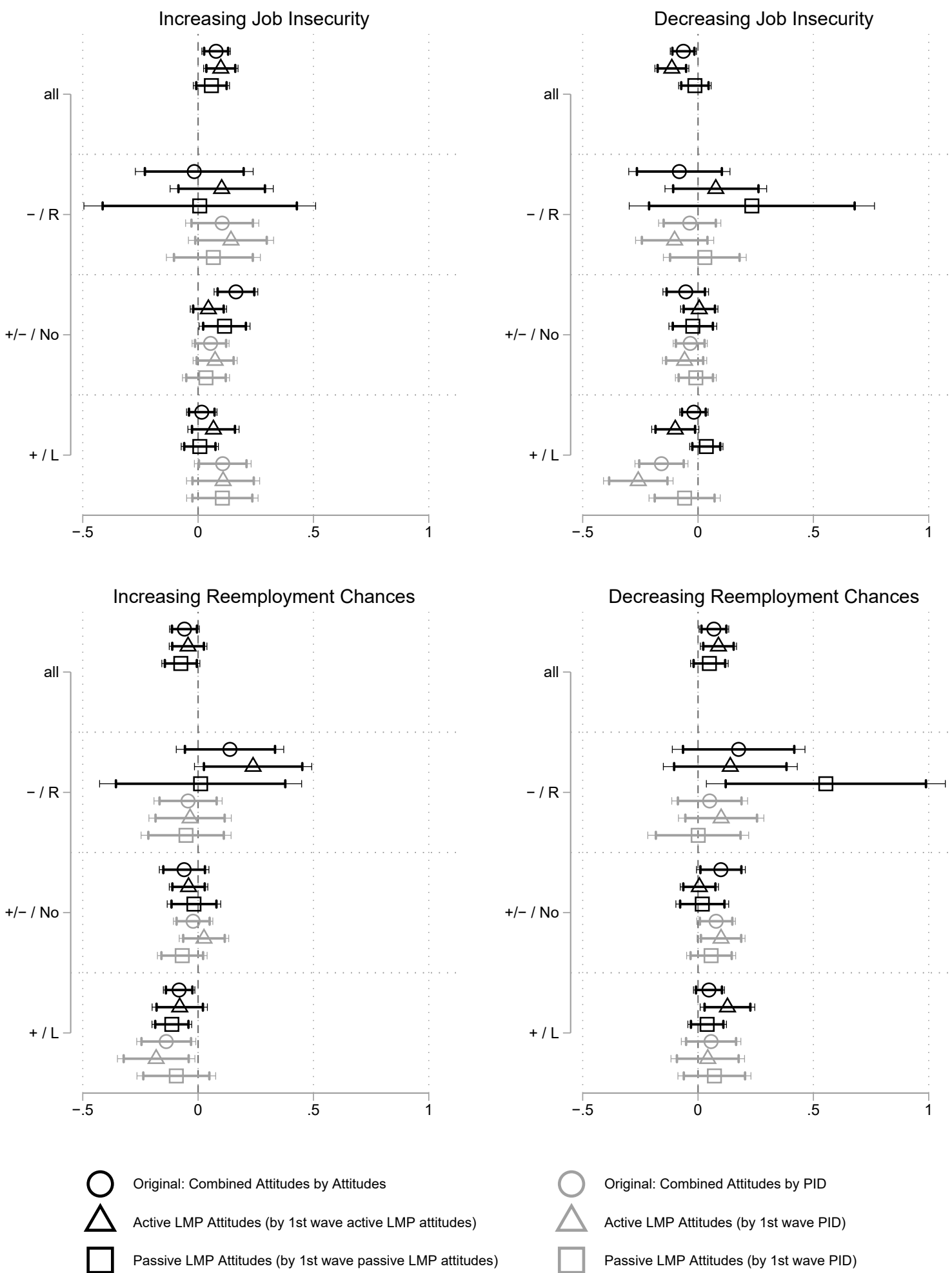

Figure B.3: SOEP Results for Job Insecurity with Separate Models for Active and Passive LMP Attitudes (FE-estimates with $90 \%$ and 95\% Confidence Intervals) 


\section{B.3 Coding}

\section{A DEPENDENT VARIABLES: LMP ATTITUDES}

A.1 SOEP: active and passive LMP attitudes

- variable plh0019 and plh0020 (1997 and 2002; source: SOEP long)

- 1997 and 2002: "At present a multitude of social services are provided not only by the state but also by private freemarket enterprises, organizations, associations, or private citizens. What is your opinion on this? Who should be responsible for the following areas: 1) only the state 2) mostly the state 3 ) state and private forces 4) mostly private forces 5) only private forces?" "Financial security in case of unemployment" (pLMP); "Job creation measures" (aLMP)

- Mean of both items used as dependent variable; scale from 1) only the state to 5) only private forces transformed to scale from 1) only private forces to 5) only the state

B MODERATORS: FIRST WAVE LMP ATTITUDES + FIRST WAVE PARTY IDENTIFICATION

\section{B.1 SOEP}

B.1.1 First wave LMP Attitudes

- Recoding of first wave LMP attitudes (see A.1) into 3 categories: 1) sceptics $=1$ to below 3 on transformed scale 2 ) neutrals $=3$ on original/transformed scale 3 ) supporters $=$ above 3 to 5 on transformed scale

\section{B.1.2 First Wave Party Identification}

- variable plh0011 (existence party ID): "Many people in Germany lean towards one party in the long term, even if they occasionally vote for another party. Do you lean towards a particular party?" (1) yes (2) no (3) don't know

- variable plh0012 (which party): “Toward which party do you lean?" (1) SPD (2) CDU (3) CSU (4) FDP (5) Bündnis '90/Grüne (6) PDS (7) DVU/Republikaner (8) Other

- Recoding into 3 categories:

- left party ID: categories 1,5, and 6 of plh0012, i.e. social democrats, greens, and far left

- no party ID: categories 2 and 3 of plh0011, i.e. no leaning and "don't know" if leaning

- right party ID: categories 2,3,4, and 7 of plh0012, i.e conservatives, liberals, and far right.

- other leanings coded as missings.

left party ID of social democrats, greens, and far left (1,5, and 6 of plh0012); right party ID

\section{INDEPENDENT VARIABLES}

\section{C.1 SOEP}

C.1.1 Employment Transitions

C.1.1.1 Job Loss and Reemployment 
- Labor Force Status: variable pglfs (source: SOEP long (pgen file containing generated variables)) differing between (1) Non-working (2) Nonworking : age 65 and older (3) Non-working: in education-training (4) Non-working : maternity leave (5) Non-working: military-community service (6) Non-working: unemployed (8) Non-working but sometimes sec. job (9) Non-working : work but past 7 days (10) Non-working but reg. sec. job (11) Working (12) Working but Non-working past 7 days

- Registration as unemployed: variable plb0021 (source: SOEP long): "Are you officially registered as unemployed at the Employment Office? Yes (1)/No (2)"

- Both variables recoded into two binary indicators: job loss and reemployment

- Job Loss: 1 if a) plb0021 2002 = 1 and b) plb0021 $1997 \neq 1$ and c) pglfs $1997=11$ or 12,0 if a) plb0021 $2002 \neq 1$ or b) plb0021 $1997=1$ or c) pglfs $1997 \neq 11$ or 12 . (Job Loss thus indicates changes from working to being registered as unemployed, while changes from non-working to unemployment are not indicated.)

- Reemployment: 1 if a) plb0021 $1997=1$ and b) plb0021 $2002 \neq 1$ and c) pglfs $2002=11$ or 12, 0 if a) plb0021 $2002=1$ or b) plb0021 1997 $\neq 1$ or c) pglfs $2002 \neq 11$ or 12 (Reemployment thus indicates changes from being registered as unemployed to working while changes from unemployment to non-working are not indicated.)

\section{C.1.1.2 Transient Job Loss}

- Registration as Unemployed: variable plb0021 (see C.1.1.1) using information from 1998-2001

- Monthly retrospective data on unemployment registration during previous year: variable kal1d01 (source: SOEP long (pkal calendar file) : "And now think back on all of 2001. We've drawn up a type of calendar below. Listed on the left are various employment characteristics that may have applied to you last year. Please go through the various months and check all the months in which you were employed, unemployed, etc." (with Yes (1) / No (2))

- Transient Job Loss: 1 if a) pglfs $1997=11$ or 12 and b) plb0021 1997 and plb0021 $2002 \neq 1$ and c) plb0021 1998 or plb0021 1999 or plb0021 2000 or plb0021 2001 or kal1d01 1998 or kal1d01 1999 or kal1d01 2000 or kal1d01 2001 or kal1d01 $2002=1,0$ if a) pglfs $1997 \neq 11$ or 12 or b) plb0021 1997 or plb0021 $2002=1$ or c) plb0021 1998 through plb0021 2001 and kal1d01 1998 through kal1d01 2002 all $\neq 1$ (Transient Job Loss thus indicates a Job Loss after 1997 and before 2002, while it does not indicate unemployment registration after nonemployment in 1997)

\section{C.1.1.3 Fixed $\rightarrow$ Perm contract and Perm $\rightarrow$ Fixed contract}

- Employment contract: variable plb0037: "Do you have a temporary or unlimited contract? Temporary (2) - Unlimited (1) Not applicable, do not have an employment contract (3/4)" 
- Information for plb0037 in 1997 and 2002 recoded into two binary indicators

- Fixed $\rightarrow$ Perm: 1 if a) plb0037 $1997=2$ and b) plb0037 $2002=1,0$ if a) plb0037 $1997 \neq 2$ or b) plb0037 $2002 \neq 1$ or c) plb0021 1997 or $2002=1$ (Fixed $\rightarrow$ Perm thus indicates changes from a fixed-term to a permanent contract, while not indicating changes to or from an employment without a contract, or a change to or from a contract while simulteanously being registered as unemployed)

- Perm $\rightarrow$ Fixed: 1 if a) plb0037 $1997=1$ and b) plb0037 $2002=2,0$ if a) plb0037 $1997 \neq 1$ or b) plb0037 $2002 \neq 2$ or c) plb0021 1997 or $2002=1$ (Perm $\rightarrow$ Fixed thus indicates changes from a permanent to a fixed-term contract, while not indicating changes to or from an employment without a contract, or a change to or from a contract while simulteanously being registered as unemployed)

C.1.1.4 Improvements and Deteriorations of Employment Situation

- Main analyses are based on a combination of deteriorations and on a combination of improvements of the employment situation

- Employment Related Deterioration: binary indicator: 1 if job loss $=1$ or Permanent $\rightarrow$ Fixed-term contract $==1,0$ if otherwise

- Employment Related Improvement: binary indicator: 1 if reemployment $=1$ or Fixed-term $\rightarrow$ Permanent contract $==1,0$ if otherwise

\section{C.1.2 Job Insecurity Perception Changes}

- "What is your attitude towards the following areas - are you concerned about them?" "If you are employed: Your job security" "(1) Very concerned - (2) somewhat concerned - (3) not concerned at all" (plh0042, job insecurity)

- Answers from 1997 and 2002 recoded into two binary variables

- increasing job insecurity (1 if plh0042 $2002<$ plh0042 1997, 0 if plh0042 $2002 \geq$ plh0042 1997

- decreasing job insecurity ( 1 if plh0042 $2002>$ plh0042 1997, 0 if plh0042 $2002 \leq$ plh0042 1997

- "If you lost your job today, would it be easy, difficult, or almost impossible for you to find a new position which is at least as good as your current one?" “(1) Easy - (2) Difficult - (3) Almost impossible. (plb0043, reemployment chances)

- Answers from 1997 and 2002 recoded into two binary variables

- increasing reemployment chances(1 if plb0043 $2002<$ plb0043 1997, 0 if plb0043 $2002 \geq$ plb0043 1997

- decreasing reemployment chances (1 if plb0043 $2002>$ plb0043 1997, 0 if plb0043 $2002 \leq$ plb0043 1997

\section{CONTROL VARIABLES}

\section{D.1 SOEP}

D.1.1 Further Education

- variable plg0012 
- "Are you currently in some sort of education? In other words, do you attend a school or institution of higher education, are you engaged in an apprenticeship or are you participating in further education or training?" [yes/no]

- Information of plg0012 for all waves between 1997 and 2002 recoded into one binary indicator: 1 if further education in at least one of the waves between 1997-2002; 0 if no further education in all waves 1997-2002 or if already in further training in 1997

D.1.2 Child Birth

- variable pld0152

- "Has your family situation changed after [last 1 or 2 years]? Please indicate if any of the following apply to you and if so, when this change occurred."

- Creation of binary indicator indicating 1 , if event occured in any of the years 1998-2002, 0 otherwise

- For 1998 cases are excluded where the child birth happened before the interview in 1997 - based on the interview data in 1997 (variable pmonin) and the month of the child birth (variables pld0153 month present year - 1997 - and pld0154 month previous year - 1996 -)

D.1.3 Subjective Health

D.1.3.1 Subjective Health Changes 1997-2002

- variable ple0008

- "How would you describe your current health?"

- Answers on 5-point scale: 1 "very good" 2 "good" 3 "satisfactory" 4 "poor" 5 "bad"

- No recoding

D.1.3.2 Subjective Health Changes Between Waves

- Computation of individual average subjective health in years 1998-2001

- Final variable compares change from first wave (1997) subjective health to average 1998-2001 for second wave (2002) 


\section{Appendix for Article 3}

\section{Appendix}

Appendix for "The Dynamics of Unemployment, Risk, and Left-Right Ideology. Constrained Change or Changed Constraints?"

A similar version of this appendix and the Stata-code for the analyses can be found at OSF :

https: //osf . io/zmnkq/?view_only=d64ec122febe41a7a5edfcf9ae421c06

\section{Contents}

C.1 Robustness Checks . . . . . . . . . . . . . . . . . . . . . . 190

C.1.1 Main Effects Including Lagged Treatment Effects . . . . . . . . . 190

C.1.2 Main Effects (Netherlands) Using Lagged Measurement of Insecurity 193

C.1.3 Respecifications for Prior Left-Right Interactions . . . . . . . . 195

C.1.4 Respecifications for Age Interactions . . . . . . . . . . . . . 197

C.1.5 Results (Netherlands and Switzerland) Using Alternative Labor Force Status Measurements . . . . . . . . . . . . . . . 199

C.2 Salience: Descriptives and Robustness checks _ . . . . . . . . . 203

C.2.1 Descriptives of Contextual Salience . . . . . . . . . . . . 203

C.2.2 Results (Netherlands) during High Economic Salience Period . . . 203

C.3 Main Results: Tabular Version . . . . . . . . . . . . . . . . . . . . . 209

C.3.1 Tabular Results for Figure 1 . . . . . . . . . . . . . . . . . . . 209

C.3.2 Tabular Results for Figure $2 \ldots \ldots \ldots$

C.3.3 Tabular Results for Figure 3 . . . . . . . . . . . . . 213

C.4 Descriptives . . . . . . . . . . . . . . . . . . . . . . 215

C.5 Illustration of FE and FEIS with Artificial Example $\ldots \ldots \ldots$

C.6 Items \& Coding . . . . . . . . . . . . . . . . . . . . . . . . . . . . . 219 
Appendix

\section{C.1 Robustness Checks}

C.1.1 Main Effects Including Lagged Treatment Effects 


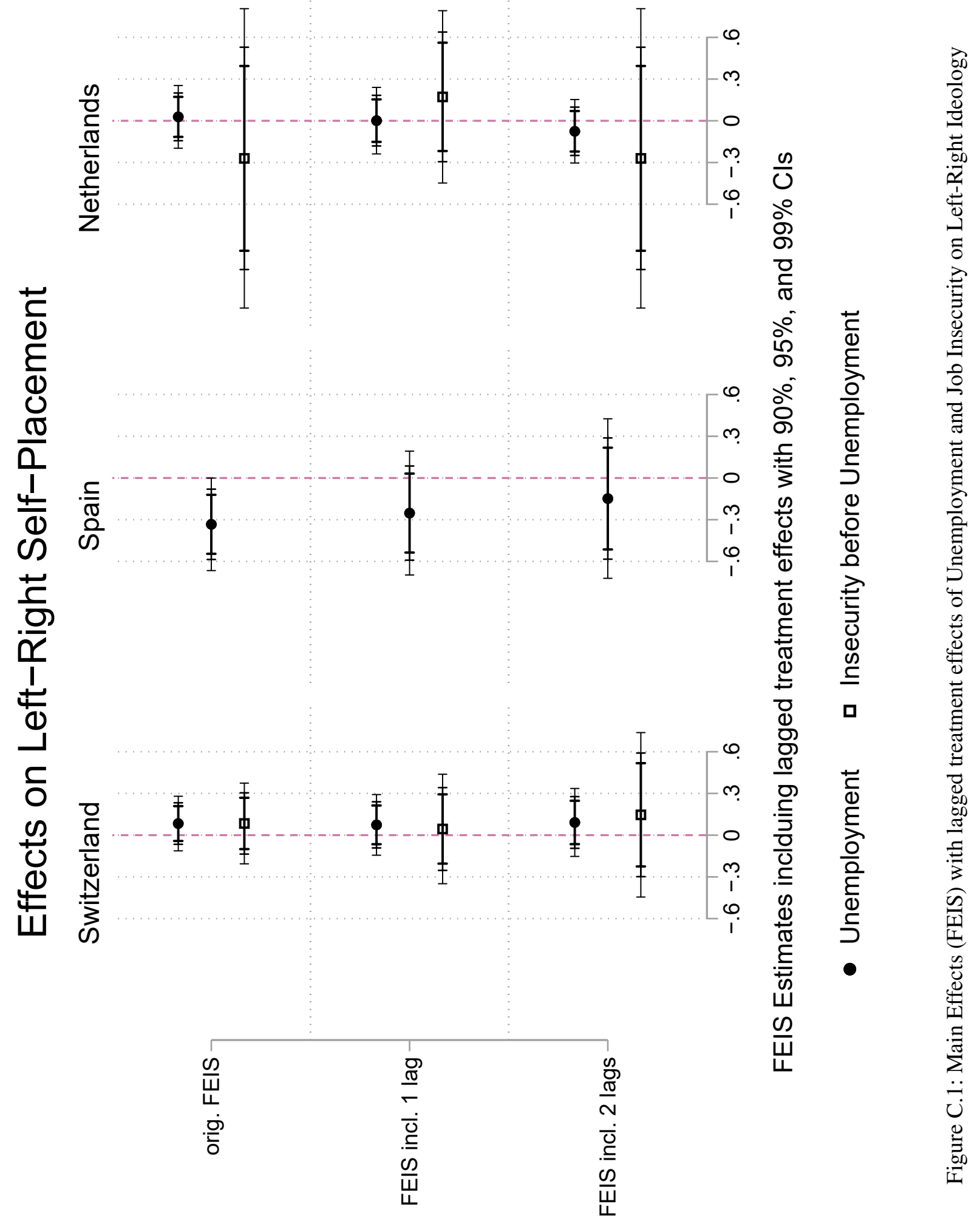



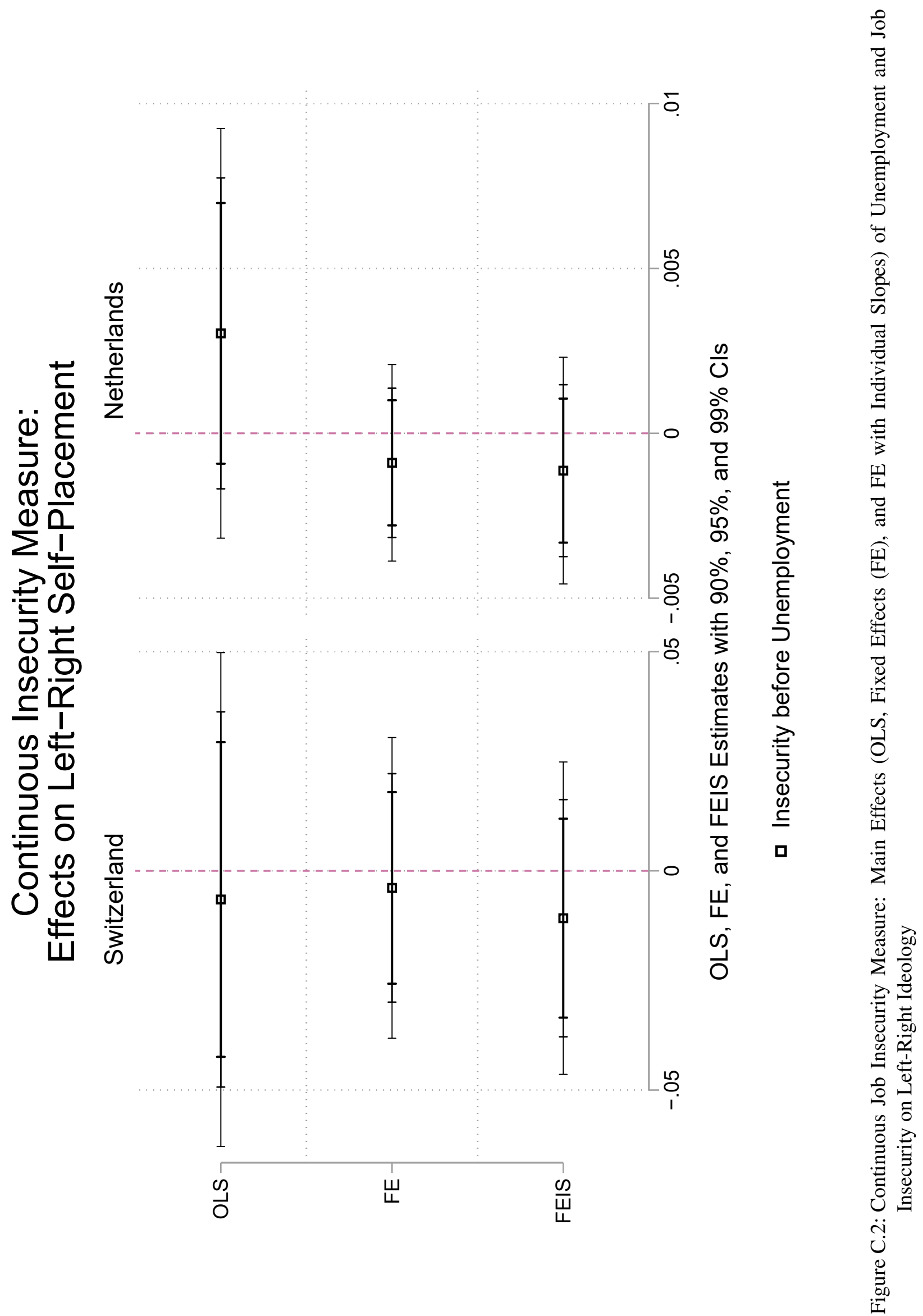
C.1.2 Main Effects (Netherlands) Using Lagged Measurement of Insecurity 

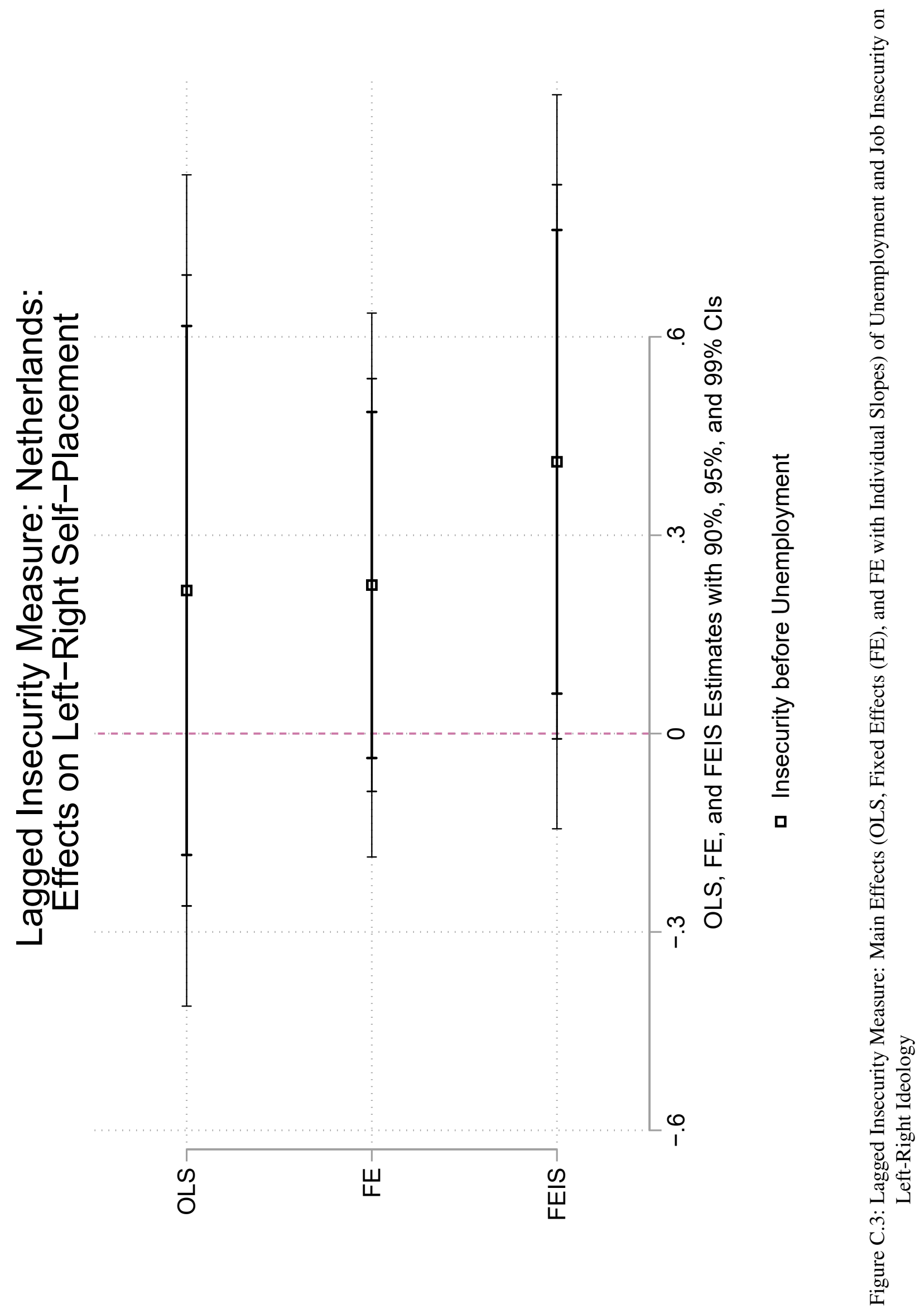
C.1.3 Respecifications for Prior Left-Right Interactions 


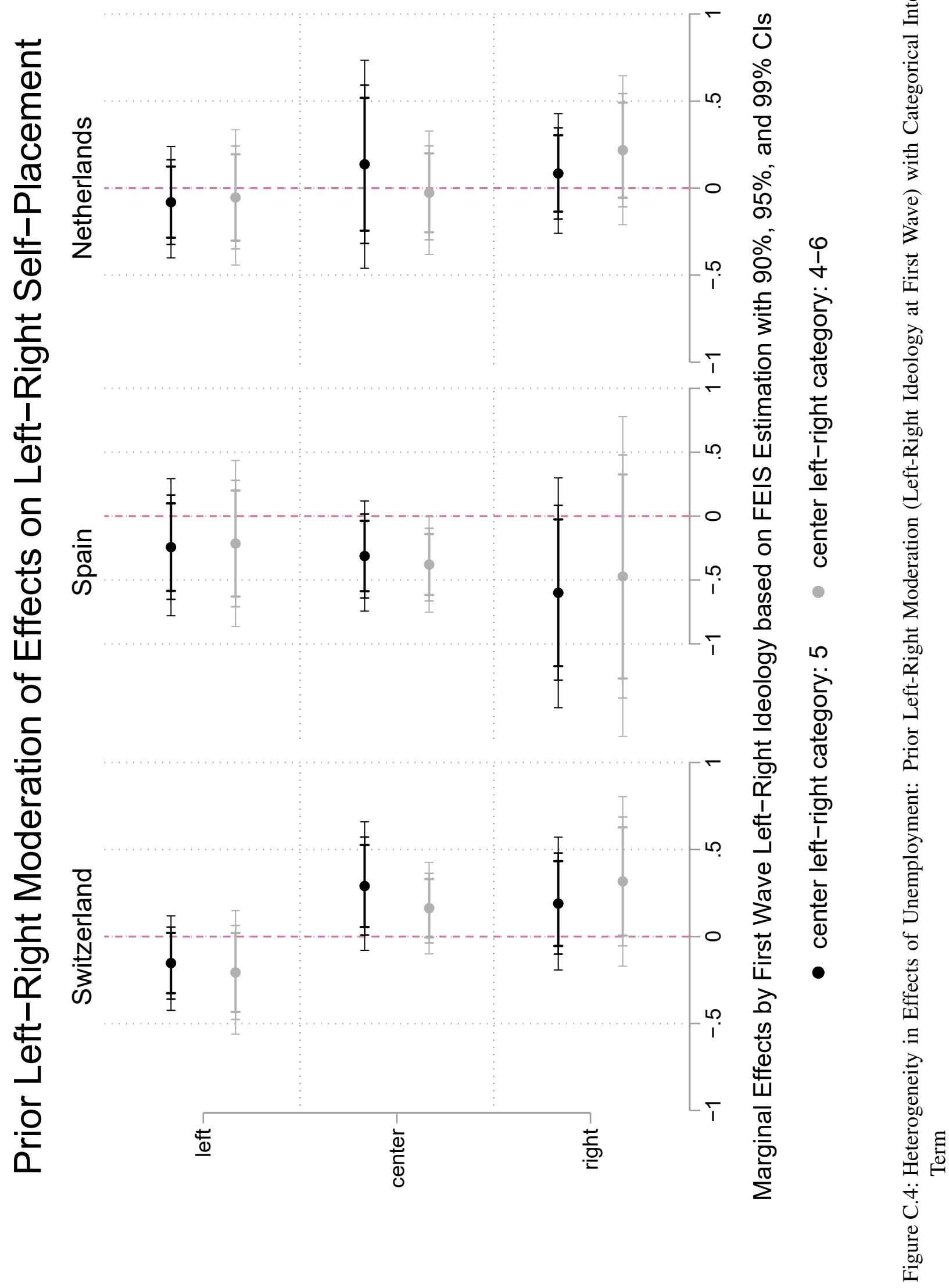


C.1.4 Respecifications for Age Interactions 


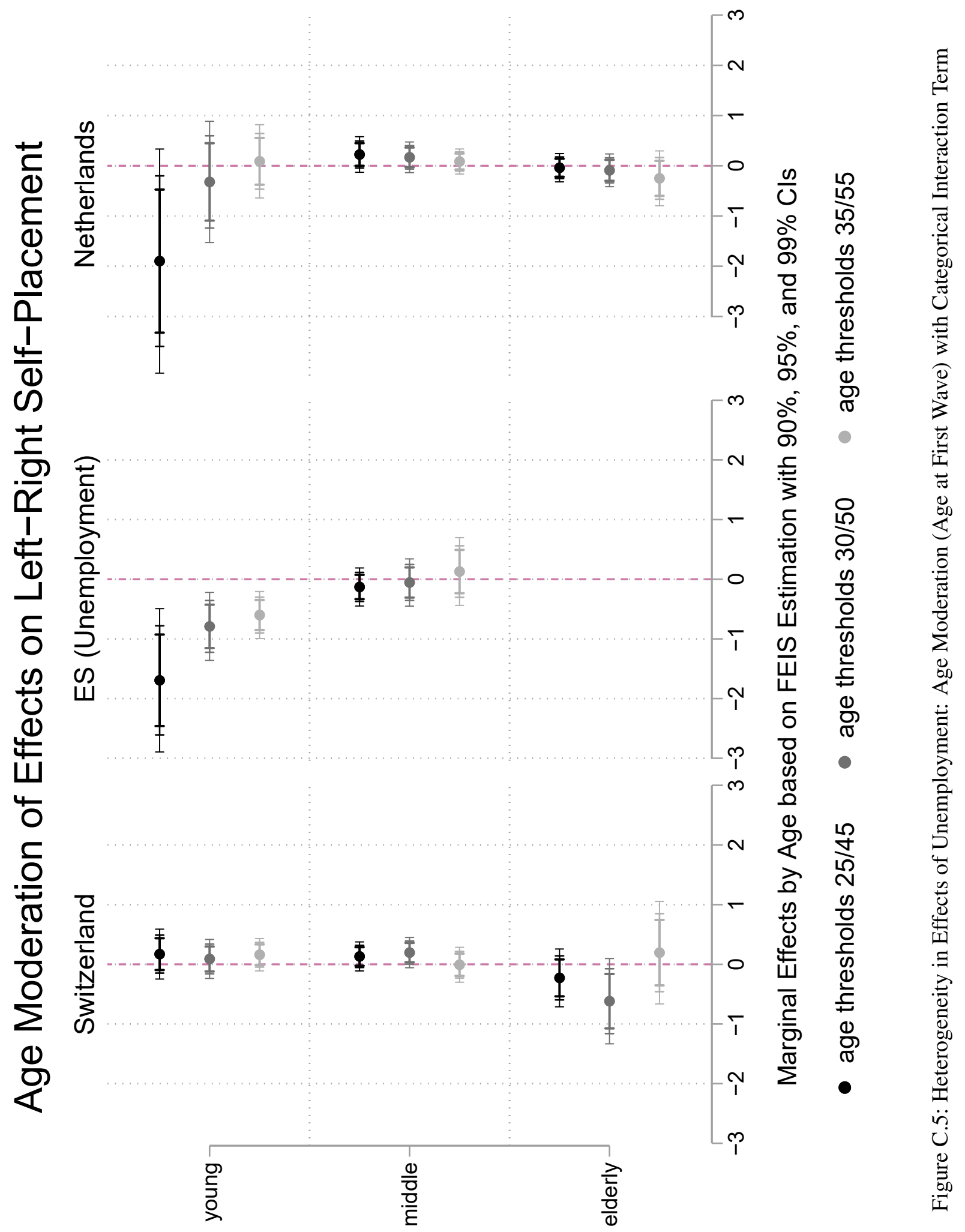


C.1.5 Results (Netherlands and Switzerland) Using Alternative Labor Force Status Measurements 


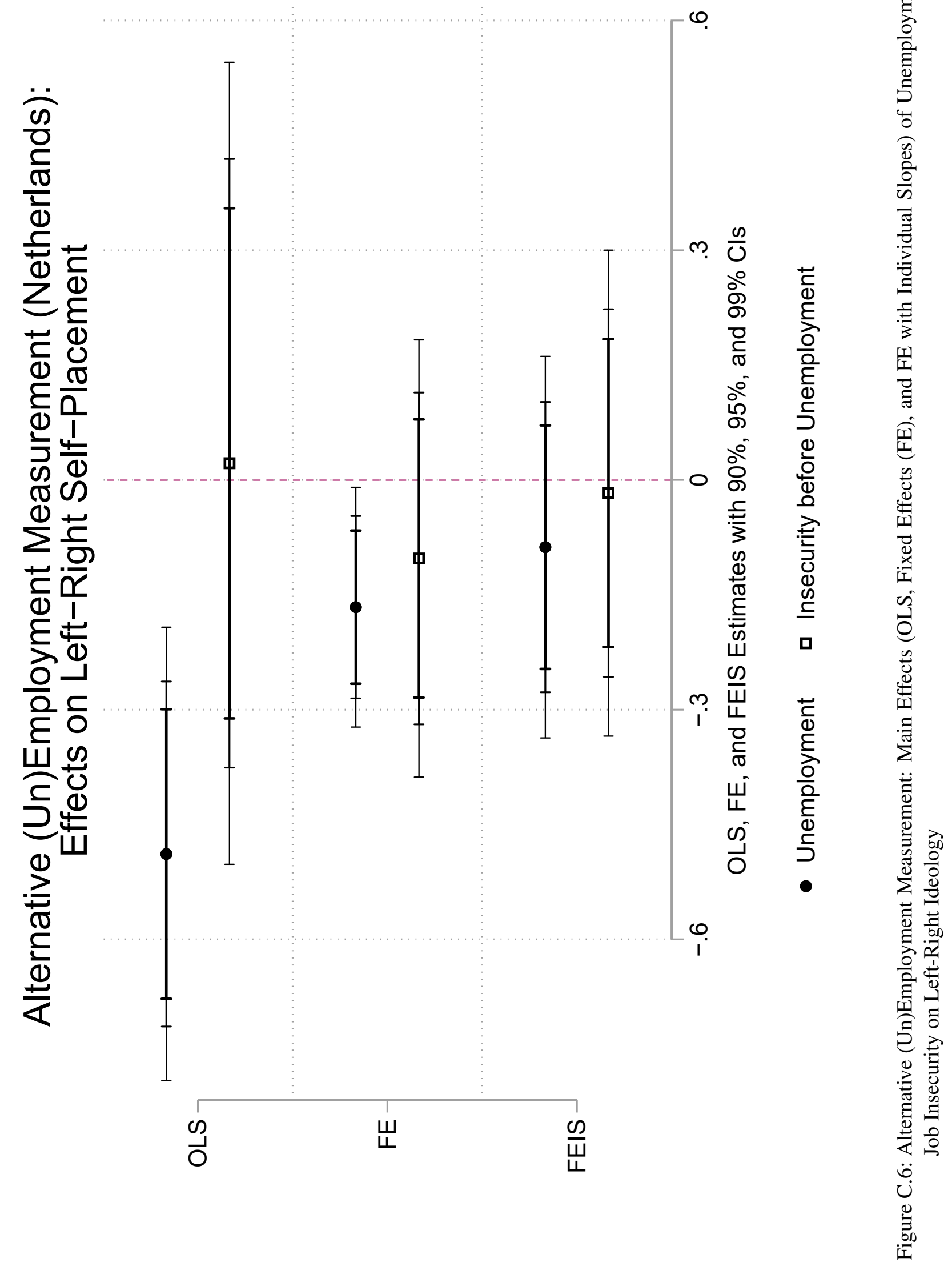



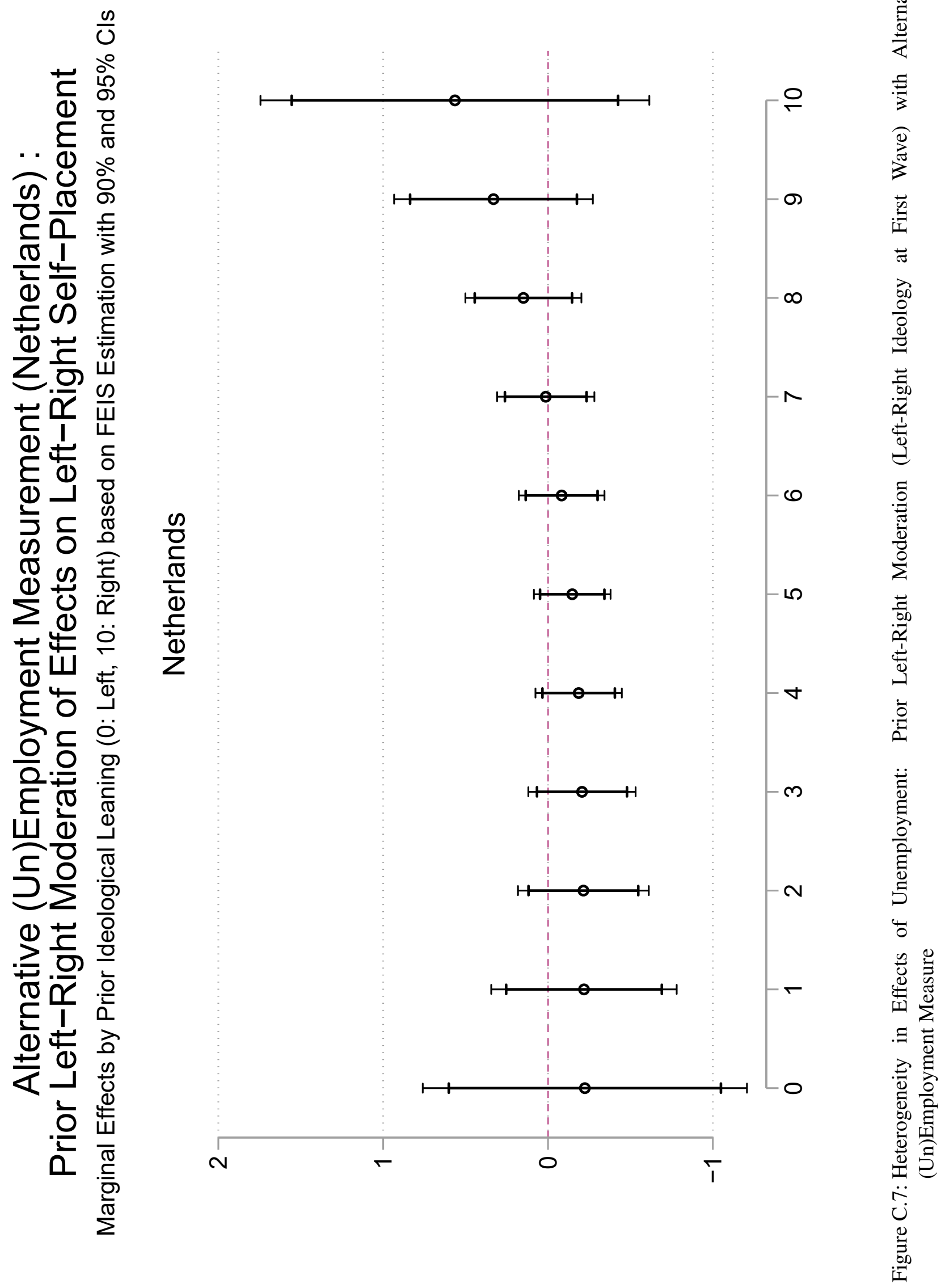

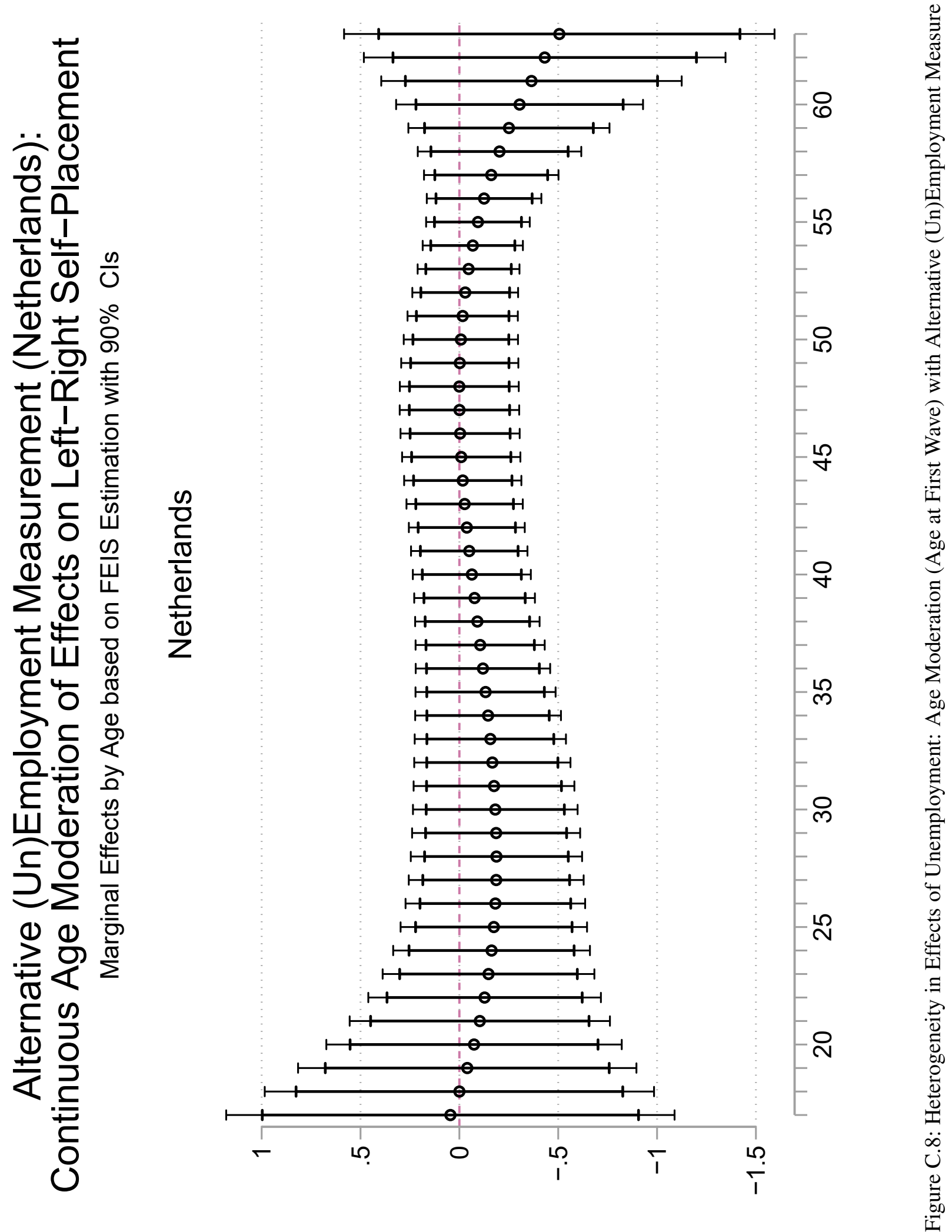


\section{C.2 Salience: Descriptives and Robustness checks}

C.2.1 Descriptives of Contextual Salience

C.2.2 Results (Netherlands) during High Economic Salience Period 


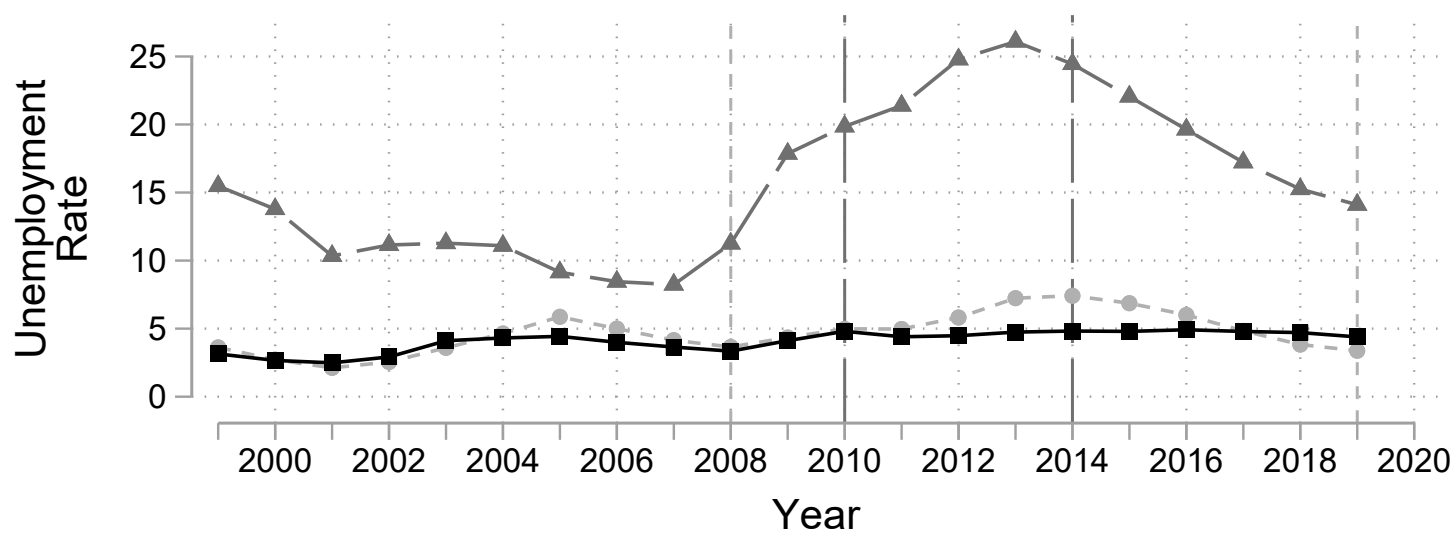

$\neg \mathrm{ES} \quad-\mathrm{NL} \rightarrow \mathrm{CH}$

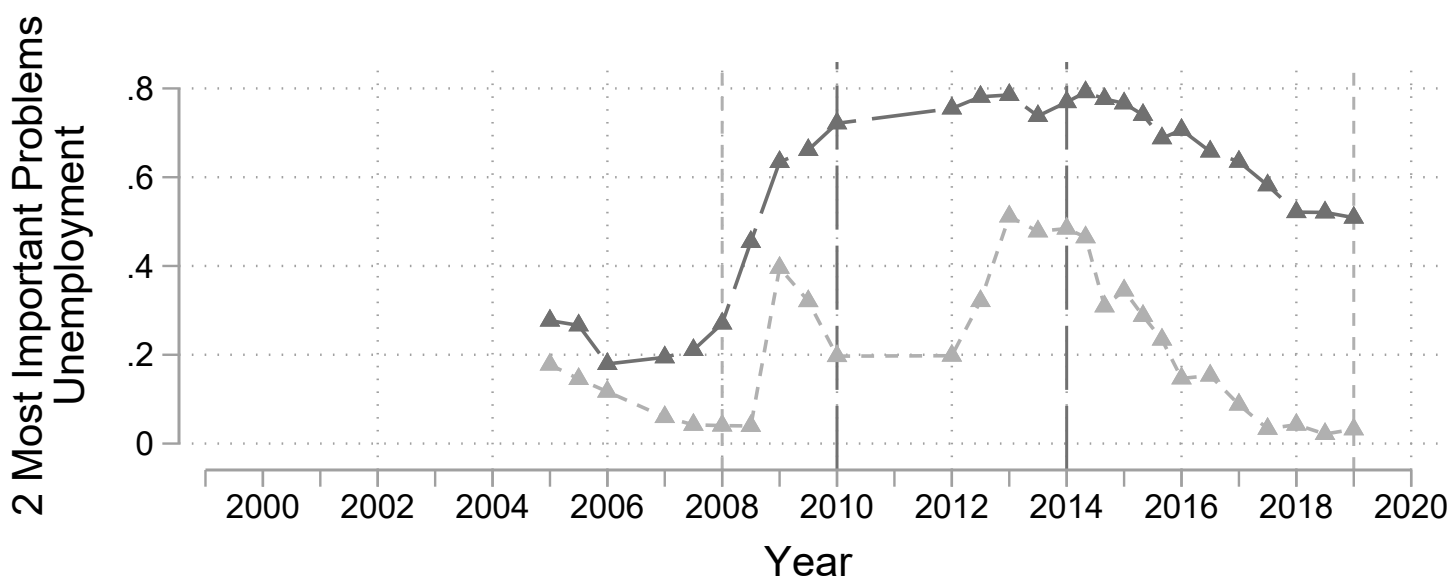

$\perp$ ES $-\mathrm{NL}$

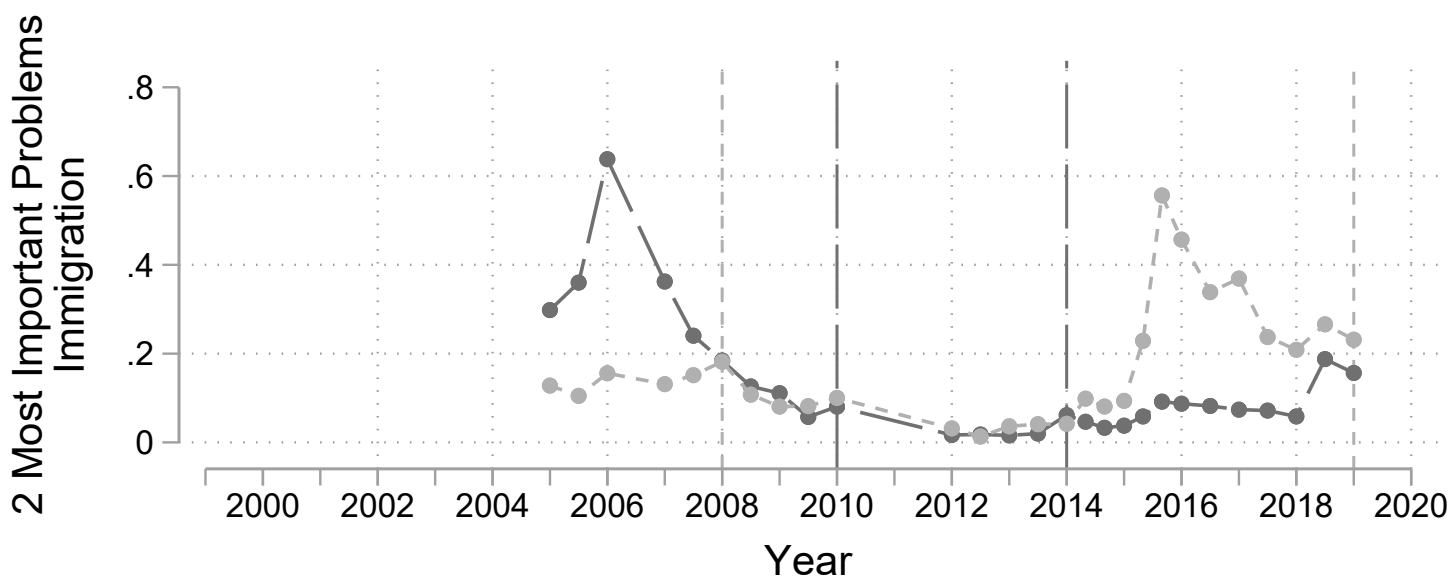

$\rightarrow$ ES $\quad-\cdots \cdot \mathrm{NL}$

Figure C.9: Salience Indicators: Unemployment Rate (World Development Indicators) and Unemployment and Immigration as Most Important Problem (Eurobarometer) 


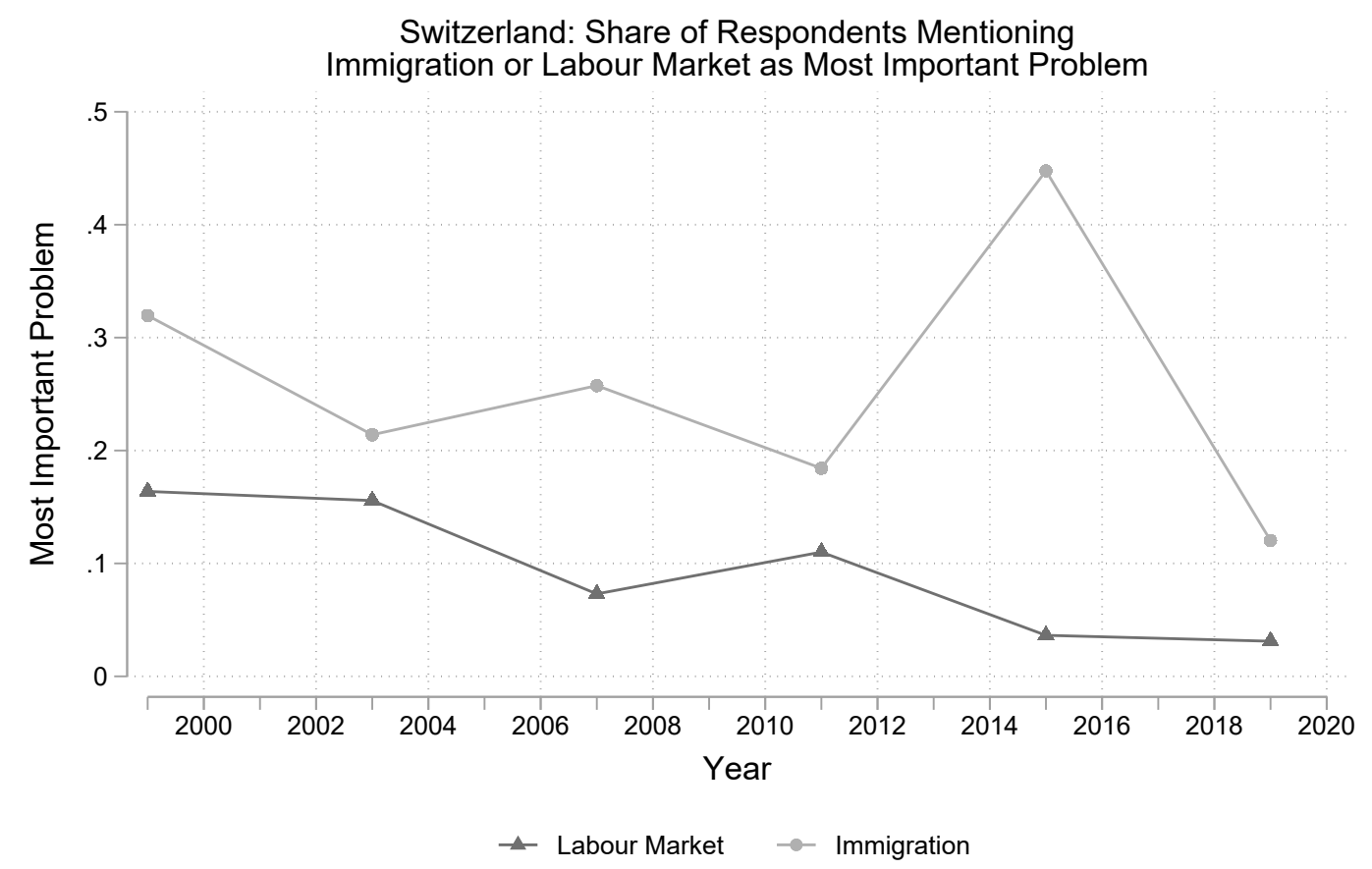

Figure C.10: Salience Indicators: Switzerland: Labour Market and Immigration as Most Important Problems (Selects) 


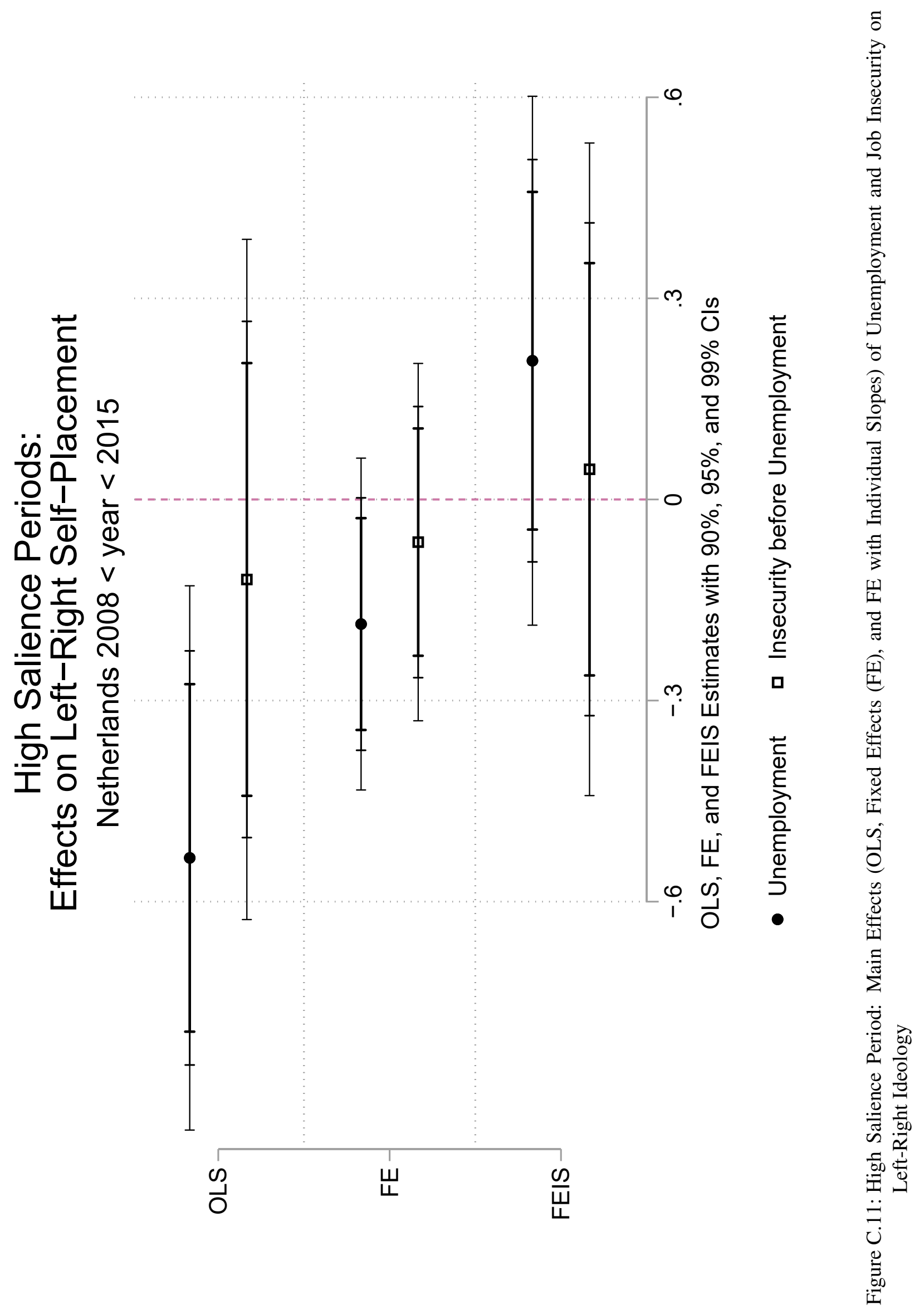




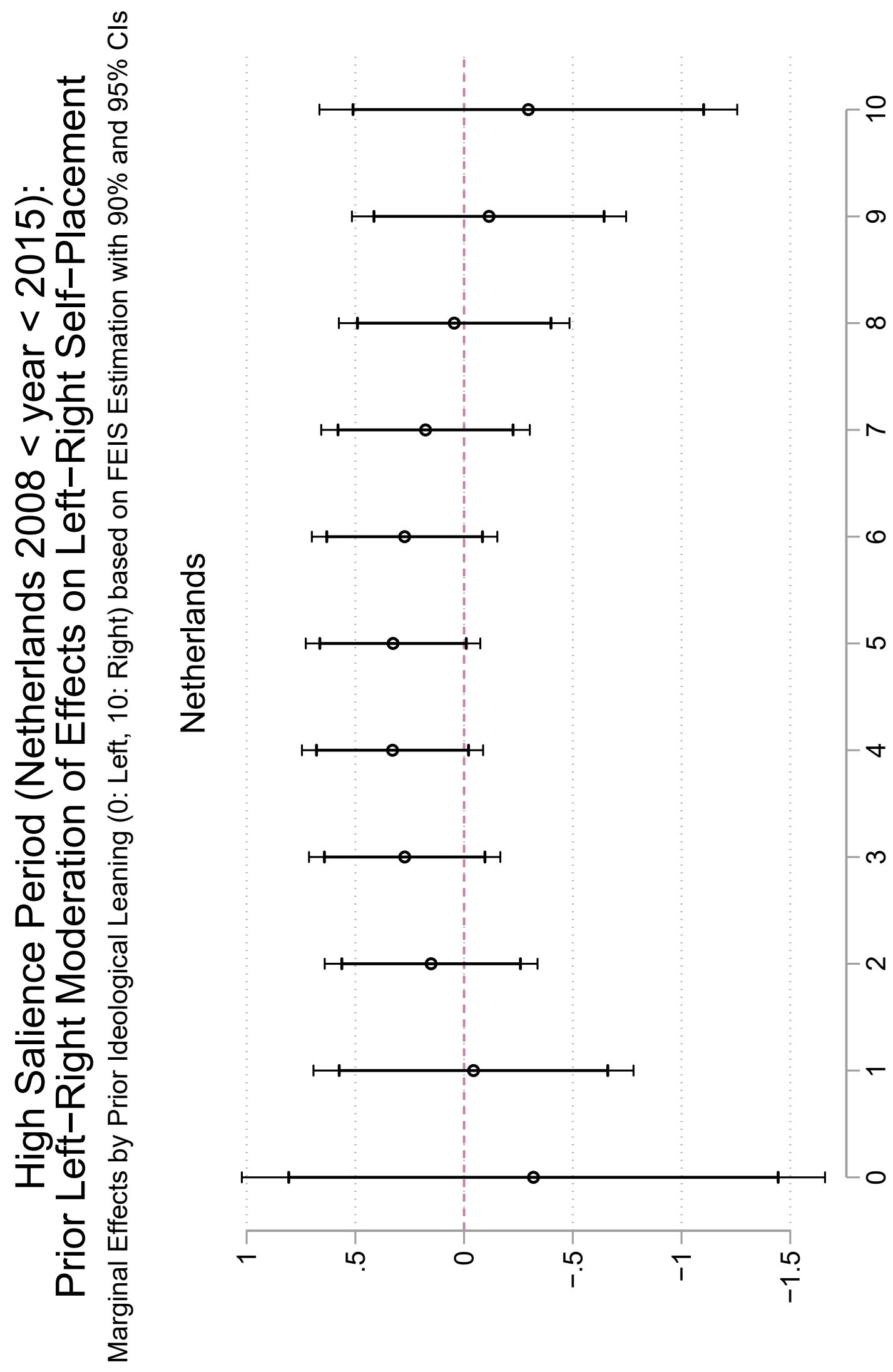



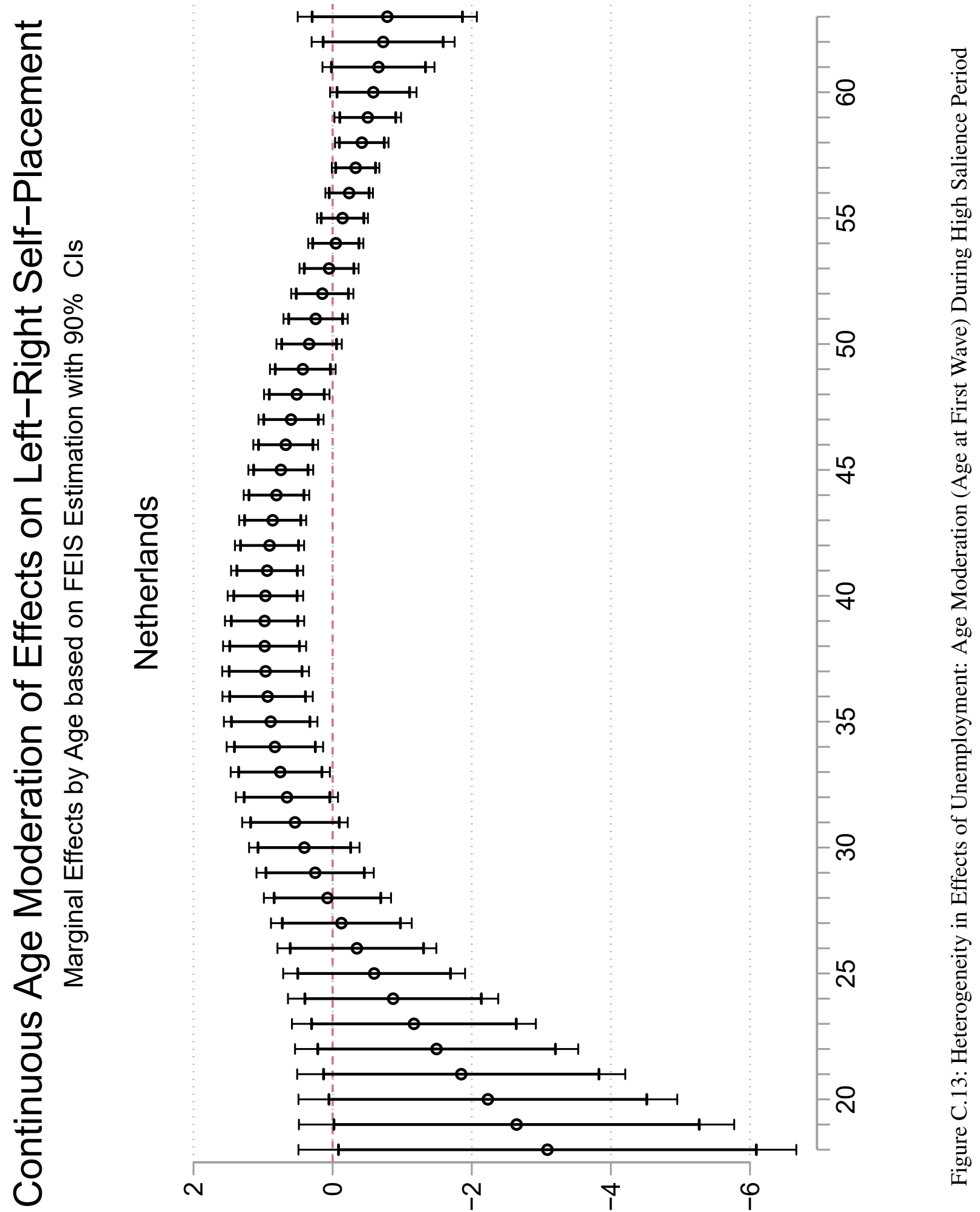


\section{C.3 Main Results: Tabular Version}

C.3.1 Tabular Results for Figure 1 


\begin{tabular}{|c|c|c|c|c|c|}
\hline & \multicolumn{2}{|c|}{ Switzerland } & \multirow{2}{*}{$\begin{array}{l}\text { Spain } \\
\text { Ue. }\end{array}$} & \multicolumn{2}{|r|}{ Netherlands } \\
\hline & Ue. & Insec bf. Ue. & & Ue. & Insec bf. Ue. \\
\hline Into Unemployment & $\begin{array}{c}-0.2440^{* *} \\
(0.0901)\end{array}$ & & $\begin{array}{l}-0.1093 \\
(0.1327)\end{array}$ & $\begin{array}{c}-0.5478^{* * *} \\
(0.1197)\end{array}$ & \\
\hline Increasing Job Insecurity & & $\begin{array}{c}0.0870 \\
(0.1210)\end{array}$ & & & $\begin{array}{c}-0.0940 \\
(0.1867)\end{array}$ \\
\hline Constant & $\begin{array}{c}4.6518^{* * *} \\
(0.0379)\end{array}$ & $\begin{array}{c}4.6102^{* * *} \\
(0.1649)\end{array}$ & $\begin{array}{c}4.3356^{* * *} \\
(0.0568)\end{array}$ & $\begin{array}{c}5.1528^{* * *} \\
(0.0415)\end{array}$ & $\begin{array}{c}4.9351^{* * *} \\
(0.1582)\end{array}$ \\
\hline Person-Years & 74098 & 1321 & 5662 & 25179 & 821 \\
\hline$R^{2}$ & 0.00 & 0.02 & 0.00 & 0.00 & 0.01 \\
\hline
\end{tabular}

Panel Robust Standard Errors in Parentheses. Wave Dummies not shown. Ue. = Unemployment; Insec. bf. Ue. = Insecurity before Unemployment $+p<0.10,{ }^{*} p<0.05,{ }^{* *} p<0.01,{ }^{* * *} p<0.001$

Table C.1: Main Results: Effects on Left-Right Ideology (OLS)

\begin{tabular}{lccccc}
\hline \hline & \multicolumn{2}{c}{ Switzerland } & Spain & \multicolumn{2}{c}{ Netherlands } \\
& Ue. & Insec bf. Ue. & Ue. & Ue. & Insec bf. Ue. \\
\hline Into Unemployment & -0.0130 & & $-0.1539^{+}$ & $-0.1010^{+}$ & \\
& $(0.0589)$ & & $(0.0832)$ & $(0.0606)$ & -0.0926 \\
Increasing Job Insecurity & & -0.1209 & & & $(0.0975)$ \\
& & $(0.0965)$ & & & $4.9493^{* * *}$ \\
Constant & & & & & $(0.0891)$ \\
& $4.6306^{* * *}$ & $4.5775^{* * *}$ & $4.3587^{* * *}$ & $5.2414^{* * *}$ & 821 \\
Person-Years & $(0.0279)$ & $(0.1383)$ & $(0.0281)$ & $(0.0248)$ & 280 \\
Persons & 74098 & 1321 & 5662 & 25179 & 0.03 \\
$R^{2}$ & 11682 & 452 & 1363 & 5178 & 0.01 \\
\hline \hline
\end{tabular}

Panel Robust Standard Errors in Parentheses. Wave Dummies not shown. Ue. = Unemployment; Insec. bf. Ue. = Insecurity before Unemployment $+p<0.10,{ }^{*} p<0.05,{ }^{* *} p<0.01,{ }^{* * *} p<0.001$

Table C.2: Main Results: Effects on Left-Right Ideology (Fixed Effects)

\begin{tabular}{lccccc}
\hline \hline & \multicolumn{2}{c}{ Switzerland } & Spain & & Netherlands \\
& Ue. & Insec bf. Ue. & Ue. & Ue. & Insec bf. Ue. \\
\hline Into Unemployment & 0.0835 & & $-0.3332^{* *}$ & 0.0281 & \\
& $(0.0762)$ & & $(0.1289)$ & $(0.0875)$ & -0.0197 \\
Increasing Job Insecurity & & 0.0841 & & & $(0.1424)$ \\
& & $(0.1117)$ & & & 139 \\
Persons & 9194 & 216 & 1082 & 3668 & 0.04 \\
$R^{2}$ & 0.00 & 0.05 & 0.00 & 0.01 & \\
\hline \hline
\end{tabular}

Panel Robust Standard Errors in Parentheses. Wave Dummies not shown. Ue. = Unemployment; Insec. bf. Ue. = Insecurity before Unemployment ${ }^{+} p<0.10,{ }^{*} p<0.05,{ }^{* *} p<0.01,{ }^{* * *} p<0.001$

Table C.3: Main Results: Effects on Left-Right Ideology (Fixed Effects with Individual Slopes) 
C.3.2 Tabular Results for Figure 2 


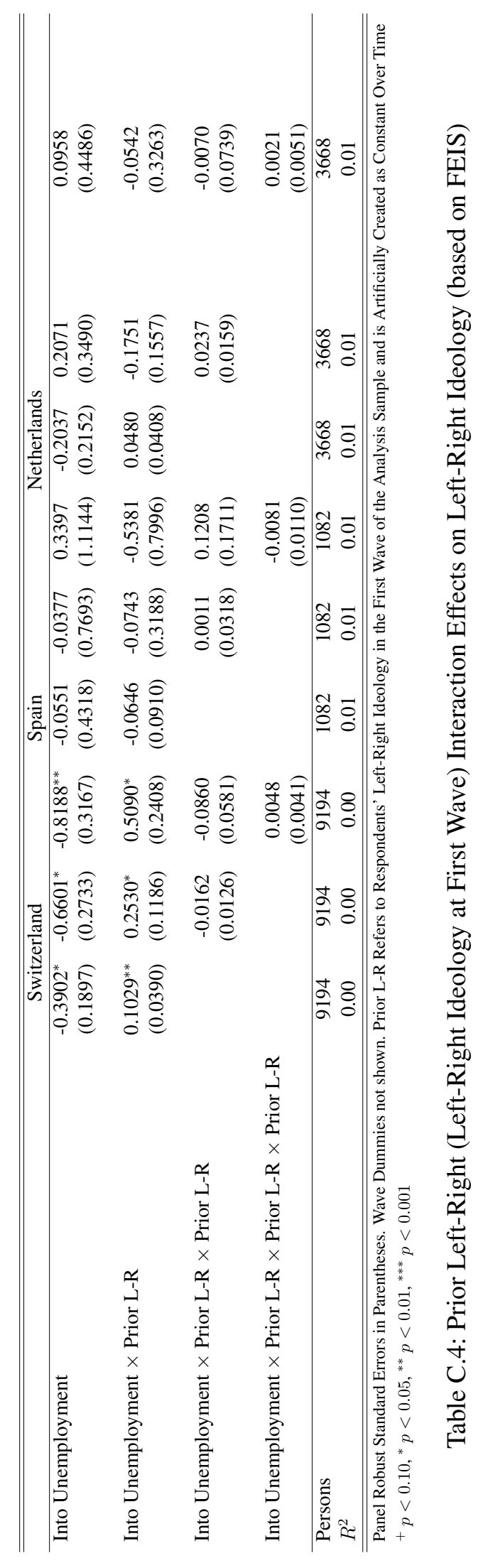


C.3.3 Tabular Results for Figure 3 


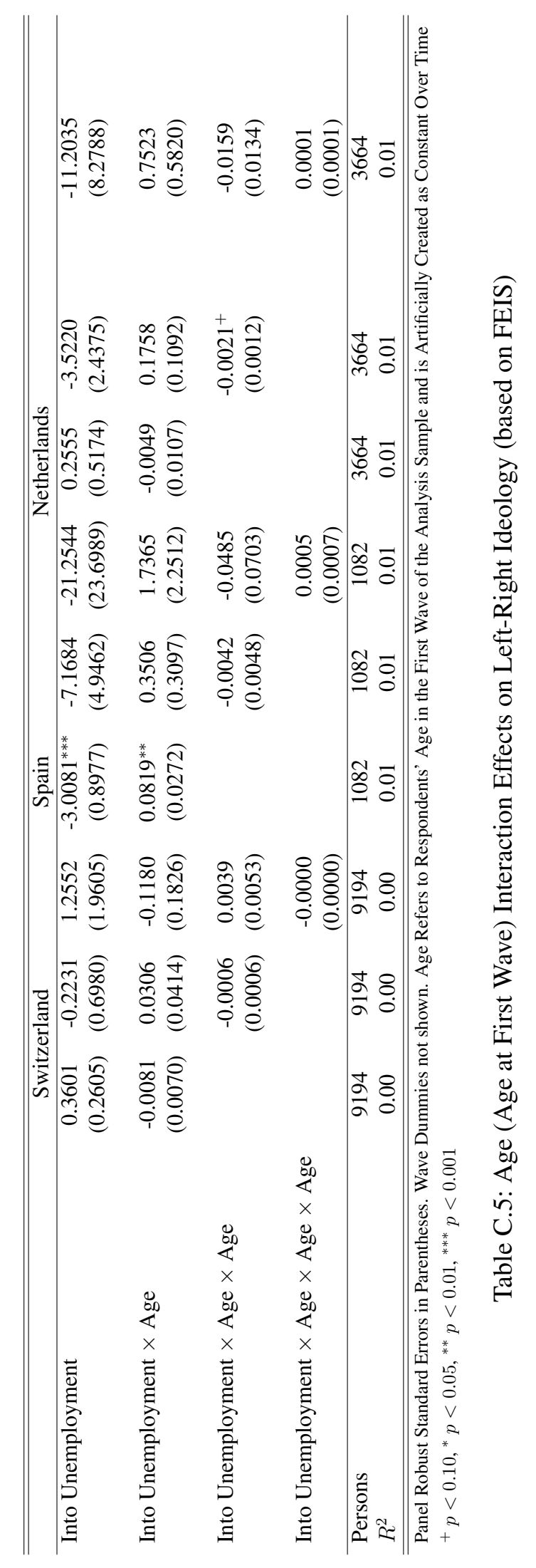




\section{C.4 Descriptives}




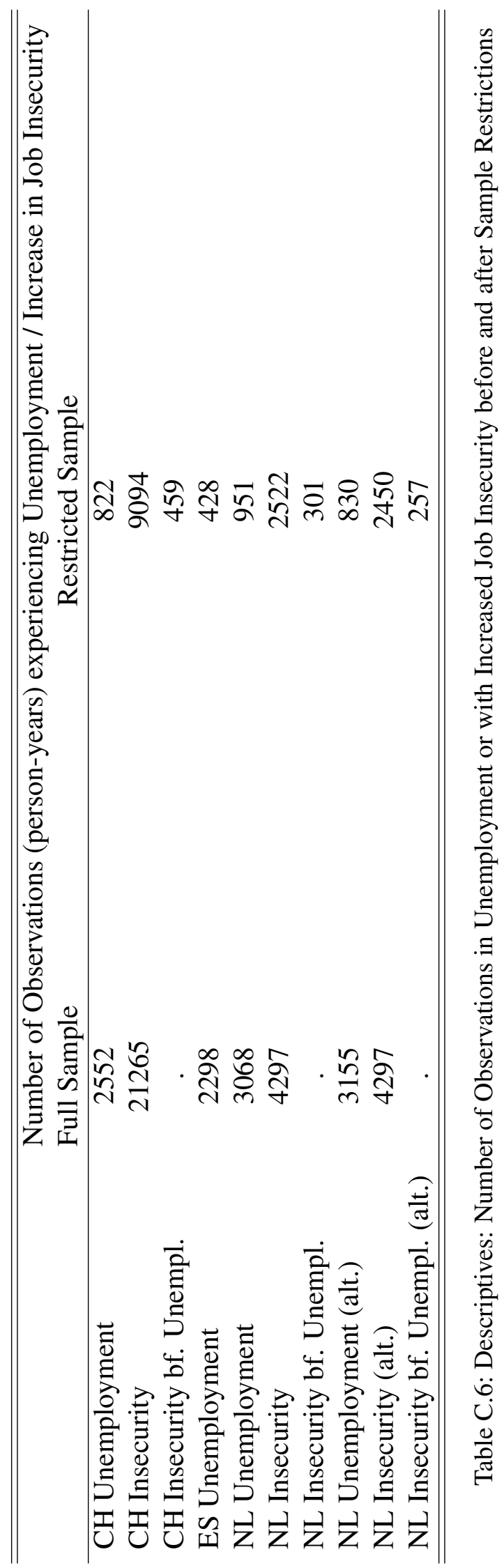




\section{C.5 Illustration of FE and FEIS with Artificial Example}

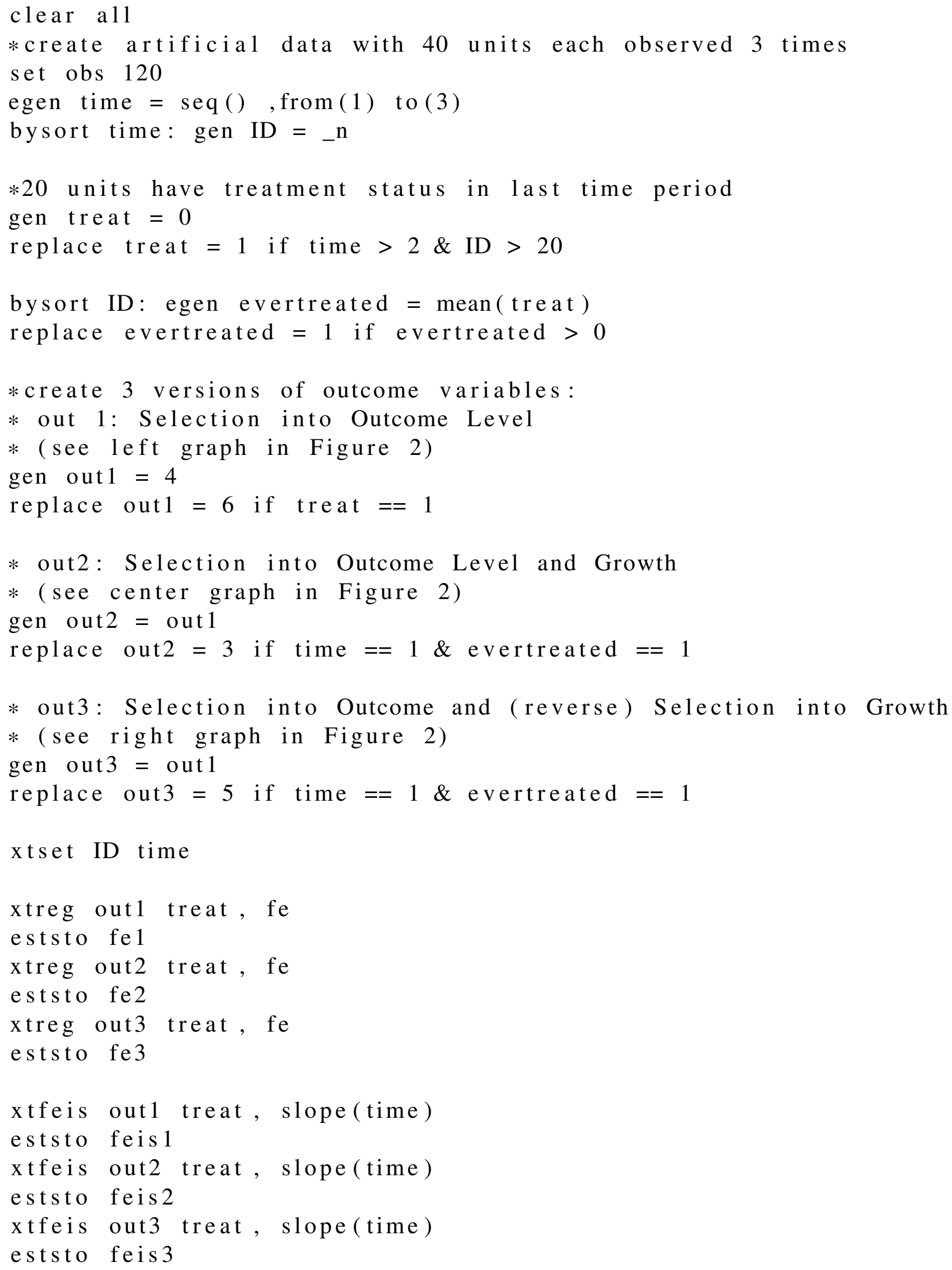


*"manual" solution with OLS estimation

regress out 1 treat i.ID

eststo fe1_manual

regress out2 treat i.ID

eststo fe2_manual

regress out3 treat i.ID

eststo fe3_manual

regress out 1 treat i.ID i.ID\#c.time

eststo feis 1_manual

regress out 2 treat i.ID i.ID\#c.time

eststo feis 2_manual

regress out 3 treat i.ID i.ID\#c.time

eststo feis3_manual

\begin{tabular}{lcccccc}
\hline \hline & \multicolumn{2}{c}{ Out1 - No bias } & \multicolumn{2}{c}{ Out2 - FE overestimates } & \multicolumn{2}{c}{ Out3 - FE Underestimates } \\
& FE 1 & FEIS 1 & FE 2 & FEIS 2 & FE 3 & FEIS 3 \\
\hline treat & 2.00 & $2.00^{* * *}$ & $2.50^{* * *}$ & $1.00^{* * *}$ & $1.50^{* * *}$ & $3.00^{* * *}$ \\
& $()$. & $(0.00)$ & $(0.10)$ & $(0.00)$ & $(0.10)$ & $(0.00)$ \\
Constant & 4.00 & & $3.75^{* * *}$ & & & $4.25^{* * *}$ \\
& $()$. & & $(0.04)$ & & $(0.04)$ & \\
\hline Observations & 120 & 120 & 120 & 120 & 120 & 120 \\
\hline \hline
\end{tabular}

Standard errors in parentheses

${ }^{*} p<0.05,{ }^{* *} p<0.01,{ }^{* * *} p<0.001$

Table C.7: Results from Artificial Example

\begin{tabular}{lcccccc}
\hline \hline & \multicolumn{2}{c}{ Out1 - No bias } & \multicolumn{2}{c}{ Out2 - FE overestimates } & \multicolumn{2}{c}{ Out3 - FE Underestimates } \\
& FE 1 & FEIS 1 & FE 2 & FEIS 2 & FE 3 & FEIS 3 \\
\hline treat & 2.00 & 2.00 & $2.50^{* * *}$ & 1.00 & $1.50^{* * *}$ & 3.00 \\
& $()$. & $()$. & $(0.10)$ & $()$. & $(0.10)$ & $()$. \\
Constant & 4.00 & 4.00 & $4.00^{* * *}$ & 4.00 & $4.00^{* * *}$ & 4.00 \\
& $()$. & $()$. & $(0.21)$ & $()$. & $(0.21)$ & $()$. \\
\hline Observations & 120 & 120 & 120 & 120 & 120 & 120 \\
\hline \hline
\end{tabular}

Standard errors in parentheses

${ }^{*} p<0.05,{ }^{* *} p<0.01,{ }^{* * *} p<0.001$

Table C.8: "Manual" OLS Results from Artificial Example 


\section{C.6 Items \& Coding}

\section{Dependent Variable: Left-Right Ideology}

\section{Left-Right Ideology in Swiss SHP Data}

Variable var10:

When they talk about politics, people mention left and right. Personally, where do you position yourself, 0 means "left" and 10 "right" ? Indicate a value between 0 and 10.

\section{Left-Right Ideology in Spanish POLAT Data}

Variable lrself:

Cuando se habla de política se utilizan normalmente las expresiones izquierda y derecha. ¿En qué casilla de la siguiente escala te colocarías tú?

Extrema Izquierda (0) - Extrema Derecha (10)

Translation:

When they talk about politics, people typcially use the expressions left and right. In which field of the following scale would you position yourself?

Extreme left (0) - Extreme Right (10)

\section{Left-Right Ideology in Dutch LISS Data}

Variable cv[wave]101 (cv08a101 - cv19k101) (Module Politics and Values):

In politics, a distinction is often made between "the left" and "the right". Where would you place yourself on the scale below, where 0 means left and 10 means right?

\section{Independent Variables: Unemployment and Unemployment Risk}

\section{Unemployment and Unemployment Risk in Swiss SHP Data}

Unemployment: Variable WSTAT (constructed variable)

1. active occupied

2. unemployed

3. not in labor force 
Recoding into binary indicator ( $2=$ unemployed, $1 \& 3=$ reference category)

Unemployment Risk: Variable p[Wave]101 (p99w101-p18w101)

How do you evaluate the risk of becoming personally unemployed in the next 12 months, if 0 means "no risk at all" and 10 "a real risk"?

\section{Unemployment in Spanish POLAT Data}

Variable sitlab:

¿En cuál de las siguientes situaciones te encuentras actualmente?

1. Trabajo

2. Jubilado/pensionista (he trabajado)

3. Pensionista (no he trabajado)

4. Parado y he trabajado antes

5. Parado y busco mi primer empleo

6. Estudiante

7. Trabajo doméstico no remunerado

8. Otra situación

Translation:

In which of the following situations are you currently?

1. Employed

2. Pensioner (have worked)

3. Pensioner (have never worked)

4. Unemployed (and have worked before)

5. Unemployed (and am looking for my first employment)

6. Student

7. Unpaid Housework

8. Other Situation

Recoding into binary indicator: ( $4 \& 5=$ unemployed, rest $=$ reference category)

\section{Unemployment and Unemployment Risk in Dutch LISS Data}

Unemployment: Variable belbezig: (Module Background Variables)

Please indicate in the list below what best describes the members of your household: Yourself [Person 2] [Etc.]

1. Paid employment

2. Works or assists in family business

3. Autonomous professional, freelancer, or self-employed 
4. Job seeker following job loss

5. First-time job seeker

6. Exempted from job seeking following job loss

7. Attends school or is studying

8. Takes care of the housekeeping

9. Is pensioner ([voluntary] early retirement, old age pension scheme)

10. Has (partial) work disability

11. Performs unpaid work while retaining unemployment benefit

12. Performs voluntary work

13. Does something else

14. Is too young to have an occupation

Recoding into binary indicator: ( $4 \& 5 \& 6 \& 11=$ unemployed, rest $=$ reference category)

Unemployment: Alternative Measure based on variables cw[wave]088 - cw[wave]102 (Work and Schooling Module): binary variables indicating, whether the following statements are true:

- cw[wave]088 "I perform paid work"

- cw[wave]089 "I am not working now, but have performed paid work in the past"

- cw[wave]090 "I perform unpaid work while retaining my benefit or allowance"

- cw[wave]091 "I am looking for work following the loss of my previous job"

- $\mathrm{cw}$ [wave]092 "I have performed paid work, but am released from the obligation to find a new job following the loss of my previous job"

- cw[wave]093 "I am a first-time job seeker"

- cw[wave]094 "I am seeking work following a lengthy interruption"

- cw[wave]095 "I am a pupil / student / trainee with an expenses claim only"

- cw[wave]096 "I take care of the household"

- cw[wave]097 "I live off private means"

- cw[wave]098 "I have taken early retirement"

- cw[wave]099 "I am a pensioner"

- cw[wave]100 "I am partly or wholly disabled for work"

- cw[wave]101 "I perform voluntary work"

- cw[wave]102 "I perform paid work, but am looking for more or other work"

Alternative Unemployment Measure indicates that someone is unemployed, when someone gives one or several positive answers to variables cw[wave]90 - cw[wave] 94 .

Unemployment Risk: Variable ci[wave]256 (ci08a256 - ci18k256, ci191379) (Module: Economic Situation: Income)

Do you think that there is any chance that you might lose your job in the coming 12 months? You can indicate this in terms of a percentage. $0 \%$ means that you are sure that you will not lose your job, and $100 \%$ means that you are sure that you will lose your job.

Recoded into / rounded to $10 \%$ steps 


\section{Individual Moderator: Age}

Swiss SHP data: Computed as difference between survey year and birth year (variable birthy) Spanish POLAT data: Variable age: ¿Y cuál es tu edad?

Dutch LISS data: Computed as difference between survey year and birth year (variable cw[wave]002 (cw08a002 - cw191002)

\section{Contextual Moderators: Aggregate Salience}

\section{Salience in Swiss Selects data}

Variable mip1 (Selects Cumulation) and variable f12700rec (Selects 2019) Most Important Problem:

1. Agriculture

2. Economy

3. Education \& culture

4. Environment \& energy

5. EU, Europe

6. Finances \& taxes

7. Gender issues \& discrimination

8. Immigration \& asylum

9. Foreign policy \& defense

10. Labour market

11. Law \& order

12. Political system, parties \& politicians

13. Public health

14. Public services \& infrastructure

15. Regions \& national cohesion

16. Social security/welfare state

17. Other problems

18. No problem

$\%$ of mentions of "labour market" and "immigration and asylum" used.

\section{Salience in Eurobarometer Data}

(Aggregated) raw data on two most important problems plotted. 


\section{Erklärungen}

\section{Erklärung über das selbstständige Anfertigen der Dissertationsschrift}

Ich erkläre hiermit, dass ich die Dissertation und ihre Bestandteile selbstständig angefertigt habe und dabei keine anderen Hilfsmittel als die im Quellen- und Literaturverzeichnis genannten benutzt sowie alle aus Quellen und Literatur wörtlich oder sinngemäß entnommenen Stellen als solche kenntlich gemacht und korrekt angegeben habe.

Versicherung, dass die Dissertation nicht bereits einer anderen Prüfungsbehörde vorlag

Ich versichere, dass ich die Bestandteile der vorliegenden Dissertation oder wesentliche Teile derselben nicht bereits einer anderen Prüfungsbehörde zur Erlangung des Doktorgrades vorgelegt habe.

\section{Erklärung über die bisher erfolgte Publikation wesentlicher Bestandteile der Arbeit}

Dies ist eine kumulative Dissertation. Zwei der drei Artikel sind bereits veröffentlicht.

Artikel 1 "The (ir)relevance of unemployment for labour market policy attitudes and welfare state attitudes" ist veröffentlicht im European Journal of Political Research 58(1), Seiten 141162.

Artikel 2 "Going beyond values versus self-interest: whose attitudes change after employment transitions?" ist veröffentlicht in Political Research Exchange 2(1), Seiten 1-23.

Artikel 3 "The Dynamics of Unemployment, Risk, and Left-Right Ideology. Constrained Change or Changed Constraints?" wurde im Rahmen des Begutachtungsverfahrens von einer internationalen, SSCI gelisteten Zeitschrift, an Reviewer gesendet.

Konstanz, 22.05.2021

(Nadja Wehl) 




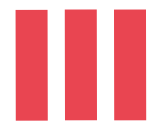

